Tesis Doctoral

Doctorado en Ciencias Naturales

Facultad de Ciencias Naturales y Museo

Universidad Nacional de La Plata

Liberación/mineralización de nitrógeno y fósforo en hojarasca de Eucalyptus grandis y leguminosas herbáceas en distintos suelos: relación con la calidad física y química del residuo, y efecto sobre el crecimiento de plantas jóvenes de eucalipto

Tesista: Lic. María Luciana Alcaraz

Director: Dr. Jorge L. Frangi

Codirectora: Dra. Corina Graciano

La Plata 
Comienza haciendo lo necesario, luego haz lo posible y terminarás haciendo lo imposible. 


\section{Agradecimientos}

En primer lugar quiero agradecer a mis directores. A Jorge L. Frangi por haberme contagiado su pasión por la Ecología, y por haberme dado la oportunidad de empezar en el camino de la investigación, brindándome su confianza y apoyo incondicional. Y a Corina Graciano, a quién considero un pilar en esta Tesis, por haberme guiado y acompañado paso a paso, siempre con la mejor predisposición para ayudarme, y siempre aportando su cuota de optimismo durante los momentos más difíciles.

A mis compañeros del LISEA. A Mariana Dabadie por su ayuda irremplazable en cada etapa experimental, y por los momentos de vida compartidos. A Juan Goya, quién me codirigiera en la etapa de becas, por ocuparse de procurarme los materiales que necesitaba, y ante cualquier consulta estar dispuesto para ayudarme.

A Marcelo Arturi, Carolina Pérez, Marcelo Barrera, que además de haber sido mis formadores en distintas materias de grado y posgrado, me aconsejaron, evacuaron dudas, compartieron material y por su buena predisposición cuando los necesité. A Victor Conzzono que de forma muy desinteresada dedicó mucho de su tiempo para guiarme en tareas de laboratorio.

A Maira Vitali, Soledad Ricciardi y Jimena Suárez, por su ayuda incansable en distintos ensayos y compartiendo momentos muy agradables.

A la Dra. Alicia Chaves, por guiarme en los ensayos de calidad de materia orgánica.

Al INFIVE, por permitirme usar sus instalaciones e instrumental en muchas de las experiencias que forman parte de esta Tesis.

A Verónica Lamas, José P. de Battista, y Natalia Tesón de los INTA EEA Cerro Azul, Misiones, Concepción del Uruguay y Concordia, Entre Ríos, respectivamente, por facilitarme el material necesario para mis ensayos.

A la UNLP y al CONOCET, por haberme dado el soporte económico que me permitió dedicarme a la investigación. 
Al International Institute of Tropical Forest (IITF-USDA FS) por los análisis químicos del material vegetal y suelos efectuados en el marco del convenio de cooperación entre la UNLP y el IIFT.

A mis amigas-colegas: a Susana Stupino, por los momentos compartidos, el intercambio de ideas y la ayuda mutua. A Ana Clara Dedoménici y Natalia Cabrera, por su incansable aliento en mi tarea.

A mi familia, quién siempre me acompaña y apoya en mis proyectos, ayudándome en todos los sentidos para que siga creciendo, especialmente a Pablo Aguirre, mi esposo y segundo pilar de esta Tesis, y a mis hijos Matías y Francisco, el principal motor que me impulsa a querer seguir creciendo cada día. 


\section{RESUMEN}

Las limitaciones nutricionales para el crecimiento de E. grandis, debido a la baja disponibilidad de nitrógeno $(\mathrm{N})$ y fósforo $(\mathrm{P})$ son comunes, y controlan la productividad de las plantaciones. El tipo de cosecha y el manejo de sus residuos son factores que inciden en el impacto de las plantaciones sobre la fertilidad del suelo. La fertilización química, si bien permite la incorporación de nutrientes, puede provocar distintos perjuicios, por lo que en el ámbito forestal la retención de los residuos de cosecha es un camino apto para manejar la fertilidad del sitio. Una manera alternativa a la fertilización para aumentar la provisión de $\mathrm{C}$ y $\mathrm{N}$ al suelo es utilizar leguminosas como cubiertas verdes.

La hojarasca proveniente de muchas especies fijadoras de nitrógeno se descompone rápidamente a diferencia de la hojarasca producida por los eucaliptos, que frecuentemente decae lentamente y se acumula en el piso de las plantaciones. El uso de cubiertas verdes de leguminosas de tasa de descomposición rápida y contenido de $\mathrm{N}$ alto, podría aportar este nutriente en el corto plazo. La calidad del material vegetal tiene dos componentes: la composición bioquímica ("calidad química") y la naturaleza física ("calidad física"). Hay muchos indicadores de calidad química relacionados con la liberación de $\mathrm{N}$, como el contenido de $\mathrm{N}$ o la relación $\mathrm{C} / \mathrm{N}$, la relación polifenol/ $\mathrm{N}$ y la relación polifenol+lignina/N. Uno de los parámetro de calidad física que ha recibido mayor atención en los estudios de ciclo de nutrientes es el tamaño de partícula.

Otro factor que interactúa con las características físico-química de los abonos y que regula su tasa de descomposición es el contenido de aire y agua en el suelo, que guardan una relación inversa ente sí: al aumentar la proporción de la fase líquida disminuye la proporción de la fase gaseosa. A su vez, el aire del suelo guarda relación con el tamaño de los poros que se forman entre los agregados. En condiciones de campo donde se planta E. grandis suelen darse situaciones de estrés hídrico (por exceso o déficit) que pueden afectar la descomposición del mantillo foliar de $E$. grandis como de los abonos que pudieran incorporarse.

A pesar de que el contenido de nutrientes en el suelo a menudo es aumentado por la aplicación de fertilizantes o abonos verdes, la disponibilidad de dichos nutrientes para las plantas se rige por una amplia gama de características fisicoquímicas, ambientales, estacionales, y por las interacciones biológicas que ocurren particularmente en la rizósfera. La rizósfera es la zona de suelo alrededor de las raíces de las plantas donde las propiedades del suelo están influenciadas por la presencia y la 
actividad de la raíz, y donde las raíces de las plantas interactúan con los microorganismos del suelo. Dado que todos los organismos vivos necesitan casi los mismos nutrientes para su mantenimiento, crecimiento y reproducción, estas interacciones suelen ser de competencia interespecífica por los nutrientes disponibles. Es así que el agregado de abonos no necesariamente implicará mayor disponibilidad de nutrientes para las plantas, ya que éstas deberán competir con los microorganismos del suelo.

En la primera etapa experimental se propuso evaluar en condiciones de laboratorio, por medio de microlisímetros, el aporte de $\mathrm{N}$ y $\mathrm{P}$ a un suelo arenoso (textura gruesa) y a un suelo arcilloso (textura fina), por el mantillo foliar de Eucalyptus grandis y de hojas de cuatro especies de leguminosas que podrían sembrarse como intercultivo con los eucaliptos. Las leguminosas utilizadas fueron Canavalia ensiformis, Cajanus cajan, Lotus corniculatus y Trifolium pratense. E1 material vegetal de eucalipto y leguminosas se incorporó dentro de microlisímetros con suelo arenoso o arcilloso, con dos modos de aplicación: en superficie (ES) o molido y mezclado con el suelo $(\mathrm{MM})$. Se realizaron lavados periódicos, se recolectaron los lixiviados y se analizó su contenido en $\mathrm{N}$ y P. En el suelo arenoso, el agregado de cualquiera de las leguminosas incrementó la concentración de $\mathrm{N}$ en el lixiviado, mientras que el agregado de E. grandis lo disminuyó con respecto al suelo sin el agregado de detritos, sin diferir según el modo de aplicación. El contenido neto de $\mathrm{N}$ proveniente de los tratamientos con agregado de L. corniculatus y C. cajan resultaron ser significativamente mayores que los de las restantes especies estudiadas, particularmente cuando se agregaron MM. En suelo arenoso podría recomendarse el uso de L. corniculatus y de C. cajan como abono verde. E. grandis ocasionó inmovilización de N. El contenido de P de los lixiviados provenientes del suelo arcilloso con agregado de detritos fueron en todos los casos significativamente menores al control. Cualquiera de los abonos aplicados y modos de aplicación no pueden ser utilizados como fuentes inmediatas de $\mathrm{P}$ aunque podrían utilizarse como estrategias de retención de este nutriente para su utilización posterior.

Posteriormente se evaluaron las relaciones entre la calidad química de los residuos foliares utilizados y la tasa de descomposición, y se relacionó con la lixiviación de N y P en la solución del suelo, por medio de correlaciones. Para ello se realizó un ensayo de descomposición en laboratorio y se realizaron los análisis químicos de la concentración de $\mathrm{P}, \mathrm{C}$ y $\mathrm{N}$ total, celulosa, hemicelulosa, lignina y 
polifenoles solubles de las hojas de E. grandis y de las 4 especies de leguminosas utilizadas en la tesis. Las hojas de eucaliptos se descompusieron más lentamente que las hojas de las leguminosas, lo que se relaciona a una mayor concentración de polifenoles solubles y con la mayor razón $\mathrm{C} / \mathrm{N}$ de los eucaliptos. La lixiviación de $\mathrm{P}$ no se relacionó con ninguna variable que permita predecir su liberación a partir de residuos.

Para comprender cuál es el impacto de las condiciones de humedad del suelo sobre la disponibilidad de $\mathrm{N}$ y $\mathrm{P}$ soluble aprovechable por las plantas, procedente de residuos de cosecha y abonos verdes, se midió la concentración N y P del lixiviado en un suelo arcilloso, con agregado de hojas de E. grandis y de leguminosas incorporado de dos modos diferentes en microlisímetros (MM y ES). Estos fueron sometidos a 2 condiciones de disponibilidad de agua: a capacidad de campo, y con alternancia de períodos inundado y drenado natural. En suelos anegados la lixiviación de $\mathrm{N}$ a partir de abonos orgánicos disminuyó con respecto a un suelo a capacidad de campo, a excepción de la especie L. corniculatus. Cuando se incorporaron abonos orgánicos en suelos anegados la lixiviación de $\mathrm{P}$ en la solución del suelo aumentó con respecto a un suelo a capacidad de campo, a excepción de las especies $L$. corniculatus y $C$. ensiformis cuyos residuos agregados $\mathrm{MM}$ disminuyeron el contenido de $\mathrm{P}$ al lixiviado. En suelos anegados, hubo mayor lixiviación de $\mathrm{N}$ y $\mathrm{P}$ cuando el abono se agregó en superficie que cuando estuvo mezclado con el suelo, a excepción de la lixiviación de $\mathrm{P}$ a partir de $E$. grandis.

Para profundizar el análisis, se realizó otro ensayo similar al anterior con microlisímetros, para analizar la lixiviación de $\mathrm{N}$ y $\mathrm{P}$ en suelos arcillosos con agregado de residuos de E. grandis y leguminosas bajo cuatro regímenes hídricos: Riego frecuente a capacidad de campo para lograr humedad constante (HC); alternancia quincenal de suelo anegado - drenado natural (AQ); alternancia mensual de suelo anegado - drenado natural (AM); y disminución de la humedad del suelo a niveles que impondrían a las plantas estrés por sequía (S). La incorporación al suelo de hojas de $E$. grandis reduce la disponibilidad de amonio y de nitrato en la solución del suelo en todas las condiciones hídricas, mientras que L. corniculatus y C. ensiformis aumentan el $\mathrm{N}$ disponible en forma de amonio bajo todas las condiciones de humedad del suelo, y de nitrato sólo en condiciones de humedad constante.

Dadas las interrelaciones complejas en la rizosfera suelo-plantamicroorganismos, se propuso evaluar el aporte de abonos orgánicos y fertilizantes sobre 
el crecimiento de plantas jóvenes de E. grandis, mediante un ensayo en macetas con suelo arenoso. Se incorporaron residuos foliares de leguminosas y de eucaliptos y urea como fertilizante inorgánico, imitando la ubicación del mantillo fraccionado sobre el suelo mineral (ES) y molido groseramente y mezclado con el suelo ( $\mathrm{MgM})$. Se observó que los eucaliptos con mantillo de leguminosas crecen más que sin el agregado de dichos abonos, particularmente cuando es incorporado $\mathrm{MgM}$ con el suelo, mientras que el abono de E. grandis ocasionó un crecimiento menor de los eucaliptos respecto al suelo sin abono. Las plantas fertilizadas con urea tuvieron un crecimiento intermedio comparativamente con los eucaliptos que crecieron con las especies de leguminosas.

Finalmente, para constatar el efecto de distintas condiciones de disponibilidad de agua del suelo y su efecto combinado con residuos de leguminosas herbáceas, sobre el crecimiento de plantas jóvenes de E. grandis en suelos arcillosos, se realizó un ensayo que consistió en macetas con suelo arcilloso donde se agregó mantillo foliar de leguminosas en las cuales se pusieron plantines de E. grandis, bajo condiciones de capacidad de campo o sequía, y se midió su crecimiento. La sequía redujo el crecimiento de E. grandis, pero la presencia de abonos orgánicos aumentó su crecimiento en forma proporcional. El agregado de L. corniculatus y $C$. ensiformis fue beneficioso para el crecimiento de las plantas, ya que, aún en condiciones de sequía, los eucaliptos crecieron más que las plantas sin residuos. Los abonos verdes además presentan la ventaja respecto a los fertilizantes inorgánicos, que no afectan negativamente la tolerancia al estrés en condiciones de sequía.

Se concluye que el uso de leguminosas como práctica de incorporación de nitrógeno, fósforo y carbono a los suelos forestales merece ser evaluada a mayor escala, porque además de mejorar el suelo estimula el crecimiento de las plantas en suelos con propiedades físico químicas contrastantes y variadas disponibilidades de agua. 


\section{ABSTRACT}

The growth of Eucalyptus grandis plantations is frequently limited by low nitrogen $(\mathrm{N})$ and phosphorus $(\mathrm{P})$ availability. Harvesting and the subsequent residue management have strong implications in forest soil fertility. Although inorganic fertilization is a possible input of nutrients to the system, this practice has some negative effects. Therefore, post-harvest residue retention could be a better way to manage site fertility and minimize the needs of fertilization. An alternative way to improve $\mathrm{C}$ and $\mathrm{N}$ in the soil is the use of legumes as inter-row cover crops.

In general, leaf litter of $\mathrm{N}$-fixing species decay faster than E. grandis leaves, which frequently remain and accumulate in the forest floor. The use of legumes as intercrops can give $\mathrm{N}$ to the soil in the short term because they have high decomposition rate and high $\mathrm{N}$ content. The quality of plant material has two components: biochemical composition (chemical quality) and physical properties (physical quality). There are many indicators of the chemical quality related with $\mathrm{N}$ release like $\mathrm{C} / \mathrm{N}$ ratio, polyphenol/ $\mathrm{N}$ ratio and poliphenol+lignin/ $\mathrm{N}$ ratio. One of the indicator of physical quality that has received more attention in relation with nutrient release is particle size.

Other factors that are related with physical and chemical quality of the green manure and also determine the decomposition rate are soil air and water contents, which are inversely related. The amounts of air and water in the soil are determined by soil porosity. In the sites where E. grandis is planted water stresses are frequent, both due to water excess or water deficit. These stresses can affect leaf litter decomposition as well as decomposition of legumes that could be added as intercrops.

Although soil nutrient content can be increased by the addition of fertilizers or green manures, the availability of nutrients for the plant is regulated by many physical, chemical and environmental conditions, as well as by biological interactions. These factors are important in the rhizosphere, which is the soil near the roots where soil properties are affected by root activity. In the rhizosphere, roots interact with microorganisms. As microorganisms need to live almost the same nutrients as plants, the interactions between them are in general of competition for the available nutrients. In this way, the addition of green manures does not necessary increase the availability of nutrients for the plants, because they compete with soil microorganisms.

In a first experiment, the release of $\mathrm{N}$ and $\mathrm{P}$ to the leaching from E. grandis and four legume species leaves was measured in microlysimeters filled with a sandy 
soil (coarse texture) and a clay soil (fine texture). The legume species used were: Canavalia ensiformis, Cajanus cajan, Lotus corniculatus y Trifolium pratense. The leaf material was added in two different ways: on the soil surface (ES) and mixed with the soil (MM). The percolation of water was stimulated periodically, and $\mathrm{N}$ and $\mathrm{P}$ concentration in the leaching was determined. In the sandy soil, the addition of any legume increased $\mathrm{N}$ concentration in the leaching, but the addition of E. grandis diminished $\mathrm{N}$ concentration, respect to control soil, with similar results in MM and ES. With the addition of $L$. corniculatus and $C$. cajan the increase of $\mathrm{N}$ was higher than with the other two species, especially in MM. These two species can be recommended as green manures in the sandy soil. On the other hand, E. grandis addition immobilized N. P content in the leaching of clay soil was lower with the addition of any legumes respect to control soil. Therefore, the legumes applied in either way are not suitable to increase immediate $\mathrm{P}$ availability for the plants, but they can be applied to retain nutrients in the system to be used in later plantation ages.

After that, the relationship between the chemical quality of the leaves and decomposition rate and $\mathrm{N}$ and $\mathrm{P}$ leaching was analyzed by correlation analyses. For that, a decomposition experiment was performed in a laboratory and concentration of $\mathrm{P}, \mathrm{C}, \mathrm{N}$, cellulose, hemicelulose, lignine, soluble polyphenols were determined in $E$. grandis and the leaves of the five legume species used in this thesis. E. grandis leaves had lower decomposition rate than legume species, consistent with its higher polyphenols concentration and higher $\mathrm{C} / \mathrm{N}$ rate. $\mathrm{P}$ leaching from green manures did not correlate with any of the leaf chemical variables analyzed.

To understand the impact of soil water content in $\mathrm{P}$ and $\mathrm{N}$ availability for the plants coming from harvest residues or legumes added as intercrops, $\mathrm{N}$ and $\mathrm{P}$ concentration in the leaching in a clay soil was measured. The leaves were incorporated as MM and ES. Two water regimes were analyzed: field capacity and alternation of flooding and natural drainage. In flooded soil $\mathrm{N}$ leaching from organic manures diminished respect to field capacity soil, with the exception of L. corniculatus. On the other hand, P leaching was higher in flooded soil than in field capacity soil with the exception of $L$. corniculatus y $C$. ensiformis that diminished P leaching for the MM application procedure. In flooded soil, $\mathrm{N}$ and P leaching was higher in ES application procedure than in $\mathrm{MM}$ application procedure, with the exception of $\mathrm{P}$ leaching from $E$. grandis.

To go deeper with the analysis of the impact of water availability in $\mathrm{N}$ and $\mathrm{P}$ 
leaching, an experiment similar to the previous one was performed. In this case, $\mathrm{N}$ and P lixiviaton from E. grandis and the legumes was evaluated with the soil under 4 water regimes: nearly constant field capacity $(\mathrm{HC})$; biweekly alternation of flooding and natural drainage (AQ); monthly alternation of flooding and natural drainage (AM); and drought (S). E. grandis litter addition reduced ammonium and nitrate concentration in the leaching in all water conditions. L. corniculatus and C. ensiformis increased ammonium availability in all water conditions and nitrate concentration only under HC.

We evaluated the effect of E. grandis and legumes manures and inorganic fertilization in E. grandis young plants growing in pots with sandy soil. Plant material was added on the surface (ES) and coarsely mixed with the soil (MM). Fertilization was performed with urea. Plants with legume residues grew more than control plants, particularly for MgM. E. grandis leaf addition diminished growth respect to control plants. Urea fertilized plants had an intermediate growth between control plants and those growing with legume manure.

Finally, an experiment was done to evaluate the effect of different water availability in the soil in residues decomposition and plant growth on clay soil. $E$. grandis plants grew in pots filled with clay soil, with E. grandis or legumes' plant material. Plants grew at field capacity or under drought. Drought reduced E. grandis growth, but the addition of residues increased growth in proportional relation with field capacity plants. L. corniculatus and C. ensiformis additon increased growth in both water regimes. Therefore, the addition of green manures increased plant growth and did not affect drought tolerance.

The final conclusion is that the use of legumes to add nitrogen, phosphorus and carbon to the forest soils is a tool that deserves to be evaluated in a higher scale. It improves soil quality and stimulates plant growth in soils with very different physical and chemical characteristics and different water availability. 


\section{INDICE}

1. INTRODUCCIÓN GENERAL ................................................

1.1. LIMITACIONES NUTRITIVAS EN LAS PLANTACIONES DE EUCALIPTO

EN ARGENTINA....................................................................

1.2. CICLO DEL NITRÓGENO...................................................... 2

1.2.1. Absorción del N por las plantas.......................................................................

1.2.2. Entrada y salida del $\mathrm{N}$ al sistema............................................ 4

1.2.3. Ciclo interno del $\mathrm{N}$ en el suelo................................................ 6

1.3. CICLO DEL FÓSFORO ......................................................... 8

1.3.1. Entradas y salidas del $\mathrm{P}$ al sistema...................................... 9

1.3.2. Formas de $\mathrm{P}$ en el suelo........................................................ $\quad 10$

1.3.3. Absorción del P por las plantas.................................................. $\quad 10$

1.3.4. Entradas y salidas del $\mathrm{P}$ a la dotación lábil.................................... 11

1.4. ALGUNAS FORMAS DE SUPERAR LAS LIMITACIONES NUTRITIVAS DE LAS PLANTACIONES DE EUCALYPTUS Y SUS PROBLEMA........................ 13

1.5. CALIDAD QUÍMICA Y FÍSICA DE LOS RESIDUOS............................ 18

1.6. RELACIONES ENTRE LA DISPONIBILIDAD DE AGUA EN EL SUELO Y LA DISPONIBILIDAD DE N Y P ..............................................

1.7. RESPUESTA DE LAS PLANTAS AL SUMINISTRO DE N Y P MEDIANTE RESIDUOS DE LEGUMINOSAS PROCEDENTES DE CUBIERTAS

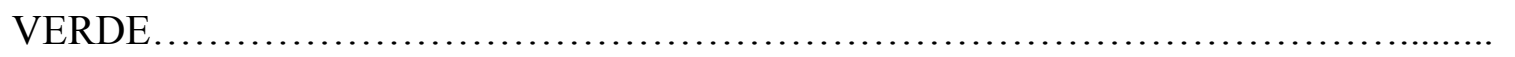

1.8. DESCRIPCIÓN DE EUCALYPTUS GRANDIS Y DE LAS ESPECIES DE LEGUMINOSAS SELECCIONADAS PARA SER UTILIZADAS COMO ABONOS ORGÁNICOS.

1.8.1. Eucalyptus grandis................................................... 22

1.8.2. Canavalia ensiformis................................................. 24

1.8.3. Cajanus cajan ....................................................... 25

1.8.4. Lotus corniculatus.................................................... 26

1.8.5. Trifolium pratense........................................................................ 27 
1.9. OBJETIVO GENERAL ........................................................ 28

1.10. OBJETIVOS PARTICULARES E HIPÓTESIS....................................................... 28

1.11. Esquema general de la tesis............................................... 31

2. SUMINISTRO DE NITRÓGENO Y FÓSFORO AL SUELO POR MANTILLOS DE EUCALYPTUS GRANDIS Y LEGUMINOSAS MEDIANTE EXPERIMENTOS DE LABORATORIO.................................................................. 32

2.1. INTRODUCCIÓN ......................................................... 32

2.2. MATERIALES Y MÉTODOS................................................ 34

2.2.1 Diseño experimental................................................ 34

2.2.2. Selección y obtención del material vegetal y suelos................................... 36

2.2.3. Microlisímetros........................................................... 37

2.2.4. Análisis químicos del lixiviado ........................................ 38

2.2.5. Análisis estadísticos........................................................ 39

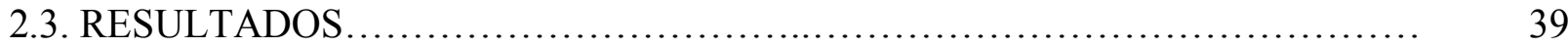

2.3.1. Contenido de $\mathrm{N}$ y $\mathrm{P}$ en los lixiviados de los suelos con agregado de detritos

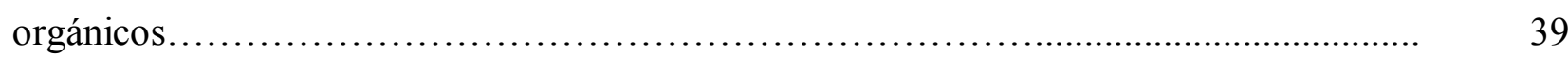

2.3.1.1 Comportamiento del Nitrógeno..................................... 39

2.3.1.2 Comportamiento del Fósforo............................................ 41

2.3.2. Lixiviado de $\mathrm{N}$ y $\mathrm{P}$ a partir de detritos de distintas especies en cada tipo de

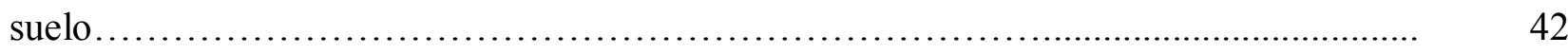

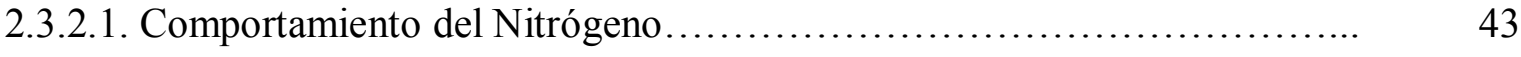

2.3.2.2. Comportamiento del Fósforo............................................ 44

2.4. DISCUSIÓN ................................................................. 45

2.5. CONCLUSIÓN ...................................................................... 48

3. RELACIÓN ENTRE LA CALIDAD QUÍMICA Y LA DESCOMPOSICIÓN DE HOJAS DE EUCALYPTUS GRANDIS Y LEGUMINOSAS HERBÁCEAS CON LA LIXIVIACIÓN DE NUTRIENTES AL SUELO.................................... 50

3.1. INTRODUCCIÓN ................................................................. 50

3.2. MATERIALES Y MÉTODOS.............................................. 56 
3.2.1. Composición química foliar de las especies................................ 56

3.2.2. Ensayo de descomposición........................................... 57

3.2.2.1. Selección y recolección del material vegetal y suelo.................................... 57

3.2.2.2. Preparación del material........................................................ 57

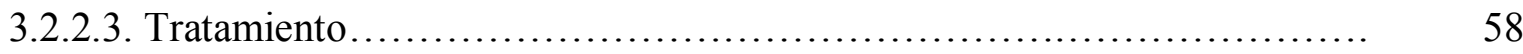

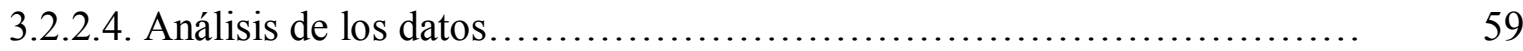

3.2.3. Análisis estadísticos.................................................. $\quad 60$

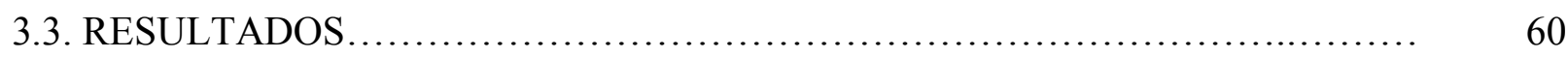

3.3.1. Composición química de las especies...................................... 60

3.3.2. Tasas de descomposición de las especies $(k)$, vida media y tiempo para perder el $95 \%$

3.3.3. Correlación entre las tasas de descomposición de las especies $(k)$, vida media y tiempo para perder el $95 \%$ y el $99 \%$ del peso, con los parámetros de calidad de todas las especies.

3.3.4. Correlación entre el contenido de $\mathrm{N}$ y $\mathrm{P}$ en el lixiviado y los parámetros de calidad química de los residuos vegetales.

3.3.4.1. Correlación entre el contenido de $\mathrm{N}$ en el lixiviado y los parámetros de calidad química.

3.3.4.2. Correlación entre el contenido de P del lixiviado y los parámetros de calidad química.

3.4.5. Correlación entre las tasas de descomposición de las especies $(k)$, vida media y tiempo para perder el $95 \%$ y el $99 \%$ del peso, con la lixiviación de $\mathrm{N}$ y $\mathrm{P}$

3.4. DISCUSIÓN.

4. SUMINISTRO DE NITRÓGENO Y FÓSFORO DE RESIDUOS DE CUBIERTAS VERDES DE EUCALYPTUS GRANDIS Y LEGUMINOSAS INCORPORADOS DE DISTINTA MANERA EN UN SUELO ARCILLOSO EN CONDICIONES DE HUMEDAD CONSTANTE Y CON CICLOS DE INUNDACIÓN Y DRENADO NATURAL 
4.1. INTRODUCCIÓN ............................................................. 77

4.2. MATERIALES Y MÉTODOS................................................ 79

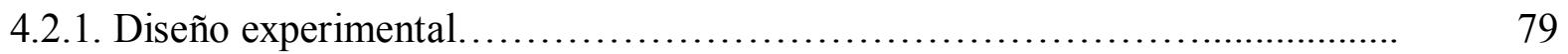

4.2.2. Selección y obtención del material vegetal y suelos.................................. $\quad 80$

4.2.3. Microlisímetros...................................................... 81

4.2.4. Tratamientos........................................................ 81

4.2.5. Análisis químicos del lixiviado........................................... 82

4.2.6. Análisis estadísticos........................................................ 82

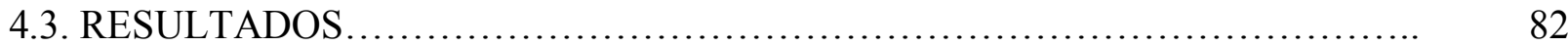

4.3.1. Lixiviación de $\mathrm{N}$ en los distintos tratamientos con y sin agregado de

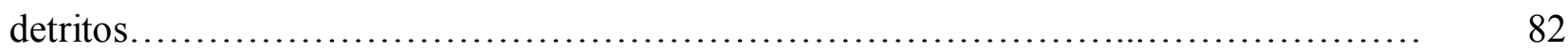

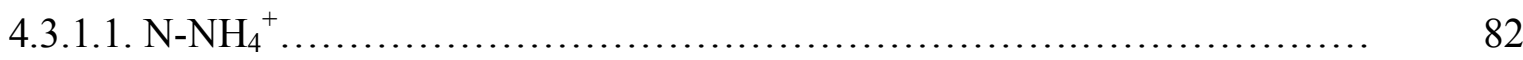

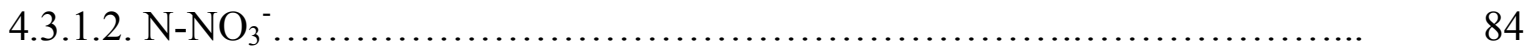

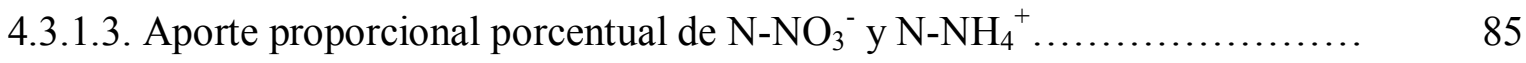

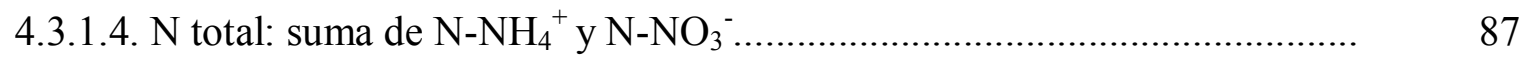

4.3.2. Lixiviación de $\mathrm{P}^{-} \mathrm{PO}_{4}{ }^{3-}$ en los distintos tratamientos con y sin agregado de detritos.............................................................................. 88

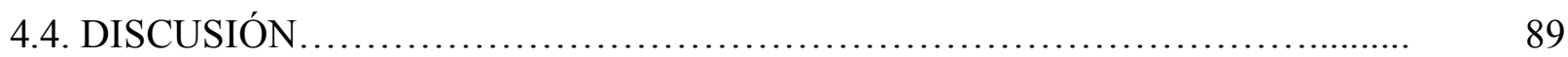

4.4.1. Liberación de $\mathrm{N}$ al lixiviado con y sin agregado de detritos....................... 89

4.4.2. Liberación de $\mathrm{P}_{-} \mathrm{PO}_{4}{ }^{3-}$ al lixiviado con y $\sin$ agregado de

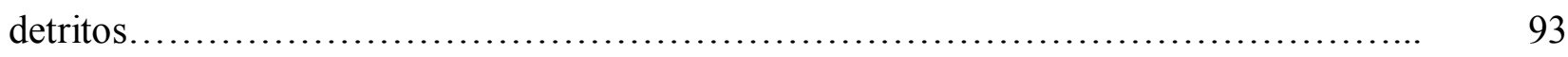

4.5. CONCLUSIÓN ...................................................................... 95

5. LIXIVIACIÓN DE NITRÓGENO Y FÓSFORO EN SUELOS ARCILLOSOS CON AGREGADO DE RESIDUOS DE EUCALYPTUS GRANDIS Y LEGUMINOSAS MOLIDOS Y MEZCLADOS BAJO CUATRO REGÍMENES HÍDRICOS................ 96

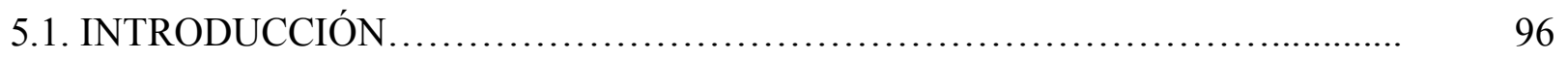

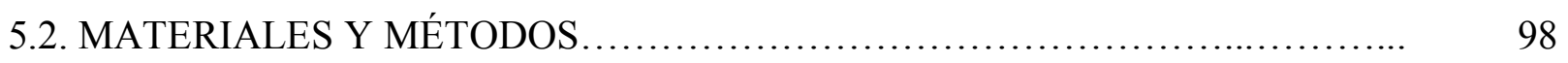

5.2.1. Diseño experimental............................................... 98

5.2.2. Selección y obtención del material vegetal y suelos.......................... 98

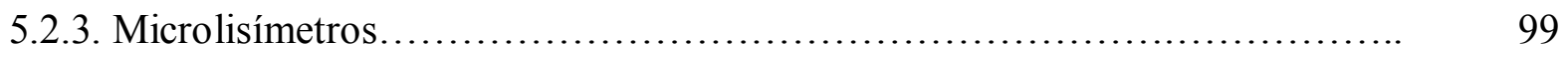




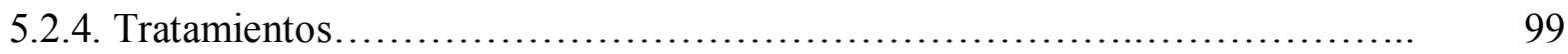

5.2.5. Análisis químicos del lixiviado......................................... 100

5.2.6. Análisis estadísticos.................................................... 100

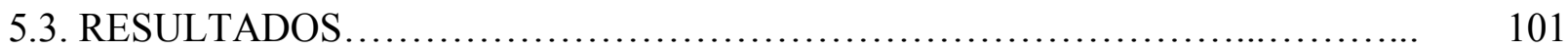

5.3.1. Lixiviación de $\mathrm{N}$ en los distintos tratamientos con y sin agregado de

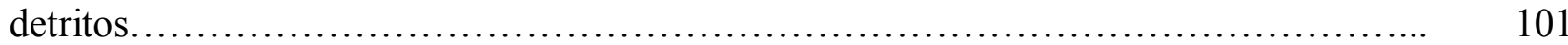

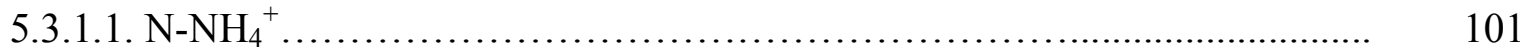

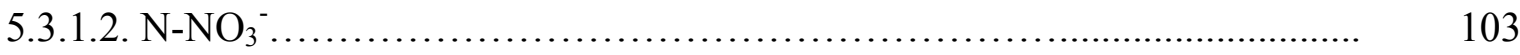

5.3.1.3. $\mathrm{N}$ total: aporte proporcional de $\mathrm{N}-\mathrm{NH}_{4}{ }^{+}$y $\mathrm{N}-\mathrm{NO}_{3}{ }^{-} \ldots \ldots \ldots \ldots \ldots \ldots \ldots \ldots . . \ldots 104$

5.3.2. Liberación de $\mathrm{P}_{-} \mathrm{PO}_{4}{ }^{3-}$ en los distintos tratamientos con y sin agregado de

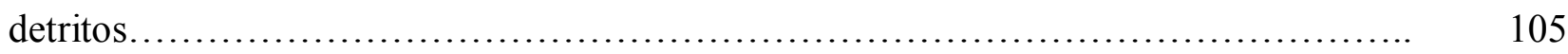

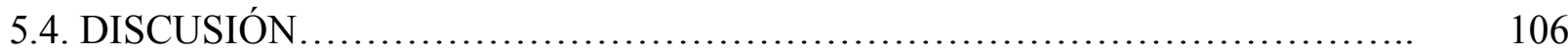

5.4.1. Liberación de $\mathrm{N}_{-} \mathrm{NH}_{4}{ }^{+}$y N-NO${ }_{3}{ }^{-}$al lixiviado con y sin agregado de detritos... 106

5.4.2. Liberación de $\mathrm{P}_{-} \mathrm{PO}_{4}{ }^{3-}$ al lixiviado con y sin agregado de detritos.............. 108

5.5. CONCLUSIÓN................................................................. 110

6. CRECIMIENTO DE PLANTAS JÓVENES DE EUCALYPTUS GRANDIS EN SUELOS ARENOSOS CON RESIDUOS DE CUBIERTAS VERDES DE LEGUMINOSAS, DE E. GRANDIS Y UREA..................................... 111

6.1. INTRODUCCIÓN ............................................................. 111

6.2. MATERIALES Y MÉTODOS.................................................... 114

6.2.1 Diseño experimental................................................. 114

6.2 .2 Análisis de los datos................................................. 116

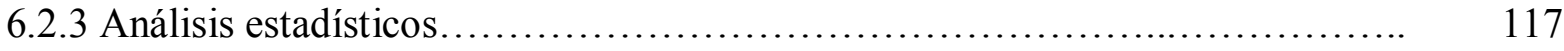

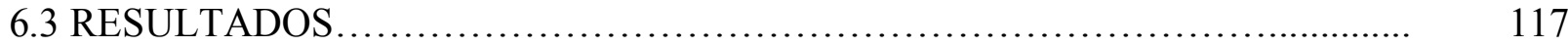

6.3.1. Efecto de la incorporación de los diferentes abonos.......................... 117

6.3.2. Efecto del modo de aplicación del abono................................... 123

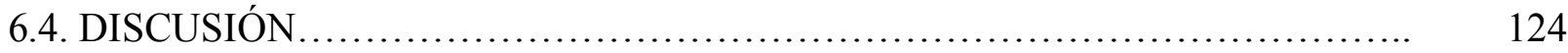

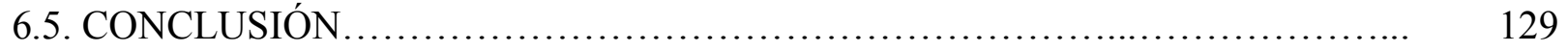

7. CRECIMIENTO DE PLANTAS JÓVENES DE EUCALYPTUS GRANDIS EN 
SUELO ARCILLOSO CON RESIDUOS DE CUBIERTAS VERDES DE LEGUMINOSAS EN CONDICIONES DE CAPACIDAD DE CAMPO Y

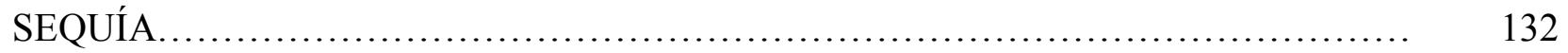

7.1. INTRODUCCIÓN ................................................................. 132

7.2. MATERIALES Y MÉTODOS................................................... 134

7.2.1 Diseño experimental.................................................. 134

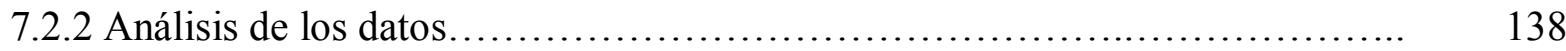

7.2.3 Análisis estadísticos..................................................... 138

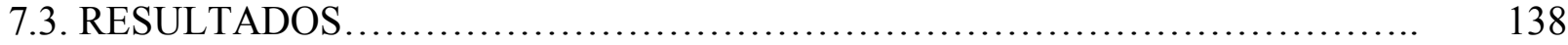

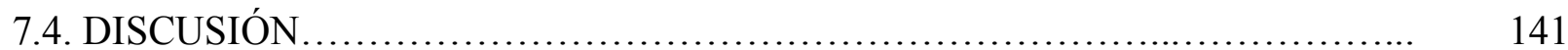

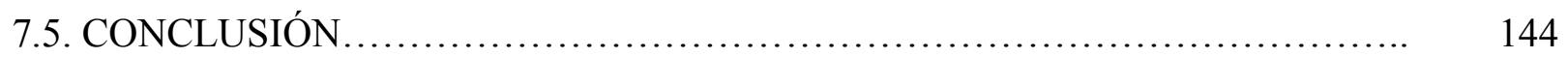

8. CONCLUSIÓN GENERAL........................................................... 146

9. BIBLIOGRAFÍA GENERAL......................................................... 156 


\section{CAPÍTULO 1}

\section{INTRODUCCIÓN}

El nitrógeno $(\mathrm{N})$ y el fósforo $(\mathrm{P})$ son dos de los nutrientes que las plantas requieren en mayor cantidad para mantener altas tasas de crecimiento. Tanto la producción agrícola como la forestal incorporan estos nutrientes, generalmente como fertilizantes inorgánicos. Sin embargo, la incorporación de abonos orgánicos ofrece ventajas ecológicas, por lo que esta alternativa debe ser evaluada. Conocer el impacto del agregado de abono en el ciclo del $\mathrm{N}$ y $\mathrm{P}$, y el resultado en el crecimiento de las plantas es indispensable para ponderar la factibilidad de implementar esta práctica en la producción forestal.

\subsection{LIMITACIONES NUTRITIVAS EN LAS PLANTACIONES DE EUCALIPTOS EN ARGENTINA}

Las plantaciones forestales de crecimiento rápido ocupan en nuestro país unas 1.120.000 hectáreas (SAGPyA 2014), de las cuales el $80 \%$ se encuentra en la Mesopotamia, siendo Eucalyptus sp el segundo género más plantado. En Argentina las mayores plantaciones de Eucalyptus grandis se hallan principalmente en las provincias de Entre Ríos y Corrientes (SAGPyA 2001), cubriendo 200.000 hectáreas con esta especie (Aparicio et al. 2005). En la zona de Concordia, Entre Ríos, E. grandis se cultiva principalmente sobre suelos de textura arenosa (localmente llamados arenosos y mestizos) de baja fertilidad, en rotaciones de entre 10 a 12 años y con incrementos de 25-40 $\mathrm{m}^{3} /$ ha año. La disminución de la disponibilidad de suelos arenosos en la franja costera del Río Uruguay y el aumento del precio de la tierra, llevaron a la forestación a desplazarse hacia el oeste de su zona original, donde los suelos tienen mayor contenido de arcilla generalmente acompañado de problemas de drenaje (Aparicio et al. 2005). Si bien el crecimiento inicial observado es inferior al que se obtiene en los suelos de mejor aptitud (Sepliarsky y Dalla Tea 1993), en turnos más largos de aprovechamiento, la forestación presenta resultados promisorios como para considerarla como una 
alternativa de diversificación y complementación productiva y rentable (Marcó et al. 1994, Jaime 2000).

Las limitaciones nutricionales para el crecimiento debido a la baja disponibilidad de $\mathrm{N}$ y $\mathrm{P}$ son comunes en los ecosistemas de eucaliptos, y a veces están asociadas con limitaciones de micro-nutrientes (Specht 1996). Si bien muchos eucaliptos y especies nativas pueden crecer y persistir en ecosistemas de baja fertilidad, la limitación de los nutrientes es el principal factor que controla la productividad y la distribución de las especies (Keith 1997).

También el uso forestal continuo puede reducir la calidad del sitio y disminuir la productividad, principalmente en suelos arenosos de baja fertilidad, debido a la exportación de nutrientes provocada por la cosecha (Gonçalves et al. 1997, Harrison et al. 2000) y turnos de corta menores a la rotación ecológica (Kimmins 1974, Sankaran et al. 2005). La mayoría de los suelos en Concordia plantados con E. grandis llevan 3 rotaciones consecutivas, lo que conlleva grandes extracciones de nutrientes que son exportados con la cosecha. El tipo de cosecha y el manejo de sus residuos son también factores que inciden de manera notoria en el impacto de las plantaciones de crecimiento rápido sobre el contenido de nutrientes del suelo y puede comprometer la productividad futura de estas plantaciones, a menos que haya mecanismos de reposición de los nutrientes (Goya et al. 2003, Graciano et al. 2008).

Para minimizar el impacto negativo de las rotaciones sucesivas en la fertilidad química de los suelos es indispensable evaluar prácticas de manejo que permitan minimizar la extracción e incluso reponer los nutrientes extraídos. Para que el manejo se realice adecuadamente, es importante conocer el ciclo de los nutrientes y el impacto que las prácticas silviculturales pueden tener en los ciclos.

\subsection{CICLO DEL NITRÓGENO}

El nitrógeno $(\mathrm{N})$ es la unidad clave de la molécula de proteína sobre la cual se basa la vida; es un componente esencial del protoplasma de plantas, animales y microorganismos (Palma y Segat 2000), por lo que todos los seres vivos incluidas las plantas, lo requieren en grandes cantidades a lo largo de su desarrollo (Stevenson 1986, Taiz y Zeiger 2002, Miller y Cramer 2004). En las plantas, el N es cuantitativamente el más abundante de los elementos minerales de los tejidos vegetales, representando aproximadamente el 2\% de la materia seca total (Miller y Cramer 2004). Se encuentra 
cumpliendo diferentes roles; entre los principales se hallan el ser componente de la molécula de clorofila, de aminoácidos, de proteínas, de vitaminas y de hormonas, así como de ácidos nucleicos y nucleótidos, estimular el desarrollo y actividad radicular, y formar parte de productos secundarios vegetales (Stevenson 1986, Taiz y Zeiger 2002, Miller y Cramer 2004). Dada la participación del N en tantos componentes celulares, su deficiencia inhibe rápidamente el crecimiento de la planta (Taiz y Zeiger 2002) que se manifiesta en una coloración amarillenta-verdosa en las hojas más viejas llamada “clorosis" (Palma y Segat 2000, Taiz y Zeiger 2002).

\subsubsection{Absorción del $\mathrm{N}$ por las plantas}

Las plantas pueden tomar el $\mathrm{N}$ del suelo en una variedad de formas orgánicas e inorgánicas, como $\mathrm{NO}_{3}{ }^{-}$o $\mathrm{NH}_{4}^{+}$(Miller y Cramer 2004), pero el $\mathrm{NO}_{3}{ }^{-}$es la principal forman en que las plantas absorben el N (Stevenson 1986), por lo que la disponibilidad de este nutriente en el suelo es a menudo una limitación importante para su crecimiento, excepto en las especies en las que las raíces desarrollan una simbiosis con microorganismos fijadores de $\mathrm{N}_{2}$. Sólo una fracción muy pequeña $(0,00024 \%)$ del $\mathrm{N}$ planetario está disponible para las plantas (Miller y Cramer 2004). El ciclo de nutrientes en el sistema suelo-planta representa un sistema muy dinámico y complejo, donde participan variados factores como el clima, el suelo y las plantas (Fageria 2009). En el ciclo ocurren transformaciones en el suelo y la absorción por las plantas, la pérdida del sistema suelo-planta y la inmovilización por los microorganismos (Fageria 2009), la cual implica la conversión del $\mathrm{N}$ inorgánico $\left(\mathrm{NH}_{4}{ }^{+}, \mathrm{NO}_{3}^{-}, \mathrm{NO}_{2}{ }^{-}\right)$a formas orgánicas, debido a reacciones asociadas principalmente con el crecimiento y metabolismo microbiano (Stevenson 1986, Palma y Segat 2000, Fageria 2009).

En la superficie del suelo mineral, el contenido de $\mathrm{N}$ varía entre 0,2 a $5,0 \mathrm{~g} \mathrm{~kg}^{-1}$ con un valor promedio de alrededor de $1,5 \mathrm{~g} \mathrm{~kg}^{-1}$ (Brady y Weil 2002), con más del 90\% del $\mathrm{N}$ en la mayoría de los suelos en forma de materia orgánica (Palma y Segat 2000, Fageria 2009), y sólo de 1 a 2\% del total de $\mathrm{N}$ en forma mineral (Brady y Weil 2002). La forma orgánica de $\mathrm{N}$ está formada por materia orgánica de descomposición rápida y compuestos húmicos de mineralización más lenta (Palma y Segat 2000). Estos compuestos húmicos, si bien tienen la ventaja de proteger al $\mathrm{N}$ de la pérdida, también lo hace no disponible para las plantas, a su vez que constituyen el reservorio más grande de N potencialmente disponible en los suelos (Stevenson 1986, Palma y Segat 2000). 
Esta forma de $\mathrm{N}$ orgánico debe ser mineralizada a $\mathrm{NH}_{4}{ }^{+}$y $\mathrm{NO}_{3}{ }^{-}$antes de su absorción por parte de las plantas (Palma y Segat 2000, Nieder y Benbi 2008, Fageria 2009).

\subsubsection{Entrada y salida del $\mathbf{N}$ al sistema}

La fuente principal natural de N para el suelo es la atmósfera (Stevenson 1986, Palma y Segat 2000) en la que el $\mathrm{N}_{2}$ es un importante constituyente (Palma y Segat 2000), ocupando el 79\% de su volumen. Sin embargo, se trata de un gas muy inerte por su alta energía de enlace, y presenta una gran dinámica de transformaciones en un complejo ciclo biogeoquímico (Palma y Segat 2000).

Las fuentes de entrada principales de $\mathrm{N}$ en el sistema suelo-planta son los fertilizantes químicos, los abonos orgánicos, la fijación biológica de $\mathrm{N}_{2}$, el retorno del $\mathrm{NH}_{3}$ y $\mathrm{NO}_{3}{ }^{-}$por lavado de hojas, tallos y otras superficies con el agua de lluvia, y la deposición atmosférica de $\mathrm{NH}_{3}, \mathrm{NH}_{4}{ }^{+}, \mathrm{y} \mathrm{NO}_{3}{ }^{-}$contenidos en la atmósfera por

precipitaciones y tormentas eléctricas (Stevenson 1986, Fageria 2009). La fijación biológica de $\mathrm{N}_{2}$ es la conversión de este gas a formas combinadas de $\mathrm{N}$ (Palma y Segat 2000), es realizada por unas pocas bacterias, actinomicetes y algas verde-azules, y puede considerarse el segundo proceso más importante que mantiene la vida después de la fotosíntesis (Stevenson 1986), y es extremadamente importante en sistemas naturales como de cultivo (Vance et al. 2001, Vessey et al. 2004). Los microorganismos fijadores de nitrógeno pueden ser de vida libre, o asociarse en simbiosis con los vegetales, tal es el caso de las bacterias del género Rhizobium y Bradyrhizobium que se asocian con leguminosas para realizar la fijación (Palma y Segat 2000).

El $\mathrm{N}$ es un nutriente muy móvil en el suelo, y sujeto a grandes pérdidas desde el sistema suelo-planta, siendo las principales fuentes de agotamiento de $\mathrm{N}$ la desnitrificación bacteriana, la volatilización de $\mathrm{NH}_{3}$, lixiviación, escurrimiento superficial, y la absorción por las plantas (Stevenson 1986, Fageria 2009).

La desnitrificación bacteriana es la rápida pérdida de $\mathrm{NO}_{3}^{-}$, que se reduce pasando a $\mathrm{N}_{2}$ y $\mathrm{N}_{2} \mathrm{O}$ que vuelven a la atmósfera (Stevenson 1986, Palma y Segat 2000, Fageria 2009). Mientras que el $\mathrm{N}_{2}$ es un gas inerte que no representa ningún riesgo conocido al medio ambiente, el $\mathrm{N}_{2} \mathrm{O}$ es uno de los gases de efecto invernadero que contribuyen a la destrucción de la capa de ozono protectora (Fageria y Gheyi 1999). Los responsables son unos pocos organismos capaces de usar el oxígeno del $\mathrm{NO}_{3}^{-}\left(\mathrm{y} \mathrm{NO}_{2}^{-}\right)$ como sustituyente del $\mathrm{O}_{2}$ (Stevenson 1986). Bacillus y Pseudomonas son los géneros de 
microorganismos anaerobios facultativos (Palma y Segat 2000) más importantes que realizan este proceso, ocupan las capas superiores del suelo $(0-30 \mathrm{~cm})$, con el número decreciente de forma exponencial hasta 120 a $150 \mathrm{~cm}$ de profundidad (Parkin y Meisinger 1989). Las condiciones necesarias para que ocurra la desnitrificación son la anaerobiosis o disponibilidad de $\mathrm{O}_{2}$ reducida, el suministro de $\mathrm{C}$ orgánico, y la presencia de una fuente de $\mathrm{NO}_{2}{ }^{-}$o $\mathrm{NO}_{3}{ }^{-}$(Stevenson 1986, Aulakh et al. 1992, Palma y Segat 2000). Por lo tanto, la mineralización también podría afectar este proceso, ya que la desnitrificación sería más severa en suelos con mayor cantidad de materia orgánica descomponible con baja relación $\mathrm{C} / \mathrm{N}$, dado que habría mineralización neta y el $\mathrm{NO}_{3}{ }^{-} \mathrm{se}$ podría acumular para que luego ocurra la desnitrificación. Por el contrario, el agregado de residuos con alta relación $\mathrm{C} / \mathrm{N}$ conservará el $\mathrm{N}$ a través de la inmovilización neta, $\mathrm{y}$ se reducirá la desnitrificación (Stevenson 1986). Por lo tanto, la desnitrificación ocurre generalmente en suelos ricos en materia orgánica, en largos períodos de condiciones de inundación y a altas temperaturas (Fageria 2009). La desnitrificación es la mayor pérdida de N del sistema suelo-planta (Fageria 2009), y dado que está influenciada por varios factores físicos y químicos, es difícil cuantificar el N perdido. Sin embargo, Aulakh et al. (1992) informó que, en general, las pérdidas de $\mathrm{N}$ por desnitrificación podría ser alrededor de $30 \%$ en un agroecosistema.

Bajo condiciones estables el $\mathrm{N}$ puede ser perdido del suelo por volatilización en forma de $\mathrm{NH}_{3}$ (Stevenson 1986), y representar una importante pérdida cuando se aplican fertilizantes nitrogenados o abonos orgánicos en superficie, especialmente en suelos alcalinos (Palma y Segat 2000, Fageria 2009), pero las pérdidas son pequeñas cuando el fertilizante es incorporado dentro del suelo (Palma y Segat 2000, Fageria 2009). Las pérdidas de $\mathrm{NH}_{3}$, dado que están relacionadas con el $\mathrm{pH}$ y con la concentración de $\mathrm{NH}_{4}{ }^{+}$en la fase solución, son de mayor importancia en suelos calcáreos, pero sólo pequeñas pérdidas ocurren en suelos a pH 6 o 7, aunque la pérdida aumenta con el aumento del $\mathrm{pH}$. Las arcillas y el humus presentes en el suelo retienen o adsorben $\mathrm{NH}_{4}{ }^{+}$y previenen su volatilización. Asimismo, las pérdidas se reducen en presencia de plantas en crecimiento, ya que la concentración de $\mathrm{NH}_{4}^{+}$baja por la absorción de las plantas, y además el $\mathrm{NH}_{3}$ puede ser reabsorbido por el canopeo (Stevenson 1986).

Los iones de $\mathrm{NO}_{3}{ }^{-}$están cargados negativamente y fácilmente se lavan con las fuertes lluvias o el riego (Fageria 2009) llegando a lagos, arroyos (Stevenson 1986) o napas, de modo que esta forma constituye otra forma de pérdida de $\mathrm{N}$. El $\mathrm{N}$ es lavado 
principalmente como $\mathrm{NO}_{3}{ }^{-}$, aunque el $\mathrm{NH}_{4}{ }^{+}$puede ser perdido por este mecanismo en suelos arenosos (Stevenson 1986). La cantidad de N lixiviado depende del tipo de suelo, fuente de fertilizantes nitrogenados, los cultivos y los métodos de aplicación de fertilizantes (Fageria 2009). Además, el $\mathrm{NO}_{3}{ }^{-}$es un factor importante asociado a la lixiviación de bases como el calcio, magnesio y potasio del suelo. $\mathrm{El} \mathrm{NO}_{3}{ }^{-} \mathrm{y}$ las bases se lixivian juntas. A medida que estas bases son removidas y reemplazadas por $\mathrm{el} \mathrm{H}^{+}$, el suelo se vuelve más ácido (Fageria 2009).

Otra manera de perder $\mathrm{N}$ del sistema es a partir de la extracción por las cosechas que ocurre en la mayoría de los cultivos (Palma y Segat 1999) y las pérdidas debidas al manejo inadecuado de los residuos (Goya et al. 2009).

\subsubsection{Ciclo interno del $\mathrm{N}$ en el suelo}

El ciclo global del $\mathrm{N}$ y el ciclo interno en el suelo comparten procesos, pero en el segundo lo más distintivo es la renovación biológica del $\mathrm{N}$ a través de la mineralización e inmovilización (Stevenson 1986, Palma y Segat 2000, Fageria 2009) (Figura 1.1):

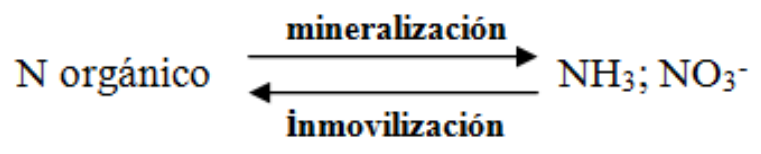

Figura 1.1. Ciclo interno del $\mathrm{N}$ en el suelo.

La mineralización incluye a todos los procesos por los cuales el $\mathrm{N}$ orgánico es transformado a formas inorgánicas disponibles para las plantas $\left(\mathrm{NH}_{4}{ }^{+}, \mathrm{NO}_{3}{ }^{-}\right)$(Stevenson 1986, Palma y Segat 2000, Nieder y Benbi 2008) por medio de reacciones bioquímicas mediadas por microorganismos heterótrofos, por lo que este proceso es influenciado por los factores que afectan a los microorganismos, como la temperatura, la humedad, el $\mathrm{pH}$, entre otros (Stevenson 1986). La mineralización se divide en 2 procesos, el primero es la amonificación, mediante el cual el $\mathrm{N}$ orgánico es transformado en $\mathrm{NH}_{3}$. Es un proceso realizado exclusivamente por microorganismos heterótrofos, entre los que se encuentran una amplia gama de bacterias, hongos y actinomicetes, que pueden liberar $\mathrm{NH}_{4}{ }^{+}$a partir de compuestos nitrogenados, de manera tanto aeróbica como anaeróbica (Stevenson 1986, Palma y Segat 2000). El segundo paso, la nitrificación, es la oxidación que transforma el $\mathrm{NH}_{3}$ a $\mathrm{NO}_{3}^{-}$, y se produce a su vez en dos etapas, en las que intervienen bacterias autotróficas nitrificantes, que usan $\mathrm{NH}_{3}$ como fuente de energía 
para sus funciones vitales, $\mathrm{CO}_{2}$ como fuente de $\mathrm{C}$ y $\mathrm{O}_{2}$ como último aceptor de electrones (quimioautótrofas) (Stevenson 1986, Palma y Segat 2000, Nieder y Benbi 2008, Fageria 2009). En la primera etapa las bacterias del género Nitrosomonas transforman el $\mathrm{NH}_{4}^{+}$en $\mathrm{NO}_{2}^{-}$, mientras que en la segunda etapa, el $\mathrm{NO}_{2}^{-}$es transformado a $\mathrm{NO}_{3}{ }^{-}$por bacterias del género Nitrobacter (Stevenson 1986, Palma y Segat 2000, Nieder y Benbi 2008, Fageria 2009). La nitrificación es fundamental para los flujos, las transferencias, las pérdidas y/o la utilización de N (Nieder y Benbi 2008). Los microorganismos nitrificantes son de gran importancia por ser el nitrato la principal fuente de nitrógeno asimilado por las plantas superiores (Palma y Segat 2000). A pesar de que la nitrificación puede ser llevada a cabo por otros microorganismos heterótrofos, la participación de las bacterias nitrificantes es la de mayor importancia. Bajo temperatura y humedad óptimas del suelo, la nitrificación se produce a un ritmo muy rápido (Fageria 2009). Además, la nitrificación es un proceso de oxidación, y la aireación del suelo aumenta la velocidad del proceso, por lo que en condiciones de bajo contenido de $\mathrm{O}_{2}$ se puede acumular $\mathrm{NH}_{4}{ }^{+}$, mientras que el $\mathrm{NO}_{3}{ }^{-}$será la forma disponible predominante en suelos bien aireados (Stevenson 1986, Palma y Segat 2000, Nieder y Benbi 2008). También puede ocurrir que haya una gran cantidad de $\mathrm{NH}_{3} \mathrm{O} \mathrm{NH}_{4}^{+}$en el suelo por aplicaciones de fertilizantes en altas dosis o con elevada frecuencia, y dado que el $\mathrm{NH}_{3}$ en exceso puede ser tóxico para Nitrobacter, se puede acumular $\mathrm{NO}_{2}^{-}$. Comúnmente el $\mathrm{NO}_{2}^{-}$se oxida rápidamente a $\mathrm{NO}_{3}^{-}$, pero a veces el $\mathrm{NO}_{2}^{-}$puede acumularse en los suelos con $\mathrm{pH}$ alto y elevada concentración de $\mathrm{N}$ amoniacal $\left(\mathrm{NH}_{4}{ }^{+}+\right.$ $\mathrm{NH}_{3}$ ) (Nieder y Benbi 2008). Dado que hay producción de dos $\mathrm{H}^{+}$por cada átomo de $\mathrm{N}$ durante la nitrificación, esto causa acidificación (Nieder y Benbi 2008). La concentración de $\mathrm{NH}_{4}{ }^{+}$, el estado de aireación del suelo (expresado en contenido de oxígeno o de humedad), la temperatura, el pH del suelo y la textura del suelo son los principales factores que rigen la nitrificación de los suelos (Nieder y Benbi 2008).

En oposición a los procesos de mineralización, se encuentra la inmovilización del $\mathrm{N}$, conversión del $\mathrm{N}$ inorgánico a orgánico, por crecimiento y metabolismo microbiano (Stevenson 1986, Palma y Segat 2000, Fageria 2009). Se utiliza el término "asimilación" para referirse al consumo de $\mathrm{NH}_{4}{ }^{+}$y $\mathrm{NO}_{3}{ }^{-}$por las plantas, e “inmovilización” cuando se refiere a los microorganismos (Stevenson 1986, Fageria 2009). La inmovilización del $\mathrm{N}$ tiene una influencia temporal en el transporte de $\mathrm{N}$ a las plantas, generándose una competencia por el $\mathrm{N}$ entre ambos tipos de organismos. Por lo 
tanto, el contenido de $\mathrm{NO}_{3}{ }^{-}$en el suelo puede reducirse por desnitrificación, o por el consumo por parte de las plantas o los microorganismos.

La fijación de $\mathrm{NH}_{4}{ }^{+}$es un paso importante del ciclo del $\mathrm{N}$ en los sistemas sueloplanta, el cual ocurre por tres procesos específicos: la fijación de minerales de la arcilla, la fijación de $\mathrm{NH}_{3}$ por la materia orgánica del suelo, y la inmovilización biológica de $\mathrm{NH}_{4}{ }^{+}$por microorganismos heterótrofos (Nommik y Vahtras 1982, Nieder y Benbi 2008). La adsorción de $\mathrm{NH}_{4}{ }^{+}$en una forma no intercambiable en la capa intermedia expandible de minerales de arcilla de aluminosilicato, puede reducir la eficiencia en el uso de fertilizantes de este nutriente cuando se añade a los suelos en los que predominan estos minerales (Stehouwer y Johnson 1991).

En síntesis, el átomo de $\mathrm{N}$ presenta diferentes estados de oxidación y en el pasaje entre ellos participan los organismos del suelo. La facilidad con que ocurren los cambios de oxidación hace que diferentes formas inorgánicas puedan perderse fácilmente del ecosistema por lixiviación y/ volatilización (Palma y Segat 2000). La mineralización e inmovilización ocurren simultáneamente, por lo que la cantidad $\mathrm{NO}_{3}^{-}$y $\mathrm{NH}_{4}{ }^{+}$encontrada representa la magnitud de los dos procesos opuestos: algo del $\mathrm{NH}_{4}{ }^{+}$y $\mathrm{NO}_{3}{ }^{-}$formados por amonificación y nitrificación es simultáneamente consumido por la microflora heterótrofa y convertido en tejido microbiano (Stevenson 1986).

\subsection{CICLO DEL FÓSFORO}

El fósforo $(\mathrm{P})$ es uno de los principales macronutrientes esenciales para el crecimiento y desarrollo biológico (Heredia 2000), es poco móvil, de baja solubilidad y de baja concentración y movilidad en la solución del suelo (Heredia 2000), en contraposición con su alta movilidad dentro de las plantas.

Su función en las células de las plantas es muy importante, ya que juega un papel en una variedad de procesos, incluyendo la generación de energía, la síntesis de ácido nucleico, la fotosíntesis, la glucólisis, la respiración, síntesis y estabilidad de la membrana, la activación/ inactivación de enzimas, reacciones redox, en el metabolismo de hidratos de carbono y en la fijación de nitrógeno (Vance et al. 2003). Los síntomas característicos de la deficiencia de fósforo incluyen retraso del crecimiento en las plantas jóvenes (Marschner 1995). 


\subsubsection{Entradas y salidas del $P$ al sistema}

El ciclo natural del P consiste en la meteorización y lavado de fosfatos desde las rocas y suelos, los cuales constituyen uno de sus reservorios globales (Stevenson y Cole 1999), y la escorrentía hacia los océanos, su principal reservorio (Heredia 2000, Bailey et al. 2002). Menos del $1 \%$ del $\mathrm{P}$ total se encuentra en los tres principales compartimientos del ecosistema terrestre, es decir la atmósfera, la biomasa vegetal y el suelo (Stevenson y Cole 1999). Es un ciclo "abierto" debido a su tendencia general de llevar el P de la tierra a los océanos, y "sedimentario" porque en última instancia, el P se incorpora en los sedimentos oceánicos (Begon et al. 2006).

A diferencia del $\mathrm{N}$, que puede ser devuelto al suelo por la fijación desde el aire (Fageria 2009), el P entra al sistema suelo-planta únicamente a través de fuentes externas. Una de las formas de entrada es a través de la meteorización del material parental, produciendo cantidades variables de P (Bünemann y Condron 2007). En suelos altamente meteorizados, el mineral primario de $\mathrm{P}$ (cuya principal fuente lo constituye la apatita) se transforma por completo en varios minerales secundarios de P (Walker y Syers 1976, Heredia 2000). Ambos tipos de minerales, primarios y secundarios, constituyen la reserva inorgánica de $\mathrm{P}$ del suelo (Heredia 2000). Los fertilizantes comerciales son una importante fuente de $\mathrm{P}$ que entra al suelo, los cuales han aumentado el contenido total de P en los suelos agrícolas (Rodríguez y Fraga 1999), siendo particularmente importante en los países industrializados (Fairhurst et al. 1999), mientras que en los países en desarrollo este fenómeno continúa rezagado (Bünemann y Condron 2007). Los abonos orgánicos, como los residuos de cosecha, son también una importante fuente de materia orgánica que puede ser devuelto a la tierra para el reciclaje de nutrientes, y que, además, mejora las propiedades físicas, químicas y biológicas del suelo (Kumar y Goh 2000).

Debido a la fuerte tendencia del fosfato a ser adsorbido sobre superficies coloidales y formar complejos insolubles con cationes di y trivalentes, las pérdidas de $\mathrm{P}$ del sistema suelo-planta son relativamente pequeñas (Stevenson 1986), exceptuando el caso de los suelos arenosos (Wild 1992). Por ejemplo, mucho del P aplicado como fertilizante ( $90 \%$ o más) no es tomado por el cultivo, sino que es retenido en formas fijadas (ver más adelante) o insolubles (Stevenson 1986). La erosión del suelo, la escorrentía superficial y subterránea, la lixiviación y la absorción por las plantas son las vías principales de pérdida de $\mathrm{P}$ del suelo (Fageria 2009). La pérdida anual de $\mathrm{P}$ del 
suelo en el drenaje del subsuelo y por flujo superficial normalmente es menor que 1 kg.ha" ${ }^{-1}$ (Condron 2004).

\subsubsection{Formas de $P$ en el suelo}

El P en el suelo se encuentra tanto en formas inorgánicas como orgánicas. El P inorgánico se encuentra principalmente en su estado oxidado como ortofosfato $\left(\mathrm{PO}_{4}{ }^{3-}\right) \mathrm{O}$ derivados del ácido ortofosfórico $\left(\mathrm{H}_{3} \mathrm{PO}_{4}\right)$ (Stevenson 1986). La fase mineral de $\mathrm{P}$ consta de minerales primarios y secundarios, principalmente fosfatos de calcio en suelos calcáreos y alcalinos en regiones áridas y semiáridas, y fosfatos de hierro y aluminio en suelos ácidos (Stevenson 1986, Bünemann y Condron 2007, Fageria 2009), así como fosfatos fuertemente adsorbidos $\mathrm{y} / \mathrm{u}$ ocluidos por óxidos hidratados de hierro $\mathrm{y}$ aluminio, y fosfatos fijados por minerales de arcilla (Stevenson 1986).

El P orgánico del suelo está constituido por compuestos orgánicos solubles en la solución del suelo ( $\mathrm{P}$ orgánico fácilmente mineralizable), $\mathrm{y}$ por formas orgánicas insolubles, como el P de la biomasa del suelo, el de los restos no descomponibles de

plantas y animales, y el que forma parte constituyente del humus (Stevenson 1986). La proporción de $\mathrm{P}$ orgánico del suelo oscila entre 20 y 80\% del P total (Heredia 2000, Brady y Weil 2002, Bünemann y Condron 2007), aunque puede variar desde un mínimo de 5\% hasta un máximo de 95\% (Paul y Clark 1988). El P en solución (tanto orgánico como inorgánico) es la reserva más lábil de este nutriente en el suelo, seguido por la biomasa microbiana, la dotación de $\mathrm{P}$ inorgánico intercambiable y la dotación de $\mathrm{P}$ orgánico lábil (Bünemann y Condron 2007).

\subsubsection{Absorción del $P$ por las plantas}

A pesar de que ambas formas (inorgánica y orgánica) de $\mathrm{P}$ están presentes en el sistema suelo-planta en gran cantidad, sólo una pequeña fracción del total de P está en una forma disponible para las plantas (Richardson et al. 2009), ya que más del 90\% del P inorgánico se encuentra en forma fijada o insoluble, (Stevenson 1986), mientras que el $\mathrm{P}$ orgánico debe ser mineralizado por la actividad microbiana antes de que esté disponible para ser absorbido por las plantas (Stevenson 1986, Fageria 2009).

Las plantas absorben el $\mathrm{P}$ desde la solución del suelo, principalmente en forma de iones $\mathrm{H}_{2} \mathrm{PO}_{4}{ }^{-}$en suelos ácidos y en la forma de iones $\mathrm{HPO}_{4}{ }^{2-}$ en los suelos básicos o 
alcalinos (Heredia 2000, Fageria 2009, Richardson et al. 2009), que son las formas predominantes a esos pH (Heredia 2000, Bailey et al. 2002). Un suelo en el rango de pH entre 6 y 7 es el mejor desde el punto de vista de la disponibilidad de $\mathrm{P}$, ya que está por encima de la máxima insolubilidad de fosfatos de hierro y aluminio y por debajo de la máxima insolubilidad de fosfatos de calcio (Stevenson 1986, Heredia 2000, Bailey et al. 2002,). A pH 7, ambos iones están presentes en más o menos la misma cantidad (Mengel et al. 2001).

Mientras que el $\mathrm{P}$ inorgánico disuelto es la forma más importante para la absorción por las plantas, una proporción de $\mathrm{P}$ orgánico disuelto puede también ser utilizado (Turner y Haygarth 2000), ya que también pueden absorber el P en forma de compuestos orgánicos de bajo peso molecular (Rodríguez y Fraga 1999).

\subsubsection{Entradas y salidas del $P$ a la dotación lábil}

La reposición del $\mathrm{P}$ inorgánico en la solución del suelo (Figura 1.2) puede ocurrir por procesos biológicos, como la mineralización/inmovilización del $\mathrm{P}$ orgánico por los microorganismos, y por procesos físico-químicos, como el equilibrio entre formas de P mineral soluble e insoluble (Stevenson 1986, Heredia 2000).

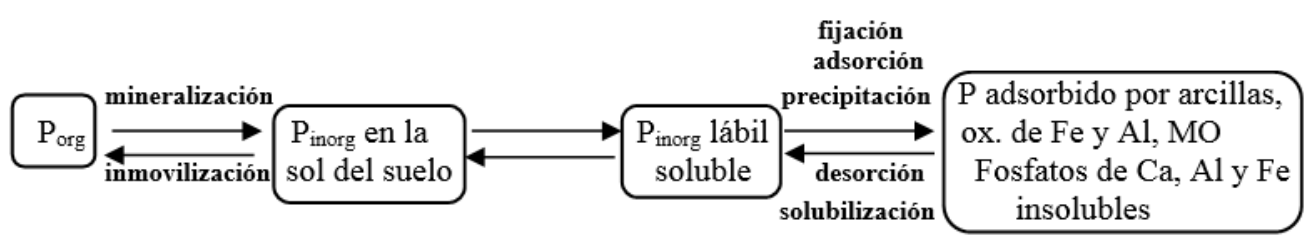

Figura 1.2. Reposición de P inorgánico en la solución del suelo.

Sin las plantas o los organismos del suelo, los flujos en el suelo serían pequeños, ya que el equilibrio químico entre las diferentes formas de $\mathrm{P}$ se vería perturbado sólo por los efectos abióticos, tales como la humedad y las fluctuaciones de temperatura, así como a través de los aportes atmosféricos y las pérdidas por lixiviación (Bünemann y Condron 2007). La biomasa microbiana desempeña un papel central en el ciclo del P natural (Stewart y Tiessen 1987, Rodríguez y Fraga 1999), y es reconocida como la fuerza impulsora en la dinámica del P orgánico del suelo (Bünemann y Condron 2007), ya que es la responsable de la descomposición del $\mathrm{P}$ orgánico del suelo permitiendo la 
liberación de fosfatos inorgánicos (Stevenson 1986). La absorción por la planta y la inmovilización microbiana también tienen un gran potencial para perturbar el equilibrio de nutrientes inorgánicos (Bünemann y Condron 2007). Asimismo, los microorganismos pueden afectar el suministro de $\mathrm{P}$ para las plantas ya que pueden promover la solubilización de formas de P mineral insoluble o fijadas (Stevenson 1986). La fauna del suelo es menos importante como reserva de nutrientes, pero aumenta la renovación de la biomasa microbiana por el pastoreo y la depredación (Bünemann y Condron 2007).

Los procesos de mineralización e inmovilización ocurren simultáneamente (Stevenson 1986, Bünemann y Condron 2007) por lo tanto el mantenimiento del fosfato soluble en la solución del suelo dependerá de igual modo de la magnitud de ambos procesos (Stevenson 1986). Muchos factores, tales como la temperatura, la humedad, la aireación, el pH del suelo, la presencia de plantas creciendo, la adición de fertilizantes orgánicos o inorgánicos, que aportan una fuente de C lábil, (Bünemann y Condron 2007), afectan la tasa de mineralización del P orgánico (Stevenson 1986).

El P es el único macronutriente esencial que cuando es agregado al suelo puede reaccionar con él formando compuestos fosfatados de baja solubilidad (Heredia 2000). Existen distintas formas de fijación o sorción de fosfatos por el suelo (Heredia 2000), las cuales constituyen los principales procesos de transformación de $\mathrm{P}$ en los sistemas suelo-planta que controlan su disponibilidad para las plantas y las pérdidas potenciales (Fageria 2009). Se utilizarán los términos "fijación” o "sorción” para referirse a los fenómenos por los cuales un nutriente pasa de una forma disponible o aprovechable a una no aprovechable (Heredia 2000). Ocurren dos reacciones de fijación principales: la adsorción y la precipitación (Murrell 2003). En las reacciones de adsorción, el P es fuertemente retenido en las superficies coloidales, sean minerales de arcilla, óxidos de hierro y aluminio, o materia orgánica (Heredia 2000, Murrell 2003, Fageria 2009). En las reacciones de precipitación, el $\mathrm{P}$ puede reaccionar con otras especies químicas en solución o con la superficie de los minerales, formando compuestos insolubles, como el fosfato de hierro, aluminio, manganeso o calcio, según el pH del medio (Heredia 2000, Murrell 2003, Fageria 2009). En suelos ácidos, el P es principalmente ligado al hierro y aluminio, mientras que en los suelos alcalinos es ligado al calcio (Stevenson 1986, Rodríguez y Fraga 1999, Fageria 2009). Los dos tipos de reacciones dejan poco P en la solución del suelo (Murrell 2003). Otra reacción de fijación que suele ocurrir en el suelo es la sustitución isomórfica, también llamada cristalización o inclusión (Duchaufour 
1975), donde el P entra en la red cristalina reemplazando a los hidroxilos (Heredia 2000). La desorción es el fenómeno por el cual se libera una sustancia a partir de una superficie, o sea que se trata del proceso opuesto a la adsorción (Fageria et al 2003), y la solubilización es proceso inverso a la precipitación (Wild 1992).

Se habla de fijación o sorción de fosfatos como términos generales ya que es difícil separar los procesos de adsorción de los de precipitación (Wild 1992, Heredia 2000). Posiblemente los mecanismos de adsorción prevalecen a bajas concentraciones de $\mathrm{P}$ y los mecanismos de precipitación a altas concentraciones de $\mathrm{P}$ (Lin et al. 1983, Rhue y Harris 1999). La adsorción de P es alta en los suelos que contienen mayor cantidad de hidróxidos amorfos de hierro y aluminio, y alofano (Fageria 2009), teniendo los óxidos de hierro y aluminio hidratados mayor capacidad de fijación de $\mathrm{P}$ que las arcillas, como materiales puros (Heredia 2000), aunque este orden puede verse afectado por otros factores como el pH, grado de hidratación del mineral, ión acompañante, etc. (Heredia 2000). La sorción de $\mathrm{P}$ es mayor en suelos que contienen alto contenido de arcilla en comparación con los suelos de textura gruesa (Fageria 2009).

Asimismo, son varios los factores ambientales que pueden modificar el grado al cual la sorción y la precipitación ocurren y pueden influenciar en la partición del P entre la fase sólida y la fase solución del suelo, como en los cambios en las condiciones redox del suelo (Scalenghe et al. 2002). Si bien una disminución en el potencial redox del suelo no afecta directamente al P, los cambios en los componentes del suelo a los que el P se asocia pueden modificar su dinámica (Ajmone-Marsan et al. 2006).

En síntesis, la adquisición de P por las plantas no es un problema de oferta total sino de la falta de disponibilidad (Fageria 2009), y su asimilabilidad dependerá de la rápida renovación de la solución mediante la desorción de los iones adsorbidos sobre la fase sólida del suelo (Fageria 2009), de la capacidad del suelo para suministrar P a las raíces (Fageria 2009), y de la mineralización de los compuestos orgánicos fosforados (Wild 1992). Como la concentración de P es muy baja en la solución del suelo, debe ser repuesto varias veces al día durante el ciclo de un cultivo (Heredia 2000).

\subsection{ALGUNAS FORMAS DE SUPERAR LAS LIMITACIONES NUTRITIVAS DE LAS PLANTACIONES DE EUCALYPTUS Y SUS PROBLEMAS}

En la agricultura es común la declinación en pocos años de la productividad de los cultivos cuando se deja de fertilizar con $\mathrm{N}$, o no se incluyen o son escasas las 
leguminosas fijadoras de nitrógeno atmosférico en las mezclas o rotaciones. La limitada biodisponibilidad de $\mathrm{N}$ y la dependencia del crecimiento de los cultivos en este elemento han generado una industria masiva de fertilizantes a base de $\mathrm{N}$ en todo el mundo (Miller y Cramer 2004), con un aumento cercano al 700\% en el uso mundial de fertilizantes (Matson et al. 1997, Tilman et al. 2001) desde fines de 1960 (Matson et al. 1997). La fertilización química provoca distintos perjuicios en los componentes del ecosistema cuando son aplicados en grandes cantidades, con aumentos significativos en las poblaciones de patógenos, incluyendo hongos, bacterias y virus, e insectos perjudiciales para los cultivos (Huber 1981, Matson et al. 1997). Si bien casi ninguno de los fertilizantes de uso común son ácidos, con excepción de los ácidos sulfúrico y fosfórico, los cuales son una pequeña parte del total (Meister 1995), muchos de los nutrientes adicionados son formadores de ácidos (Barak et al. 1997); tal es el caso del uso de fertilizantes amoniacales, los cuales son probablemente acidificantes del suelo, en especial aquellos con poca actividad de arcillas (Bolan et al 1991, Stumpe y Vlek, 1991). La acidificación de los suelos causa incrementos en la solubilidad del Al y Mn y pérdidas de $\mathrm{Ca}$ y $\mathrm{Mg}$ a través del lavado, y puede conducir a la deficiencia de nutrientes después de unos pocos años (Jones 1976, Balasubramanian y Singh 1982, Haynes y Swift 1986). La agricultura es la mayor fuente antrópica de nitrato a los acuíferos (Hallberg 1989), dado que los fertilizantes nitrogenados (orgánicos e inorgánicos) y contaminantes asociados, como el biuret (Mikkelsen 2007) aplicados en forma excesiva en un intento de garantizar los máximos rendimientos, se acumulan en algunas situaciones a niveles peligrosos o incluso tóxicos (Miller y Cramer 2004) causando diversos efectos, y siendo el contaminante más común en estas aguas (Freeze y Cherry 1979). El nitrato es una forma estable de $\mathrm{N}$ en ciertas condiciones naturales (Stumm y Morgan 1981) y forma compuestos que son muy solubles (Hook 1983) pudiéndose transportar a los acuíferos donde deriva en compuestos de $\mathrm{N}$ provocando una extensa eutrofización de las aguas superficiales y subterráneas (Miller y Cramer 2004) y la degradación de los ecosistemas acuáticos además de problemas tales como la proliferación tóxica de algas, pérdida de oxígeno, peces muertos y pérdida de biodiversidad (Carpenter et al. 1998). La concentración de nitrato en el agua potable también es importante por su posible relación con la metahemoglobinemia en niños (Addiscott et al. 1991) y con el linfoma de no Hodgkin (Ward et al. 1996). Las estimaciones de la pérdida total de $\mathrm{N}$ por lixiviación de $\mathrm{NH}_{4}{ }^{+}$a partir de abonos oscilan entre 10 y $150 \mathrm{~kg}$ de $\mathrm{N} \mathrm{ha}^{-1}$ (Hebebrand 2015). La contaminación atmosférica por $\mathrm{NH}_{3}$ 
proveniente de abonos orgánicos, urea y sulfato de amonio puede ser el resultado de la volatilización $\mathrm{NH}_{3}$ (Miller y Cramer 2004), y aunque las estimaciones están sujetas a un alto grado de incertidumbre, se estima que entre el $15 \%$ y el $25 \%$ de la cantidad aplicada de urea se pierde de este modo para Europa y para el trópico, respectivamente (Schjørring 1998). También puede haber pérdidas por desnitrificación, las cuales pueden estar en el rango de 5 a $10 \%$ del $\mathrm{N}$ aplicado, de los cuales aproximadamente el $10 \%$ está en la forma $\mathrm{N}_{2} \mathrm{O}$ (Hebebrand 2015), que es un gas de efecto invernadero (Miller y Cramer 2004). El uso de fertilizantes también conduce a un aumento en las emisiones de otros gases de efecto invernadero, como $\mathrm{CO}_{2}, \mathrm{y} \mathrm{CH}_{4}$ (Williams et al. 1992, Vitousek y Matson 1993, Galloway et al. 1995), que junto con el $\mathrm{N}_{2} \mathrm{O}$ juegan un papel crítico en la química de la tropósfera y estratósfera y la contaminación del aire (Williams et al. 1992, Matson et al. 1997). La aplicación excesiva de fertilizantes tiene enormes costos ambientales y económicos, ya que la producción de fertilizantes nitrogenados se realiza principalmente por un proceso industrial que consume combustibles fósiles (gas natural) convirtiendo abundante $\mathrm{N}$ atmosférico a las formas disponibles para las plantas, y los fertilizantes fosforados se extraen de depósitos de roca rica en $\mathrm{P}$ (Matson et al. 1997). De toda la energía consumida en la actividad agrícola, el mayor porcentaje (31\%) corresponde a la fabricación de fertilizantes inorgánicos (Pfeiffe 2003, Miller y Cramer 2004) consumiendo gas natural, mientras que se utiliza petróleo en la fabricación de pesticidas e hidrocarburos en general para la irrigación (Pfeiffe 2003).

Los abonos orgánicos se han usado desde tiempos remotos y su influencia sobre la fertilidad de los suelos se ha demostrado, aunque su composición química, el aporte de nutrimentos a los cultivos y su efecto en el suelo varían según su procedencia, edad, manejo y contenido de humedad (Lima et al. 2000). Hoy día estos abonos son la base del desarrollo de la Agricultura Orgánica y Sostenible (Paneque-Pérez 2010), quién tiene como uno de sus objetivos el reducir las pérdidas de nutrientes mediante la contención efectiva de la lixiviación, escurrimiento, erosión y mejorar el reciclado de nutrientes, mediante la utilización de leguminosas, abonos orgánicos, composta y otros mecanismos efectivos de reciclado (Altieri y Nicholls 2000). Sin embargo, existe una gran variedad de abonos orgánicos con características muy variables dependiendo de la fuente de origen y el tratamiento a que sean sometidos (Paneque-Pérez 2010). Pese a que la aplicación de los residuos orgánicos tiene sobre el suelo muchos efectos favorables debido a la adición de materia orgánica y nutrientes, también existen ciertos 
riesgos, en especial cuando se aplican dosis masivas o si éstos son lodos residuales (domésticos o industriales), considerando que los materiales básicos que los forman incorporan sustancias peligrosas, entre las cuales está la presencia de metales pesados, lo que en mayor o menor grado puede limitar su uso (Costa et al.1991, Abad 1998). Otros inconvenientes que puede presentar esta práctica son el desbalance de nutrientes que puede ocasionar un abono con muy baja y variable concentración de nutrientes, o la dificultad de encontrar fertilizantes orgánicos con la misma calidad, ya que existen muchos factores que provocan la heterogeneidad de los mismos (Herrán et al. 2008).

Es muy importante destacar que en el ámbito forestal la retención de los residuos de cosecha es un camino apto para manejar la fertilidad del sitio (Corbeels et al. 2003, Goya et al. 2004, Graciano et al. 2008). La caída de hojarasca representa el mayor proceso de transferencia de nutrientes de las partes aéreas hacia el suelo (Vitousek et al. 1994), y el conocimiento del aporte en elementos nutritivos de la hojarasca es útil para orientar el manejo nutritivo de las plantaciones de Eucalyptus sp (Schlatter et al. 2006). No obstante que el mantenimiento de los residuos de cosecha en el sitio pueda implicar un retorno significativo de $\mathrm{N}$ y otros nutrientes, el conocimiento de la dinámica de la mineralización de esos residuos es la que efectivamente permitiría medir el impacto del manejo de los residuos sobre la disponibilidad de $\mathrm{N}$ para plantas y microorganismos de suelo.

La posibilidad de incorporar leguminosas como cubiertas verdes o como árboles de producción en cultivos mixtos podría ayudar en la provisión de $\mathrm{C}$ y $\mathrm{N}$ al suelo. Esta práctica podría mejorar la estructura del suelo reduciendo la erosión, podría disminuir la necesidad de incorporar nutrientes inorgánicos, mejorar el contenido orgánico del suelo, aumentar la capacidad del suelo de retener agua, (Abdul-Baki y Teasdale 1993), aportar considerables cantidades de nitrógeno orgánico por medio del proceso de fijación biológica (Singogo et al. 1996), estimular el incremento de los rindes de los cultivos posteriores (Abdul-Baki et al. 1996a, Bowen y Freyman 1995), facilitar el control de malezas (Bordelon y Weller 1997) y permitir desarrollar agroecosistemas sustentables con mínima utilización de agroquímicos (Abdul-Baki et al. 1996b, Burket et al. 1997). Estos insumos orgánicos tienen además beneficios ambientales adicionales, ya que agilizan los ciclos de nutrientes, aumentan las tasas de mineralización y la transformación de formas inorgánicas de $\mathrm{P}$ en otras de mayor disponibilidad para las plantas (Iyamuremye et al. 1996). Además, el uso de insumos orgánicos puede transferir 
grandes cantidades de carbono soluble que los microorganismos pueden utilizar como fuente de energía (Kwabiah et al. 2003b).

El aporte de los residuos foliares de eucaliptos y, en el caso de implementar intercultivos, de leguminosas, puede significar una parte destacable de la reserva de $\mathrm{N}$ de plantaciones bajo manejo (Corbeels et al. 2003). En un sistema forestal, la eficiencia en el uso del $\mathrm{N}$ depende del sincronismo entre la liberación del nitrógeno y la demanda de los árboles. La tasa a la cual los nutrientes son liberados durante la descomposición puede diferir marcadamente entre diferentes sistemas y es influenciada por las características físicas y bioquímicas de los residuos y por la demanda heterotrófica de los organismos descomponedores (O’Connell y Sankaran 1997). La hojarasca proveniente de muchas, aunque no todas, especies fijadoras de nitrógeno se descompone rápidamente (Swamy 1989, Binkley 1992, Bernhard-Reversat 1993, Tsai 1998). Por el contrario, la hojarasca producida por los eucaliptos frecuentemente se descompone lentamente, y se acumula en el piso del bosque (Sharma y Pande 1989, Swamy 1989, Bargali y Singh 1991, Sankaran 1993, Singh et al 1993, Toky y Singh 1993). La tasa de descomposición foliar de las hojas de eucaliptos en el área de Concordia es baja para el clima del sitio (Goya et al. 1997a). Para una gran mayoría de especies de eucaliptos el contenido de nutrientes en las hojas es bajo (Bell y Williams 1997, Landsberg y Cork 1997), las hojas son esclerófilas (Williams y Brooker 1997), y la abundancia de fibras crudas y lignina es alta (Cork 1984, O’Connell 1987, Cork y Foley 1991), como también la presencia de polifenoles en las hojas (Corbeels et al. 2003). Como en otras especies, estos son algunos de los probables factores que incidirían en la tasa de descomposición (Corbeels et al. 2003) y el control de la herbivoría (Landsberg y Cork 1997); sin embargo la incidencia de algunos de estos factores en la descomposición y mineralización podría estar modificada por las condiciones del medio físico (Corbeels et al. 2003). Hay eucaliptos, entre los que se encuentra E. grandis, con mayores concentraciones de nutrientes foliares (Bell y Williams 1997). La mayoría de los eucaliptos parecen similares a muchas otras plantas de crecimiento lento en su preferencia por $\mathrm{NH}_{4}{ }^{+}$en lugar del $\mathrm{NO}_{3}{ }^{-}$(Adams y Attiwill 1986). En la mayoría de sus bosques nativos el $\mathrm{NH}_{4}{ }^{+}$es la forma dominante de $\mathrm{N}$ en el suelo y los altos cocientes $\mathrm{C} / \mathrm{N}$ se asocian con las bajas tasas de mineralización y una nitrificación limitada (Attiwill y Leeper 1987).

El uso de cubiertas verdes de leguminosas de tasa de descomposición rápida y contenido de nitrógeno altos, puede aportar $\mathrm{N}$ en el corto plazo. Asimismo es de esperar 
que, en suelos de textura contrastante, la interacción entre los procesos vinculados a los nutrientes en la hojarasca y los del complejo orgánico-biótico-mineral del suelo superficial produzca distinta disponibilidad de $\mathrm{N}$ en la solución del suelo. Por lo tanto, el conocimiento del aporte de nutrientes debido a la mineralización de las hojas de eucaliptos y de leguminosas que puedan ser cultivadas bajo árboles, podría ayudar a plantear un manejo del residuo que optimice la disponibilidad de $\mathrm{N}$ en el corto y largo plazo en aquellos suelos de mayor potencial.

\subsection{CALIDAD QUÍMICA Y FÍSICA DE LOS RESIDUOS}

La calidad del material vegetal tiene dos componentes: la composición bioquímica ("calidad química") y la naturaleza física ("calidad física") (Bending y Turner 1999). Las tasas de descomposición y la liberación de $\mathrm{N}$ están en buena medida influenciadas por su calidad o composición bioquímica (Swift et al. 1979, Cadisch y Giller 1997). La calidad de la hojarasca afecta la abundancia, composición y actividad de la comunidad descomponedora, por lo que es el factor principal que controla las tasas de descomposición de la materia orgánica y la liberación de nutrientes (Blair et al. 1990). Entre los indicadores de calidad química que se han encontrado relacionados con la liberación de $\mathrm{N}$, especialmente en leguminosas tropicales, se encuentra el contenido de $\mathrm{N}$ o la relación $\mathrm{C} / \mathrm{N}$ (Trinsoutrot et al. 2000), la relación polifenol/N y la relación (polifenol+lignina)/N (Palm y Sánchez 1991, Constantinides y Fownes 1994). Para árboles se ha encontrado una buena relación de la liberación de $\mathrm{N}$ del mantillo foliar con la relación lignina/N o concentración de lignina (Melillo et al. 1982).

Las características del material vegetal que representan su calidad física se han definido de manera más sintética o extensiva de acuerdo al interés de la misma para diferentes organismos. Por ejemplo, Landsberg y Cork (1997) definen la calidad física foliar (leaf toughness) en relación al interés para los herbívoros de acuerdo a la resistencia física a la perforación y masticación. Por otra parte, en un contexto más amplio que incluye también a fraccionadores y descomponedores, la calidad física incluye el tamaño de las partículas, la dureza, las propiedades de la superficie incluyendo el espesor y la composición de la cutícula, la presencia de estructuras de defensa tales como espinas, y el contenido de agua (Swift et al. 1979). Estas propiedades tienen la potencialidad de influir en la accesibilidad del sustrato para los 
organismos del suelo, y de esta manera alterar las tasas de colonización y los patrones de descomposición y mineralización (Bending y Turner 1999).

Uno de los parámetros de calidad física que ha recibido mayor atención en los estudios de ciclo de nutrientes es el tamaño de partícula (Bending y Turner 1999). Varios artículos han confirmado que el tamaño de partícula influye en estos procesos, aunque la naturaleza del efecto parece variable, con algunos informes que indican que reduciendo el tamaño de la partícula aumentan las tasas de los procesos microbianos (Sims y Frederick 1970, Nyhan 1976, Amato et al. 1984), mientras que otras investigaciones han mostrado el efecto contrario (Stickler y Frederick 1959, Sorensen et al 1996, Jensen 1994). Las características físicas de los residuos y su contacto con el suelo también inciden en la tasa de descomposición y en la dinámica del N (Ambus y Jensen 1997, Frangi et al. 1997), y estos factores pueden interactuar con la composición bioquímica de los residuos para influir en la tasa de inmovilización/mineralización del N (Bending y Turner 1999). Por otro lado, los métodos de incubación pueden también incidir en la relación entre calidad del material vegetal y la liberación del N (Corbeels et al. 2003). Handayanto et al. (1994) compararon 3 métodos diferentes para descomposición foliar y observaron que la descomposición bajo condiciones de lavado en laboratorio dio similares resultados que con bolsas de descomposición a campo, a diferencia del método de incubación en laboratorio sin condiciones de lavado.

\subsection{RELACIONES ENTRE LA DISPONIBILIDAD DE AGUA EN EL SUELO Y LA DISPONIBILIDAD DE N Y P}

El aire del suelo guarda una relación inversa con su contenido de agua: al aumentar la proporción de la fase líquida disminuye la proporción de la fase gaseosa. El aire del suelo a su vez guarda relación con el tamaño de los poros que se forman entre los agregados (Fassbender 1982). El contenido de oxígeno del aire en los poros de suelos bien drenados raramente cae muy por debajo del $20 \%$ encontrado en la atmósfera libre, pero el déficit de oxígeno es común en suelos pobremente drenados y de textura fina (Fisher y Binkley 2000). Las arenas contienen gran cantidad de

macroporos con una buena aireación y una escasa retención de agua. Las arcillas por el contrario, presentan mayor cantidad de microporos que pueden estar llenos de agua (Fassbender 1982). 
Muchas de las reacciones químicas inorgánicas del suelo y prácticamente todas las reacciones biológicas del carbono, nitrógeno y azufre, son reacciones de oxidación y de reducción, y dependen en gran medida de la presencia o ausencia de oxígeno (Bohn et al. 1993). Por lo general el oxígeno está disponible para las raíces de los vegetales, microorganismos y sustancias inorgánicas en suelos bien drenados, pero si la longitud de la trayectoria de difusión a través del suelo es grande, las raíces y los microorganismos pueden carecer de oxígeno, al cual requieren para metabolizar $\mathrm{u}$ obtener su energía de las moléculas orgánicas presentes en el suelo.

Las condiciones anaeróbicas del suelo provocan cambios químicos muy importantes y las reacciones que se producen varían sustancialmente: la nitrificación disminuye y aumenta considerablemente la desnitrificación (Fassbender 1982). Cambios relevantes en la disponibilidad de $\mathrm{P}$ ocurren también según las condiciones sean aeróbicas o anaeróbicas, el $\mathrm{pH}$, las reacciones con otros elementos químicos, la presencia de arcillas y el comportamiento de los microorganismos.

En condiciones de campo suelen darse situaciones de estrés hídrico (por exceso o déficit) que, además de modificar los procesos de mineralización de la materia orgánica, limitan el crecimiento de los eucaliptos en plantaciones al turno (12 a 15 años), y conlleva a un menor crecimiento en suelos arcillosos que en suelos arenosos a pesar de su mayor contenido de $\mathrm{N}$ total (Goya et al. 1997a, b). Asimismo, en condiciones de riego frecuente (sin estrés ni exceso) se ha constatado que plantas jóvenes de eucaliptos crecen más en suelos arcillosos que en arenosos (Graciano et al. 2006b). En general, el crecimiento es mayor cuanto mayor sea la disponibilidad de agua y nutrientes, siempre y cuando otros factores no sean limitantes (i.e. oxígeno en el suelo, dióxido de carbono, temperaturas). A su vez, la disponibilidad de agua y nutrientes se relaciona estrechamente con las características de los suelos que condicionan la concentración de nutrientes y su difusión hacia la rizosfera y la capacidad de retención de agua. Por lo tanto, la tasa de absorción de nutrientes que realicen las plantas dependerá del tipo de suelo (que aporta los nutrientes) y de la disponibilidad de agua (que condiciona tanto el crecimiento de la planta como la movilidad de los nutrientes en el suelo). En consecuencia, la absorción de nutrientes que realicen las plantas influirá en la cantidad de nutrientes que quede en el suelo disponible para los microorganismos, y por lo tanto afectará la descomposición de la materia orgánica. Es por eso que la dinámica de la descomposición de la materia orgánica que 
ocurra en un sistema sin presencia de plantas (suelo-microorganismos) nos es directamente comparable con la dinámica de un sistema suelo- microorganismos-planta.

\subsection{RESPUESTA DE LAS PLANTAS AL SUMINISTRO DE N Y P MEDIANTE RESIDUOS DE LEGUMINOSAS PROCEDENTES DE CUBIERTAS VERDES}

La fertilización en E. grandis en la zona de estudio suele limitarse al agregado de fertilizante al lado de las raíces de cada planta en el momento de plantación. Por esa razón resulta posible pensar en el empleo de cubiertas verdes de leguminosas herbáceas que se instalen junto con los plantines aprovechando la disponibilidad de luz por la presencia de un dosel arbóreo incipiente. El crecimiento de las plantas arbóreas es tan rápido ( $3 \mathrm{~m}$ de altura en un año en plantas no fertilizadas según Graciano et al. (2008)) que cabe esperar que, al final del primer año, esa disponibilidad lumínica sea reducida y que la cubierta verde no prospere, pasando sus residuos a formar parte del suelo. Estos acontecimientos pueden ayudar al reemplazo de la fertilización inorgánica por aportes orgánicos ricos en nitrógeno. Los beneficios de esto son que las cubiertas verdes protegen al suelo de la erosión que produce el viento y el agua sobre suelos descubiertos, y reduce el lixiviado de nutrientes y el establecimiento de malezas en los sectores no ocupados por los árboles, hasta que la plantación cubra totalmente el sitio (Fisher y Binkley 2000). Este modelo requiere realizar una verificación de las consecuencias del aporte nitrogenado sobre el crecimiento de las plantas de eucaliptos juveniles, ya que si el agregado de mantillo disminuye la disponibilidad de nutrientes en la solución del suelo, el crecimiento de las plantas puede disminuir. Por otro lado, en la competencia por los nutrientes del suelo, pueden ganar los microorganismos o las

plantas, dependiendo de las especies involucradas, la disponibilidad de agua y las características del suelo (Rodríguez et al. 2009). Por otra parte, la presencia de raíces en el suelo puede afectar la tasa de mineralización de la materia orgánica, ya sea por los efectos directos de la disminución de la concentración de nutrientes en la rizosfera, como por efectos mediados por el cambio físico que realizan las raíces en el suelo (mayor estructura del suelo), cambios químicos (liberación de ácidos orgánicos, enzimas, exudados radicales) y por el recambio de raíces finas que brindan un sustrato adicional a los microorganismos.

Dada la complejidad de las interacciones en sistemas formados por suelo, plantas y microorganismos, es difícil predecir los resultados en el crecimiento de las 
plantas de la adición de abonos de leguminosas. Esta tesis hace un aporte en esta dirección utilizando plantas cultivadas en condiciones semicontroladas, para evaluar el resultado de la aplicación de abonos en los diferentes tipos de suelos y con diferente disponibilidad de agua.

\subsection{DESCRIPCIÓN DE EUCALYPTUS GRANDIS Y DE LAS ESPECIES DE LEGUMINOSAS SELECCIONADAS PARA SER UTILIZADAS COMO ABONOS ORGÁNICOS}

\subsubsection{Eucalyptus grandis}

El género Eucalyptus comprende más de 700 especies e híbridos, originarios de los bosques naturales de Australia, Indonesia y Papúa Nueva Guinea (Boland et al. 1992, González et al. 2011). La madera de los eucaliptos se encuentra entre las más duras entre las especies plantadas, con 18 millones de hectáreas en 90 países bajo condiciones climáticas templadas, tropicales y subtropicales (Meskimen y Francis 1990, Rockwood et al. 2008). Las diferentes especies se cultivan en diferentes países, de acuerdo a la capacidad de adaptación a las condiciones climáticas y de suelo (Neiva et al. 2015). Dado el rápido crecimiento de los eucaliptos en rotaciones cortas, con un crecimiento en altura promedio de 2 m por año (National Academy of Sciences 1980), varias de estas especies fueron seleccionadas y plantadas en todo el mundo como bosques de rotación corta para uso industrial y comercial, para el aprovechamiento de la pulpa y la madera, asimismo como fuente renovable de energía (Guo et al. 2002, Ferreira et al. 2013, Knapic et al. 2014).

La especie Eucalyptus grandis Hill ex Maiden es nativa de la costa este de Australia (Meskimen y Francis 1990). Su nombre común es "eucalipto rosado" (Meskimen y Francis 1990), y es una de las especies de mayor importancia comercial (Meskimen y Francis 1990). Argentina es uno de los principales países plantadores de esta especie, tanto para las plantaciones industriales, cortinas rompevientos, cortinas protectoras, como para las ornamentales (FAO 1980). La importancia de esta especie radica en la elevada productividad de los cultivos y en las excelentes propiedades de la madera, de variada aptitud industrial (Guarnaschelli et al. 2009). Uno de los principales usos de la madera de eucalipto es como materia prima para la industria de la pulpa y el papel (Neiva et al. 2015) debido al alto rendimiento de la pasta y la alta calidad de la 
pulpa de fibra corta con muy buenas propiedades físicas y ópticas (Kordsachia et al. 1992, Kibblewhite et al. 2000, Paavilainen 2000, Ona et al. 2001). Otros usos de esta madera son para tableros aglomerados, hornos de carbón vegetal para la industria del hierro, trozas para aserrado y, en forma amplia, para postes y estacas (Brown 1978, FAO 1980, Boland et al. 1984, Meskimen y Francis 1990).

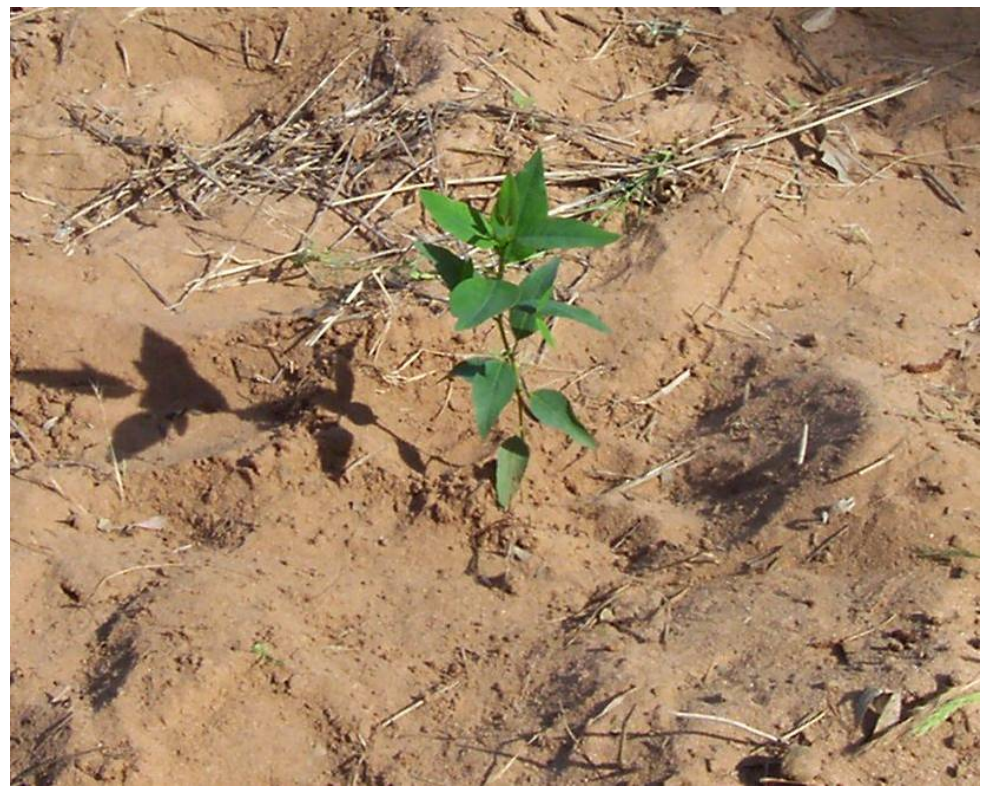

Imagen 1.1. Planta juvenil de E. grandis

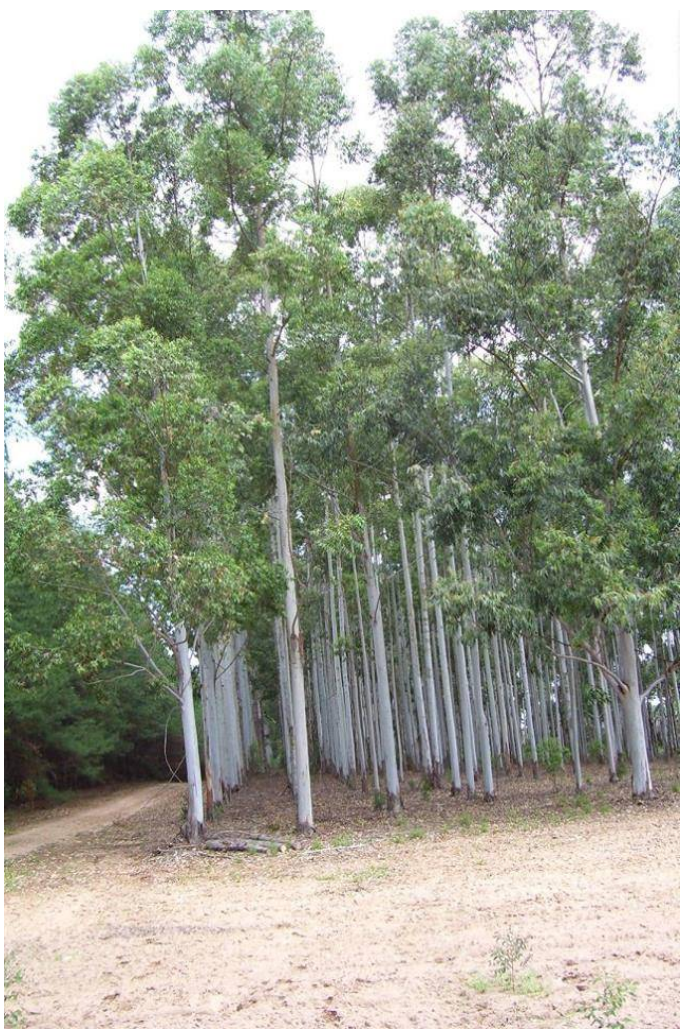

Imagen 1.2. Plantación de E. grandis de 10 años de edad. 
E. grandis alcanza alturas de 45-55 m, con una copa bien abierta bastante rala (Imagen 1.2). Sus hojas juveniles son alternas, con pecíolos cortos, y forma lanceolada oblonga, levemente ondulada (Imagen 1.1). Las hojas adultas son alternas, pecioladas, lanceoladas, levemente onduladas con una larga punta. La madera es rosada a pardo rojizo clara (FAO 1980).

\subsubsection{Canavalia ensiformis}

Canavalia ensiformis L., llamada vulgarmente "frijol de chancho", "frijol espada", "frijol machete" o "frijol mantequilla", es una leguminosa herbácea erecta. Algunas líneas dentro de la especie presentan características trepadoras (Alemán y Flores 1993). Es anual a perenne (Alemán y Flores 1993), con un ciclo de cultivo de entre 170 y 240 días, con germinación rápida. Puede alcanzar una altura de entre 60 y $100 \mathrm{~cm}$. Sus tallos son pocos ramificados, glabros y de color púrpura, sus flores de color blanco a rosado. Su fruto son vainas de forma oblongas o redondas, algo aplastadas, lisas y de color blanco, con $30 \mathrm{~cm}$ de largo y $3.5 \mathrm{~cm}$ de ancho, ensiformes e indehiscente, con entre 12 y 20 semillas por vaina (Imagen 1.3).

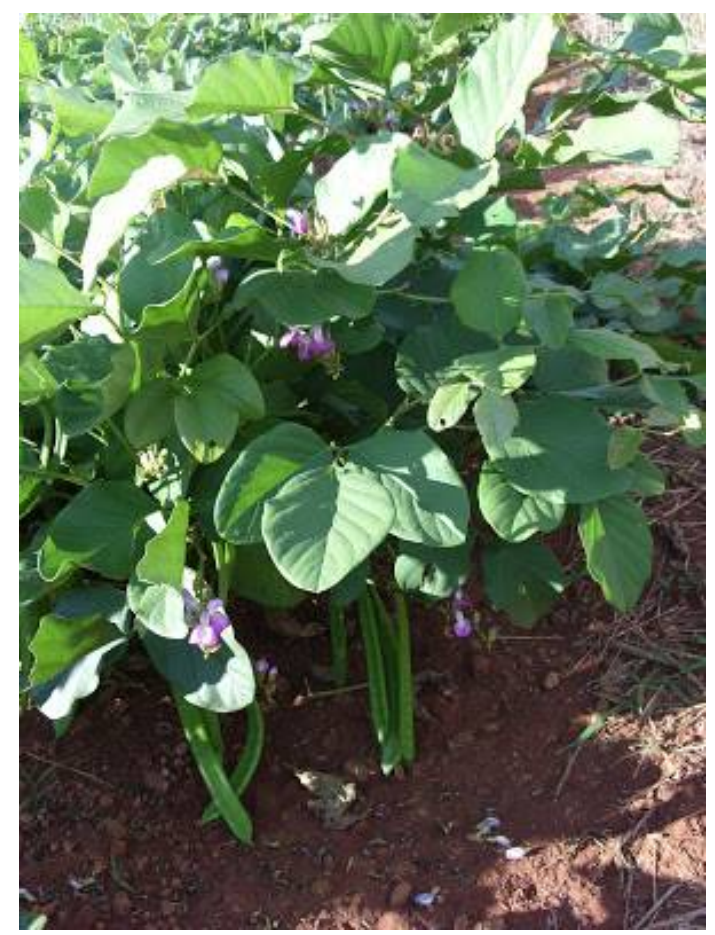

Imagen 1.3. Canavalia ensiformis.

Su origen probable es la India y Centroamérica (National Academy of Sciences 1979). Su utilización como cultivo de cobertura está tomando mayor importancia en una 
variedad de sistemas agrícolas en donde se aprovecha como abono verde o cultivo de cobertura durante temporadas de sequía (Alemán y Flores 1993). Entre las principales ventajas del uso de esta leguminosa como cultivo de cobertura y abono verde se pueden enumerar el control de malezas, el aumento de los niveles de materia orgánica en el suelo, la fijación de nitrógeno atmosférico, el control de la erosión cuando se utiliza como cultivo de cobertura (Alemán y Flores 1993).

\subsubsection{Cajanus cajan}

El "guandul”, "gandul”, "guandú", "frijol de palo", "frijol caballero", "frijol arveja" o "chícharo", es una leguminosa arbustiva, que se cultiva hace por lo menos 3 mil años, y cuyo origen se discute si es África occidental o la India. Es anual o perenne, y puede llegar a alcanzar de 3 a 5 metros de altura. Sus hojas son trifoliadas, con foliolos elípticos, agudos en ambos extremos con el haz de color verde oscuro y el envés de color verde claro cubierto por una pubescencia blancuzca y fina. Las flores se presentan en racimos, y son de color amarillo con manchas rojizas o de combinaciones amarillas y púrpura. Las vainas tienen entre 5 y 7 granos, de color verde en los primeros estadios y amarillento o crema en la maduración, según la variedad (Imagen 1.4).

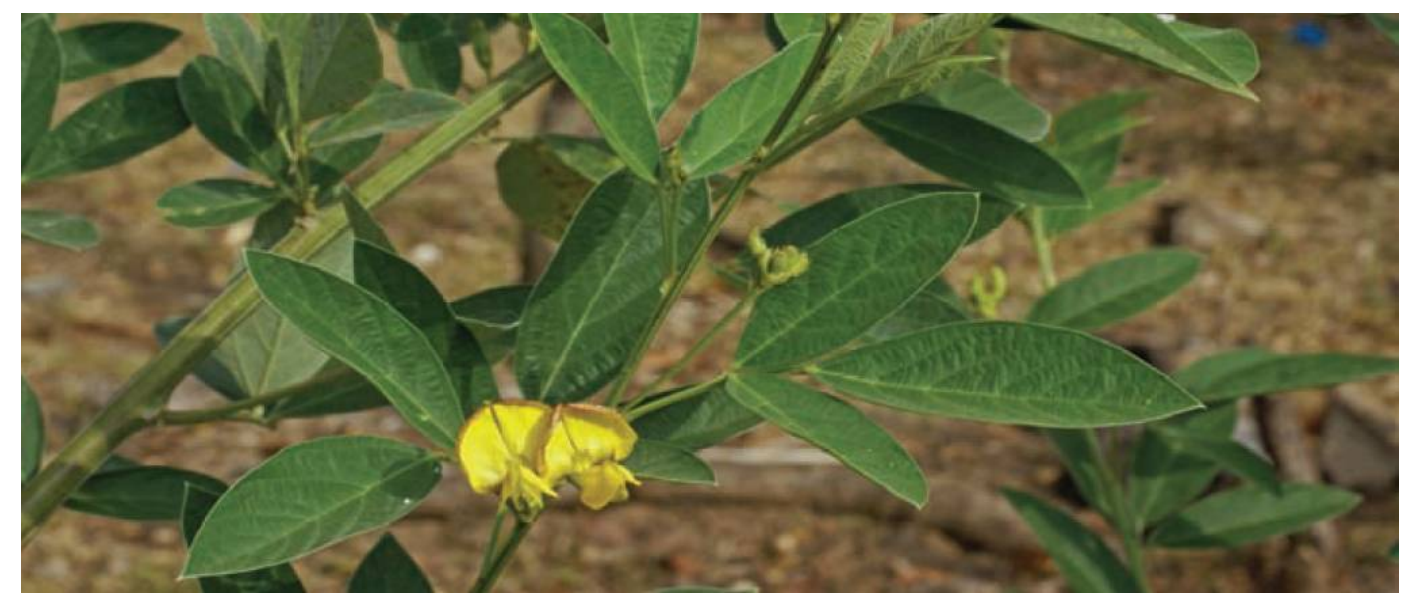

Imagen 1.4. Cajanus cajan.

Es una planta con capacidad de fijar una elevada cantidad de nitrógeno en el suelo. Sus semillas son utilizadas en la alimentación humana y como forraje para la alimentación animal. Contienen entre 10 y $17 \%$ de proteína. Una de las aplicaciones es su empleo como abono verde. Varias investigaciones resaltaron las bondades del guandú para ser utilizado como abono verde en el sur del Brasil, debido a su elevada capacidad de fijación simbiótica de nitrógeno y su alta producción de fitomasa. 


\subsubsection{Lotus corniculatus}

El género Lotus cuenta con alrededor de 200 especies, tanto perennes como anuales (Criado 2014), y es originario de Europa y Asia menor, en la Cuenca del Mediterráneo. La especie Lotus conrniculatus L., llamada vulgarmente "trébol de cuernitos", "loto corniculado", "zapaticos de la virgen", "loto de cuernecillos", "pie de gallo", "trébol de las arenas", "chauchillas", "trébol criollo" o "corona de rey", es una leguminosa nativa de praderas templadas de Eurasia y norte de África, y una de las especies más interesantes dentro del género en cuanto a su aprovechamiento como forrajera, y está muy difundido en Estados Unidos, Australia, Chile y Argentina (Barbarossa et al. 2013a).

Es una especie perenne, generalmente con la base leñosa, de talla variable hasta los $40 \mathrm{~cm}$ de longitud, aunque se suele quedar en $\operatorname{los} 20 \mathrm{~cm}$ por su porte decumbente y rastrero (Barbarossa et al. 2013a). Tras su primer año de crecimiento desarrolla la corona de la que nacen axilarmente las ramificaciones (Barbarossa et al. 2013a) (Imagen 1.5). De ésta también surge una raíz pivotante (Universidad Pública de Navarra 2007). Presenta hojas sésiles ( opuestos, y en la base del raquis dos estípulas desarrolladas. Los foliolos alcanzan una longitud nunca superior a los $17 \mathrm{~cm}$, con una forma ovoidea (Imagen 1.6).

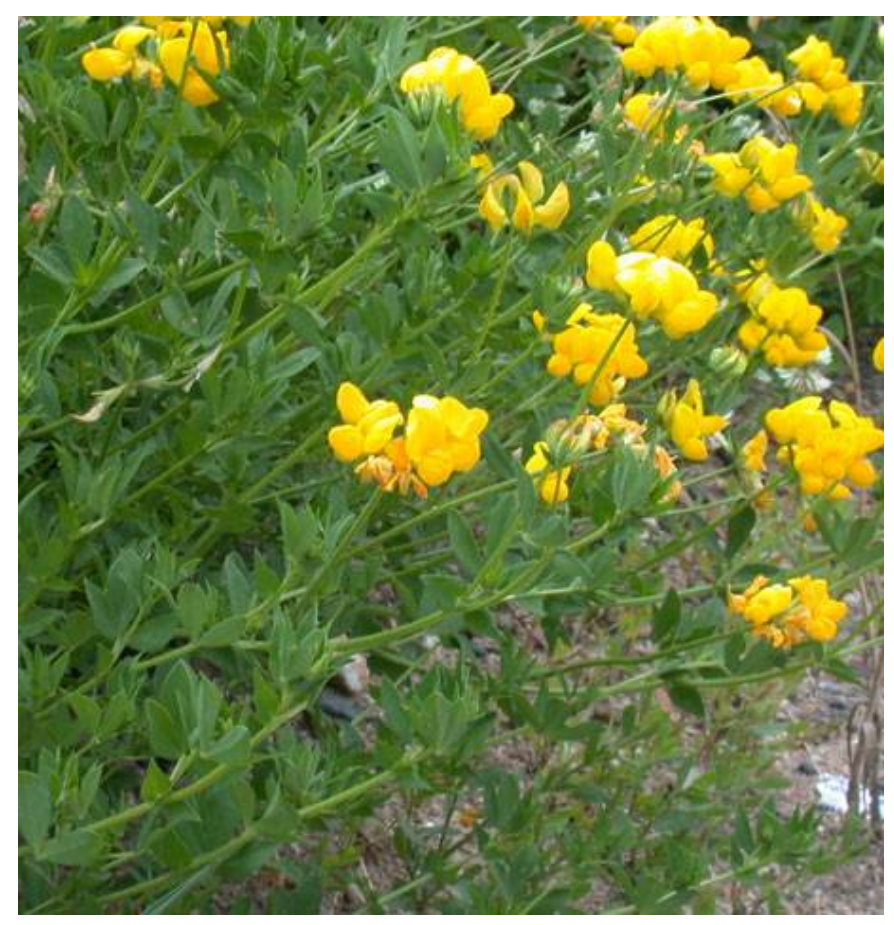


Imagen 1.5. Lotus corniculatus.

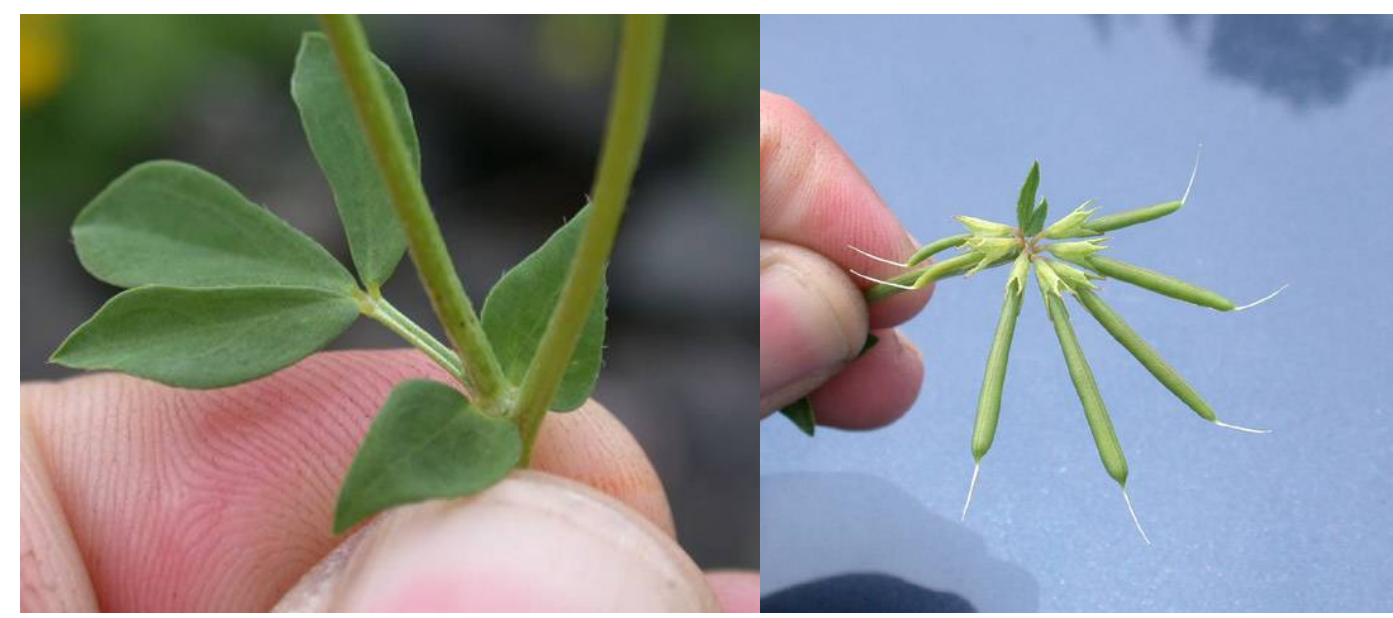

Imagen 1.6. Folíolos y fruto de Lotus corniculatus.

El pedúnculo en el que se inserta la inflorescencia en umbela es de origen axilar.

$\mathrm{Su}$ corola es amarilla, con la forma típica que presentan las leguminosas: de simetría zigomorfa con cinco pétalos (estandarte, quilla y dos alas). El cáliz presenta sépalos de igual longitud y derechos. El fruto es una legumbre de dehiscencia longitudinal, de menos de $4 \mathrm{~mm}$ de grosor. Tiene la forma característica de una pata de pájaro (Imagen 1.6). La legumbre contiene de 10 a 30 semillas y tiene un alto grado de dehiscencia en la madurez, retorciéndose en forma de espiral, especialmente cuando su humedad es inferior al 40\%. Su semilla es redonda de 1 a $1,5 \mathrm{~mm}$ de diámetro, de color marrón a veces punteadas de violeta.

Lotus corniculatus establece asociaciones con bacterias del tipo Rhizobium y es una especie que fija cantidades moderadas de $\mathrm{N}$ aunque requiere de inoculantes, especialmente en aquellos suelos dónde nunca se la cultivó (Frame 1998). Está especialmente difundida en Entre Ríos en suelos de tipo vertisoles, ocupando alrededor de 1,6 millones de hectáreas, dónde la incorporación de pasturas polifíticas permite elevar la oferta forrajera en cantidad y calidad (Barbarossa et al. 2013a). Lotus corniculatus es la principal leguminosa perenne utilizada en los pastizales del área (Barbarossa et al. 2013a).

\subsubsection{Trifolium pratense}

El trébol rojo es una planta perteneciente a la familia de las leguminosas, nativa de Europa, oeste de Asia y noroeste de África (Barbarossa et al. 2013b). Es una herbácea perenne de 10 a $60 \mathrm{~cm}$ de altura, aunque puede alcanzar hasta $110 \mathrm{~cm}$. Se 
comporta como perenne en zonas frías o como cortamente perenne en ambientes más cálidos. Se ha naturalizado en muchas áreas de América.

Tiene tallos erectos y ascendentes (Imagen 1.7), un sistema radical pivotante y numerosas raíces adventicias que forman una corona en el cuello de la planta (Barbarossa et al. 2013b). Tiene además una elevada capacidad de fijación de nitrógeno (Muslera Pardo y Ratera García 1984).

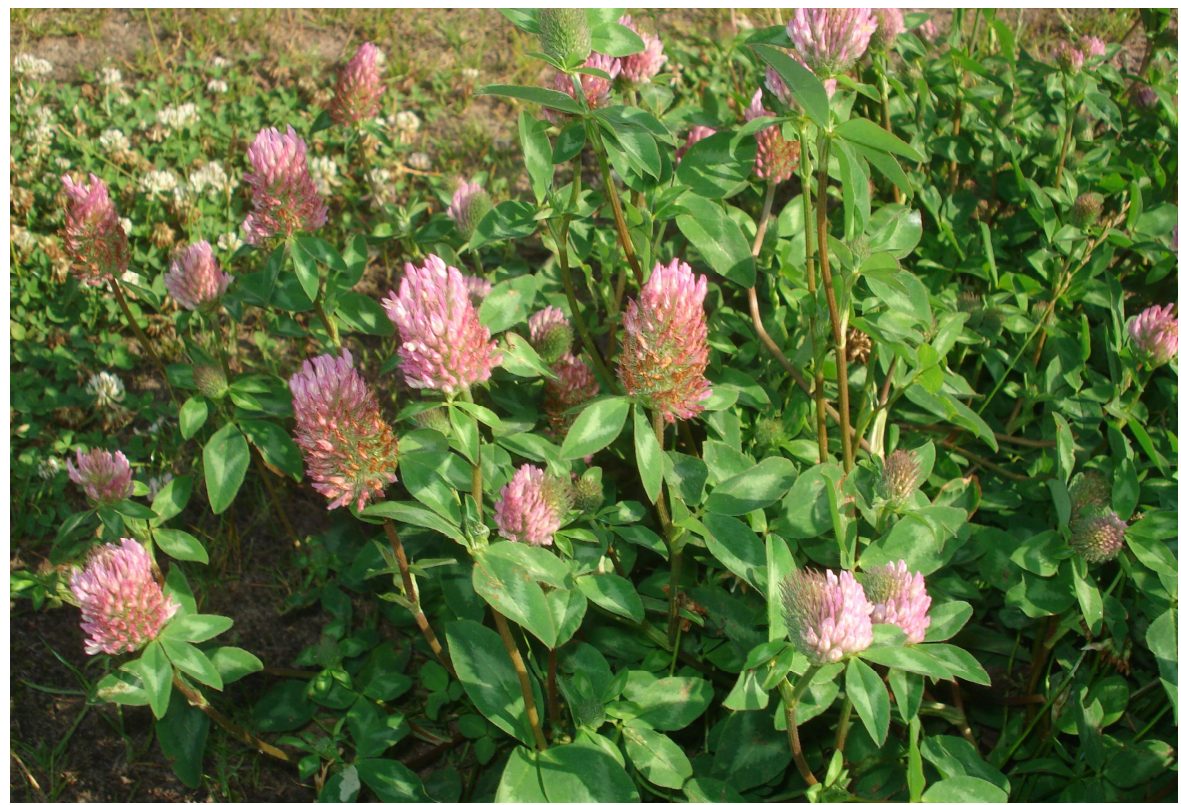

Imagen 1.7. Trifolium pratense.

Es una especie que proporciona forraje abundante y de muy buena calidad, incluso en verano si recibe suficientes aportes hídricos.

\subsection{OBJETIVO GENERAL}

El objetivo general de esta Tesis es indagar el aporte de $\mathrm{N}$ y P al piso forestal y su disponibilidad para ser absorbidos por las plantas, ligado al empleo de residuos de cosecha y de plantas herbáceas fijadoras de $\mathrm{N}$ como posibles reemplazantes de la fertilización química.

\subsection{OBJETIVOS PARTICULARES E HIPÓTESIS}

Objetivo $1^{\mathrm{o}}$ : Evaluar en condiciones controladas, el aporte de $\mathrm{N}$ y P disponible en solución en un suelo arenoso y un suelo arcilloso, por la aplicación de mantillo foliar 
de Eucalyptus grandis y de especies de leguminosas utilizando dos formas de aplicación.

Hipótesis:

- Las hojas de eucaliptos proveen una menor cantidad de $\mathrm{N}$ y de $\mathrm{P}$ al suelo que las especies de leguminosas herbáceas, porque contienen menor concentración de estos nutrientes y porque se descomponen más lentamente debido al mayor grosor de las hojas y mayor contenido de compuestos fenólicos.

Objetivo $2^{\circ}$ : Evaluar las relaciones entre la calidad química de los residuos foliares utilizados y la tasa de descomposición, y relacionarla con el aporte de $\mathrm{N}$ y $\mathrm{P}$ a la solución del suelo.

Hipótesis:

- La calidad química de los residuos afecta la tasa de descomposición y la liberación de $\mathrm{N}$ y $\mathrm{P}$ disponible para las plantas.

Objetivo $3^{\circ}$ : Conocer la influencia del anegamiento en la concentración de $\mathrm{N}$ y $\mathrm{P}$ en la solución de un suelo arcilloso, según el contacto con el suelo del material de hojas de E. grandis y de leguminosas agregado.

\section{Hipótesis:}

- La anoxia reduce la actividad microbiana por lo tanto, en los suelos anegados, la descomposición de los detritos que no estén en contacto con el oxígeno atmosférico será menor que la de los expuestos en superficie.

Objetivo $4^{\circ}$ : Conocer la influencia de las distintas condiciones de disponibilidad de agua (frecuencia de inundación, capacidad de campo y déficit hídrico) en la concentración de $\mathrm{N}$ y $\mathrm{P}$ en la solución de un suelo arcilloso con agregado de hojas de $E$. grandis y de leguminosas.

Hipótesis:

- La disponibilidad de agua y oxígeno en el suelo influye en la actividad microbiana del suelo, de manera que el déficit y el exceso de agua por periodos prolongados reducirán la tasa de descomposición de los detritos. 
Objetivo $5^{\circ}$ : Evaluar el efecto de la incorporación de residuos foliares de leguminosas, de eucaliptos y de urea sobre el crecimiento de plantas jóvenes de $E$. grandis en el suelo arenoso.

Hipótesis:

A) La forma de disposición de los abonos y su calidad química afecta la tasa de crecimiento de las plantas de E. grandis porque aportan diferente cantidad de N y P a la solución del suelo.

B) El agregado de urea aporta $\mathrm{N}$ más disponible a corto plazo para las plantas de eucaliptos que los residuos vegetales.

Objetivo $6^{\circ}$ : Constatar el efecto de un suelo bien provisto de agua y uno con sequía, combinado con residuos de leguminosas herbáceas sobre el crecimiento de plantas jóvenes de E. grandis en un suelo arcilloso.

Hipótesis:

- El crecimiento de plantas de E grandis en suelos arcillosos es limitado en mayor medida por la baja disponibilidad de agua que por la disponibilidad de nutrientes. 


\subsection{Esquema general de la tesis}

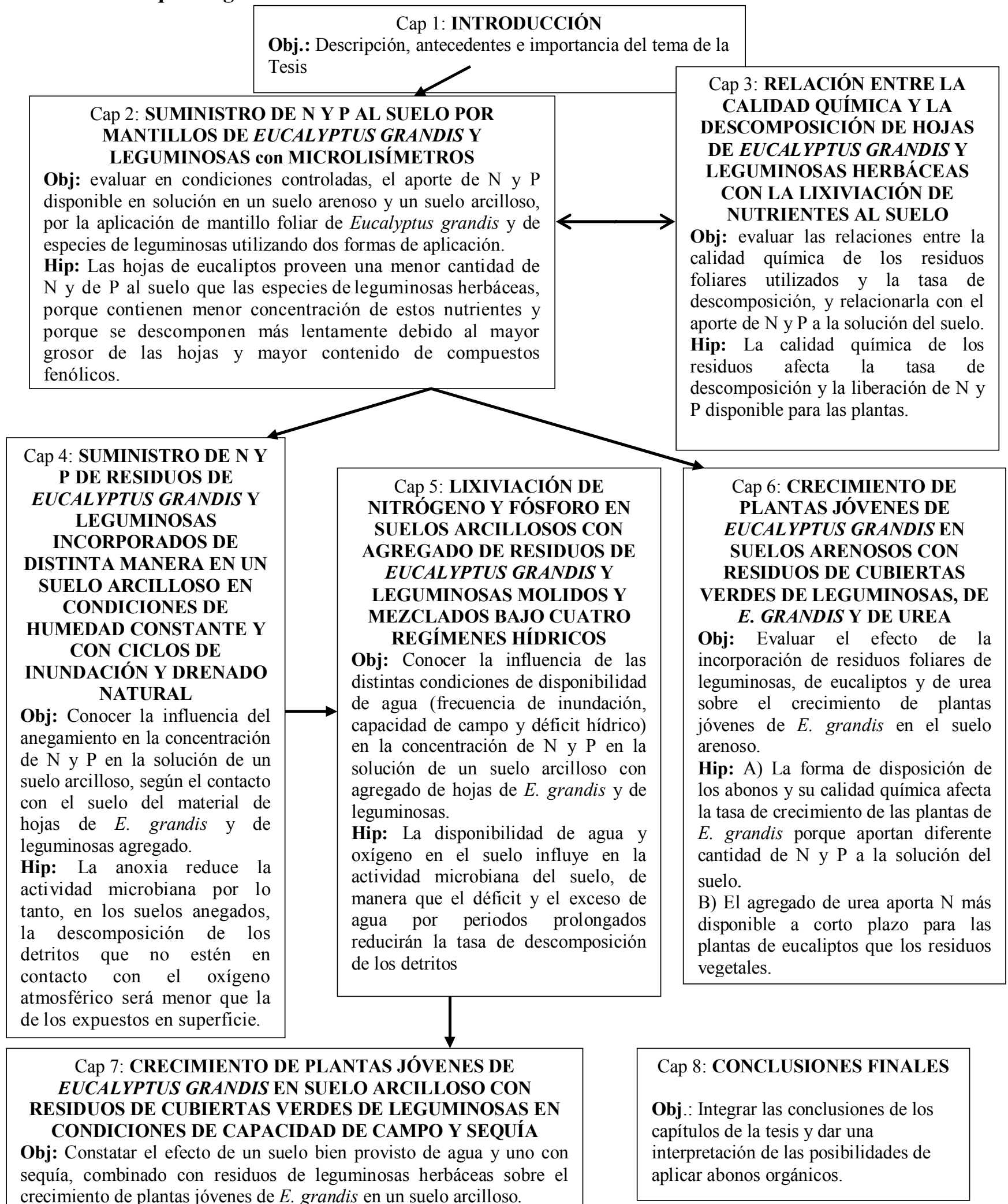

Hip: El crecimiento de plantas de E grandis en suelos arcillosos es limitado en mayor medida por la baja disponibilidad de agua que por la disponibilidad de nutrientes. 


\section{CAPÍTULO 2}

\section{SUMINISTRO DE NITRÓGENO Y FÓSFORO AL SUELO POR MANTILLOS DE EUCAL YPTUS GRANDIS Y LEGUMINOSAS MEDIANTE EXPERIMENTOS DE LABORATORIO}

\subsection{INTRODUCCIÓN}

Las plantas toman los nutrientes esenciales a partir de la solución del suelo (Comerford 2005). La cantidad de nutrientes en solución en general es baja en relación a la demanda de la planta (Comerford 2005). Por ejemplo, el nitrógeno (N) mineral rara vez cuenta con más de 1 a $2 \%$ del total de $\mathrm{N}$ en el suelo (Brady y Weil 2002), mientras que más del $90 \%$ del fósforo (P) inorgánico se encuentra en forma fijada o insoluble (Stevenson 1986). Las limitaciones nutricionales para el crecimiento, debido a la baja disponibilidad de $\mathrm{N}$ y $\mathrm{P}$, son comunes en los ecosistemas de eucaliptos y a veces están asociadas con limitaciones de micro-nutrientes (Specht 1996). Si bien muchos eucaliptos y otras especies nativas de Australia pueden crecer y persistir en ecosistemas de baja fertilidad, la limitación de los nutrientes es el principal factor que controla la productividad y la distribución de las especies (Keith 1997).

El tipo de cosecha y el manejo de los residuos de la misma inciden en el impacto de las plantaciones de crecimiento rápido sobre el contenido de nutrientes del suelo y pueden comprometer la productividad futura de estas plantaciones, a menos que haya mecanismos para su reposición (Goya et al. 2003). En el ámbito forestal la retención de los residuos de cosecha es un camino apto para manejar la fertilidad del sitio (Corbeels et al. 2003, Goya et al. 2009). La posibilidad de incorporar leguminosas como cubiertas verdes o como árboles de producción en cultivos mixtos podría ayudar en la provisión de $\mathrm{C}$ y $\mathrm{N}$ al suelo. En el caso de las plantaciones, el uso de leguminosas herbáceas perennes como intercultivo podría liberar más nutrientes después del cierre del canopeo, cuando ocurre la muerte de estas plantas herbáceas debido a limitaciones en la cantidad de luz que llega a los estratos inferiores. Las hojas de muchas especies fijadoras de $\mathrm{N}$ se descomponen rápidamente (Swamy 1989, Binkley 1992, Bernhard-Reversat 1993, Tsai 1998), al contrario de lo que ocurre con la hojas de los eucaliptos, las cuales se descomponen lentamente, y se acumulan en el piso del bosque 
(Sharma y Pande 1989, Swamy 1989, Bargali y Singh 1991, Sankaran 1993, Singh et al. 1993, Toky y Singh 1993, Goya et al. 2008). Sin embargo, dependiendo del tamaño de las plantas y sus necesidades de nutrientes, una rápida o lenta descomposición y liberación de nutrientes puede ser deseable. La ventaja de la rápida liberación de nutrientes es la inmediata disponibilidad de los mismos, pero si las plantas no son lo suficientemente grandes para tomarlos, pueden ser lixiviados del sistema. Por otro lado, la descomposición lenta o inmovilización de nutrientes en el comienzo de la plantación podría aumentar el suministro de nutrientes para las plantas a la edad de rotación media o tardía.

Las tasas de descomposición y la liberación de nutrientes del mantillo están en buena medida influenciadas por la "calidad" o composición bioquímica del material que lo compone (Swift et al. 1979, Cadisch y Giller 1997). La calidad, que puede ser descripta como la disponibilidad del sustrato como fuente de carbono, de energía y de nutrientes para los organismos que la degradan (Swift et al. 1979), tiene dos componentes: su composición bioquímica y su naturaleza física. La calidad física interactúa con la calidad química y ambas influyen en la tasa de inmovilización/mineralización del N (Bending y Turner 1999). Existe poca información sobre el modo en que la calidad física afecta a la mineralización. Uno de los parámetros de la calidad física que ha recibido mayor atención en estudios de ciclo de nutrientes es el tamaño de partículas de la fracción a descomponer (Bending y Turner 1999), factor de suma importancia desde un punto de vista práctico a la hora de definir cómo deben ser incorporados al suelo los residuos de cosecha. Una fracción más grosera representaría mejor una fase inicial, con pocos días o semanas después de la incorporación del abono, mientras que una fracción molida representaría una fase posterior, con el material vegetal luego de ser atacado por la fauna del suelo e incorporado a capas más profundas del suelo. Sin embargo, los antecedentes son contradictorios en el efecto del tamaño de los residuos de la planta sobre la descomposición y la dinámica de la liberación de nutrientes después de la incorporación en el suelo (Sims y Frederick 1970, Ambus y Jensen 1997, Bending y Turner 1999). Con la reducción de tamaño de partícula, el cociente del área de la superficie del residuo vegetal por la masa del suelo se incrementa (Angers y Recous 1997); en consecuencia se podría esperar que los residuos más pequeños se descompongan más rápidamente que los más grandes. Sin embargo, la protección física del material vegetal por el mayor contacto con la arcilla y otras partículas del suelo, podría disminuir la tasa de descomposición, especialmente en la fase temprana posterior a la incorporación (Sims y Frederick 1970, Jensen 1994). 
Sin embargo, no sólo la calidad del residuo vegetal afecta la tasa de descomposición y de inmovilización/liberación de nutrientes. También son influenciadas por las propiedades biológicas, químicas y físicas del suelo. La textura del suelo tiene un efecto primordial en características tales como la capacidad de retención de agua, la aireación, y la retención de la materia orgánica (Fisher y Binkley 2000), y por eso ejerce control sobre los procesos de descomposición y mineralización, porque para optimizar estos procesos se requieren cantidades adecuadas de agua y oxígeno (Baldock y Skjemstad 2000).

En el presente capítulo, se evalúa en condiciones controladas, el aporte de $\mathrm{N}$ y $\mathrm{P}$ disponible en solución en un suelo arenoso y un suelo arcilloso, por la aplicación de mantillo foliar de Eucalyptus grandis y de especies de leguminosas utilizando dos formas de aplicación. La hipótesis es que las hojas de eucaliptos proveen una menor cantidad de $\mathrm{N}$ y de $\mathrm{P}$ al suelo que las especies de leguminosas herbáceas, porque contienen menor concentración de estos nutrientes y porque se descomponen más lentamente debido al mayor grosor de las hojas y mayor contenido de compuestos fenólicos.

\section{Predicciones:}

El aporte de N y P a la solución del suelo:

- será mayor si se incorporan leguminosas con respecto a suelo sin abonos o al aporte de la hojarasca de E. grandis.

- será mayor si la hojarasca es más pequeña e incorporada dentro del suelo en comparación con aquella de mayor tamaño dispuesta en la superficie.

- será mayor en los suelos de textura más gruesa (arenoso) que contiene menor dotación de nutrientes que en el suelo arcilloso.

\subsection{MATERIALES Y MÉTODOS}

\subsubsection{Diseño experimental}

En el ensayo se emplearon microlisímetros conteniendo suelo superficial, a los cuales se les agregaron residuos de hojas de E. grandis o de una de 4 especies de leguminosas (Imagen 2.1). El diseño experimental consistió en: 2 tipos de suelo, 2 tipos de aplicación de los residuos y 5 tipos de materiales vegetales. Se realizaron 4 repeticiones para cada tratamiento, que hacen un total de 80 microlisímetros. Además, se reservaron 4 microlisímetros sin residuos vegetales de cada tipo de suelo como control. Todos los microlisímetros se colocaron en cámara con una temperatura de $23{ }^{\circ} \mathrm{C}$ con un desvío estándar 
de $2{ }^{\circ} \mathrm{C}$. Los microlisímetros fueron cubiertos con una tela negra para evitar el posible crecimiento de algas y para protegerlos de otros agentes físicos que pudieran afectarlos.

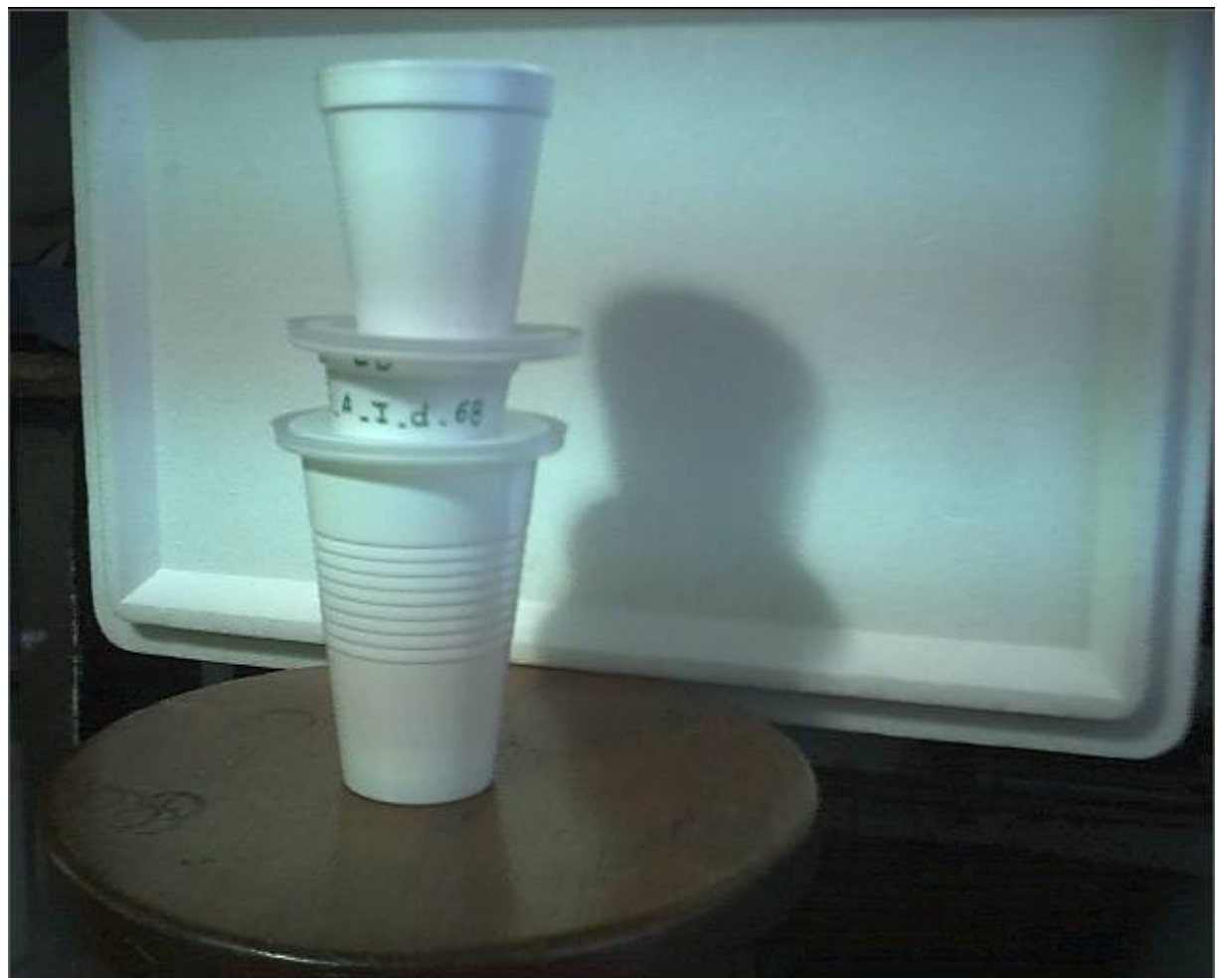

Imagen 2.1. Microlisímetro con vaso colector por debajo, y vaso para incorporación de solución de lavado por arriba.

Estos microlisímetros fueron "irrigados" simulando lluvia en los días 0, 14, 28, 42, 56, $84,98,126,154,182,217,259,315$ y 371 con $240 \mathrm{ml}$ de solución acuosa de $0,01 \mathrm{M} \mathrm{CaCl}_{2}$ y $0,01 \mathrm{M} \mathrm{KCl}$. Se utilizó esta solución acuosa porque el $\mathrm{N}$ disponible del suelo suele medirse en solución salina de estas características (Houba et al. 1986, Maynard y Kalra 1993, Corbeels et al. 2003) y el $\mathrm{P}$ se puede medir directamente en la solución del suelo con una solución diluida de sales tales como 0,01M $\mathrm{CaCl}_{2}$ (Schofield 1955, Aslyng 1964). Asimismo, con esta solución se asegura que el lixiviado ocurra bajo condiciones que evitan una subestimación de las cantidades de nutrientes liberadas durante un evento de precipitación, sin modificar drásticamente el ambiente de la solución del suelo. El lixiviado fue recolectado luego de dejar escurrir durante 24 horas en un vaso de plástico de $500 \mathrm{~cm}^{3}$ colocado por debajo con un soporte de plástico sobre el que se apoya el microlisímetro (Imagen 2.1), y el líquido percolado fue recogido para el análisis de su contenido de $\mathrm{N}$ y P. 


\subsubsection{Selección y obtención del material vegetal y suelos}

Se utilizaron hojas de Eucalyptus grandis, y hojas y tallos de Canavalia ensiformis L.; Cajanus cajan L.; Lotus corniculatus L. y Trifolium pratense L. Las dos primeras leguminosas son forrajeras empleadas en zonas subtropicales y las dos últimas en sitios de clima templado. De las cuatro especies de leguminosas utilizadas, tres son herbáceas, mientras que C. cajan es arbustiva. De esta especie, se utilizaron tallos no lignificados. El material de las especies de clima subtropical fueron provistas por la EEA INTA Cerro Azul, Misiones; las especies de clima templado por la EEA INTA Concepción del Uruguay, Entre Ríos. Las hojas de E. grandis fueron recolectadas en plantaciones de la EEA INTA Concordia, Entre Ríos. La recolección de hojas de E. grandis se hizo en 3 parcelas al turno (12 a 15 años) por tipo de suelo, de la parte inferior de la copa de 3 o 4 árboles distintos. Las hojas provenientes de cada parcela fueron mezcladas homogéneamente para usarse como abono verde. Todo el material vegetal fue secado al aire.

El modo de obtención de las hojas de los E. grandis y de las leguminosas fue por corte, lo que permitió conservar los nutrientes en la hoja antes de la reabsorción previa a la senescencia.

Los suelos utilizados para llenar los microlisímetros procedieron de Concordia, Entre Ríos, de plantaciones de E. grandis. El suelo arenoso fue un Quartzipsamment Oxico (localmente arenoso), y el arcilloso, un Argiacuol Vertico (localmente arcilloso). Se quitó el mantillo y se tomaron 30 submuestras de la capa superior mineral de $0-10 \mathrm{~cm}$ de profundidad en cada tipo de suelo, de 3 rodales distintos, con el muestreador de densidad aparente. El suelo contenido en bolsas de nylon se mantuvo en un lugar fresco y aislado hasta su traslado al laboratorio. Las características de los suelos se indican en la Tabla 2.1. 
Tabla 2.1. Características físicas y químicas de los suelos usados en este trabajo. El error estándar se indica entre paréntesis. La textura fue determinada por el método granulométrico de Bouyoucos. El P fue extraído con el método de Olsen y determinado con un espectrofotómetro de emisión de plasma Beckman Spectra-Span V. La concentración de N y C fue determinada con un analizador de combustión seca LECO CNS-2000. El pH fue determinado en agua 1:1 (suelo:agua).

\begin{tabular}{ccccccccc}
\hline Suelo & $\%$ arcilla & \% limo & $\%$ arena & $\mathrm{C}(\mathrm{mg} / \mathrm{g})$ & $\mathrm{N}(\mathrm{mg} / \mathrm{g})$ & $\mathrm{C} / \mathrm{N}$ & $\mathrm{P}(\mathrm{mg} / \mathrm{g})$ & $\mathrm{pH}$ \\
\hline \multirow{2}{*}{ Arcilloso } & 42,5 & 27,5 & \multirow{2}{*}{30} & $\begin{array}{c}23,2 \\
(0,23)\end{array}$ & $\begin{array}{c}2,2 \\
(0,027)\end{array}$ & $\begin{array}{c}10,71 \\
(0,165)\end{array}$ & $\begin{array}{c}0,022 \\
(0,0013)\end{array}$ & $\begin{array}{c}5,57 \\
(0,196)\end{array}$ \\
& & & & & & & & \\
Arenoso & 7,5 & 5 & 87,5 & 5,9 & 0,4 & 14,10 & 0,029 & 4,53 \\
& & & & $(0,20)$ & $(0,01)$ & $(0,897)$ & $(0,0006)$ & $(0,254)$ \\
\hline
\end{tabular}

\subsubsection{Microlisímetros}

Fueron construidos con vasos de poliestireno expandido de $10 \mathrm{~cm}$ de altura y $180 \mathrm{ml}$ de capacidad. A cada vaso se le reemplazó la base por una malla de acero inoxidable de poro de $55 \mu \mathrm{m}$ de lado. Cada microlisímetro se llenó con $50 \mathrm{~cm}^{3}$ de suelo, más el material vegetal correspondiente en la ubicación prevista en cada tratamiento (Imagen 2.2).

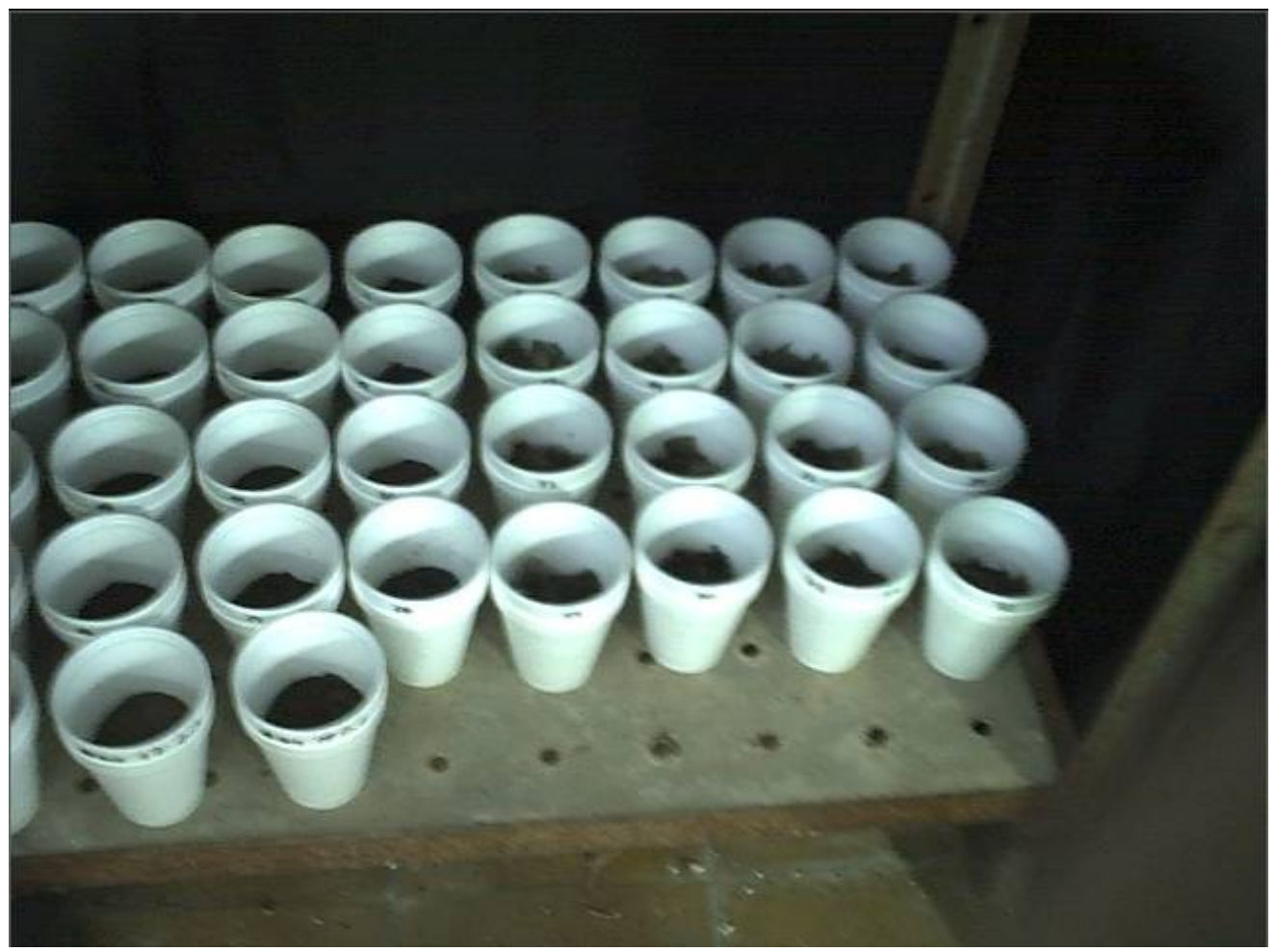

Imagen 2.2. Microlisímetros. 
Los suelos fueron tamizados con tamiz de $2 \mathrm{~mm}$ de malla; luego fueron incubados en heladera a $4^{\circ} \mathrm{C}$ durante 1 mes con el contenido de humedad a capacidad de campo. El suelo dentro de los microlisímetros se buscó que tuviera la densidad aparente del horizonte muestreado a campo. Para ello los $50 \mathrm{~cm}^{3}$ de suelo correspondieron a $79 \mathrm{~g}$ de suelo arenoso y $53 \mathrm{~g}$ de arcilloso.

El material vegetal fue secado a estufa a $65{ }^{\circ} \mathrm{C}$ por 24 horas previo al armado de los microlisímtros. La cantidad de mantillo incorporada a cada microlisímetro tuvo en cuenta el peso seco/unidad de superficie de mantillo existente en una plantación de E. grandis al turno (12 a 15 años) y al peso de las leguminosas por área de superficie en los cultivos de estas especies de leguminosas; por lo tanto se agregó $1 \mathrm{~g}$ de E. grandis, y 0,5 g de las especies de leguminosas. Se consideró el peso seco máximo por área en los cultivos de estas leguminosas, aunque en una plantación joven donde estas especies podrían crecer como intercultivo, el peso seco producido por las leguminosas podría ser menor. El mantillo fue agregado al suelo de dos maneras diferentes: 1) el material vegetal seco se molió con molino Wiley, se tamizó en malla de $0,5 \mathrm{~mm}$, se mezcló y homogeneizó para obtener el máximo contacto posible entre material vegetal y el suelo (MM); 2) el mantillo se fraccionó con tijera en partes de $<1 \mathrm{~cm}^{2}$ que se dispusieron sobre la superficie del suelo (ES).

\subsubsection{Análisis químicos del lixiviado}

El volumen de líquido que percoló fue medido para conocer la cantidad de nutrientes lavados. En él se determinó el contenido de amonio $\left(\mathrm{NH}_{4}{ }^{+}\right)$y de nitrato $\left(\mathrm{NO}_{3}{ }^{-}\right)$mediante la utilización de un electrodo ión-específico (Orion, Thermo Electron Corporation, Beverly, MA). Cuando la concentración de $\mathrm{NH}_{4}{ }^{+}$fue muy baja para ser medida con el electrodo, se utilizó el Kit de Uremia de Wiener Lab. y se realizó la lectura espectrofotométrica a $630 \mathrm{~nm}$ (Espectrofotómetro UV-VIS Metrolab 325). La suma del $\mathrm{N}$ proveniente del $\mathrm{NH}_{4}{ }^{+}$y del $\mathrm{NO}_{3}{ }^{-}$ se denominó nitrógeno total $(\mathrm{N})$. El fosfato $\left(\mathrm{PO}_{4}{ }^{3-}\right)$ se determinó mediante la reacción del ácido ascórbico, con lectura espectrofotométrica a $885 \mathrm{~nm}$ (Greenberg et al. 1985).

Los miligramos de $\mathrm{N}\left(\mathrm{N}-\mathrm{NH}_{4}{ }^{+}+\mathrm{N}_{-} \mathrm{NO}_{3}{ }^{-}\right)$y de $\mathrm{P}\left(\mathrm{P}_{-}-\mathrm{PO}_{4}{ }^{3-}\right)$ lavados en el lixiviado en cada fecha de muestreo se calcularon multiplicando el volumen de líquido lixiviado por la concentración de $\mathrm{NH}_{4}{ }^{+}, \mathrm{NO}_{3}{ }^{-}$o $\mathrm{PO}_{4}{ }^{3-}$. El resultado fue dividido por el peso de suelo, expresado en kilogramos, contenido en cada microlisímetro. Los datos del día 0 (o sea el $1^{\circ}$ muestreo) no fueron considerados ya que se asume que la rápida liberación inicial de nutrientes proveniente de la mineralización de la materia orgánica nativa que se produce ante 
el agregado de residuos de plantas (efecto priming) puede ser equiparable para todas las especies (Corbeels et al. 2003). Finalmente, los datos de mg de nutrientes por kilogramo de suelo de cada fecha de lavado se añadieron a los acumulados de nutrientes de lavados anteriores hasta el final del experimento, por lo que se calcularon los $\mathrm{mg}$ de nutrientes acumulados para cada especie y para los controles, en cada suelo.

Para advertir mejor si cada material incorporado en cada suelo aumentaba o disminuía la disponibilidad de $\mathrm{N}$ o $\mathrm{P}$ en el lixiviado con respecto al suelo solo, al valor de la concentración acumulada en la fecha final para cada especie, se le restó el valor del control del tipo de suelo correspondiente.

\subsubsection{Análisis estadísticos}

Se realizó un ANOVA con los factores suelo (arenoso o arcilloso) y tratamiento (MM o ES) para cada especie con los datos acumulados de la última fecha. Las medias se compararon mediante el test de Tukey $(\mathrm{p}<0,05)$.

Asimismo se realizó un ANOVA con los factores especie y tratamiento (MM o ES) para cada tipo de suelo, con los valores de concentración de nutrientes acumuladas menos el control al final del experimento. Las medias se compararon mediante el test de Tukey $(\mathrm{p}<0,05)$.

\subsection{RESULTADOS}

\subsubsection{Contenido de $\mathbf{N}$ y $\mathrm{P}$ en los lixiviados de los suelos con agregado de detritos orgánicos}

En éste acápite se exponen los resultados del contenido de nutrientes del lixiviado en los suelos arenosos y arcillosos a los que se les agregaron detritos de las diferentes especies estudiadas.

\subsubsection{Comportamiento del Nitrógeno}

El contenido de $\mathrm{N}$ de los lixiviados provenientes del suelo arcilloso fue siempre significativamente mayor que los del suelo arenoso, tanto en los tratamientos de control como en los tratamientos con agregado de residuos de eucalipto o leguminosas (Figura 2.1). 
En el suelo arenoso, la diferencia en el contenido de $\mathrm{N}$ del lixiviado de los tratamientos con agregado de detritos respecto al control casi siempre es significativa, ya sea por tener mayor o menor concentración de $\mathrm{N}$, con excepción de $C$. ensiformis cuando se aplica de modo ES, y de T. pratense cuando se aplica MM (Figura 2.1), casos donde el contenido de $\mathrm{N}$ del lixiviado del control y los mencionados tratamientos no son significativamente diferentes.
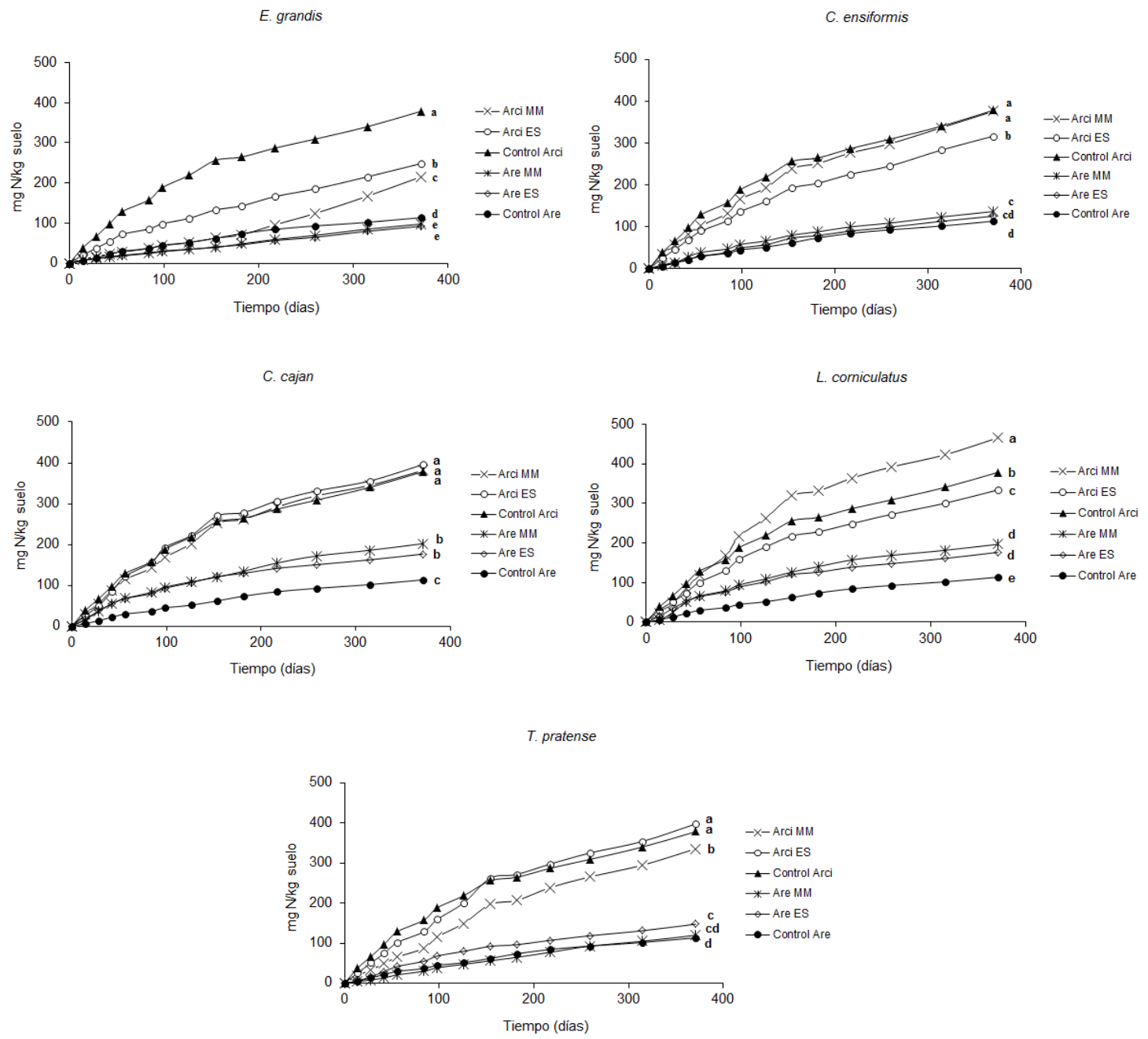

Figura 2.1. Nitrógeno acumulado por $\mathrm{kg}$ de suelo a lo largo del periodo de ensayo para distintos suelos y tratamientos. Arci MM: suelo arcilloso con material vegetal molido y mezclado; Arci ES: suelo arcilloso con material vegetal entero y superficial; Control Arci: suelo arcilloso sin agregado de detritos vegetales; Are MM: suelo arenoso con material vegetal molido y mezclado; Are ES: suelo arenoso con material vegetal entero y superficial; Control Are: suelo arenoso sin agregado de detritos vegetales. Con letras minúsculas se indica la significancia en la última fecha con datos acumulados, y sólo permiten comparar la significancia para cada especie. 
En el suelo arcilloso, la diferencia en el contenido de $\mathrm{N}$ del lixiviado de los tratamientos con agregado de detritos respecto al control, sea por tener mayor o menor concentración de N, es significativa para las especies $E$. grandis y L. corniculatus con ambos modos de aplicación, para C. ensiformis cuando se aplica ES, y para T. pratense cuando se aplica MM, mientras que no es significativa para C. cajan (Figura 2.1).

\subsubsection{Comportamiento del Fósforo}

De manera semejante a lo ocurrido con el $\mathrm{N}$, el contenido de $\mathrm{P}$ de los lixiviados provenientes del suelo arcilloso fue siempre significativamente mayor que el del suelo arenoso, tanto en los tratamientos de control como en los tratamientos con agregado de residuos de eucalipto o leguminosas (Figura 2.2).

El contenido de $\mathrm{P}$ de los lixiviados provenientes del suelo arenoso, tanto del control como de los tratamientos con agregados de detritos, no tuvo diferencias significativas, y en todos los casos tuvieron valores prácticamente nulos (Figura 2.2).

Por el contrario, el contenido de $\mathrm{P}$ de los lixiviados provenientes del suelo arcilloso con agregado de detritos fueron en todos los casos significativamente menores al control, a excepción del agregado de L. corniculatus, ya que el contenido de $\mathrm{P}$ del lixiviado proveniente del agregado de material de esta especie, tanto ES como MM, no difiere del control (Figura 2.2). 
E. grandis

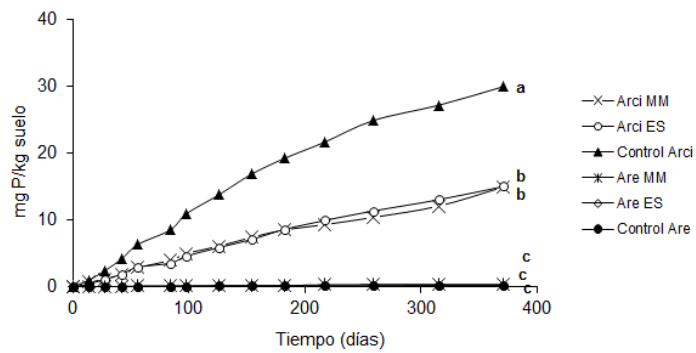

C. cajan

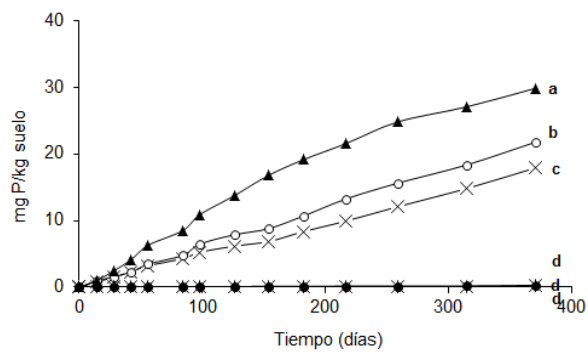

C. ensiformis

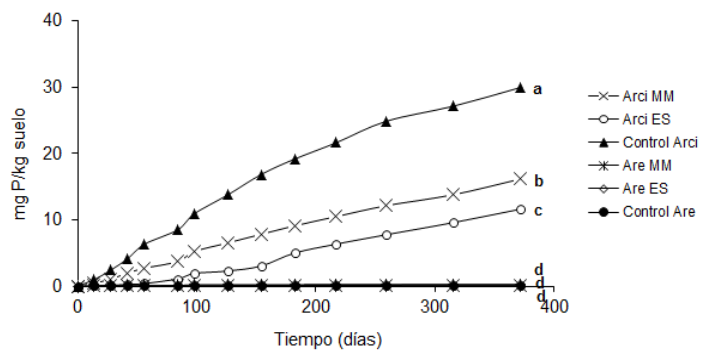

L. corniculatus

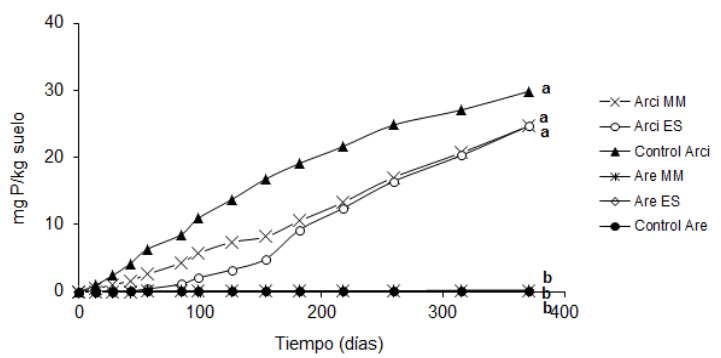

T. pratense

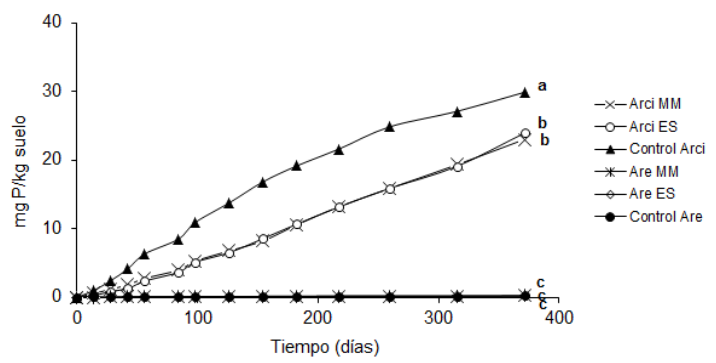

Figura 2.2. Fósforo acumulado por kg de suelo a lo largo del periodo de ensayo para distintos suelos y tratamientos. Arci MM: suelo arcilloso con material vegetal molido y mezclado; Arci ES: suelo arcilloso con material vegetal entero y superficial; Control Arci: suelo arcilloso sin agregado de detritos vegetales; Are MM: suelo arenoso con material vegetal molido y mezclado; Are ES: suelo arenoso con material vegetal entero y superficial; Control Are: suelo arenoso sin agregado de detritos vegetales. Con letras minúsculas se indica la significancia en la última fecha con datos acumulados, y sólo permiten comparar la significancia para cada especie.

\subsubsection{Lixiviado de $\mathbf{N}$ y $\mathbf{P}$ a partir de detritos de distintas especies en cada tipo de suelo}

En éste acápite se exponen los resultados comparados del contenido de nutrientes del lixiviado acumulado al final del experimento, con respecto al control (contenido de nutrientes del lixiviado proveniente de cada suelo con agregado de detritos menos contenido de 
nutrientes del lixiviado en el control) de las distintas especies según el modo de aplicación (MM y ES) en los distintos suelos.

\subsubsection{Comportamiento del Nitrógeno}

En el suelo arenoso, el agregado de cualquiera de las leguminosas incrementó la concentración de $\mathrm{N}$ en el lixiviado, mientras que el agregado de E. grandis lo disminuyó con respecto al suelo sin el agregado de detritos, sin diferir según el modo de aplicación (Figura 2.3, a). El contenido neto de $\mathrm{N}$ proveniente de los tratamientos con agregado de $L$. corniculatus y $C$. cajan resultaron ser significativamente mayores que los de las restantes especies. En ambas especies se observó que cuando los residuos fueron agregados de modo MM se produjo significativamente mayor lixiviación de $\mathrm{N}$ que cuando se agregó el residuo ES (Figura 2.3, a).

En los tratamientos con agregado de C. ensiformis se observó un contenido de $\mathrm{N}$ neto positivo sin diferencia entre el modo de aplicación. Por otro lado, con el agregado de $T$. pratense se produjo mayor lixiviación cuando los residuos se agregaron $\mathrm{ES}$, que cuando se agregaron MM (Figura 2.3, a).

En el suelo arcilloso en general la diferencia entre el contenido de $\mathrm{N}$ del lixiviado de los tratamientos con agregado de detritos y el control fue negativa (Figura 2.3, b), a excepción del tratamiento con agregado MM de L. corniculatus, donde el contenido de $\mathrm{N}$ del lixiviado fue significativamente mayor que en el control (Figura 2.1 y 2.3, b). También hubo diferencias positivas en los tratamientos con agregado de $C$. cajan con ambos modos de aplicación, y de $T$. pratense con los residuos agregados ES, pero en éstos casos el contenido de $\mathrm{N}$ del lixiviado no fue significativamente diferente al del control, por lo que no se puede considerar una diferencia positiva significativa (Figura 2.1 y $2.3, \mathrm{~b}$ ).

Con el agregado de E. grandis se produjeron las mayores diferencias en el contenido de $\mathrm{N}$ del lixiviado con el control, siendo el tratamiento $\mathrm{MM}$ el que más redujo la cantidad de $\mathrm{N}$ neto lixiviado (Figura 2.3, b). Asimismo, se produjeron valores menores al control en los tratamientos con agregado de C. ensiformis y L. corniculatus con el modo de aplicación ES, y de $T$. pratense con los residuos agregados de modo MM, aunque la diferencia con el control fue menor a la que ocurrió con el agregado de E. grandis (Figura 2.3, b). 

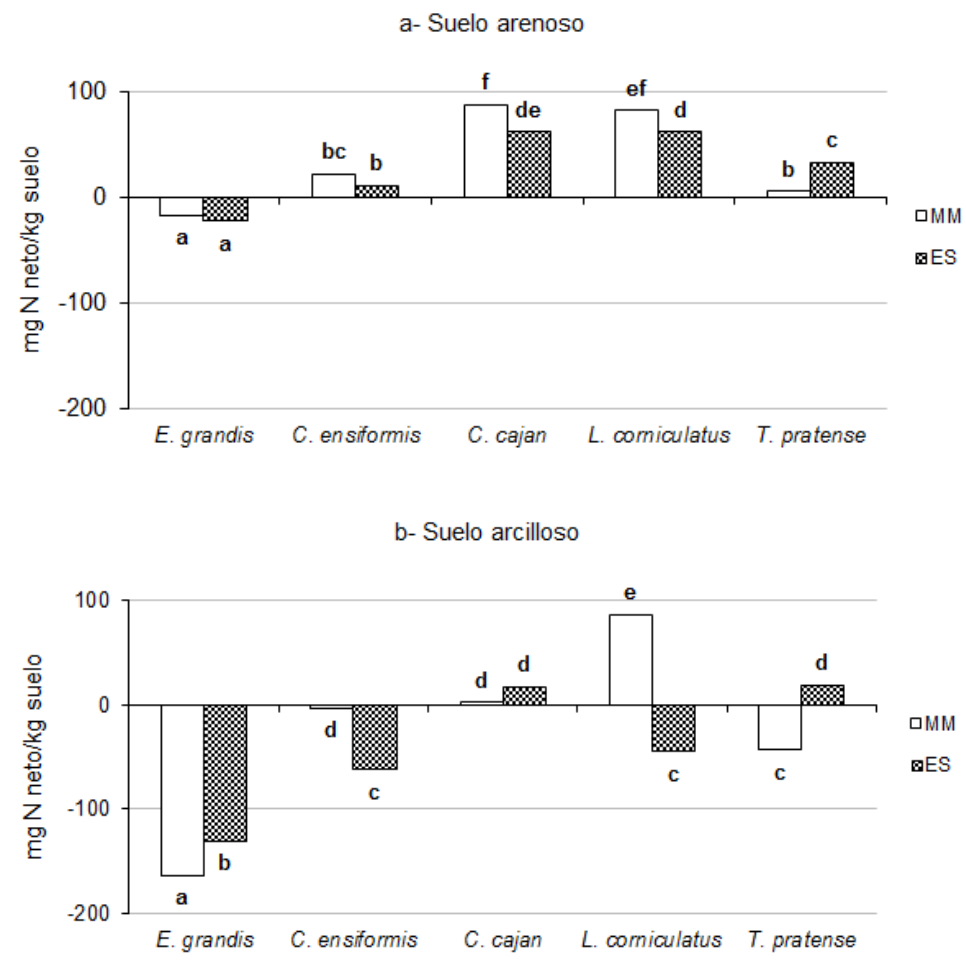

Figura 2.3. Nitrógeno neto (contenido de nitrógeno del lixiviado de los tratamientos con agregado de detritos menos el contenido de nitrógeno del lixiviado del suelo sin agregado de detritos, considerado control) por kg de suelo por especie y modo de aplicación al final del tratamiento (371 días). (a) Suelo arenoso. (b) Suelo arcilloso. MM: material vegetal agregado molido y mezclado; ES: material vegetal agregado entero y superficial. Las letras minúsculas indican la significancia entre tratamientos (combinación de especie y modo de aplicación), y sólo permite comparar dentro de cada tipo de suelo.

\subsubsection{Comportamiento del Fósforo}

En el suelo arenoso, no hubo diferencias significativas en el contenido de $\mathrm{P}$ de los lixiviados provenientes de tratamientos con agregados de detritos con el control, para ambos modos de aplicación (Figura 2.2).

En el suelo arcilloso no se observaron diferencias significativas para el modo de aplicación de los residuos para ninguna especie utilizada como abono (Figura 2.4). Las diferencias en el contenido de $\mathrm{P}$ del lixiviado de los tratamientos con detritos y el control fueron negativas para todas las especies estudiadas (Figura 2.4). Sin embargo, la especie que produjo los valores de contenido de $\mathrm{P}$ neto más negativo fue $C$. ensiformis, seguida por $E$. grandis, luego por C. cajan y finalmente T. pratense (Figura 2.4), y L. corniculatus, cuya diferencia con el control fue no significativa (Figura 2.2). 


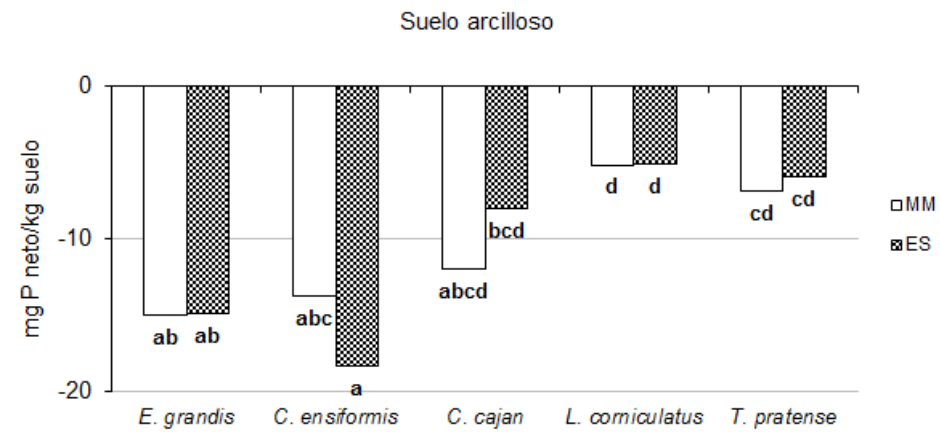

Figura 2.4. Fósforo neto (contenido de fósforo del lixiviado de los tratamientos con agregado de detritos menos el contenido de fósforo del lixiviado del suelo sin agregado de detritos, considerado control) por kg de suelo arcilloso por especie y modo de aplicación al final del tratamiento (371 días). MM: material vegetal agregado molido y mezclado; ES: material vegetal agregado entero y superficial. Las letras minúsculas indican la significancia entre tratamientos (combinación de especie y modo de aplicación), y sólo permite comparar dentro de cada tipo de suelo.

\subsection{DISCUSIÓN}

La fase sólida del suelo mantiene la concentración de nutrientes de la solución del suelo a través de procesos bioquímicos, como la mineralización e inmovilización, o fisicoquímicos, como la adsorción y desorción, y la precipitación y la disolución de los nutrientes (Comerford 2005). En el caso del N, si bien la fijación de $\mathrm{NH}_{4}{ }^{+}$a minerales de arcilla o a la materia orgánica es un componente importante de su ciclo (Nommik y Vahtras 1982, Stevenson 1986), la característica clave del ciclo es la renovación del N por mineralización/inmovilización (Stevenson 1986). Por tal motivo, para el caso del N se hablará de mineralización cuando haya una diferencia positiva entre el contenido de $\mathrm{N}$ del lixiviado en los tratamientos con agregado de detritos respecto al control, e inmovilización de $\mathrm{N}$ cuando dicha diferencia sea negativa. Cuando el texto se refiere al $\mathrm{P}$, en cambio, la reposición de este nutriente en la solución del suelo es afectada tanto por la mineralización/inmovilización del P orgánico por los microorganismos (Stevenson 1986, Bünemann y Condron 2007) como por el equilibrio químico entre formas de P mineral soluble e insoluble (Stevenson 1986, Heredia 2000) a través de distintas formas de fijación o sorción de fosfatos por el suelo (Heredia 2000) controlando su disponibilidad para las plantas y las pérdidas potenciales (Fageria 2009). Por lo tanto, no se puede hablar exclusivamente de inmovilización cuando la diferencia entre el 
contenido de $\mathrm{P}$ del lixiviado en los tratamientos con agregado de detritos respecto al control es negativa, ya que esta diferencia puede deberse también a la disminución de $\mathrm{P}$ en el lixiviado dado por la sorción o fijación de P por partículas del suelo (Heredia 2000, Murrell 2003, Fageria 2009), siendo este proceso particularmente importante en suelo arcilloso (Fageria 2009).

La textura del suelo afecta la disponibilidad de N y P por influencia de la acumulación total de materia orgánica (Schimel et al. 1985) o por la actividad microbiana del suelo (Coleman et al. 1984, Hassink et al. 1993). En el suelo arenoso, a pesar de tener menor concentración de $\mathrm{N}$ que el arcilloso, se produjo la mineralización de $\mathrm{N}$ a partir de los detritos agregados de leguminosas. Por el contrario, en el suelo arcilloso con mayor contenido de N, prevalece la inmovilización de este nutriente. En el suelo arenoso el P no fue lixiviado ni inmovilizado luego de la incorporación de detritos, indicando que todo el P contenido en el material en descomposición fue incorporado por los microorganismos del suelo. Esto indicaría una demanda microbiana de $\mathrm{P}$ en este tipo de suelo que no es satisfecha por el $\mathrm{P}$ mineral (Figura 2.2). En este suelo, el crecimiento de los microorganismos es regulado por la disponibilidad de $\mathrm{P}$, y el $\mathrm{N}$ que los microorganismos no pueden tomar es perdido del sistema por lixiviación. En el suelo arcilloso, hay inmovilización de $\mathrm{P}$ o fijación o sorción de $\mathrm{P}$ por partículas del suelo luego del agregado de detritos. Los suelos de textura fina (con alto contenido de arcilla) generalmente contienen más biomasa microbiana, y tienen más baja renovación de la biomasa y descomposición de la materia orgánica que sus contrapartes de textura gruesa, con bajo contenido de arcilla (Saggar et al. 1996), posiblemente debido a que las partículas de arcilla incrementan la estabilidad de los sustratos orgánicos y aumentan la biosíntesis microbiana (Martin et al. 1976, Sørensen 1981), al mismo tiempo que ofrecen mayores superficies de fijación para el P. La actividad microbiana es influenciada por el ambiente físico a través de la distribución de tamaños de poros y continuidad de los poros que modifican la disponibilidad de agua del suelo, la difusión de los gases, y el movimiento de los organismos del suelo (Elliott et al. 1980, Coleman et al. 1984, Hassink et al. 1993). El contenido de agua del suelo, o su distribución, afecta la permeabilidad del $\mathrm{O}_{2}$ y la difusión de sustratos hacia los organismos del suelo. La interacción de estos procesos determina el contenido óptimo de agua del suelo para la actividad microbiana (Sommers et al. 1981, Stott et al. 1986, Skopp et al. 1990). El movimiento de los organismos del suelo y la distribución de los sustratos microbianos son también controlados por el tamaño y continuidad de los poros del suelo. Consecuentemente, en los suelos arenosos que con frecuencia son pobremente estructurados (Asghari et al. 2009), y tienen baja capacidad de retención de agua 
y nutrientes (Tester 1990, Al-Darby 1996, Nyamangara et al. 2001, Sen y Bhadoria 1987), la actividad microbiana será baja. En cambio en los suelos arcillosos que tienen estructuras complejas y una superficie específica grande que retiene nutrientes contra el lavado (Newman 1984) permiten mayor proliferación de microorganismos. También se comprobó en estudios anteriores que el tamaño de las células microbianas está correlacionado positivamente con el contenido de partículas de limo y arcilla, así como con el contenido de la materia orgánica en el suelo (Weyman-Kaczmarkowa y Pedziwilk 2000).

La posible inmovilización de $\mathrm{N}$ y retención de $\mathrm{P}$ observada en los suelos arcillosos con la adición de los materiales vegetales refleja también los altos requerimientos de estos nutrientes por los microorganismos del suelo por tener ellos mismos muy altos contenidos de N y P (Findlay 1934, Thayer 1974, Swift et al. 1979, Goldman et al. 1987, Vadstein y Olsen 1989). La respuesta rápida de los microorganismos a la adición de sustratos, se produce ya que los minerales de arcilla incrementan la eficiencia en la utilización de sustratos por los microorganismos (Martin et al. 1976) pudiendo enlentecer la liberación de nutrientes por un mecanismo de protección, incrementando la inmovilización de N (Egelkraut et al. 2000).

En cuanto al tamaño de las partículas del detrito orgánico, se ha sugerido que las partículas pequeñas pueden descomponerse más rápido que las más grandes, porque la mayor área de superficie aumentaría la susceptibilidad para el ataque microbiano (Sims y Frederik 1970, Allison 1973, Amato et al. 1984). Sin embargo la literatura es contradictoria en el efecto del tamaño de los residuos de la planta sobre la descomposición y la dinámica de la liberación de nutriente después de la incorporación en el suelo (Sims y Frederick 1970, Ambus y Jensen 1997, Bending y Turner 1999), principalmente porque el tamaño de partícula del residuo obra recíprocamente con otros factores para influenciar la descomposición (Bhupinderpal-Singh et al. 2006), como por ejemplo el contenido de arcilla y limo del suelo, los productos metabólicos secundarios, la composición química del residuo vegetal, el período de descomposición y la actividad de la fauna del suelo (Jensen 1994). En esta Tesis, en el suelo arenoso los dos modos de aplicación de leguminosas aumentaron la disponibilidad de $\mathrm{N}$ en la solución del suelo, y en la mayoría de las leguminosas empleadas la incorporación del material pequeño en contacto con el suelo incrementó la liberación de $\mathrm{N}$ más que la aplicación superficial de fragmentos mayores. Sin embargo, la inmovilización de N producido por el agregado de E. grandis se produjo en igual magnitud con ambos modos de aplicación. En el suelo arcilloso, el modo de incorporar los detritos produjo diferencias en la disponibilidad de $\mathrm{N}$ en la solución del suelo para la mayoría de las especies, pero no afectó la reducción en la disponibilidad de $\mathrm{P}$, que se produjo con la adición de todos los abonos. 
En conclusión, E. grandis con ambos modos de aplicación inmoviliza más $\mathrm{N}$ que cualquiera de las leguminosas. Esto es consistente con lo comprobado en varios trabajos, donde se observa una disminución de $\mathrm{C}$ y $\mathrm{N}$ del suelo como consecuencia de la transformación de sistemas naturales a plantaciones de E. grandis (Tesón 2012, Sandoval et al. 2012, Goya et al. 2013). Las causas de este cambio incluyen al efecto del consumo de nutrientes por los árboles de crecimiento rápido, como también a aquellos efectos de las distintas etapas del manejo, tales como la preparación del terreno, los tratamientos intermedios, la cosecha y tratamiento pos-cosecha, la duración y número de turnos (Sandoval et al. 2012), al que se agregaría la inmovilización de $\mathrm{N}$ que las hojas de E. grandis producen en el piso del bosque.

\subsection{CONCLUSION}

Los resultados encontrados coinciden con la hipótesis planteada Las hojas de eucaliptos proveen una menor cantidad de $N$ y de $P$ al suelo que las especies de leguminosas herbáceas porque contienen menor concentración de estos nutrientes y porque se descomponen más lentamente debido al mayor grosor de las hojas y mayor contenido de compuestos fenólicos. Puede destacarse que las hojas de eucaliptos proveyeron menor cantidad de N y P que las especies de leguminosas (Predicción 1), ya que en ambos tipos de suelos este tipo de abono inmoviliza $\mathrm{N}$ e inmoviliza o fija P. Por otro lado, la fracción de hojarasca más pequeña incorporada dentro del suelo (Predicción 2) no siempre dio lugar a un suministro más rápido de $\mathrm{N}$ que aquella de mayor tamaño dispuesta en la superficie, ya que dependiendo de la especie de leguminosa, este tipo de disposición puede aumentar la lixiviación de $\mathrm{N}$ con respecto al otro modo de incorporación, o generar el efecto contrario. Finalmente, el suelo influyó en la lixiviación de nutrientes (Predicción 3) ya que el N neto lixiviado provisto por las distintas especies ensayadas fue mayor en los suelos arenosos de textura más gruesa que en los arcillosos, en tanto que la lixiviación de P fue mínima en suelos arenosos.

En suelo arenoso podría recomendarse el uso de L. corniculatus y de C. cajan como abono verde que aumente la disponibilidad inmediata de $\mathrm{N}$ en la solución del suelo, $\mathrm{y}$ en segundo lugar $T$. pratense aplicado en superficie o $C$. ensiformis incorporado en el suelo.

En el suelo arenoso la incorporación de abonos verdes no resultaría efectiva como fuente de $\mathrm{P}$ porque ninguna de las especies incorporadas produjo lixiviación ni inmovilización de P. 
En suelo arcilloso según la especie aplicada es conveniente incorporar el material vegetal molido y mezclado o entero y superficial. L corniculatus molido sería la opción de abono verde que lixivia más $\mathrm{N}$.

Cualquiera de los abonos aplicados y modos de aplicación produjeron inmovilización o fijación de $\mathrm{P}$ en el suelo arcilloso. Por lo tanto, no es de esperar que la aplicación de este tipo de abono verde sea efectiva como fuentes inmediatas de $\mathrm{P}$ aunque sí como estrategias de retención de este nutriente para su utilización posterior. Los nutrientes inmovilizados por la biomasa microbiana pueden aumentar el potencial de suministro de nutrientes del suelo mediante la rotación de la biomasa microbiana con el tiempo.

Por último, el uso de intercultivos de leguminosas como fuente de $\mathrm{N}$ debe considerar el efecto de este cultivo en la disponibilidad de P para las plantas y el lapso en que los nutrientes serán liberados/inmovilizados para que coincida con las necesidades de las plantas. La selección de las especies de leguminosas debe considerar el tipo de suelo y la forma en que el intercultivo será manejado, es decir, si el material vegetal se mezclará con el suelo o se dejará en la superficie, y con qué grado de molido. 


\section{CAPÍTULO 3}

\section{RELACIÓN ENTRE LA CALIDAD QUÍMICA Y LA DESCOMPOSICIÓN DE HOJAS DE EUCALYPTUS GRANDIS Y LEGUMINOSAS HERBÁCEAS CON LA LIXIVIACIÓN DE NUTRIENTES AL SUELO}

\subsection{INTRODUCCIÓN}

El crecimiento de las plantas y la productividad primaria neta en la mayoría de los ecosistemas terrestres dependen del suministro de nutrientes reciclados, ya que los aportes de nutrientes externos contribuyen generalmente sólo en una proporción menor a la exigencia total (Hättenschwiler y Vitousek 2000). Esta entrada de residuos por encima y por debajo del suelo constituye la principal fuente de materia y de energía para una comunidad extraordinariamente diversa de organismos del suelo conectados por interacciones altamente complejas (Hättenschwiler et al. 2005), y para la comunidad vegetal, por lo que la descomposición de la hojarasca y la mineralización de la materia orgánica son dos procesos fundamentales (Wang et al. 2010). Por medio de estos procesos los nutrientes retornan al suelo dejándolos disponibles para ser tomados por las plantas, representando un factor determinante de los ciclos de nutrientes y de la renovación de la materia orgánica en ecosistemas terrestres (Swift et al. 1979). Se trata de procesos biofísico-químicos que regulan la disponibilidad de nutrientes y son funciones del suelo y de las plantas (Comerford 2005). La comprensión de los patrones de descomposición y liberación de nutrientes de materiales de plantas es un importante primer paso para mejorar la gestión de los insumos orgánicos (Thippayarugs et al. 2008).

La descomposición es ante todo un proceso biológico resultante de las actividades enzimáticas de los microorganismos del suelo, hace referencia a la descomposición física del material, generalmente medida como la pérdida de masa (Prescott 2005), y es 
influenciada en una variedad de maneras por la actividad de la fauna del suelo (Visser 1985). La mineralización se refiere a la liberación de nutrientes inorgánicos disponibles para las plantas (Prescott 2005).

En el ciclo biogeoquímico de los bosques la descomposición suele ser un paso clave, ya que si es demasiado lenta la mayoría de los nutrientes quedarán fuera de la circulación activa por largos períodos, reduciendo la productividad del bosque (Kimmins 1974). Por el contrario, una descomposición excesivamente rápida puede liberar los nutrientes antes de que las plantas puedan tomarlos, y en caso de quedar en el suelo pueden lavarse por fuera de la zona de raíces (Kimmins 1974). Por lo tanto, la comprensión de los patrones de descomposición y liberación de nutrientes provenientes de materiales de plantas es un importante primer paso para mejorar la gestión de los insumos orgánicos (Thippayarugs et al. 2008).

Varias etapas pueden ser delineadas en la descomposición de los residuos orgánicos (Stevenson 1986). Melillo et al. (1989) por ejemplo, describen el proceso en dos etapas: en la etapa temprana hay una pérdida rápida de los componentes solubles en agua fácilmente descomponibles (azúcares simples, aminoácidos, proteínas) y de celulosa, y suele haber inmovilización de nutrientes limitantes y ganancia relativa de lignina. Los mohos y bacterias formadoras de esporas son especialmente activos en esta etapa (Nieder y Benbi 2008). En la etapa tardía (Melillo et al. 1989) hay una lenta caída de todos los componentes, mineralización neta de $\mathrm{N}$ y pérdida neta de las partes de las plantas más resistentes, tales como lignina, para lo cual los actinomicetes y hongos juegan un papel importante (Nieder y Benbi 2008). La inmovilización de N que ocurre en la etapa temprana resulta en un aumento gradual en las concentraciones de $\mathrm{N}$ en el material que se está descomponiendo, constituido por los residuos vegetales más los microorganismos asociados, y por lo tanto hay un estrechamiento de la relación $\mathrm{C} / \mathrm{N}$ de este material durante la descomposición (Staaf 1980, Vesterdal 1999) que incrementa la mineralización de N (Stevenson 1986). En cambio, el patrón de liberación P es más variable, ya que se ha encontrado una liberación inicial (Lousier y Parkinson 1978, Peterson y Rolfe 1982, Rustad 1994, Monleon y Cromack 1996, Titus y Malcolm 1999) o bien una inmovilización de este nutriente (Gosz et al. 1973, Bartos y DeByle 1981, Staaf y Berg 1982, Berg y Laskowski 1997). 
Tanto el proceso de descomposición como el de mineralización están influenciados por factores físicos, químicos y biológicos (Andrén et al. 1994), siendo los principales el clima, los microorganismos y la fauna del suelo y la calidad química de los materiales que se descomponen (Heal et al. 1997). Respecto a las condiciones climáticas, la temperatura y la humedad son los principales factores que afectan la velocidad de descomposición (Robinson et al. 1995, Hobbie 1996, Aerts 1997, Ågren et al. 2001, Liski et al. 2003, Nieder y Benbi 2008). Sin embargo, es muy difícil separar los efectos de la temperatura de los de muchos otros factores ambientales, debido a que ésta covaría con otros factores que también afectan a la descomposición, por lo que la evapotranspiración real, que incorpora temperatura y humedad, es generalmente el mejor predictor de la tasa de descomposición en una amplia gama de climas (Prescott 2005). A escalas geográficas más amplias el clima es el principal determinante de la velocidad de desintegración (Meentemeyer 1978, Berg et al. 1993, Aerts 1997), mientras que a escala local, donde el clima es casi constante, la dinámica de la descomposición se encuentra fuertemente afectada por la "calidad química" y física del sustrato (Meentemeyer 1978, Swift et al. 1979, Aber et al. 1990, Gillon et al. 1994, Couteaux et al. 1995, Hobbie 1996, Aerts 1997, Cadisch y Giller 1997, Chapin et al. 1997, Tilman et al. 1997, Wardle et al. 1997, Berendse 1998, Binkley y Giardina 1998, Grime 2001, Eviner y Chapin 2003, Vaieretti 2005, Adair et al. 2008, Cusack et al. 2009) así también como de la estructura de la hoja (Cadisch y Giller 1997). Estos componentes estructurales de la hoja, dependen, en cierta medida, de las características de las plantas vivas y de sus hojas. Por ejemplo, las formas de vida caducifolias frente aquellas siempreverdes (Cornelissen 1996, Pérez-Harguindeguy et al. 2000, Quested et al. 2003, Frangi et al. 2004, Dorrepaal et al. 2005), la longevidad foliar, el contenido de nutrientes foliares, los componentes de la estructura de la hoja (Cornelissen y Thompson 1997, Gillon et al. 1994, Kazakou et al. 2006), las defensas de las plantas (Grime et al. 1996, Wardle et al. 1998, Cornelissen et al. 2004), la dureza de la hoja (Gallardo y Merino 1993), y las barreras físicas, como pelos, espinas, cera sobre la superficie (Cornelisesen 1996), se relacionan con la tasa de descomposición de la hoja. De manera más general, las especies de crecimiento rápido con pocas defensas producen hojarasca con una alta tasa de descomposición, mientras que las especies de crecimiento más lento, especies mejor 
defendidas, producen residuos de mala calidad con tasas de descomposición bajas (Cornelissen et al. 1999).

Entre los indicadores de calidad química que se han encontrado relacionados con la liberación de $\mathrm{N}$, se encuentra el contenido de $\mathrm{N}$ (Trinsoutrot et al. 2000) o la relación $\mathrm{C} / \mathrm{N}$ (Aber y Melillo 1980, Vigil y Kissel 1991, Aerts et al. 1997, Heal et al. 1997, Trinsoutrot et al. 2000, Wang et al. 2004, Güsewell y Verhoeven 2006), así también como las relaciones polifenol/N y (polifenol+lignina)/N (Palm y Sánchez 1991, Vigil y Kissel 1991, Constantinides y Fownes 1994, Wang et al. 2004). Para los árboles se ha encontrado una buena relación de la liberación de $\mathrm{N}$ del mantillo foliar con la relación lignina/ $\mathrm{N}$ (Melillo et al. 1982, Cotrufo et al. 1994), y con la concentración de lignina y polifenoles (Melillo et al. 1982, Taylor et al. 1989, Fox et al. 1990, Palm y Sanchez 1991, Vigil y Kissel 1991, Berg et al. 1993, Van Vuuren et al. 1993, Wang et al. 2004). Residuos con relación C/N alta usualmente se descomponen más lentamente que aquellos con baja relación $\mathrm{C} / \mathrm{N}$, donde además el $\mathrm{N}$ es inmovilizado por la población microbiana (Nguluu et al. 1996). La relación $\mathrm{C} / \mathrm{N}$ de los materiales debajo del cual la mineralización neta ocurre es cercana a 25 (Stevenson 1986), y los residuos de plantas con alto contenido de N (bajas relaciones $\mathrm{C} / \mathrm{N}$ ) tienen una alta tasa de descomposición y liberación de nutrientes (Kumar y Goh 2000). Sin embargo, no siempre una baja relación $\mathrm{C} / \mathrm{N}$ implicó una liberación de $\mathrm{N}$ alta, como lo reportado por Vallis y Jones (1973), quienes atribuyen a la presencia de polifenoles la baja tasa de liberación de $\mathrm{N}$ de material de leguminosas, los cuales se unen a proteínas reduciendo la liberación de $\mathrm{N}$ (Handayanto et al. 1994). No obstante, otros autores como Constantinides y Fownes (1994) observaron que en una amplia gama de materiales de plantas, los polifenoles fueron secundarios en cuanto al control en la liberación del $\mathrm{N}$, siendo la concentración de $\mathrm{N}$ de los residuos el parámetro que mejor explica su mineralización. Los polifenoles serían importantes sólo cuando están en bajas concentraciones (Handayanto et al. 1994, Seneviratne et al. 1998), y también bajo condiciones no limitantes de N (Seneviratne et al.1998). Los compuestos fenólicos pueden afectar las tasas de descomposición y el ciclo de nutrientes actuando directamente sobre la composición y la actividad de las comunidades de descomponedores (Hättenschwiler y Vitousek 2000), estimulando o inhibiendo la germinación de esporas y el crecimiento de las hifas de los hongos saprofíticos (Kuiters 1990), inhibiendo la actividad de los 
nitrificandores (Baldwin 1983, Rice y Pancholy 1973), suprimiendo o estimulando el crecimiento y la actividad simbiótica de fijación de $\mathrm{N}_{2}$ (Schimel et al. 1998). También pueden actuar restringiendo la actividad y la abundancia de la macrofauna del suelo (Neuhauser y Hartenstein 1978), lo que disminuye la biodegradación y mineralización de la materia orgánica asociada a esta fauna (Wardle y Lavelle 1997), aunque estos efectos directos pueden ser difíciles de demostrar debido a la covariabilidad con otros compuestos y la complejidad de las redes tróficas del suelo. (Hättenschwiler y Vitousek 2000). Otra manera en cómo los polifenoles influyen sobre las tasas de descomposición y mineralización de nutrientes es actuando sobre procesos físico-químicos en las reservas de nutrientes y las formas de los nutrientes por diferentes mecanismos (Hättenschwiler y Vitousek 2000), como la adsorción de minerales de arcilla y/o la formación de complejos con sesquióxidos que protege a los polifenoles del ataque microbiano y compite eficazmente con otros compuestos cargados negativamente para los sitios de sorción (Northup et al. 1998). Los polifenoles que se unen a sesquióxidos pueden prevenir la sorción del fosfato, por lo tanto, altas concentraciones de polifenoles podrían contribuir al mantenimiento de la disponibilidad de P en suelos (Hättenschwiler y Vitousek 2000).

A pesar de no existir un consenso en estos estudios con respecto a qué parámetro químico es la mejor determinante de descomposición y liberación de $\mathrm{N}$, las concentraciones iniciales de $\mathrm{C}, \mathrm{N}$, lignina, polifenoles y sus relaciones con $\mathrm{N}$ se consideran los principales determinantes (Seneviratne et al. 1999). Sin embargo, son relativamente difíciles de medir para un gran número de especies, y ninguno de estos parámetros se ha convertido en un sólido predictor de velocidad de descomposición a través de las especies, los tipos funcionales y los ecosistemas (Cornelissen et al. 2006).

La concentración de $\mathrm{P}$ de los residuos también puede ser un factor que incida en el proceso de descomposición y liberación de $\mathrm{N}$ (Enriquez et al. 1993). Respecto a la disponibilidad de $\mathrm{P}$, existe gran variación en los niveles críticos de los factores de calidad de los residuos (Kwabiah et al. 2003a). Algunos de los parámetros de calidad que se sabe controlan los patrones de disponibilidad de $\mathrm{P}$ son la concentración total de $\mathrm{P}$, y las relaciones C/P y N/P (Singh y Jones 1976, Vogt et al. 1986, Nziguheba et al. 2000, Kwabiah et al. 2003b). Nziguheba et al. (2000) han encontrado que materiales con alta concentración de $\mathrm{P}$ resultan en una mineralización neta de $\mathrm{P}$ y un aumento en la 
disponibilidad de este nutriente en el suelo, mientras que aquellos con baja concentración de $\mathrm{P}$ resultaron en una inmovilización microbiana. La relación $\mathrm{C} / \mathrm{P}$ es considerada un indicador crítico de la mineralización o inmovilización de $\mathrm{P}$ durante la descomposición (Curtin et al. 2003), considerándose un valor de este parámetro mayor a 300 el causante de la inmovilización neta de P (Brady y Weil 1996, Iyamuremye et al. 1996). Otros autores (Goya et al. 2008) encontraron valores mayores a 1000 en la relación C/P como límite a partir del cual se produce la inmovilización de $\mathrm{N}$ y $\mathrm{P}$ a partir de residuos de hojas de $E$. grandis en suelos arenosos en la zona de Entre Ríos.

Además de la calidad del material, otro factor importante en el proceso de descomposición son los microorganismos y la macrofauna del suelo (Lee 1974, Cornelissen 1996, Aerts 1997, Shaw y Harte 2001, Vaieretti et al. 2005, Parton et al. 2007). Cuando los residuos de plantas son incorporados en el suelo, la biomasa microbiana y su actividad se incrementan (Kaiser y Heinemeyer 1993, Jensen 1997), dado que los residuos de cosecha y sus productos de descomposición proveen energía y nutrientes a la población microbiana del suelo (McKenney et al. 1995). La mineralización de los nutrientes por los microorganismos del suelo es generalmente vista como el paso limitante de la velocidad en el ciclo de nutrientes (Heal et al. 1997). Se sabe que la macrofauna del suelo tiene un gran efecto en la descomposición de la hojarasca (Prescott 2005) mejorando la capacidad de los descomponedores microbianos para utilizar los residuos orgánicos por la fragmentación de restos vegetales, y mediante la distribución de materiales orgánicos en toda la matriz del suelo (Nieder y Benbi 2008).

El objetivo del presente capítulo es evaluar las relaciones entre la calidad química de los residuos foliares utilizados y la tasa de descomposición, y relacionarla con el aporte de $\mathrm{N}$ y $\mathrm{P}$ a la solución del suelo. La hipótesis es que la calidad química de los residuos afecta la tasa de descomposición y la liberación de N y P disponible para las plantas.

\section{Predicciones:}

- Bajo condiciones controladas, las hojas de eucaliptos se descomponen más lentamente que las hojas de las leguminosas herbáceas, lo que se relaciona a una menor calidad química de las primeras. 
- De existir diferencias químicas entre las especies de leguminosas, cabría esperar diferencias en sus tasas de liberación de $\mathrm{N}$ y de $\mathrm{P}$.

\subsection{MATERIALES Y MÉTODOS}

\subsubsection{Composición química foliar de las especies}

Residuos foliares de las 5 especies fueron analizadas para medir los siguientes parámetros de calidad química: concentración de C, N y P total, celulosa, hemicelulosa, lignina y polifenoles solubles.

Las muestras se molieron en molino Wiley y tamizaron con malla $20(0,85 \mathrm{~mm})$. Las concentraciones de $\mathrm{C}$ y $\mathrm{N}$ total en el tejido de la planta se midieron por el método de combustión en seco. El C Total fue determinado por detector IR individual (infrarrojos). El $\mathrm{N}$ total fue determinado por un detector TC (termo-conductividad) de célula. Para la concentración de $\mathrm{P}$, el tejido vegetal se digirió utilizando una modificación del procedimiento de Huang y Schulte (1985). Cinco mililitros de $\mathrm{HNO}_{3}$ concentrado se añadieron a una muestra de $0,5 \mathrm{~g}$, y se dejaron reposar durante la noche a temperatura ambiente. Al día siguiente la mezcla se calentó a $100^{\circ} \mathrm{C}$ durante 15 minutos por medio de un IPC Mod Block digestor, bloque de aluminio con un controlador de temperatura a distancia. Después de un período de enfriamiento, se añadieron $10 \mathrm{ml}$ de una mezcla 1:1 de $\mathrm{HNO}_{3}$ y $\mathrm{H}_{2} \mathrm{O}$ deionizada, y se volvió a calentar a $95^{\circ} \mathrm{C}$ durante 2 horas. Luego de otro período de enfriamiento, se añadieron $4 \mathrm{ml}$ de $\mathrm{H}_{2} \mathrm{O}_{2}$ al $30 \%$ y volvió a calentarse a $95^{\circ} \mathrm{C}$ durante 10 minutos. Luego del enfriamiento se adicionaron $2 \mathrm{ml}$ de $\mathrm{HCl}$ concentrado, y volvió a calentarse a $95^{\circ} \mathrm{C}$ durante 30 minutos. Una vez frío, el volumen de la muestra se completó a 50,0 ml con agua deionizada. Finalmente se filtró la muestra con papel de filtro Q8 (marca Fisher) y se recogió en botellas de LDPE. El cuerpo del recipiente de digestión fue de teflón PFA y los "vidrios de reloj" fueron de polipropileno, para evitar cualquier posible contaminación de metal y de boro durante el proceso de digestión. La muestra de digestión se analizó para el P por medio de un plasma acoplado inductivamente (ICP) Espectrómetro de Emisión (Spectro Ciros CCD). 
Para la determinación de celulosa, hemicelulosa y lignina se utilizó el método de Van Söest (Göering y Van Söest 1970). Para la determinación de polifenoles solubles, se colocó una muestra molida en alcohol al $80 \%$ a baño de María durante 1 hora, y se dejó enfriar. Se filtró la muestra, se secó el material sólido filtrado y se recolectó el líquido. Con alcohol $80 \%$ se dejó al sólido filtrado en el paso anterior en extracción en soxhlet por 12 horas. Se filtró, y se juntó el líquido con el líquido filtrado en el paso anterior, y se llevó a un volumen de $50 \mathrm{ml}$. Se agregó $1 \mathrm{ml}$ del reactivo de Folin-Ciocalteau, $10 \mathrm{ml}$ de carbonato-tartrato, y se midió en espectrofotómetro a $650 \mathrm{~nm}$.

\subsubsection{Ensayo de descomposición}

Se realizó un ensayo de descomposición en laboratorio, en condiciones controladas de humedad, temperatura y tamaño de las fracciones de hojas de E. grandis y de las distintas especies de leguminosas, manteniendo todas las muestras de las distintas especies en un mismo espacio físico.

\subsubsection{Selección y recolección del material vegetal y suelo}

Las especies utilizadas fueron Eucalyptus grandis y las siguientes especies de leguminosas: Canavalia ensiformis L., Cajanus cajan L., Lotus corniculatus L. y Trifolium pratense L. El suelo utilizado fue un Quartzipsamment Oxico (localmente arenoso) La procedencia y recolección del material vegetal y el suelo se realizó como se describe en el Capítulo 2 (ver sección 2.2.2).

\subsubsection{Preparación del material}

Las hojas de las 5 especies se secaron al aire y luego fueron groseramente molidas con la mano, en trozos de entre $0.5 \times 0.5 \mathrm{~cm}-1 \times 1 \mathrm{~cm}$, aproximadamente. Se prepararon alícuotas de $3 \mathrm{~g}$ de hojas molidas de cada especie que constituyeron las submuestras. Cinco submuestras de cada especie se dispusieron cada una dentro de un sobre o bolsa de $10 \times 10$ $\mathrm{cm}$ de lado realizada con una malla inerte de acero inoxidable de $0,4 \mathrm{~mm}$. 
Además, para cada especie, 3 submuestras de hojas se secaron al aire y luego de pesarse, se llevaron a estufa a $70^{\circ} \mathrm{C}$ por $48 \mathrm{~h}$, para calcular el contenido de humedad inicial del material y obtener un factor de corrección de humedad a emplear en el cálculo del peso seco inicial de las alícuotas de cada especie.

El ensayo consistió en 5 especies; 3 fechas de recolección y 5 repeticiones por especie/fecha; que hacen un total de 75 bolsas iniciales.

\subsubsection{Tratamiento}

Todas las muestras se humedecieron y se enterraron simultáneamente en una cama de descomposición de suelo arenoso húmedo (Imagen 3.1 y 3.2). La cama midió $120 \mathrm{~cm} \mathrm{x}$ $77 \mathrm{~cm}$, y fue llenada con suelo en un espesor de $20 \mathrm{~cm}$ de alto. Las bolsas fueron colocadas al azar a una profundidad de $5 \mathrm{~cm}$ dentro de la cama, previamente re-humedecidas con un aspersor con agua. La cama se mantuvo durante todo el tratamiento en un lugar al resguardo de la intemperie, a temperatura entre $20-22{ }^{\circ} \mathrm{C}$ y entre $70-80 \%$ de humedad.

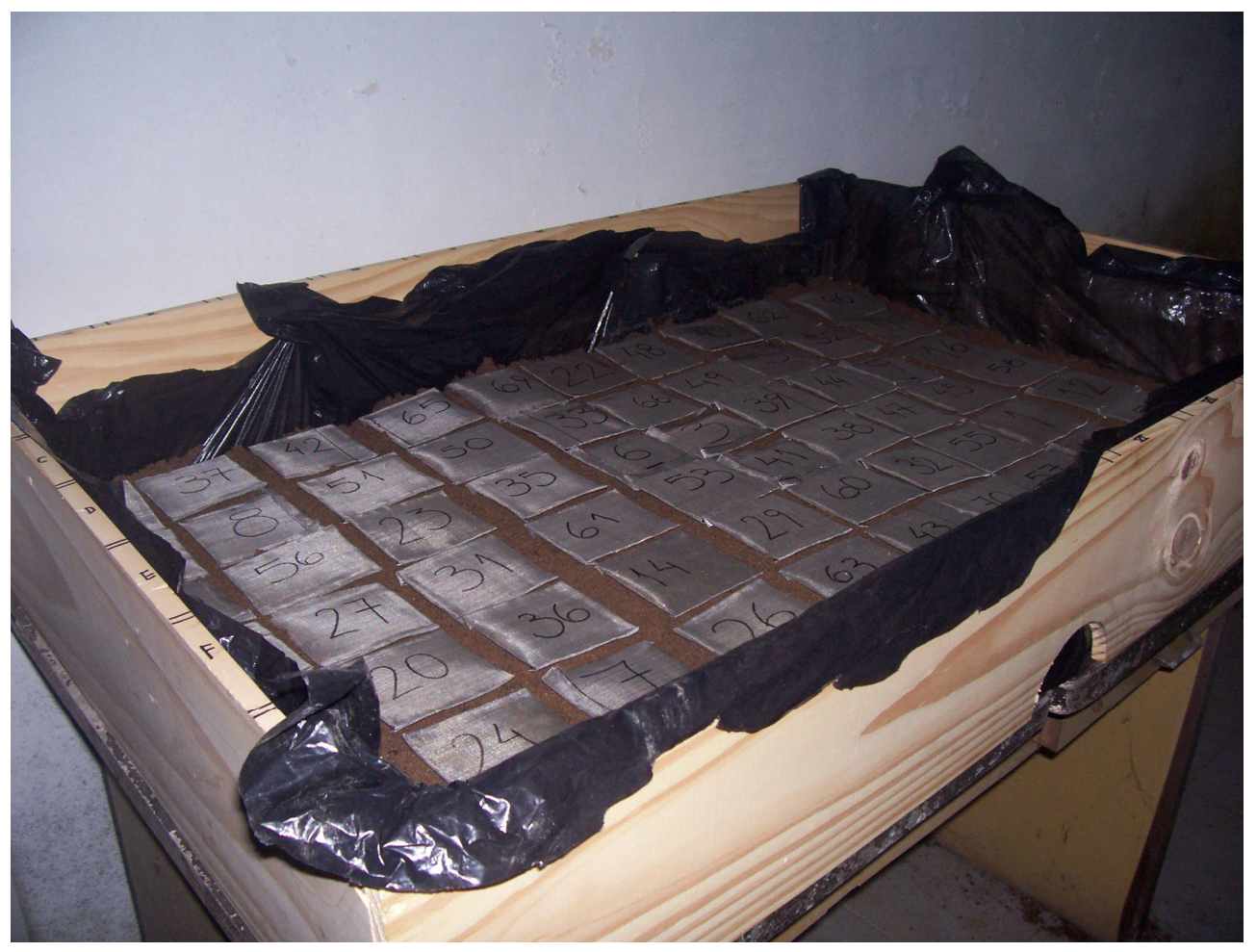

Imagen 3.1. Bolsas conteniendo hojas de eucaliptos y leguminosas dispuestas en la cama de descomposición. 


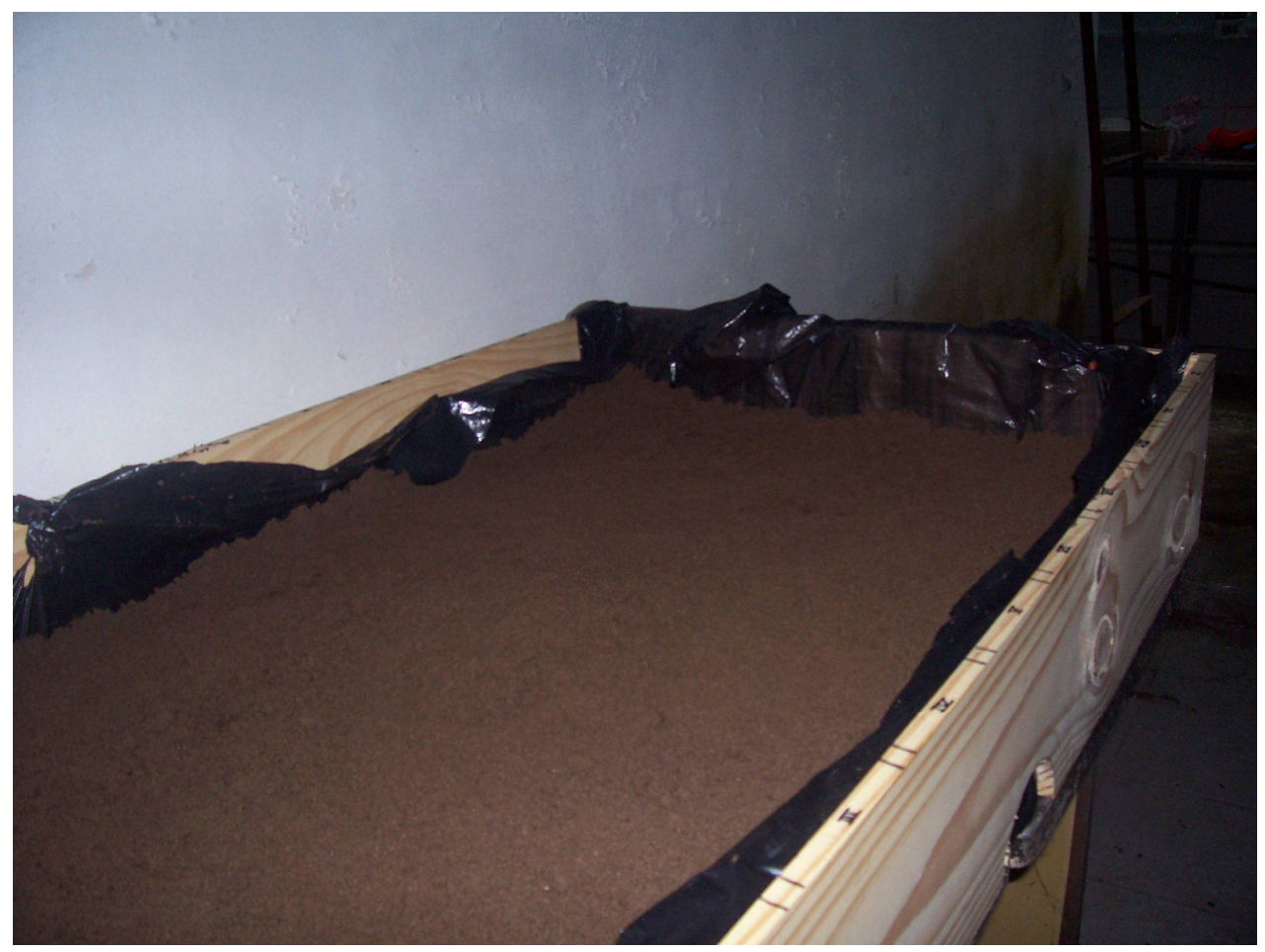

Imagen 3.2. Cama de descomposición.

Para cada especie se colectaron al azar 5 bolsas luego de 21 días ( 3 semanas), luego de 63 días (9 semanas) y finalmente a los 140 días (20 semanas) de iniciada la experiencia. Las mismas, una vez retiradas de la cama, se limpiaron de impurezas, se secaron a estufa a $70^{\circ} \mathrm{C}$ durante $48 \mathrm{~h}$, y se calculó el peso seco remanente en cada fecha; para cada una de ellas el peso seco inicial fue calculado con el peso inicial de la alícuota y el factor de corrección de humedad.

\subsubsection{Análisis de los datos}

Con los datos de porciento de peso seco remanente respecto del peso seco inicial vs tiempo de exposición a la descomposición se ajustó para cada especie una función exponencial negativa para obtener la tasa anual de descomposición k (Olson 1963), la vida media para cada especie $(0,693 / \mathrm{k})$, el tiempo para perder el $95 \%$ peso $(1 / \mathrm{k})$, y el tiempo para perder $99 \%$ del peso $(3 / \mathrm{k})$. 


\subsubsection{Análisis estadísticos}

Se hicieron ANOVA de 1 vía para cada parámetro de calidad química comparando a las especies entre sí.

Con un objetivo exploratorio, se hicieron análisis de correlación entre: 1- los parámetros de calidad de todas las especies con la tasa de descomposición anual (k), la vida media $(0,693 / \mathrm{k})$ y el tiempo que tarda en perder el $95 \%(1 / \mathrm{k})$ y el $99 \%$ del peso (3/k); 2- el contenido de N y P en el lixiviado para los 2 tipos de suelo (arenoso y arcilloso) y los dos modos de aplicación del material (molido y mezclado y entero y superficial) obtenidas en el Capítulo 2, con cada uno de los parámetros de calidad química de las 5 especies; y , 3- el contenido de N y P en el lixiviado para los 2 tipos de suelo (arenoso y arcilloso) y los dos modos de aplicación del material (molido y mezclado y entero y superficial) obtenidas en el Capítulo 2, con la tasa de descomposición anual (k), la vida media $(0,693 / \mathrm{k})$ y el tiempo que tarda en perder el 95\% (1/k) y el 99\% del peso (3/k).

Los cálculos estadísticos se realizaron empleando el programa Statistica.7.

\subsection{RESULTADOS}

\subsubsection{Composición química de las especies}

E. grandis presentó la concentración de $\mathrm{N}$ más baja y de $\mathrm{C}$ más alta, en comparación con las leguminosas, y una concentración de P intermedia (Tabla 3.1). Entre las leguminosas, $T$. pratense presentó la mayor concentración de $\mathrm{N}$, seguida por $L$. corniculatus y $C$. cajan, siendo esta última la especie con mayor concentración de $\mathrm{C}$ y $\mathrm{P}$ (Tabla 3.1). Con respecto a la relación $\mathrm{C} / \mathrm{N}$, E. grandis tuvo un valor significativamente mayor, y dentro de las leguminosas se encontró poca diferencia, siendo C. ensiformis la leguminosa con una relación mayor. Esta especie tuvo también las relaciones C/P y N/P más altas, seguida por E. grandis (ambas especies con valores mayores a 300 para C/P), seguidas por las restantes leguminosas con valores inferiores a 300 para C/P (Tabla 3.1). Respecto a la hemicelulosa $(\mathrm{He})$, L. corniculatus fue la especie con más alta concentración y $C$. ensiformis con la más baja, mientras que con la concentración de celulosa (Cel) hubo 
pocas diferencias entre las especies analizadas, incluso con E. grandis. Al analizar la holocelulosa (Ho), que incluye a hemiceulosa y celulosa, tanto C. cajan como $L$. corniculatus tuvieron las más altas concentraciones (Tabla 3.1). C. cajan y T. pratense fueron las especies con más concentración de lignina (L), seguidas por E. grandis, y finalmente L. corniculatus y C. ensiformis. Con respecto a los polifenoles solubles (PS), E. grandis es la especie con mayor concentración a diferencia de las leguminosas que presentaron concentraciones mucho más bajas y con poca diferencia entre sí. En cuanto a los parámetros Lignina/N $(\mathrm{L} / \mathrm{N})$, polifenoles/N (PS/N), y (Lignina+polifenoles)/N [(L + $\mathrm{PS}) / \mathrm{N}]$, siempre E. grandis presentó los valores más elevados (Tabla 3.1).

Tabla 3.1. Composición química de las especies usadas como abono verde. $\mathrm{He}=$ hemicelulosa. $\mathrm{Cel}=$ celulosa $\mathrm{Ho}=$ holocelulosa $($ celulosa + hemicelulosa $) \mathrm{L}=$ lignina. $\mathrm{PS}=$ polifenoles solubles. Con letras minúsculas se indica, para cada fila, las diferencias significativas entre especies para cada variable $(\mathrm{p}<0,05)$.

\begin{tabular}{cccccc}
\hline Variable & E. grandis & C. ensiformis & C. cajan & L. corniculatus & T. pratense \\
\hline $\mathrm{N}(\mathrm{mg} / \mathrm{g})$ & $22 \mathbf{d}$ & $27 \mathbf{c}$ & $38 \mathbf{b}$ & $41 \mathbf{b}$ & $46 \mathbf{a}$ \\
$\mathrm{C}(\mathrm{mg} / \mathrm{g})$ & $520 \mathbf{a}$ & $417 \mathbf{d}$ & $513 \mathbf{b}$ & $467 \mathbf{c}$ & $474 \mathbf{c}$ \\
$\mathrm{P}(\mathrm{mg} / \mathrm{g})$ & $1,24 \mathbf{c}$ & $0,85 \mathbf{d}$ & $2,80 \mathbf{a}$ & $1,98 \mathbf{b}$ & $2,28 \mathbf{b}$ \\
$\mathrm{C} / \mathrm{N}$ & $23 \mathbf{a}$ & $15 \mathbf{b}$ & $14 \mathbf{b c}$ & $12 \mathbf{c d}$ & $10 \mathbf{d}$ \\
$\mathrm{C} / \mathrm{P}$ & $426 \mathbf{b}$ & $491 \mathbf{a}$ & $184 \mathbf{c}$ & $239 \mathbf{c}$ & $205 \mathbf{c}$ \\
$\mathrm{N} / \mathrm{P}$ & $18 \mathbf{b}$ & $32 \mathbf{a}$ & $13 \mathbf{c}$ & $20 \mathbf{b}$ & $20 \mathbf{b}$ \\
$\mathrm{He}(\mathrm{mg} / \mathrm{g})$ & $148 \mathbf{b}$ & $80 \mathbf{d}$ & $164 \mathbf{b}$ & $229 \mathbf{a}$ & $119 \mathbf{c}$ \\
$\mathrm{Cel}(\mathrm{mg} / \mathrm{g})$ & $136 \mathbf{a}$ & $147 \mathbf{a}$ & $156 \mathbf{a}$ & $103 \mathbf{b}$ & $159 \mathbf{a}$ \\
$\mathrm{Ho}(\mathrm{mg} / \mathrm{g})$ & $284 \mathbf{b}$ & $227 \mathbf{c}$ & $320 \mathbf{a}$ & $332 \mathbf{a}$ & $278 \mathbf{b}$ \\
$\mathrm{L}(\mathrm{mg} / \mathrm{g})$ & $123 \mathbf{b}$ & $47 \mathbf{c}$ & $162 \mathbf{a}$ & $72 \mathbf{c}$ & $157 \mathbf{a}$ \\
$\mathrm{PS}(\mathrm{mg} / \mathrm{g})$ & $93 \mathbf{a}$ & $20 \mathbf{b}$ & $25 \mathbf{b}$ & $20 \mathbf{b}$ & $19 \mathbf{b}$ \\
$\mathrm{L} / \mathrm{N}$ & 5,55 & 1,74 & 4,28 & 1,78 & 3,44 \\
$\mathrm{PS} / \mathrm{N}$ & 4,21 & 0,74 & 0,65 & 0,51 & 0,42 \\
$(\mathrm{~L}+\mathrm{PS}) / \mathrm{N}$ & 9,76 & 2,48 & 4,93 & 2,30 & 3,87 \\
\hline
\end{tabular}




\subsubsection{Tasas de descomposición de las especies $(k)$, vida media y tiempo para perder el}

$95 \%$

En la fase 1 de la descomposición a los 21 días de iniciado el ensayo (Figura 3.1), se observó una tasa de descomposición mayor en $L$. corniculatus, intermedia y similar entre sí para C. cajan, C. ensiformis y T. pratense, y menor para E. grandis.

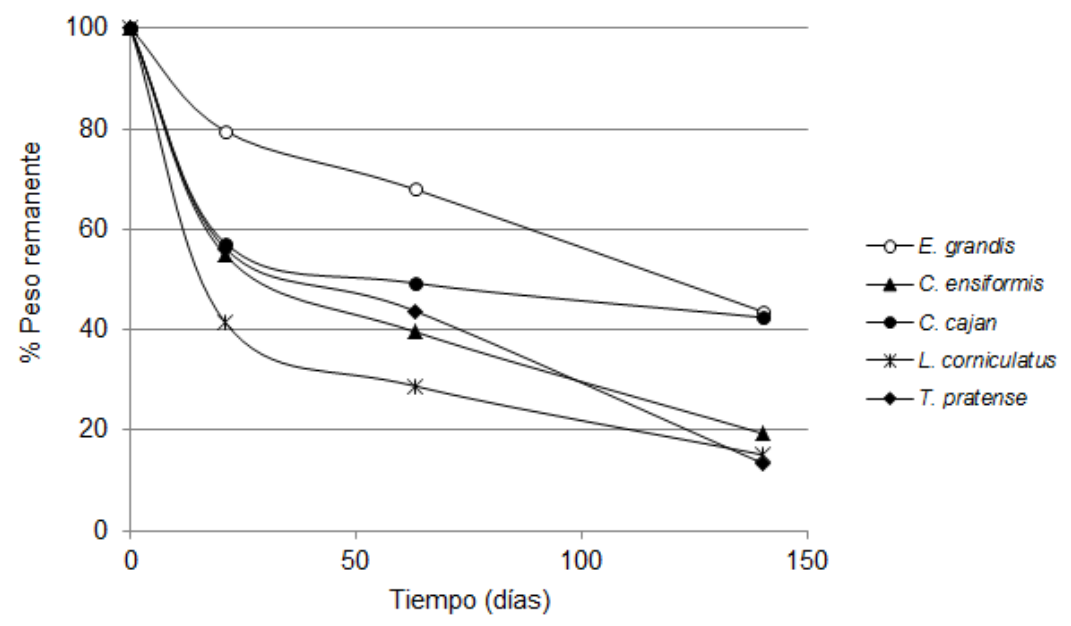

Figura 3.1. Peso remanente para las especies a los 21 días, 63 días y 140 días de descomposición.

Si se consideran las tasas de descomposición anuales, se observa un orden decreciente de las mismas según: $L$. corniculatus $>C$. ensiformis $>T$. pratense $>C$. cajan $>$ E. grandis (Figura 3.1 y Tabla 3.2).

Tabla 3.2. Tasas de descomposición anual $\mathrm{k}\left(\mathrm{anno}^{-1}\right)$, vida media $(0,693 / \mathrm{k})$, tiempo para perder el 95 $\%$ del peso $(1 / \mathrm{k})$, tiempo que tarda en perder el $99 \%$ del peso $(3 / \mathrm{k})$. Las especies están en orden creciente de $\mathrm{k}$.

\begin{tabular}{ccccc}
\hline Especies & $\begin{array}{c}\mathrm{k} \\
\left(\mathrm{anno}^{-1}\right)\end{array}$ & $\begin{array}{c}\text { Vida media } \\
(\mathrm{años})\end{array}$ & $\begin{array}{c}1 / \mathrm{k} \\
(\mathrm{años})\end{array}$ & $\begin{array}{c}3 / \mathrm{k} \\
\text { (años) }\end{array}$ \\
\hline E. grandis & 2,19 & 0,32 & 0,46 & 1,37 \\
C. cajan & 4,38 & 0,16 & 0,23 & 0,68 \\
T. pratense & 5,11 & 0,14 & 0,19 & 0,59 \\
C. ensiformis & 5,84 & 0,12 & 0,17 & 0,51 \\
L. corniculatus & 8,40 & 0,08 & 0,12 & 0,36 \\
\hline
\end{tabular}


E. grandis se descompuso entre 2 y hasta casi 4 veces más lento que las leguminosas (Tabla 3.2). Las leguminosas mostraron una tendencia creciente gradual entre C. cajan, T. pratense y C. ensiformis, pero L. corniculatus se descompone mucho más rápido que las anteriores (Tabla 3.2).

En las condiciones del experimento, E. grandis tarda unos 5,5 meses para perder el 95\% de la masa de las hojas; las tres leguminosas mencionadas antes entre 2 y 3 meses aproximadamente; y L. corniculatus menos de 45 días (Tabla 3.2).

\subsubsection{Correlación entre las tasas de descomposición de las especies $(k)$, vida media y tiempo para perder el $95 \%$ y el $99 \%$ del peso, con los parámetros de calidad de todas las especies}

La tasa anual de descomposición se correlacionó significativamente y de forma directa con el contenido de $\mathrm{N}$ de las especies y de forma inversa con la relación $\mathrm{C} / \mathrm{N}$ (Tabla 3.3). La relación $\mathrm{C} / \mathrm{N}$ asimismo se correlacionó en forma directa tanto con la vida media, como con el tiempo que tarda en perder el 95\% y el 99\% del peso, al igual que el contenido de PS y la relación PS/N (Tabla 3.3). Por otro lado, en los parámetros de calidad Cel + PS, y las relaciones $\mathrm{L} / \mathrm{N}$ y $(\mathrm{L}+\mathrm{PS}) / \mathrm{N}$ se observó una correlación directa y significativa con la vida media y con el tiempo que tarda el material en perder el 99\% del peso (Tabla 3.3). 
Tabla 3.3. Valores $r$ de correlación entre los parámetros de calidad de todas las especies con la tasa de descomposición anual, la vida media $(0,693 / \mathrm{k})$ medida en años, el tiempo que tarda en perder el 95\% del peso (años), y el tiempo que tarda en perder el 99\% del peso (años). $\mathrm{He}=$ hemicelulosa. $\mathrm{Cel}=$ celulosa $\mathrm{Ho}=$ holocelulosa $($ celulosa + hemicelulosa $) \mathrm{L}=$ lignina. $\mathrm{PS}=$ polifenoles solubles. En negrita se indican los valores significativos $(\mathrm{p}<0,05)$.

\begin{tabular}{|c|c|c|c|c|}
\hline $\begin{array}{l}\text { Parámetros de } \\
\text { calidad química } \\
\end{array}$ & $\begin{array}{l}\mathrm{k} \text { anual } \\
\left(\mathrm{añon}{ }^{-1}\right)\end{array}$ & $\begin{array}{l}\text { Vida media } \\
\text { (años) }\end{array}$ & $\begin{array}{c}\text { Tiempo que tarda en } \\
\text { perder el } 95 \% \text { del } \\
\text { peso (años) }\end{array}$ & $\begin{array}{c}\text { Tiempo que tarda en } \\
\text { perder el 99\% del peso } \\
\text { (años) }\end{array}$ \\
\hline $\mathrm{N}$ & 0,9 & $-0,68$ & $-0,88$ & $-0,68$ \\
\hline $\mathrm{C}$ & $-0,3$ & 0,67 & 0,44 & 0,67 \\
\hline $\mathrm{P}$ & 0,6 & $-0,27$ & $-0,55$ & $-0,27$ \\
\hline $\mathrm{C} / \mathrm{N}$ & $-0,9$ & 0,90 & 0,99 & 0,90 \\
\hline $\mathrm{C} / \mathrm{P}$ & $-0,8$ & 0,36 & 0,68 & 0,36 \\
\hline $\mathrm{N} / \mathrm{P}$ & 0,0 & $-0,35$ & $-0,09$ & $-0,35$ \\
\hline $\mathrm{He}$ & 0,0 & $-0,14$ & $-0,07$ & $-0,14$ \\
\hline $\mathrm{Cel}$ & 0,2 & 0,17 & $-0,13$ & 0,17 \\
\hline Ho & 0,2 & $-0,09$ & $-0,16$ & $-0,09$ \\
\hline $\mathrm{L}$ & 0,3 & 0,34 & $-0,07$ & 0,34 \\
\hline PS & $-0,8$ & 0,96 & 0,96 & 0,96 \\
\hline $\mathrm{Cel}+\mathrm{L}$ & 0,3 & 0,32 & $-0,09$ & 0,32 \\
\hline $\mathrm{Cel}+\mathrm{PS}$ & $-0,5$ & 0,93 & 0,75 & 0,93 \\
\hline $\mathrm{L}+\mathrm{PS}$ & $-0,2$ & 0,76 & 0,43 & 0,76 \\
\hline $\mathrm{Cel}+\mathrm{L}+\mathrm{PS}$ & $-0,1$ & 0,69 & 0,33 & 0,69 \\
\hline $\mathrm{L} / \mathrm{N}$ & $-0,4$ & $\mathbf{0 , 8 9}$ & 0,64 & 0,89 \\
\hline $\mathrm{PS} / \mathrm{N}$ & $-0,8$ & 0,95 & 0,97 & 0,95 \\
\hline$(\mathrm{L}+\mathrm{PS}) / \mathrm{N}$ & $-0,6$ & 0,99 & 0,87 & 0,99 \\
\hline
\end{tabular}

\subsubsection{Correlación entre el contenido de $\mathbf{N}$ y $\mathrm{P}$ en el lixiviado y los parámetros de calidad química de los residuos vegetales}

3.3.4.1. Correlación entre el contenido de $N$ en el lixiviado y los parámetros de calidad química

En suelos arenosos con ambos modos de incorporación del material, no hubo ningún parámetro de calidad química que se correlacionara significativamente con la lixiviación de $\mathrm{N}$ proveniente de los residuos utilizados (Tabla 3.4). En los suelos arcillosos con el residuo incorporado MM, se encontró una correlación inversa significativa entre la 
lixiviación de $\mathrm{N}$ y la concentración de $\mathrm{Cel}+\mathrm{PS}$ y la relación $(\mathrm{L}+\mathrm{PS}) / \mathrm{N}$ del material vegetal (Tabla 3.4).

Tabla 3.4. Valores $\mathrm{r}$ de correlación, entre la lixiviación de $\mathrm{N}(\mathrm{mgN} / \mathrm{kg}$ suelo) para cada tipo de suelo y modos de incorporación obtenidos en el Capítulo 2 con los parámetros de calidad química analizadas para todas las especies. Are $\mathrm{MM}=$ suelo arenoso, con modo de incorporación del material molido y mezclado; Are ES= suelo arenoso, con modo de incorporación del material entero y superficial; Arci $\mathrm{MM}=$ suelo arcilloso, con modo de incorporación del material molido y mezclado; Arci ES= suelo arcilloso, con modo de incorporación del material entero y superficial. $\mathrm{He}=$ hemicelulosa. $\mathrm{Cel}=$ celulosa. $\mathrm{Ho}=$ holocelulosa $($ celulosa + hemicelulosa $) . \mathrm{L}=$ lignina. $\mathrm{PS}=$ polifenoles solubles. En negrita se indican los valores significativos $(\mathrm{p}<0,05)$.

\begin{tabular}{ccccc}
\hline Parámetros de & \multicolumn{4}{c}{ Lixiviación de N (mgN/kg suelo) } \\
\cline { 2 - 5 } calidad química & Are MM & Are ES & Arci MM & Arci ES \\
\hline N & 0,48 & 0,80 & 0,60 & 0,87 \\
C & 0,00 & $-0,05$ & $-0,49$ & $-0,06$ \\
P & 0,60 & 0,77 & 0,33 & 0,80 \\
C/N & $-0,55$ & $-0,83$ & $-0,79$ & $-0,87$ \\
C/P & $-0,39$ & $-0,70$ & $-0,33$ & $-0,82$ \\
N/P & $-0,29$ & $-0,31$ & 0,17 & $-0,27$ \\
He & 0,62 & 0,54 & 0,42 & 0,02 \\
Cel & $-0,32$ & $-0,16$ & $-0,40$ & 0,43 \\
Ho & 0,66 & 0,64 & 0,35 & 0,27 \\
L & $-0,03$ & 0,15 & $-0,37$ & 0,48 \\
PS & $-0,60$ & $-0,78$ & $-0,85$ & $-0,79$ \\
Cel + L & $-0,14$ & 0,06 & $-0,42$ & 0,52 \\
Cel + PS & $-0,71$ & $-0,77$ & $-\mathbf{0 , 9 7}$ & $-0,42$ \\
L + PS & $-0,33$ & $-0,27$ & $-0,72$ & $-0,02$ \\
Cel + L + PS & $-0,37$ & $-0,28$ & $-0,73$ & 0,11 \\
L/N & $-0,40$ & $-0,44$ & $-0,82$ & $-0,24$ \\
PS/N & $-0,62$ & $-0,82$ & $-0,85$ & $-0,83$ \\
(L + PS)/N & $-0,55$ & $-0,68$ & $-\mathbf{0 , 9 0}$ & $-0,57$ \\
\hline
\end{tabular}

Iguales tendencias se encontraron al correlacionar únicamente los parámetros de calidad química de las leguminosas con la liberación de $\mathrm{N}$ al lixiviado desde estos residuos en suelos arenosos (Tabla 3.5), a excepción de la Ho que tuvo una correlación directa significativa cuando los residuos se agregaron ES. En suelos arcillosos, se encontró una 
correlación inversa significativa entre la lixiviación de $\mathrm{N}$ y la concentración de celulosa de las leguminosas, así también como con el parámetro Cel + PS, cuando el material se incorporó MM (Tabla 3.5). Asimismo, en este tipo de suelo, pero con el material incorporado ES, hubo correlaciones directas significativas entre los parámetros $\mathrm{L}, \mathrm{Cel}+\mathrm{L}$, $\mathrm{L}+\mathrm{PS}, \mathrm{Cel}+\mathrm{L}+\mathrm{PS}, \mathrm{L} / \mathrm{N}$ y $(\mathrm{L}+\mathrm{PS}) / \mathrm{N}$ de las leguminosas y la lixiviación de $\mathrm{N}$ (Tabla $3.5)$.

Tabla 3.5. Valores $\mathrm{r}$ de correlación, entre la lixiviación de $\mathrm{N}(\mathrm{mgN} / \mathrm{kg}$ suelo) para cada tipo de suelo y modos de incorporación obtenidos en el Capítulo 2 con los parámetros de calidad química analizadas para las especies de leguminosas. Are $\mathrm{MM}=$ suelo arenoso, con modo de incorporación del material molido y mezclado; Are ES= suelo arenoso, con modo de incorporación del material entero y superficial; Arci $\mathrm{MM}=$ suelo arcilloso, con modo de incorporación del material molido y mezclado; Arci ES= suelo arcilloso, con modo de incorporación del material entero y superficial. $\mathrm{He}=$ hemicelulosa. $\mathrm{Cel}=$ celulosa $. \mathrm{Ho}=$ holocelulosa $($ celulosa + hemicelulosa $) . \mathrm{L}=$ lignina. PS= polifenoles solubles. En negrita se indican los valores significativos $(\mathrm{p}<0,05)$.

\begin{tabular}{ccccc}
\hline Parámetros de & \multicolumn{4}{c}{ Lixiviación de N (mgN/kg suelo) } \\
\cline { 2 - 5 } calidad química & Are MM & Are ES & Arci MM & Arci ES \\
\hline N & 0,04 & 0,55 & $-0,05$ & 0,70 \\
$\mathrm{C}$ & 0,57 & 0,82 & $-0,01$ & 0,83 \\
$\mathrm{P}$ & 0,48 & 0,80 & $-0,05$ & 0,87 \\
$\mathrm{C} / \mathrm{N}$ & 0,13 & $-0,38$ & 0,03 & $-0,53$ \\
$\mathrm{C} / \mathrm{P}$ & $-0,14$ & $-0,62$ & 0,16 & $-0,86$ \\
$\mathrm{~N} / \mathrm{P}$ & $-0,58$ & $-0,86$ & $-0,06$ & $-0,80$ \\
$\mathrm{He}$ & 0,80 & 0,90 & 0,81 & 0,04 \\
$\mathrm{Cel}$ & $-0,51$ & $-0,42$ & $-\mathbf{0 , 9 6}$ & 0,59 \\
$\mathrm{Ho}$ & 0,80 & $\mathbf{0 , 9 9}$ & 0,57 & 0,38 \\
$\mathrm{~L}$ & 0,05 & 0,42 & $-0,52$ & $\mathbf{1 , 0 0}$ \\
$\mathrm{PS}$ & 0,69 & 0,55 & 0,02 & 0,42 \\
$\mathrm{Cel}+\mathrm{L}$ & $-0,13$ & 0,18 & $-0,72$ & $\mathbf{0 , 9 6}$ \\
$\mathrm{Cel}+\mathrm{PS}$ & $-0,43$ & $-0,36$ & $-\mathbf{0 , 9 3}$ & 0,61 \\
$\mathrm{~L}+\mathrm{PS}$ & 0,08 & 0,43 & $-0,51$ & $\mathbf{1 , 0 0}$ \\
Cel + L + PS & $-0,11$ & 0,19 & $-0,71$ & $\mathbf{0 , 9 6}$ \\
$\mathrm{L} / \mathrm{N}$ & 0,15 & 0,39 & $-0,53$ & $\mathbf{0 , 9 5}$ \\
PS/N & 0,18 & $-0,32$ & 0,03 & $-0,48$ \\
(L + PS)/N & 0,17 & 0,36 & $-0,53$ & $\mathbf{0 , 9 0}$ \\
\hline
\end{tabular}


3.3.4.2. Correlación entre el contenido de P del lixiviado y los parámetros de calidad química

Para suelos arenosos con el material incorporado MM, la lixiviación de $\mathrm{P}$ se correlacionó en forma directa significativamente con la concentración de C, L + PS, y con la relación $\mathrm{L} / \mathrm{N}$ del residuo, y con el material incorporado ES se correlacionó de forma directa con la relación N/P (Tabla 3.6).

Tabla 3.6. Valores $r$ de correlación, entre la lixiviación de $\mathrm{P}(\mathrm{mgP} / \mathrm{kg}$ suelo) para cada tipo de suelo y modos de incorporación obtenidos en el Capítulo 2 con los parámetros de calidad química analizadas para todas las especies. Are $\mathrm{MM}=$ suelo arenoso, con modo de incorporación del material molido y mezclado; Are ES= suelo arenoso, con modo de incorporación del material entero y superficial; Arci MM= suelo arcilloso, con modo de incorporación del material molido y mezclado; Arci ES= suelo arcilloso, con modo de incorporación del material entero y superficial. $\mathrm{He}=$ hemicelulosa $. \mathrm{Cel}=$ celulosa $. \mathrm{Ho}=$ holocelulosa (celulosa + hemicelulosa). $\mathrm{L}=$ lignina. $\mathrm{PS}=$ polifenoles solubles. En negrita se indican los valores significativos $(p<0,05)$.

\begin{tabular}{ccccc}
\hline \multirow{2}{*}{$\begin{array}{c}\text { Parámetros de } \\
\text { calidad química }\end{array}$} & \multicolumn{4}{c}{ Lixiviación de P (mgP/kg suelo) } \\
\cline { 2 - 5 } Are MM & Are ES & Arci MM & Arci ES \\
C & $-0,22$ & $-0,19$ & $\mathbf{0 , 8 8}$ & $\mathbf{0 , 9 0}$ \\
P & $\mathbf{0 , 9 5}$ & $-0,85$ & $-0,16$ & 0,31 \\
C/N & 0,38 & $-0,73$ & 0,51 & 0,84 \\
C/P & 0,52 & $-0,06$ & $-0,81$ & $-0,69$ \\
N/P & $-0,16$ & 0,46 & $-0,73$ & $-\mathbf{0 , 9 3}$ \\
He & $-0,82$ & $\mathbf{0 , 9 3}$ & $-0,14$ & $-0,61$ \\
Cel & 0,16 & $-0,66$ & 0,55 & 0,67 \\
Ho & 0,30 & 0,08 & $-0,40$ & $-0,21$ \\
L & 0,38 & $-0,85$ & 0,52 & 0,79 \\
PS & 0,76 & $-0,62$ & 0,05 & 0,48 \\
Cel + L & 0,66 & $-0,20$ & $-0,60$ & $-0,42$ \\
Cel + PS & 0,69 & $-0,45$ & $-0,10$ & 0,30 \\
L + PS & 0,74 & $-0,12$ & $-0,75$ & $-0,49$ \\
Cel + L + PS & $\mathbf{0 , 9 3}$ & $-0,59$ & $-0,26$ & 0,17 \\
L/N & 0,88 & $-0,48$ & $-0,34$ & 0,08 \\
PS/N & $\mathbf{0 , 9 6}$ & $-0,55$ & $-0,49$ & $-0,08$ \\
(L + PS)/N & 0,61 & $-0,14$ & $-0,63$ & $-0,48$ \\
\hline & 0,84 & $-0,37$ & $-0,60$ & $-0,30$ \\
\hline
\end{tabular}


En suelos arcillosos ambos modos de incorporación se correlacionaron positivamente con la concentración de $\mathrm{N}$, y en el caso de incorporación de los residuos de modo ES también se correlacionó pero de forma inversa con la relación C/P (Tabla 3.6).

Cuando se analizaron los parámetros de calidad sólo para leguminosas (Tabla 3.7), la lixiviación de $\mathrm{P}$ en suelos arenosos con ambos modos de incorporación del material se correlacionó con la concentración de $\mathrm{C}$ inicial del residuo, pero de forma directa cuando el material se incorporó MM e indirecta cuando se agregó ES. En este tipo de suelo con material incorporado MM, hubo correlación positiva con las relaciones $\mathrm{L} / \mathrm{N}$ y $(\mathrm{L}+\mathrm{PS}) / \mathrm{N}$, y con el material ES se correlacionó de forma directa las relaciones N/P (Tabla 3.7). En tanto, en suelos arcillosos con el material incorporado ES, se correlacionaron de forma directa con la concentración de $\mathrm{N}$ de los residuos y de forma inversa con las relaciones $\mathrm{C} / \mathrm{P}$ (Tabla 3.7). 
Tabla 3.7. Valores $\mathrm{r}$ de correlación, entre la lixiviación de $\mathrm{P}(\mathrm{mgP} / \mathrm{kg}$ suelo) para cada tipo de suelo y modos de incorporación obtenidos en el Capítulo 2 con los parámetros de calidad química analizadas para las especies de leguminosas. Are $\mathrm{MM}=$ suelo arenoso, con modo de incorporación del material molido y mezclado; Are ES= suelo arenoso, con modo de incorporación del material entero y superficial; Arci MM= suelo arcilloso, con modo de incorporación del material molido y mezclado; Arci ES= suelo arcilloso, con modo de incorporación del material entero y superficial. $\mathrm{He}=$ hemicelulosa. $\mathrm{Cel}=$ celulosa. $\mathrm{Ho}=$ holocelulosa $($ celulosa + hemicelulosa $) . \mathrm{L}=$ lignina. $\mathrm{PS}=$ polifenoles solubles. En negrita se indican los valores significativos $(\mathrm{p}<0,05)$.

\begin{tabular}{ccccc}
\hline Parámetros de & \multicolumn{4}{c}{ Lixiviación de P $(\mathrm{mgP} / \mathrm{kg}$ suelo $)$} \\
\cline { 2 - 5 } calidad química & Are MM & Are ES & Arci MM & Arci ES \\
\hline N & 0,40 & $-0,42$ & 0,82 & $\mathbf{0 , 9 4}$ \\
C & $\mathbf{0 , 9 3}$ & $\mathbf{- 0 , 9 4}$ & 0,24 & 0,74 \\
P & 0,89 & $-0,88$ & 0,36 & 0,81 \\
C/N & $-0,15$ & 0,19 & $-0,89$ & $-0,87$ \\
C/P & $-0,65$ & 0,60 & $-0,63$ & $-\mathbf{0 , 9 1}$ \\
N/P & $-0,88$ & $\mathbf{0 , 9 3}$ & $-0,35$ & $-0,80$ \\
He & 0,20 & $-0,67$ & 0,67 & 0,75 \\
Cel & 0,47 & 0,07 & $-0,57$ & $-0,29$ \\
Ho & 0,53 & $-0,86$ & 0,60 & 0,85 \\
L & 0,88 & $-0,62$ & 0,14 & 0,59 \\
PS & 0,83 & $-0,81$ & $-0,45$ & 0,07 \\
Cel + L & 0,83 & $-0,45$ & $-0,08$ & 0,35 \\
Cel + PS & 0,53 & $-0,01$ & $-0,59$ & $-0,27$ \\
L + PS & 0,90 & $-0,64$ & 0,12 & 0,58 \\
Cel + L + PS & 0,85 & $-0,47$ & $-0,10$ & 0,35 \\
L/N & $\mathbf{0 , 9 6}$ & $-0,67$ & $-0,12$ & 0,40 \\
PS/N & $-0,08$ & 0,12 & $-0,90$ & $-0,83$ \\
L + PS)/N & $\mathbf{0 , 9 6}$ & $-0,67$ & $-0,23$ & 0,31 \\
\hline
\end{tabular}

\subsubsection{Correlación entre las tasas de descomposición de las especies $(k)$, vida media y tiempo para perder el $95 \%$ y el $99 \%$ del peso, con la lixiviación de $\mathbf{N}$ y $\mathrm{P}$}

En suelos arenosos no hubo correlación entre la tasa de descomposición, la vida media, ni el tiempo para perder el 95\% y el 99\% del peso con la lixiviación de $\mathrm{N}$ en los microlisímetros analizados en el Capítulo 2, con ninguna de los modos de incorporación del material vegetal (Tabla 3.8). En suelos arcillosos en cambio, la lixiviación de $\mathrm{N}$ al microlisímetro donde se agregaron residuos vegetales MM con el suelo se correlacionó de 
forma inversa significativamente con la vida media y con el tiempo que tarda el material en perder el $99 \%$ del peso, en tanto que cuando el material se incorporó ES, se correlacionó en forma inversa con el tiempo en que tarda en perder el 95\% del peso (Tabla 3.8).

Tabla 3.8. Valores $\mathrm{r}$ de correlación, entre la lixiviación de $\mathrm{N}(\mathrm{mgN} / \mathrm{kg}$ suelo) para cada tipo de suelo y modos de incorporación obtenidos en el capítulo 2 con la tasa de descomposición anual, la vida media $(0,693 / \mathrm{k})$ medida en años, el tiempo que tarda en perder el $95 \%$ del peso (años), y el tiempo que tarda en perder el $99 \%$ del peso (años). Are MM= suelo arenoso, con modo de incorporación del material molido y mezclado; Are ES= suelo arenoso, con modo de incorporación del material entero y superficial; Arci $\mathrm{MM}=$ suelo arcilloso, con modo de incorporación del material molido y mezclado; Arci ES= suelo arcilloso, con modo de incorporación del material entero y superficial. En negrita se indican los valores significativos $(p<0,05)$.

\begin{tabular}{ccccc}
\hline & \multicolumn{4}{c}{ Lixiviación de N (mgN/kg suelo) } \\
\cline { 2 - 5 } & Are MM & Are ES & Arci MM & Arci ES \\
\hline Tasas de descomposición & 0,23 & 0,62 & 0,50 & 0,84 \\
k anual (año $\left.{ }^{-1}\right)$ & $-0,63$ & $-0,77$ & $-\mathbf{0 , 9 4}$ & $-0,64$ \\
Vida media (años) & $-0,54$ & $-0,81$ & $-0,78$ & $\mathbf{- 0 , 8 8}$ \\
$\begin{array}{c}\text { Tiempo que tarda en perder } \\
\text { el 95\% del peso (años) }\end{array}$ & & & & \\
$\begin{array}{c}\text { Tiempo que tarda en perder } \\
\text { el 99\% del peso (años) }\end{array}$ & $-0,63$ & $-0,77$ & $\mathbf{- 0 , 9 4}$ & $-0,64$ \\
\hline
\end{tabular}

En cuanto al P, no se encontraron correlaciones entre el contenido de este nutriente en el lixiviado de los microlisímetros estudiados en el Capítulo 2 con la tasa de descomposición, la vida media, o el tiempo para perder el $95 \%$ y el $99 \%$ del peso, en ninguno de los suelos estudiados, y con ninguna de los modos de incorporación del material vegetal (Tabla 3.9). 
Tabla 3.9. Valores $\mathrm{r}$ de correlación, entre la lixiviación de $\mathrm{P}(\mathrm{mgP} / \mathrm{kg}$ suelo) para cada tipo de suelo y modos de incorporación obtenidos en el Capítulo 2 con la tasa de descomposición anual, la vida media $(0,693 / \mathrm{k})$ medida en años, el tiempo que tarda en perder el 95\% del peso (años), y el tiempo que tarda en perder el 99\% del peso (años). Are MM= suelo arenoso, con modo de incorporación del material molido y mezclado; Are ES= suelo arenoso, con modo de incorporación del material entero y superficial; Arci $\mathrm{MM}=$ suelo arcilloso, con modo de incorporación del material molido y mezclado; Arci ES= suelo arcilloso, con modo de incorporación del material entero y superficial.

En negrita se indican los valores significativos $(\mathrm{p}<0,05)$.

\begin{tabular}{ccccc}
\hline & \multicolumn{4}{c}{ Lixiviación de P (mgP/kg suelo) } \\
\cline { 2 - 5 } & Are MM & Are ES & Arci MM & Arci ES \\
\hline Tasas de descomposición & $-0,39$ & 0,13 & 0,80 & 0,71 \\
k anual $\left(\right.$ año $\left.^{-1}\right)$ & & & & \\
$\quad$ Vida media(años) & 0,77 & $-0,24$ & $-0,68$ & $-0,43$ \\
$\begin{array}{c}\text { Tiempo que tarda en perder } \\
\text { el 95\% del peso (años) }\end{array}$ & 0,54 & $-0,10$ & $-0,74$ & $-0,62$ \\
$\begin{array}{c}\text { Tiempo que tarda en perder } \\
\text { el 99\% del peso (años) }\end{array}$ & 0,77 & $-0,24$ & $-0,68$ & $-0,43$ \\
\hline
\end{tabular}

\subsection{DISCUSIÓN}

En numerosos estudios de campo, así también como en laboratorio donde se ha mantenido constante la temperatura y humedad, la dinámica de la descomposición de los residuos vegetales presenta el mismo patrón: los residuos son atacados rápidamente al principio pero después la tasa se ralentiza a un valor muy bajo (Nieder y Benbi 2008). La misma dinámica presentaron nuestras 5 especies, pudiéndose considerar los primeros 21 días de ensayo como la "etapa temprana" de la descomposición. E. grandis fue la especie que más tardó en descomponerse en comparación con las especies de leguminosas. Esta tendencia concuerda con lo estudiado por otros autores (Swamy 1989, Binkley 1992, Bernhard-Reversat 1993, Tsai 1998), quienes encontraron que en general las especies de leguminosas fijadoras de nitrógeno se descomponen rápidamente. Por el contrario, la hojarasca producida por eucalipto se descompone a una tasa menor (Sharma y Pande 1989, Swamy 1989, Bargali y Singh 1991, Binkley 1992, Bernhard-Reversat 1993, Sankaran 1993, Singh et al. 1993, Toky y Singh 1993, Goya et al. 2008). 
Uno de los factores de los cuales depende la tasa de descomposición de la materia orgánica es de la proporción relativa de sustratos orgánicos individuales (Nieder y Benbi 2008). El orden de rapidez de descomposición se da como sigue: compuestos orgánicos solubles en agua $>$ hemicelulosas $>$ celulosas $>$ lignina (Tenny y Waksman 1929). Por lo tanto, la desaceleración de la descomposición con el tiempo se debe principalmente a las diferencias en la velocidad a la que los diversos componentes de la planta se descomponen (Nieder y Benbi 2008).

Muchos autores han buscado un parámetro de calidad química que se correlacione con las tasas de descomposición. Sin embargo, el factor de calidad que mejor se correlaciona depende de los tipos de mantillos examinados (Prescott 2005). Dada la gran demanda y dependencia que los microorganismos descomponedores tienen de $\mathrm{N}$ (Nieder y Benbi 2008) la relación $\mathrm{C} / \mathrm{N}$ puede ser el mejor indicador de las tasas de descomposición (Taylor et al. 1989, Enriquez et al. 1993, Seneviratne 2000, Nieder y Benbi 2008), a través de una amplia gama de sustratos (Prescott 2005). Cuanto menor sea el contenido de $\mathrm{N}$ de un sustrato o la relación $\mathrm{C} / \mathrm{N}$ tenga un valor más grande, más lenta será la velocidad de descomposición (Nieder y Benbi 2008). A pesar de que otros autores como Wang et al. (2004) sugirieron que sólo las fases iniciales de la descomposición de los residuos son afectadas por la relación $\mathrm{C} / \mathrm{N}$ del residuo, se encontró en esta Tesis que este parámetro tuvo una correlación directa con la tasa anual de descomposición, y una correlación inversa con la vida media y el tiempo que tarda en perder el $95 \%$ y el $99 \%$ del peso, lo que indica la importancia de este parámetro como buen predictor durante todo el proceso de descomposición.

Mucha atención ha tenido la concentración de lignina en los residuos como factor de control para la descomposición y mineralización. Berg y Staaf (1980) sugieren que la concentración de lignina es el factor dominante que controla la descomposición en la última etapa, al igual que otros autores quienes han encontrado que las tasas de descomposición en la etapa tardía están inversamente relacionadas con la concentración inicial de lignina (McClaugherty et al. 1985, Berg et al. 2000). Nieder y Benbi (2008) también encontraron tasas de descomposición que se correlacionan significativamente con el contenido de lignina inicial. En esta Tesis no hubo correlaciones significativas entre la concentración de lignina y la tasa de descomposición, la vida media y el tiempo que tarda 
en perder el 95\% y 99\% del peso, ni con la lixiviación de nutrientes, pero el parámetro L/N se correlacionó en forma directa significativamente con la vida media y con el tiempo que tarda en perder el 99\% del peso, al igual que la relación $(\mathrm{L}+\mathrm{PS}) / \mathrm{N}$ que involucra a la lignina. La relación $\mathrm{L} / \mathrm{N}$ es el indicador más frecuentemente recomendado para analizar la relación entre la calidad de la hojarasca y la dinámica del $\mathrm{N}$ del suelo en sitios individuales (Gower y Son 1992), y a través de gradientes de suelo y clima (Scott y Binkley 1997), y parece ser un buen predictor de la tasa de descomposición para residuos con contenido inicial de lignina entre 10 y 28 \% (Taylor et al. 1989, 1991). En nuestro estudio estos valores difirieron levemente con los reportados por Taylor et al. (1989), con contenidos de lignina dentro de las 5 especies que oscilaron entre 4,7\% y 16,2\%. En mantillos con contenido de lignina $<10 \%$, otros factores limitan la descomposición; mientras que en mantillos con contenido de lignina $>28 \%$, el decaimiento está limitado por el alto contenido de lignina pero una correlación puede no ser evidente, porque las tasas de descomposición serán uniformemente bajas (Prescott 2005). La lignina ejerce su control sobre la tasa de descomposición a través de su propia resistencia al ataque microbiano, y por interferir físicamente en la descomposición de otras fracciones químicas de las células de la hoja. Por lo tanto, la influencia de la lignina será más fuerte en hojarasca con alto contenido de lignina, como las acículas del pino, que en hierbas en las cuales el contenido de lignina es muy bajo (Taylor et al. 1989). Cuando se analizan exclusivamente a las especies de leguminosas, la concentración inicial de lignina, al igual que otros parámetros asociados como la relación ( $\mathrm{L}+\mathrm{PS}) / \mathrm{N}$, presenta una gran correlación con la liberación de $\mathrm{N}$ en suelos arcillosos. Sin embargo, estos resultados no tienen un valor biológico, y pueden explicarse dado que C. ensiformis tiene menos lignina que las otras leguminosas, pero también tiene valores absolutos muy bajos de $\mathrm{N}$ y es especialmente deficiente en $\mathrm{P}$ (las relaciones N/P y C/P son muy altas); por lo tanto, libera poco $\mathrm{N}$ y poco P (Tabla 3.1, Figuras 2.3 y 2.4). Las otras 3 leguminosas a pesar de tener más lignina, tienen significativamente mucho más $\mathrm{N}$ y $\mathrm{P}, \mathrm{y}$ relaciones $\mathrm{N} / \mathrm{P}, \mathrm{C} / \mathrm{P}$ e incluso $\mathrm{C} / \mathrm{N}$ significativamente más bajas (Tabla 3.1), lo que les permite liberar más $\mathrm{N}$ y P, pero como tienen más lignina que $C$. ensiformis la correlación da más lixiviación de $\mathrm{N}$ a más lignina.

Hay otras sustancias químicas presentes, incluso en sustratos con altos contenidos de lignina, tales como nutrientes o carbohidratos, que potencialmente influencian la tasa de 
descomposición. En una serie de tipos de hojarasca con contenido de lignina progresivamente más bajo, el grado de control de la lignina sobre la tasa de descomposición irá decreciendo, mientras que el control por los nutrientes u otras fracciones químicas irá progresivamente aumentando (Taylor et al. 1989). En esta Tesis el contenido inicial de $\mathrm{N}$ fue particularmente importante al correlacionarse positivamente con la tasa anual de descomposición, y con la lixiviación de $\mathrm{P}$ en suelos arcillosos. De modo semejante, Prause y Fernandez López (2007) encontraron que la concentración inicial de N fue un buen indicador de las tasas de descomposición en cuatro especies de árboles del bosque chaqueño.

Los polifenoles son la clase más amplia de los metabolitos secundarios de las plantas y varios miles de compuestos diferentes han sido identificados (Hättenschwiler y Vitousek 2000). Desempeñan muchos papeles en las plantas, incluidos el ser compuestos de defensa contra los herbívoros y patógenos, por ejemplo al contribuir en la determinación de su color y sabor (Haslam 1981, Bernays 1989). Los polifenoles afectan la calidad de los residuos vegetales, y a veces tienen un efecto mayor sobre las tasas de descomposición que otros parámetros como la concentración de N o de lignina (Palm y Sánchez 1990). En esta Tesis se encontró una correlación directa significativa entre el contenido de PS y la vida media y el tiempo que tarda en perderse el 95\% y el 99\% del peso, al igual que correlaciones con otros parámetros que incluyen a los polifenoles, como $\mathrm{Cel}+\mathrm{PS}$ y las relaciones PS/N, (L + PS)/N. Anteriores estudios (Vallis y Jones 1973, Palm y Sanchez 1991) confirmaban que el contenido de polifenoles inicial y la relación PS/N fueron más fuertemente correlacionadas con la mineralización de $\mathrm{N}$ a partir de abonos verdes de leguminosas que lignina, $\mathrm{N}$ o relación L/N. En esta Tesis las 4 leguminosas no difirieron en su contenido de polifenoles, por lo que no permiten correlacionar este parámetro con la liberación de $\mathrm{N}$ o $\mathrm{P}$.

Con respecto a la concentración de $\mathrm{P}$ de los residuos y su relación con la lixiviación de $\mathrm{N}$, distintos autores demostraron que la tasa de mineralización de $\mathrm{N}$ fue reducida significantemente cuando la concentración de $\mathrm{P}$ en el residuo es baja, con valores menores a 1,6 $\mathrm{g} \mathrm{Kg}^{-1}$, que corresponde con una tasa C/P de 250 (Nguluu et al. 1996). En esta Tesis no se encontró una correlación entre la liberación de $\mathrm{N}$ en suelos arenoso ni arcillosos, sin embargo las concentraciones iniciales de $\mathrm{P}$ de $E$. grandis y de $C$. ensiformis $\left(1,24 \mathrm{~g} \mathrm{mg}^{-1} \mathrm{y}\right.$ 
0,85 $\mathrm{g} \mathrm{mg}^{-1}$ respectivamente), y sus relaciones C/P (425,6 y 490,6 respectivamente), se podrían relacionar con la inmovilización de $\mathrm{N}$ observada en el Capítulo 2, en tanto que para las especies $C$. cajan, T. pratense y L. corniculatus cuyas concentraciones de $\mathrm{P}$ son mayores $\left(2,8 \mathrm{~g} \mathrm{mg}^{-1}, 2,28 \mathrm{~g} \mathrm{mg}^{-1}\right.$ y $1,98 \mathrm{~g} \mathrm{mg}^{-1}$ respectivamente), y tienen menores relaciones C/P (183,54, 204,98 y 238,97 respectivamente), tuvieron lixiviaciones de $\mathrm{N}$ netas en suelo arenoso y con la mencionada manera de incorporación de los residuos en dicho Capítulo.

Otro aspecto que debe tenerse en cuenta al analizar los factores que controlan la descomposición, es que dichos factores cambian con el tiempo. Por ejemplo, Berg y Staaf (1980) mostraron que los nutrientes controlan las primeras etapas de descomposición de la hojarasca de Pinus sylvestris, mientras que el contenido de lignina controla la descomposición en las etapas posteriores (Cortez et al. 2007). Por lo tanto, los factores que mejor se correlacionan con la tasa de descomposición dependen de la duración del estudio (Prescott 2005). Sin embargo, los nutrientes inmovilizados en la biomasa microbiana son re-mineralizados cuando las células lisan como consecuencia de las condiciones ambientales cambiantes o en respuesta a la fauna de pastoreo (Haynes 1986). Por lo tanto, en escalas de tiempo más amplias, la tasa de mineralización de nutrientes en materia orgánica se podría predecir en gran medida según las características iniciales de los residuos (Pastor et al. 1984, Wedin y Tilman 1990, Reich et al. 1997, Scott y Binkley 1997, Prescott et al. 2000).

Durante el proceso de descomposición, parte del material orgánico es completamente mineralizado, algunos se incorporan en el tejido microbiano, y otra parte se convierte en sustancias húmicas, al mismo tiempo que el humus nativo se mineraliza de forma simultánea. Así, aunque grandes cantidades de residuos orgánicos pueden ser devueltos al suelo, la descomposición no conduce necesariamente a un incremento en el contenido de materia orgánica del suelo, sino que hay un balance entre la cantidad de C que entra en el suelo y la cantidad de $\mathrm{C}$ que deja el suelo por lixiviación o descomposición (Nieder y Benbi 2008). Asimismo, las relaciones de C/P y N/P de la materia orgánica del suelo pueden variar ampliamente en dependencia de varios factores, dado que el contenido de P es más variable que el de otros elementos (Nieder y Benbi 2008). 
Dado el alto grado de autocorrelación entre las características químicas de los residuos (Taylor et al. 1991, Parton et al. 1994), y su integración biológica dentro de los tejidos, la búsqueda de un único factor que controla la velocidad de decaimiento muchas veces puede ser un ejercicio inútil (Prescott 2005).

\subsection{CONCLUSIÓN}

Los resultados observados concuerdan con la hipótesis planteada de que la calidad química de los residuos afecta la tasa de descomposición y la liberación de $\mathrm{N}$ y $\mathrm{P}$ disponible para las plantas. Bajo condiciones controladas, las hojas de eucaliptos se descompusieron más lentamente que las hojas de las leguminosas herbáceas (Predicción 1), lo que se relaciona en parte a una mayor concentración de polifenoles solubles y con la mayor relación $\mathrm{C} / \mathrm{N}$, como parámetros de menor calidad química.

Con respecto a las leguminosas, las diferencias químicas entre estas especies influyeron en las diferencias en sus tasas de liberación de $\mathrm{N}$ y de $\mathrm{P}$ (Predicción 2), aunque no se encontrara un único parámetro de calidad química que se correlacione con la lixiviación de $\mathrm{N}$ y $\mathrm{P}$ en todos los suelos y tratamientos. Asimismo, aunque un factor que se correlacione bien con las tasas de descomposición se puede utilizar para predecir dicho proceso, no necesariamente permite dilucidar el mecanismo de acción. Más bien, puede ser simplemente el factor que mejor integra el conjunto de características físicas y químicas de los residuos que determina la tasa de descomposición.

Para el $\mathrm{P}$ no se encontró un parámetro que permita predecir su lixiviación a partir de residuos. Esto puede deberse a la compleja relación entre los restos orgánicos y los microorganismos involucrados en su descomposición. 


\section{CAPÍTULO 4}

\section{SUMINISTRO DE NITRÓGENO Y FÓSFORO DE RESIDUOS DE CUBIERTAS VERDES DE EUCALYPTUS GRANDIS Y LEGUMINOSAS INCORPORADOS DE DISTINTA MANERA EN UN SUELO ARCILLOSO EN CONDICIONES DE HUMEDAD CONSTANTE Y CON CICLOS DE INUNDACIÓN Y DRENADO NATURAL}

\subsection{INTRODUCCIÓN}

El uso de cubiertas vegetales o abonos orgánicos es una práctica útil para incrementar la disponibilidad de $\mathrm{C}, \mathrm{N}$ y $\mathrm{P}$ en el suelo, fomentando la actividad microbiana, la cual es influenciada tanto por la disponibilidad de sustratos orgánicos como de $\mathrm{O}_{2}$ y agua en el suelo, indispensables para la actividad biológica (Pulleman y Tietema 1999). Sin embargo, el contenido de agua y aire no es constante en el suelo, en particular en las capas superiores (Appel 1988), ya que naturalmente ocurren ciclos de secado y rehumedecimiento, que influyen tanto en el ciclo de la materia orgánica como en el de los nutrientes y su mineralización (Grierson et al. 1998, Wu y Brookes 2005), y por lo tanto afectan significativamente la fertilidad del suelo (Chepkwony et al. 2001). La zona de Concordia se caracteriza por tener un clima húmedo, con promedio de lluvias que oscilan entre 1000 y $1200 \mathrm{~mm}$ anuales, pero que se distribuyen de manera dispar, ya que en cualquier estación del año puede presentarse sequía o exceso de precipitaciones (Secretaría de Minería de La Nación 2016). En los ecosistemas de eucaliptos sobre suelos arcillosos ocurren situaciones de estrés por exceso o déficit de agua que limitan el crecimiento de las plantaciones al turno (12 a 15 años), porque a pesar de que contienen mayor $\mathrm{N}$ total crecen menos en los suelos arcillosos que en los arenosos (Goya et al. 1997a, b). Asimismo, en condiciones de riego frecuente (sin estrés hídrico) se ha constatado que estas plantas jóvenes crecen más en suelos arcillosos que en arenosos (Graciano et al. 2006a). 
Las condiciones de humedad del suelo también influencian las reacciones del ciclo del $\mathrm{N}$ y del P. En el caso del $\mathrm{N}$, cuando hay buena disponibilidad de $\mathrm{O}_{2}$ edáfico, la mineralización se inicia con la transformación de compuestos de $\mathrm{N}$ combinado en $\mathrm{NH}_{3}$ y $\mathrm{NH}_{4}^{+}$(amonificación) y rápidamente continúa con la transformación del $\mathrm{NH}_{4}^{+} \mathrm{a} \mathrm{NO}_{2}^{-}$y luego a $\mathrm{NO}_{3}{ }^{-}$por las bacterias nitrificantes (Stevenson 1986), por lo que el $\mathrm{NO}_{3}{ }^{-}$es la principal forma de $\mathrm{N}$ disponible para la mayoría de las plantas en suelos bien aireados (Yamaya y Oaks 2004). En condiciones anaeróbicas, la nitrificación disminuye, y la mineralización no avanza más allá de la etapa de $\mathrm{NH}_{4}^{+}$, a pesar de que la posterior oxidación podría ocurrir en la capa superior del suelo que está expuesta a condiciones oxidativas por su cercanía a la atmósfera. Por otro lado, aumenta considerablemente la desnitrificación, ya que el $\mathrm{NO}_{3}{ }^{-}$presente en el suelo, aplicado como fertilizante o formado en la capa de oxidación, está particularmente sujeto a la pérdida gaseosa (Fassbender 1982, Stevenson 1986). Por lo tanto los iones de $\mathrm{NH}_{4}{ }^{+}$son la principal forma de $\mathrm{N}$ inorgánico tomado por las plantas en los suelos carentes de $\mathrm{O}_{2}$, tales como los campos inundados de los arrozales o suelos forestales maduros de coníferas con $\mathrm{pH}$ ácido (Kronzucker et al. 1997).

El contenido de $\mathrm{P}$ disponible para las plantas según el contenido de humedad del suelo es afectado de modo más indirecto que el de N. Por un lado, la aparición de condiciones de anoxia genera un cambio en los equilibrios redox hacia un sistema más reductivo, produciendo la solubilización de los componentes minerales redox sensibles (Mn, Al y Fe) y la liberación simultánea de aniones $\mathrm{P}$ asociados, adsorbidos o precipitados (Scalenghe 2010), incluyendo también la liberación de P de la fracción orgánica, que actúa como un donador de electrones (Scalenghe et al. 2010, Ceballos et al. 2012). Asimismo, dado que la toma de $\mathrm{P}$ por las plantas también depende en gran medida de las transformaciones del P orgánico mediadas biológicamente (Hedley et al. 1995, Dias-Filho et al. 1999), las condiciones de anoxia influyen indirectamente sobre la tasa de descomposición y mineralización de la materia orgánica del suelo.

Para comprender cuál es el impacto de las condiciones de humedad del suelo sobre la disponibilidad de $\mathrm{N}$ y $\mathrm{P}$ soluble aprovechable por las plantas, procedente de residuos de cosecha de árboles implantados y de cubiertas herbáceas de leguminosas, se realizó un estudio experimental en laboratorio. El objetivo fue conocer la influencia del anegamiento 
en la concentración de $\mathrm{N}$ y $\mathrm{P}$ en la solución de un suelo arcilloso, según el contacto con el suelo del material de hojas de E. grandis y de leguminosas agregado. La hipótesis es que la anoxia reduce la actividad microbiana por lo tanto, en los suelos anegados, la descomposición de los detritos que no estén en contacto con el oxígeno atmosférico será menor que la de los expuestos en la superficie.

\section{Predicciones:}

- Cuando se incorporan abonos orgánicos en suelos anegados la liberación de N y P en la solución del suelo disminuye con respecto a un suelo a capacidad de campo.

- En suelos anegados, si el abono está en superficie la liberación será mayor que si está mezclado con el suelo.

\subsection{MATERIALES Y MÉTODOS}

\subsubsection{Diseño experimental}

El ensayo empleó microlisímetros conteniendo suelo superficial, a los cuales se les agregó residuos de hojas de una sola especie: E. grandis o una de dos leguminosas (Canavalia ensiformis y Lotus corniculatus), los cuales fueron agregados de modo molidos y mezclados con el suelo (MM) o enteros y superficialmente sobre el suelo (ES) (Imagen 4.1). Estos microlisímetros fueron sometidos a condiciones de anegamiento temporario que alternaron con períodos de escurrimiento, o mantenidos a capacidad de campo. El diseño experimental consistió entonces en 3 tipos de materiales vegetales, 2 modos de aplicación del material vegetal y 2 condiciones de disponibilidad de agua. Se realizaron 3 repeticiones para cada tratamiento, que hacen un total de 36 microlisímetros. Además, se reservaron 6 microlisímetros sin residuos vegetales como control, 3 por cada tipo de disponibilidad de agua. Todos los microlisímetros se colocaron en cámara con una temperatura de $23{ }^{\circ} \mathrm{C}$ con un desvío estándar de $2{ }^{\circ} \mathrm{C}$.

Semanalmente se corroboró por diferencia de peso el estado hídrico de cada microlisímetro. Para mantener el contenido de humedad correspondiente a cada tratamiento, en caso de ser necesario, se agregó la cantidad necesaria de solución acuosa de 0,01 $\mathrm{M} \mathrm{CaCl}_{2}$ y 0,01M KCl. Para determinar la lixiviación de nutrientes, los microlisímetros 
fueron irrigados simulando lluvia cada 4 semanas, durante 10 lavados (último lavado a los 280 días) (Imagen 4.1). El lavado se realizó con solución acuosa de $0,01 \mathrm{M} \mathrm{CaCl}_{2}$ y $0,01 \mathrm{M}$ $\mathrm{KCl}$, y la cantidad agregada fue la necesaria para recolectar $200 \mathrm{ml}$ de lixiviado. El líquido percolado fue recogido como se describió en el Capítulo 2 (ver sección 2.2.1, Imagen 2.1) y llevado al laboratorio para analizar su contenido de $\mathrm{N}_{-} \mathrm{NH}_{4}{ }^{+}, \mathrm{N}_{-} \mathrm{NO}_{3}{ }^{-}$y $\mathrm{P}-\mathrm{PO}_{4}{ }^{3-}$.

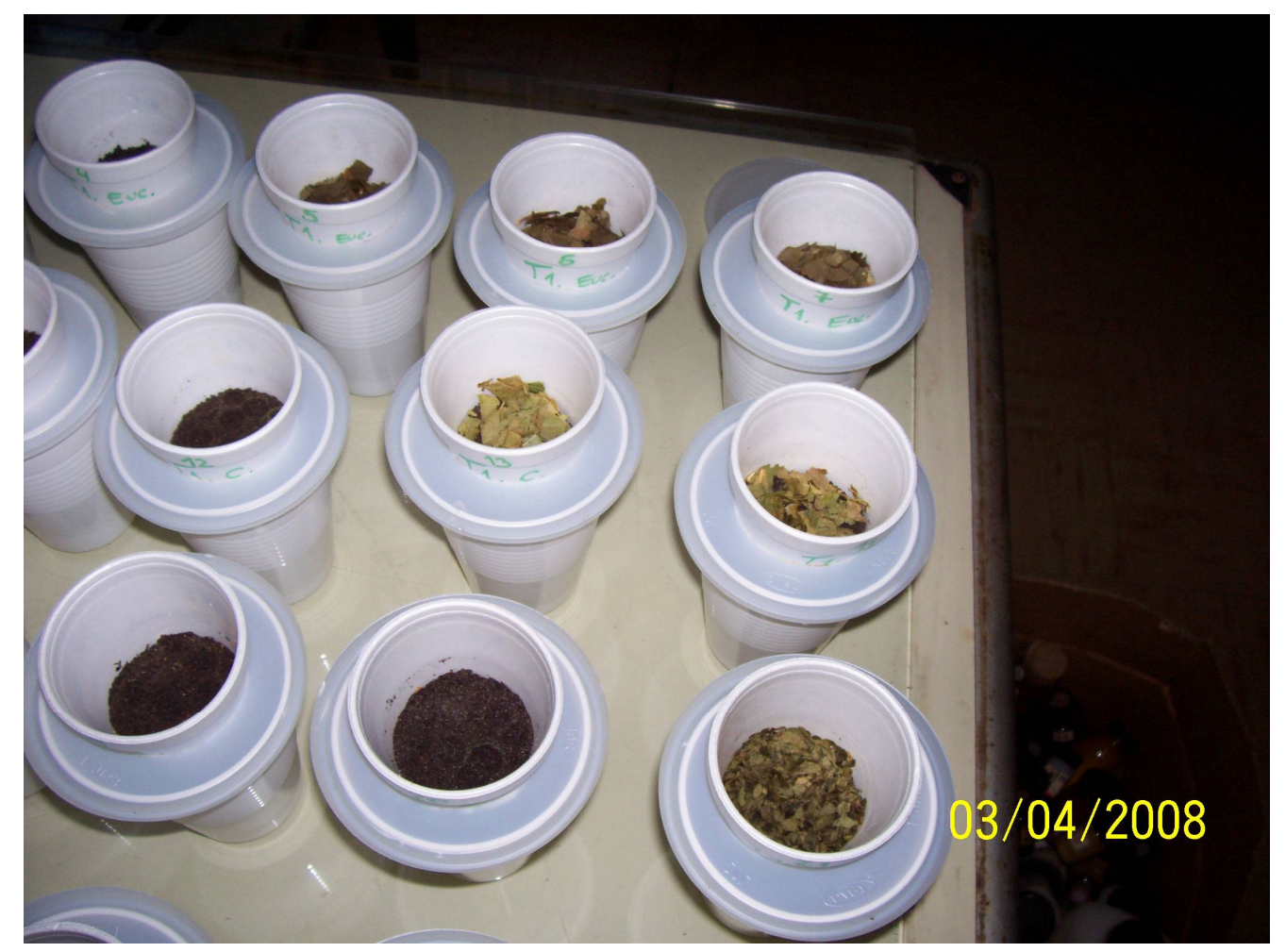

Imagen 4.1. Microlisímetros con material ES y MM, sobre el vaso colector de solución de lavado.

\subsubsection{Selección y obtención del material vegetal y suelos}

Se utilizaron hojas de E. grandis, y material herbáceo de Canavalia ensiformis L. y Lotus corniculatus L. El suelo utilizado fue un Argiacuol Vertico (localmente arcilloso). La procedencia y recolección del material vegetal y el suelo se realizó como se describe en el Capítulo 2 (ver sección 2.2.2). 


\subsubsection{Microlisímetros}

Fueron construidos como se describe en el Capítulo 2 (ver sección 2.2.3, Imagen 2.2). Para los tratamientos con suelos anegados estos vasos fueron dispuestos en el interior de otro vaso similar sin perforar para contener el agua agregada durante la etapa de inundación, de manera que el volumen de agua sin contacto con el suelo sea mínimo.

El suelo y el material vegetal fueron acondicionados como se describe en el Capítulo 2 (sección 2.2.3). El mantillo fue agregado al suelo de dos maneras diferentes: 1) el material vegetal seco se molió con molino Wiley, se tamizó en malla de 0,5 mm, se mezcló y homogeneizó con el suelo (MM); 2) el mantillo se fraccionó en partes de $<1 \mathrm{~cm}^{2}$ que se dispusieron sobre la superficie del suelo (ES).

\subsubsection{Tratamientos}

Cada microlisímetro fue sometido a las siguientes condiciones hídricas:

1- Riego frecuente sin estrés para lograr humedad constante (HC): se controló el peso del lisímetro semanalmente, agregándose agua para mantener al suelo constantemente húmedo, a capacidad de campo, y cada 4 semanas se realizó un lavado durante diez ciclos consecutivos.

2- Alternancia quincenal de suelo drenado natural - anegado (AQ): se comenzó el ensayo con un lavado, y durante las 2 siguientes semanas se permitió el drenaje y secado del suelo. Posteriormente, al inicio de la tercera semana se agregó agua a saturación y se mantuvo así durante 2 semanas, en cantidad suficiente para que formara una capa de $1 \mathrm{~mm}$ de agua sobre la superficie del suelo. Finalizado el período de anegamiento se realizó el lavado para recolectar el lixiviado, recomenzando el ciclo. El lixiviado fue recolectado luego de dejar escurrir durante 24 horas, y estuvo constituido por el líquido agregado durante la inundación más la solución de lavado agregada de modo de alcanzar $200 \mathrm{ml}$ totales. Finalizado este período el microlisímetro fue nuevamente dispuesto dentro de otro vaso similar para reiniciar la etapa de sequía. Estas mediciones se realizaron durante diez ciclos consecutivos cada 4 semanas. 


\subsubsection{Análisis químicos del lixiviado}

En el líquido lixiviado se determinó el contenido de amonio $\left(\mathrm{N}-\mathrm{NH}_{4}{ }^{+}\right)$, nitrato $(\mathrm{N}-$ $\mathrm{NO}_{3}{ }^{-}$) y fosfato $\left(\mathrm{P}-\mathrm{PO}_{4}{ }^{3-}\right)$ como se describe en la sección 2.2.4.

Los miligramos de $\mathrm{N}-\mathrm{NH}_{4}{ }^{+}, \mathrm{N}-\mathrm{NO}_{3}{ }^{-}$y de $\mathrm{P}_{-} \mathrm{PO}_{4}{ }^{3-}$ lavados en el lixiviado en cada fecha de muestreo se calcularon multiplicando el volumen de líquido lixiviado por la concentración de $\mathrm{NH}_{4}{ }^{+}, \mathrm{NO}_{3}{ }^{-} \mathrm{o} \mathrm{PO}_{4}{ }^{3-}$. Se calcularon los miligramos de nutrientes acumulados por kilogramo de suelo para cada especie y para los controles como se describe en la sección 2.2.4.

\subsubsection{Análisis estadísticos}

Se realizó un ANOVA con los nutrientes acumulados al final del ensayo de 280 días, considerando un solo factor con 7 niveles, que combina la especie y modo de aplicación del abono (E. grandis MM; E. grandis ES; C. ensiformis MM; C. ensiformis ES; L. corniculatus MM; L. corniculatus ES; Control). Los datos de cada régimen hídrico (HC o AQ) se analizaron por separado. Las medias se compararon mediante el test de Tukey $(\mathrm{p}<0,05)$.

\subsection{RESULTADOS}

\subsubsection{Lixiviación de $\mathrm{N}$ en los distintos tratamientos con $\mathrm{y}$ sin agregado de detritos}

$$
\text { 4.3.1.1. } \mathrm{N}-\mathrm{NH}_{4}^{+}
$$

En los tratamientos con AQ la liberación de $\mathrm{N}^{-\mathrm{NH}_{4}}{ }^{+}$siempre fue mayor, con o sin agregado de detritos, que en el tratamiento HC (Figura 4.1, a y c). En el tratamiento AQ la liberación media de $\mathrm{N}_{-} \mathrm{NH}_{4}{ }^{+}$al final del experimento varió entre 83 y $222 \mathrm{mg} \mathrm{N}-\mathrm{NH}_{4}{ }^{+} \mathrm{kg}^{-1}$ suelo según el material vegetal colocado, mientras que en $\mathrm{HC}$ los valores medios estuvieron entre 49 y $170 \mathrm{mg} \mathrm{N}-\mathrm{NH}_{4}{ }^{+} \mathrm{kg}^{-1}$ suelo (Figura 4.1, a y c). El agregado de detrito foliar de $L$. 
corniculatus fue el único que se asoció con un incremento significativo de $\mathrm{N}_{-} \mathrm{NH}_{4}^{+}$en el lixiviado con respecto al control, siendo mayor en el tratamiento AQ que en HC.

El agregado de cualquiera de las dos especies de leguminosas bajo el régimen $\mathrm{HC}$ dio lugar a un mayor lixiviado de $\mathrm{N}_{-} \mathrm{NH}_{4}{ }^{+}$que con E. grandis, independientemente del modo de aplicación de los residuos. No obstante las diferencias sólo fueron significativas entre L. corniculatus y E. grandis (Figura 4.1, a).
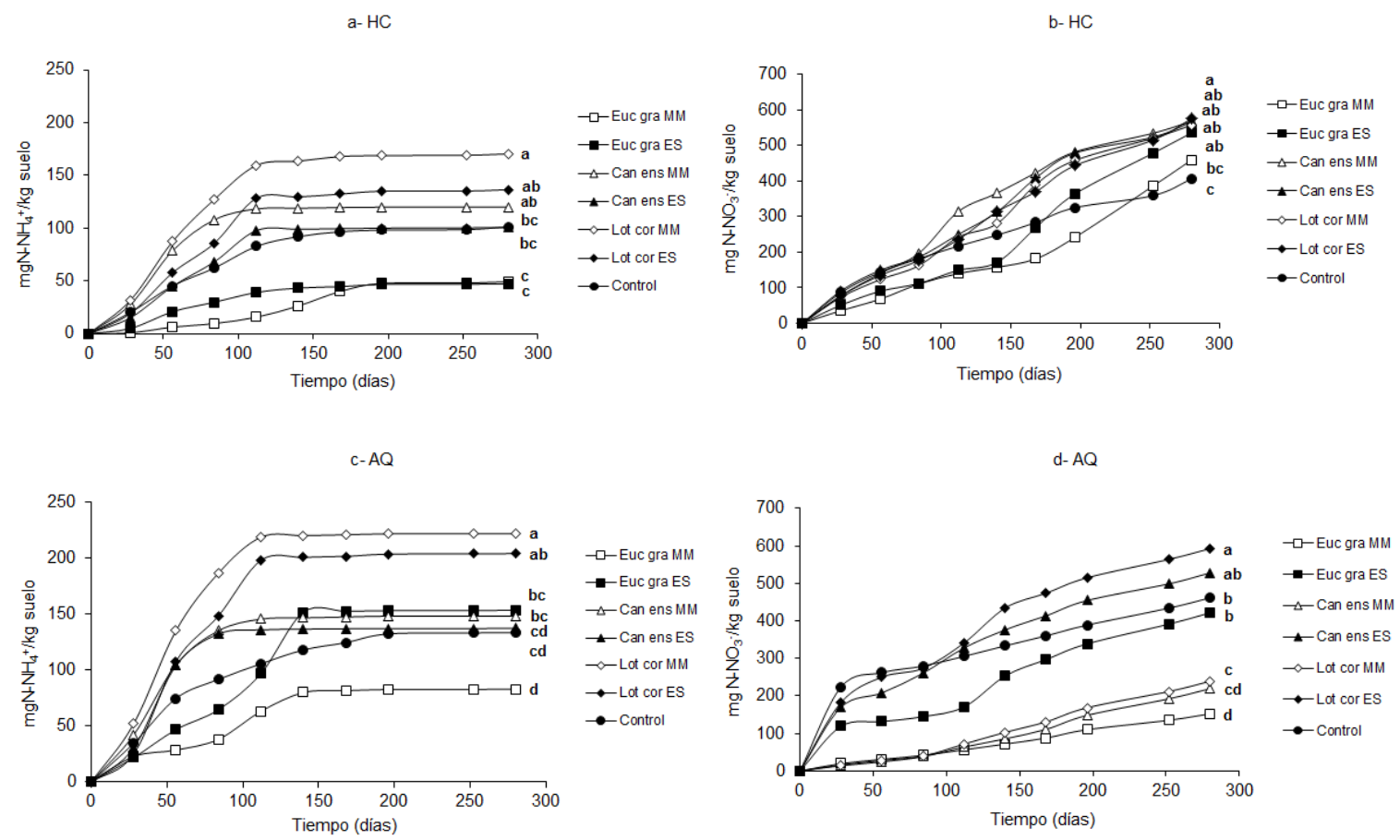

Figura 4.1. a) $\mathrm{N}^{-\mathrm{NH}_{4}}{ }^{+}$acumulado por kg de suelo para distintos modos de aplicación del material a Humedad constante $(\mathrm{HC})$; b) $\mathrm{N}-\mathrm{N}_{-} \mathrm{NO}_{3}{ }^{-}$acumulado por $\mathrm{kg}$ de suelo para distintos modos de aplicación del material a $\mathrm{HC}$; c) $\mathrm{N}_{-} \mathrm{NH}_{4}{ }^{+}$acumulado por $\mathrm{kg}$ de suelo para distintos modos de aplicación del material con Anegamiento quincenal (AQ); d) N- $\mathrm{N}_{-} \mathrm{NO}_{3}{ }^{-}$acumulado por $\mathrm{kg}$ de suelo para distintos modos de aplicación del material con AQ. MM: material vegetal molido y mezclado con el suelo. ES: material vegetal en pequeños trozos y sobre la superficie del suelo. Euc gra: $E$. grandis; Can ens: C. ensiformis; Lot cor: L. corniculatus. Con letras minúsculas se indica la significancia en la última fecha con datos acumulados, y sólo permiten comparar dentro de cada tipo de disponibilidad de agua. 
En HC la lixiviación prácticamente cesa a partir de unos 120 días en casi todos los casos salvo en E. grandis MM que continúa su lenta lixiviación hasta unos 180 días. En el régimen $\mathrm{AQ}, L$. corniculatus $\mathrm{MM}$ es la que más lixivia y se diferencia significativamente del control y de E. grandis. Hay algunas diferencias respecto al régimen anterior: $E$. grandis ES lixivia más $\mathrm{N}^{-\mathrm{NH}_{4}}{ }^{+}$en forma significativamente mayor que el control. Como en el régimen anterior, la lixiviación se produce durante los primeros 120 días con agregado de leguminosas y continúa hasta unos 180 días con E. grandis y en el control (Figura 4.1, c).

Al comparar los lixiviados de $\mathrm{N}-\mathrm{NH}_{4}{ }^{+}$según el modo de incorporación del material, el agregado de ambas leguminosas en los 2 regímenes de agua (HC y AQ) no mostraron diferencias. En el caso de la aplicación de E. grandis, no hubo diferencias en el modo de aplicación en los tratamientos a $\mathrm{HC}$, en tanto que para AQ se dieron significativamente mayores lixiviaciones de $\mathrm{N}^{-\mathrm{NH}_{4}}{ }^{+}$cuando los residuos se agregaron ES (Figura 4.1, a y c).

\subsubsection{2. ${\mathrm{N}-\mathrm{NO}_{3}^{-}}^{-}$}

La lixiviación de $\mathrm{N}$ en forma de $\mathrm{NO}_{3}{ }^{-}$en general fue mayor que en forma de $\mathrm{NH}_{4}{ }^{+}$. En el tratamiento con $\mathrm{HC}$, el agregado de L. corniculatus y de C. ensiformis produjo una lixiviación de $\mathrm{N}^{-\mathrm{NO}_{3}}{ }^{-}$significantemente mayor al control con ambos modos de aplicación (Figura 4.1, b), y sin diferencias significativas ni en las especies ni en el modo de aplicación de los residuos. E. grandis aumentó la lixiviación de $\mathrm{N}_{-} \mathrm{NO}_{3}{ }^{-}$con respecto al control cuando el residuo se agregó ES, y no fue significativo en el caso MM (Figura 4.1, b).

En los tratamientos con $\mathrm{AQ}$ hubo una marcada diferencia según el modo de aplicación de los residuos vegetales (Figura 4.1, d): cuando los residuos se agregaron ES, se observaron contenidos de $\mathrm{N}^{-\mathrm{NO}_{3}}{ }^{-}$en el lixiviado mayores que en el control, aunque esta diferencia resultó únicamente significativa para $L$. corniculatus. Cuando los residuos se agregaron $\mathrm{MM}$, las lixiviaciones de $\mathrm{N}^{-\mathrm{NO}_{3}}{ }^{-}$resultaron para las 3 especies, significativamente menores al control.

Con $\mathrm{AQ}$ la lixiviación tiende a ser menor que en $\mathrm{HC}$, con el agregado de $C$. ensiformis y de E. grandis cualquiera sea la forma de agregado del mantillo. Para $L$. 
corniculatus ES y para el control la lixiviación de $\mathrm{N}_{-} \mathrm{NO}_{3}{ }^{-}$en el régimen $\mathrm{AQ}$ fue mayor que en HC (Figura 4.1, b y d).

Por otra parte a diferencia del $\mathrm{N}-\mathrm{NH}_{4}{ }^{+}$, el N-NO${ }_{3}^{-}$continúa lixiviándose a tasa más o menos constante durante los 280 días del ensayo (Figura 4.1).

\subsubsection{Aporte proporcional porcentual de $\mathrm{N}_{-} \mathrm{NO}_{3}^{-}$y $\mathrm{N}-\mathrm{NH}_{4}{ }^{+}$}

En el análisis de la lixiviación proporcional porcentual de $\mathrm{N}_{-} \mathrm{NO}_{3}{ }^{-}$y $\mathrm{N}_{-}-\mathrm{NH}_{4}{ }^{+}$en las dos situaciones hídricas estudiadas y con el aporte de E. grandis, de C. ensiformis y de L. corniculatus, se encontraron dos patrones diferentes según el modo de incorporación de los residuos MM o ES (Figura 4.2, a-f).

Cuando los residuos se agregaron $\mathrm{MM}$ a $\mathrm{HC}$ la relación $\mathrm{N}-\mathrm{NO}_{3}{ }^{-} / \mathrm{N}_{-}-\mathrm{NH}_{4}{ }^{+}$fue alta con el agregado de las 3 especies (Figura 4.2, a, c y e). Bajo condiciones de AQ con el agregado de los 3 tipos de residuos, la relación $\mathrm{N}_{-} \mathrm{NO}_{3}{ }^{-} / \mathrm{N}-\mathrm{NH}_{4}{ }^{+}$fue muy baja, pero fue aumentando a medida que transcurrió el tiempo de ensayo. Con el agregado de E. grandis este aumento ocurrió en etapas más tempranas, con $C$. ensiformis en etapas intermedias y con L. corniculatus hacia el final del tiempo de estudio (Figura 4.2, a, c y d).

Cuando los residuos de las 3 especies se incorporaron ES (Figura 4.2, b, d y f), tanto en condiciones de $\mathrm{HC}$ como de $\mathrm{AQ}$, la relación es $\mathrm{N}-\mathrm{NO}_{3}{ }^{-} / \mathrm{N}-\mathrm{NH}_{4}{ }^{+}$fue alta durante todo el tiempo transcurrido bajo estudio. Igual tendencia se observó en el control sin agregado de residuos vegetales (Figura 4.2, g). 

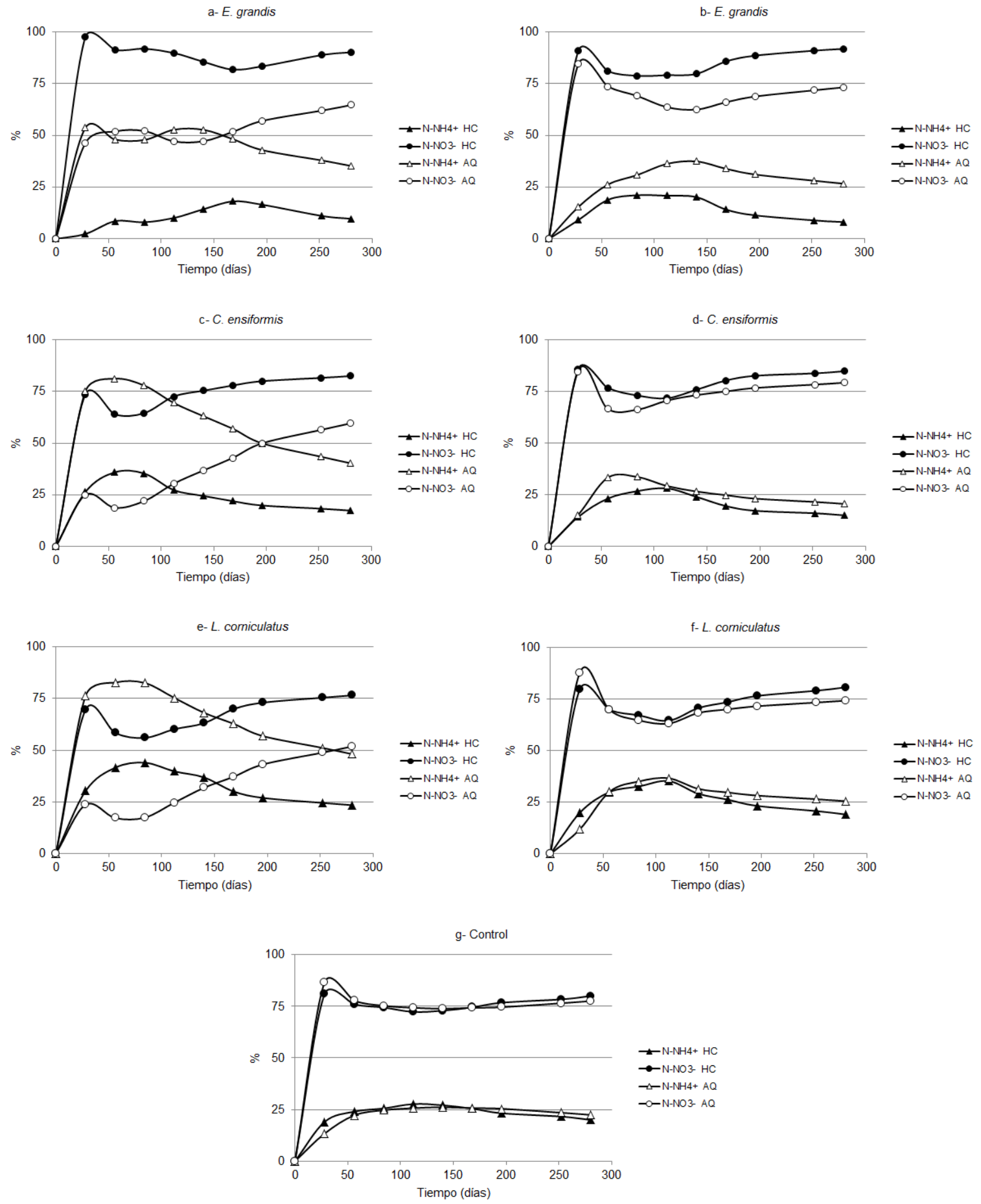

Figura 4.2. Proporción porcentual entre $\mathrm{N}_{-} \mathrm{NO}_{3}{ }^{-}$y $\mathrm{N}-\mathrm{NH}_{4}{ }^{+}$en el lixiviado de microlisímetros. a) Con agregado de E. grandis MM; b) Con agregado de E. grandis ES; c) Con agregado de $C$. ensiformis MM; d) Con agregado de C. ensiformis ES; e) Con agregado de L. cornicultaus MM; f) Con agregado de L. cornicultaus $\mathrm{ES} ; \mathrm{g})$ Control. $\mathrm{HC}=$ Humedad constante. $\mathrm{AQ}=$ Anegamiento quincenal. 


\subsubsection{4. $\mathrm{N}$ total: suma de $\mathrm{N}-\mathrm{NH}_{4}{ }^{+}$y $\mathrm{N}-\mathrm{NO}_{3}{ }^{-}$}

En los tratamientos con $\mathrm{HC}$ hubo lixiviaciones de $\mathrm{N}$ total significativamente mayores al control para L. corniculatus y C. ensiformis, sin diferencias entre ellas, ni con el modo de aplicación de los residuos (Figura 4.3, a). Con los residuos de E. grandis no hubo diferencias significativas con el control y tampoco en el modo de aplicación de los residuos.

En los tratamientos con AQ se dieron resultados muy diferentes según el modo de aplicación del material (Figura 4.3, c), ya que cuando los residuos se incorporaron ES sólo hubo una lixiviación de $\mathrm{N}$ total significativamente mayor al control para L. corniculatus, sin presentar diferencias significativas con el control los tratamientos con residuos ES de $C$. ensiformis ni de E. grandis. En cambio, cuando los residuos se incorporaron MM, todas las especies presentaron contenidos de $\mathrm{N}$ total al lixiviado menores que en el control, $L$. corniculatus y $C$. ensiformis sin diferencias entre sí, y E. grandis con los valores significativamente menores (Figura 4.3, c).

Cuando los residuos se incorporaron ES, la acumulación de $\mathrm{N}$ al lixiviado resultó mayor en el tratamiento con AQ que a $\mathrm{HC}$ cuando se agregaron residuos de L. corniculatus (797,1 $\mathrm{mg} \mathrm{N} \mathrm{kg}^{-1}$ suelo en AQ y 712,1 $\mathrm{mg} \mathrm{N} \mathrm{kg}^{-1}$ de suelo en $\mathrm{HC}$ ) y para el control (595,2 mg N kg${ }^{-1}$ suelo en AQ y 507,1 $\mathrm{mg} \mathrm{N} \mathrm{kg}^{-1}$ de suelo en $\mathrm{HC}$ ). Con los residuos ES de $C$. ensiformis las acumulaciones de $\mathrm{N}$ al lixiviado fueron similares en ambos tratamientos (665,8 $\mathrm{mg} \mathrm{N} \mathrm{kg}^{-1}$ suelo en AQ y 666,6 $\mathrm{mg} \mathrm{N} \mathrm{kg}^{-1}$ de suelo en $\mathrm{HC}$ ) al igual que para los residuos de E. grandis (575,4 $\mathrm{mg} \mathrm{N} \mathrm{kg}^{-1}$ suelo en AQ y 582,6 mg N kg${ }^{-1}$ de suelo en $\mathrm{HC}$ ) (Figura 4.3, a y c). 

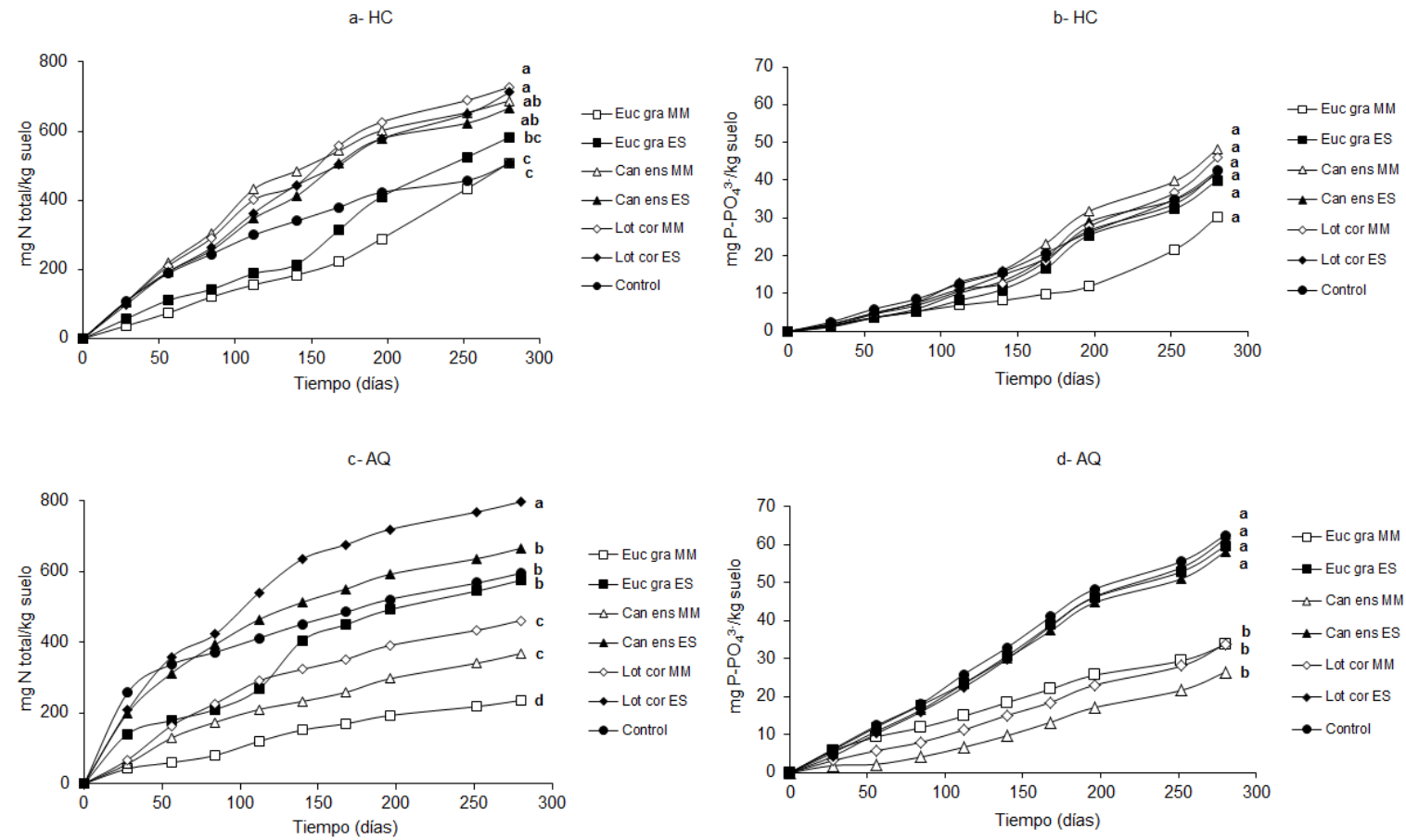

Figura 4.3. a) $\mathrm{N}$ total $\left(\mathrm{NH}_{4}^{+}+\mathrm{NO}_{3}^{-}\right)$acumulado por $\mathrm{kg}$ de suelo para distintos modos de aplicación del material y a $\mathrm{HC}$; b) $\mathrm{P}_{-} \mathrm{PO}_{4}{ }^{3-}$ acumulado por $\mathrm{kg}$ de suelo para distintos modos de aplicación del material y a $\mathrm{HC}$; c) $\mathrm{N}$ total $\left(\mathrm{NH}_{4}{ }^{+}+\mathrm{NO}_{3}{ }^{-}\right)$acumulado por $\mathrm{kg}$ de suelo para distintos modos de aplicación del material y con $\mathrm{AQ}$; d) $\mathrm{P}_{-} \mathrm{PO}_{4}{ }^{3-}$ acumulado por $\mathrm{kg}$ de suelo para distintos modos de aplicación del material y con AQ. MM: material vegetal molido y mezclado con el suelo. ES: material vegetal en pequeños trozos y sobre la superficie del suelo. Euc gra: E. grandis; Can ens: $C$. ensiformis; Lot cor: L. corniculatus. Con letras minúsculas se indica la significancia en la última fecha con datos acumulados, y sólo permiten comparar dentro de cada tipo de disponibilidad de agua.

\subsubsection{Lixiviación de $\mathrm{P}_{-} \mathrm{PO}_{4}{ }^{3-}$ en los distintos tratamientos con y sin agregado de detritos}

En condiciones de $\mathrm{HC}$ no hubo diferencias significativas en la lixiviación de P$\mathrm{PO}_{4}{ }^{3-}$ con o sin agregado de detritos (Figura 4.3, b), y sin diferencias con el modo de aplicación de los residuos. Independientemente de la significancia, la tendencia es que $E$. grandis siempre muestra valores más bajos de lixiviado de $\mathrm{P}_{-} \mathrm{PO}_{4}{ }^{3}$, en especial cuando se incorporó en forma MM. 
En el tratamiento con $\mathrm{AQ}$, en cambio, se encontraron valores de lixiviación de P$\mathrm{PO}_{4}{ }^{3-}$ sin diferencias con el control cuando los residuos se incorporaron ES, y con diferencias significativas menores al control cuando se incorporaron MM para los 3 tipos de residuos foliares de plantas utilizados, y sin diferencias entre sí (Figura 4.3,d).

Cuando los residuos se incorporaron ES, la contribución acumulada de $\mathrm{P}$ al lixiviado resultó mayor en el tratamiento AQ (valores entre 58,1 y 62,5 mg P/kg suelo) que a $\mathrm{HC}$ (valores entre 40 y $42,5 \mathrm{mg} \mathrm{P} / \mathrm{kg}$ suelo) tanto cuando se agregaron residuos de las leguminosas y de eucalipto, como en el control (Figura 4.3, b y d).

\subsection{DISCUSIÓN}

\subsubsection{Liberación de $\mathrm{N}$ al lixiviado con $\mathrm{y}$ sin agregado de detritos}

La lixiviación de $\mathrm{N}_{-} \mathrm{NH}_{4}{ }^{+}$fue mayor en el tratamiento de inundación-drenado que en condiciones de humedad constante. El abono de la leguminosa L. corniculatus incorporado tanto MM como ES lixivió $\mathrm{N}_{-} \mathrm{NH}_{4}{ }^{+}$de manera significativamente mayor al control cuando hubo ciclos de inundación-drenado, probablemente debido a la acumulación de $\mathrm{N}-\mathrm{NH}_{4}{ }^{+}$ durante la inundación producto de la presencia de materia orgánica descomponible en las condiciones anaeróbicas reinantes en esos períodos. Los estudios de Yadvinder-Singh et al. (1988) observaron en ensayos de inundación cantidades más altas de $\mathrm{N}_{-} \mathrm{NH}_{4}{ }^{+}$cuando el suelo fue abonado con residuos de trigo, arroz y leguminosas en contraste con suelo sin abono, mientras que Aulakh et al. (2000a) observaron en suelos casi saturados e inundados una acumulación de $\mathrm{N}_{-} \mathrm{NH}_{4}{ }^{+}$, producto de la mineralización relativamente baja de los residuos vegetales agregados y una reducción en la nitrificación. Si bien con los residuos de C. ensiformis se presentó la misma tendencia a lixiviar más $\mathrm{N}-\mathrm{NH}_{4}{ }^{+}$que el control, no se encontraron diferencias significativas. A diferencia de las leguminosas, el abono de $E$. grandis provocó siempre concentración de $\mathrm{N}_{-} \mathrm{NH}_{4}{ }^{+}$en el lixiviado menor al control, independientemente de la condición hídrica evaluada, de acuerdo con los resultados obtenidos en el Capítulo 2. Por otro lado, no se encontraron diferencias por incorporar el material vegetal de diferente modo, al menos en la concentración al lixiviado de esta forma química. 
Se encontraron diferentes situaciones en la liberación de $\mathrm{N}-\mathrm{NO}_{3}{ }^{-}$cuando se mantuvo el suelo a HC: con el agregado de abonos de leguminosas, la liberación de nitrato fue aumentando la diferencia con el control, sin diferencias en el modo de aplicación de los residuos. Estos resultados indicarían que la descomposición de la materia orgánica del suelo, formada por la materia orgánica preexistente más la agregada por el abono, ocurre desde el inicio del experimento, pero la descomposición de los abonos agregados comienzan a diferenciarse del control a partir de los 70 días aproximadamente, momento en que la materia orgánica del control comienza a disminuir la tasa de lixiviación, mientras que las que tienen abono continúan a igual tasa o mayor. Con la incorporación de $E$. grandis la liberación de $\mathrm{N}_{-} \mathrm{NO}_{3}{ }^{-}$durante los primeros 150 días fue menor a la del suelo sin abono, pero luego de esa fecha la tasa de liberación de $\mathrm{NO}_{3}{ }^{-}$aumenta, de manera que al final del experimento la lixiviación fue mayor cuando los residuos fueron agregados ES, mientras que cuando se agregaron $\mathrm{MM}$ no liberó más $\mathrm{NO}_{3}{ }^{-}$que el control. Sin embargo MM mostró la misma tendencia a aumentar que ES (de hecho no se diferencia del control pero tampoco de la mayor parte de los tratamientos), por lo tanto, es posible que en el tiempo este tratamiento se diferencie del control igual que los demás tratamientos.

En el tratamiento con AQ se dio un importante contraste según se hubieran aplicado o no residuos vegetales y según el modo en cómo éstos fueron aplicados. En los

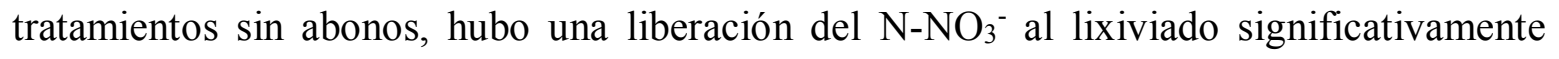
mayor que en los tratamientos con abonos agregados $\mathrm{MM}$. Este $\mathrm{N}-\mathrm{NO}_{3}{ }^{-}$provino del suelo, y la mayor liberación se produjo al inicio del ensayo. Estos resultados coinciden con los encontrados por Yadvinder-Singh et al. (1988) que observaron mayor liberación de nitrato en el suelo sin abono en comparación con el nitrato liberado del suelo con abono en condiciones de anegamiento. El agregado de abonos vegetales incorporados MM disminuye la liberación de $\mathrm{N}_{-} \mathrm{NO}_{3}{ }^{-}$porque este mineral podría ser sujeto a la desnitrificación, dadas las condiciones anaeróbicas presentes durante los períodos de inundación en el seno del suelo. Es probable que la desnitrificación ocurra a una tasa menor en suelos que no contienen abonos, ya que si bien varios factores determinan la desnitrificación, tales como el grado de aireación del suelo, la temperatura, el pH del suelo, y la textura (Ottow y Fabig 1985, Tiedje 1988, Aulakh et al. 1992, Qian et al. 1997), los controles clave para este proceso son la presencia de un adecuado suministro de $\mathrm{NO}_{3}{ }^{-}$, y la oferta de $\mathrm{C}$ disponible susceptible a la 
mineralización (Bijay-Singh et al. 1988, Rice et al. 1988, Beauchamp et al. 1989, Dendooven et al. 1996, Qian et al. 1997, Aulakh et al. 2000b), siendo éste último factor el que probablemente pudo limitar la desnitrificación en el suelo sin abono. El agregado de abonos verdes cuando fue incorporado MM, aumentó tanto la disponibilidad de $\mathrm{N}$ como de C, por lo que es esperable que la intensidad de la desnitrificación sea mayor. En cambio, cuando los residuos fueron agregados ES, éstos se mantuvieron en contacto con la superficie, de modo que permanecieron en condiciones aeróbicas, y por lo tanto el proceso de desnitrificación fue mínimo.

Aparte de la desnitrificación, la inmovilización también pudo ser responsable de la disminución del $\mathrm{N}^{-\mathrm{NO}_{3}}{ }^{-}$en los lixiviados del suelo cuando los residuos se agregaron MM (Yadvinder-Singh et al. 1988). En condiciones de humedad constante, que favorecen el crecimiento de la flora del suelo, no hubo inmovilización cuando se agregaron leguminosas, pero las condiciones de alternancia de períodos de inundación y drenado, pueden haber favorecido la mineralización aumentando la disponibilidad de nutrientes, dado por el "efecto Birch", por lo que la inmovilización de nutrientes podría explicar también la lixiviación de $\mathrm{N}^{-\mathrm{NO}_{3}}{ }^{-}$menor al control. Este fenómeno (Birch y Friend 1956) que consiste en el súbito aumento de la respiración del suelo, es decir, en un aumento de la emisión de $\mathrm{CO}_{2}$ a la atmósfera (Navarro-García et al. 2012) causado por las primeras lluvias luego de un período prolongado de sequía, pueden movilizar grandes cantidades de C (NavarroGarcía et al. 2012). Las causas de este fenómeno aún se hallan en estudio (Xiang et al. 2008, Borken y Matzner 2009), implicándose fenómenos biológico-metabólicos, tales como un incremento inmediato en la biomasa microbiana, el consumo masivo de diversas sustancias protectoras -conocidas como osmolitos- producidas por los microorganismos en su adaptación a la sequía, o el consumo rápido de los microorganismos muertos y sus restos tras la humectación (Halverson et al. 2000, Xiang et al. 2008); o simplemente físicos como puede ser la fractura de los agregados del suelo tras la humectación y liberación del carbono protegido (Utomo y Dexter 1982, Denef et al. 2001, Miller et al. 2005). Este mismo fenómeno podría explicar los valores más altos de liberación de $\mathrm{N}$ al lixiviado en los tratamientos con AQ que con $\mathrm{HC}$ en el suelo sin abono: los ciclos de inundación-drenado podrían haber activado la mineralización de la materia orgánica que contenía el suelo, con el consecuente aumento de la población de microorganismos del suelo. Durante el período 
de inundación se produce la muerte de estos microorganismos, los cuales resultan como nueva materia orgánica lábil durante el siguiente período con buena disponibilidad de agua y oxígeno. Por lo tanto, la disminución de $\mathrm{N}^{-\mathrm{NO}_{3}}{ }^{-}$cuando se agregaron abonos al suelo respecto al control en condiciones de anegamiento seguida de sequía, podría explicarse tanto por desnitrificación como por inmovilización de este nutriente.

Dado que si bien el $\mathrm{N}$ total resulta de la suma de $\mathrm{NH}_{4}{ }^{+}$y $\mathrm{NO}_{3}{ }^{-}$, este último se encuentra en una cantidad mucho mayor que el $\mathrm{NH}_{4}{ }^{+}$, y por lo tanto las tendencias para $\mathrm{N}$ total son muy semejantes a las descriptas para el $\mathrm{NO}_{3}{ }^{-}$. En $\mathrm{HC}$ el material agregado de leguminosas ( $\sin$ importar el modo de aplicación) lixivió más $\mathrm{N}$ que en el suelo sin abono, en tanto que para la especie E. grandis no produjo una lixiviación significativa diferente al control. Esto podría explicarse ya que el material vegetal de las leguminosas se descompone más fácilmente comparado con el eucalipto: E. grandis presentó una tasa de descomposición anual k de 2,19 año ${ }^{-1}$, mientras que C. ensiformis y L. corniculatus tuvieron tasas $\mathrm{k}$ de 5,84 año $^{-1}$ y 8,40 año $^{-1}$ respectivamente (Tabla 3.2). Por lo tanto las leguminosas lixivian nutrientes de manera más rápida.

El contraste entre el modo de aplicación de los residuos MM o ES en los tratamientos con alternancia de inundación-drenado también fue evidente al analizar el $\mathrm{N}$ total, encontrándose que con los residuos MM para los 3 tipos de abonos utilizados siempre se liberó menos $\mathrm{N}$ al lixiviado que en el suelo sin residuos, por lo que el $\mathrm{N}$, proveniente de la mineralización de los abonos causada por el "efecto Birch", pudo perderse por inmovilización o desnitrificación. Por otro lado, cuando los residuos se agregaron ES, al igual que en el Capítulo 2, L. corniculatus es la única especie que provee significativamente más $\mathrm{N}$ al lixiviado que el control.

El modo en que se agregan los residuos vegetales también resultó ser un factor a tener en cuenta considerando la posibilidad de que el suelo atraviese períodos de anegamiento y sequía, ya que cuando estos son agregados $\mathrm{MM}$, la proporción de $\mathrm{NH}_{4}{ }^{+}$ aumenta y la de $\mathrm{NO}_{3}{ }^{-}$disminuye. Si bien muchos autores han documentado que las plantas pueden utilizar ambas formas químicas como fuente de N (Epstein 1972, Mengel y Kirkby 1987, Jingquan y Dewei 1988, Hageman 1992, Maldonado 1993, y Salisbury y Ross 1994, Below 2002), hay resultados contradictorios respecto a la forma más adecuada para obtener una máxima productividad (Gallegos-Vázquez et al. 2000). En varios trabajos recopilados 
por Mengel y Kirkby (1987) se estableció que muchas especies de plantas crecen mejor cuando son suministradas con $\mathrm{NO}_{3}{ }^{-}$que con sales de $\mathrm{NH}_{4}{ }^{+}$. Otros autores, como Jingquan y Dewei (1988) analizaron la proporción óptima de $\mathrm{NH}_{4}{ }^{+} / \mathrm{NO}_{3}{ }^{-}$que favorece el crecimiento de la planta de tomate, mientras que Kwak et al. (1989) estudió qué proporción mejoraba su rendimiento. Otro aspecto por los que sería importante conocer la proporción de $\mathrm{NO}_{3}^{-}$ disponibles en el suelo por el aporte de residuos, es que esta especie química es también responsable por las mayores pérdidas de $\mathrm{N}$ del suelo, ya que es susceptible a lixiviación, desnitrificación, e inmovilización microbiana, con importantes implicancias económicas (Below 2002).

\subsubsection{Liberación de $\mathrm{P}-\mathrm{PO}_{4}{ }^{3-}$ al lixiviado con $\mathrm{y}$ sin agregado de detritos}

En condiciones de $\mathrm{HC}$ los residuos agregados no significan un aporte de $\mathrm{P}$ al lixiviado ya que no hay diferencias con el control cuando se agregaron estos residuos con ambos modos de incorporación. Dado que la concentración de P al lixiviado aportado en los tratamientos con incorporación tanto MM como ES por todas las especies fueron muy semejantes a los del control, es de suponer que este $\mathrm{P}$ estaba presente en el suelo previamente (como materia orgánica e inorgánica), y no es aportado por la descomposición de los distintos residuos. Sin embargo, al analizar lo sucedido con la lixiviación de N en estas mismas condiciones, se observó un aporte de este nutriente con el agregado como abono de las especies de leguminosas, por lo que es de suponer que procesos de descomposición y mineralización están ocurriendo en el suelo. Teniendo en cuenta que los métodos más comunes para medir el $\mathrm{P}$ del suelo, como el utilizado en esta Tesis, miden el $\mathrm{P}$ en la solución del suelo luego de un proceso de extracción (Facultad de Agronomía, Universidad de la República 2015), esta fracción no representa la cantidad total de P disponible en el suelo, sino que se trata de un índice relativo (Facultad de Agronomía, Universidad de la República 2015) y la mayoría de los extractantes de suelo sólo extraen una proporción de $\mathrm{P}$ lábil en forma inorgánica. Muchas de las variaciones estacionales observadas en los niveles de $\mathrm{P}$ asimilable de los suelos podrían ser explicadas por la contribución de la mineralización de formas orgánicas de P (Facultad de Agronomía, Universidad de la República 2015). Por lo tanto, los contenidos de $\mathrm{P}_{-} \mathrm{PO}_{4}{ }^{3+}$ observados en 
los lixiviados podría provenir de la mineralización de la materia orgánica proveniente del suelo en los ensayos con abonos y sin abonos, y el P proveniente de la descomposición de la materia orgánica aportada por los abonos podría estar en formas de $\mathrm{P}$ orgánico, sin poder ser detectadas.

Las mayores lixiviaciones de $\mathrm{P}$ en condiciones de $\mathrm{AQ}$ con respecto a $\mathrm{HC}$ tanto en suelos con abono agregados ES como en el control, podrían explicarse por la mayor mineralización que ocurre en situaciones de alternancia de sequía-inundación, a semejanza de lo ocurrido con el $\mathrm{N}$ en el tratamiento control y con agregado de L. corniculatus con material ES. La anoxia provocada durante la inundación del suelo tiende a hacer aumentar la disponibilidad de este nutriente a través de efectos indirectos sobre la solubilidad de los minerales de Fe y Mn provocadas por los cambios en el potencial redox (Scalengue 2002) que producen la liberación del P adsorbido (Willett 1986, Stumm y Sulzberger 1992, Scalenghe 2010), y además porque el drenado y posterior remojo del suelo induce la rápida mineralización de P durante el re humedecimiento (Chepkwony 2001, Butterly 2010). Sin embargo, no hubo diferencias entre el control y los tratamientos con abonos agregados ES, que probablemente al estar en contacto con el aire, tuvieron un comportamiento semejante a los tratamientos con residuos a $\mathrm{HC}$ : el $\mathrm{P}_{-} \mathrm{PO}_{4}{ }^{3+}$ lixiviado puedo provenir de la mineralización de la materia orgánica del suelo, mientras que, la descomposición y mineralización proveniente de los abonos pudo ocurrir a una tasa menor, dado el tamaño de la fracción a descomponer. Asimismo, una fracción de $\mathrm{P}$ orgánico lábil proveniente del material vegetal pudo estar presente en la solución del suelo sin ser detectado.

Por otro lado, cuando los residuos se agregaron MM y los lisímetros sometidos a períodos de inundación-drenado, la liberación de $\mathrm{P}$ al lixiviado fue menor que en los suelos sin abonos, dado que los ciclos de secado y humectación suelen estimular la actividad microbiana y la mineralización del C orgánico y N del suelo (Birch 1960, Haynes 1986, Harris 1988, Cabrera 1993, Bauhus y Khanna 1994), por lo tanto, sería esperable un aumento en la actividad microbiana por el agregado de los abonos con la consecuente mineralización de $\mathrm{P}$, de modo que lo que podría estar ocurriendo es una inmovilización de este nutriente en la biomasa bacteriana. 


\subsection{CONCLUSIÓN}

Los resultados encontrados dan apoyo parcialmente a la hipótesis del presente Capítulo: La anoxia reduce la actividad microbiana por lo tanto, en los suelos anegados, la descomposición de los detritos que no estén en contacto con el oxígeno atmosférico será menor que la de los expuestos en la superficie.

Cuando se incorporaron abonos orgánicos en suelos anegados la liberación de $\mathrm{N}$ en la solución del suelo disminuyó con respecto a un suelo a capacidad de campo (Predicción 1), a excepción de la especie L. corniculatus cuyos residuos agregados enteros y sobre la superficie aumentaron la lixiviación de $\mathrm{N}$ en el suelo anegado con respecto al suelo a capacidad de campo. Cuando se incorporaron abonos orgánicos en suelos anegados la lixiviación de $\mathrm{P}$ en la solución del suelo aumentó con respecto a un suelo a capacidad de campo, pero cuando los residuos se agregaron molidos y mezclados con el suelo disminuyeron el contenido de $\mathrm{P}$ al lixiviado en el suelo anegado con respecto al suelo a capacidad de campo.

En suelos anegados, hubo mayor lixiviación de $\mathrm{N}$ y $\mathrm{P}$ cuando el abono se agregó en superficie que cuando estuvo mezclado con el suelo (Predicción 2), a excepción de la lixiviación de $\mathrm{P}$ a partir de E. grandis que con este modo de aplicación aportó menos nutriente al lixiviado.

Si bien en los tratamientos a humedad constante es indistinta la incorporación del material vegetal agregado como abono molido y mezclado con el suelo, o entero y sobre la superficie, cuando existen condiciones que alternan períodos de inundación y de drenado, el modo de incorporar el residuo será determinante en la concentración de nutrientes obtenida en el lixiviado. Si éstos se incorporan molidos y mezclados con el suelo, se darán concentraciones tanto de $\mathrm{N}$ como de $\mathrm{P}$ menores al control, a pesar de la diferente calidad del residuo aportado con las diferentes especies utilizadas. En cambio, cuando el material vegetal se incorpora entero y sobre la superficie del suelo, se podrá esperar una lixiviación de $\mathrm{N}$ mayor al control únicamente con la incorporación de L. corniculatus, aunque no de $\mathrm{P}$. La inmovilización de nutrientes será el proceso dominante en estas condiciones. 


\section{CAPÍTULO 5}

\section{LIXIVIACIÓN DE NITRÓGENO Y FÓSFORO EN SUELOS \\ ARCILLOSOS CON AGREGADO DE RESIDUOS DE EUCALYPTUS GRANDIS Y LEGUMINOSAS MOLIDOS Y MEZCLADOS BAJO CUATRO REGÍMENES HÍDRICOS}

\subsection{INTRODUCCIÓN}

Los suelos superficiales con frecuencia están expuestos a ciclos de secado y rehumectación que son importantes para la renovación de carbono (Adu y Oades 1977), fósforo (Sparling et al. 1985, Magid y Nielsen 1992, Butterly et al. 2009) y nitrógeno (Fierer y Schimel 2002, Kruse et al. 2004). Cuando se rehumedece un suelo seco, se producen a corto plazo aumentos rápidos en la liberación de $\mathrm{CO}_{2}$ y nutrientes debido a una mayor actividad microbiana y a la mineralización (Butterly et al. 2010).

Por otro lado, el secado y re-humedecimiento es una de las formas de estrés abiótico más comunes y generalizadas experimentada por los suelos (Soulides y Allison 1961), que afecta a los procesos microbianos tanto por altos como bajos contenidos de humedad (Drury et al. 2003), y desempeñan un papel importante en la mineralización de los nutrientes (Grierson 1998). Cuando el contenido de humedad del suelo supera la capacidad de campo, la actividad de los microorganismos decrece con el aumento de la humedad, debido a que baja la disponibilidad de $\mathrm{O}_{2}$ (Killham 1994). Los sedimentos húmedos y los saturados de humedad sustentan diferente flora de microorganismos que los suelos bien aireados, y la descomposición de la materia orgánica se produce a una tasa mucho menor (Stevenson 1986). Hay una marcada caída del $\mathrm{O}_{2}$ y un aumento en el contenido de $\mathrm{CO}_{2}$ provocados por la utilización de materia orgánica por los microorganismos (Stevenson 1986). El resultado neto es un descenso simultáneo en el potencial de óxido-reducción (Stevenson 1986), factor de suma importancia ya que muchas de las reacciones químicas inorgánicas del suelo y prácticamente todas las reacciones biológicas del $\mathrm{C}, \mathrm{N}$ y $\mathrm{S}$, son reacciones de óxido-reducción, y dependen de la presencia o ausencia de $\mathrm{O}_{2}$ (Bohn et al. 1993). También se producen cambios en el pH y 
varios componentes inorgánicos como el fosfato pueden hacerse más solubles (Stevenson 1986).

Cuando el suelo se seca por debajo de un determinado nivel se produce la muerte o la inactividad de los microorganismos, lo que provoca el descenso o la inhibición de la mineralización (Kieft et al. 1987). Asimismo, la accesibilidad a los sustratos orgánicos e inorgánicos por los microorganismos y la movilidad de las enzimas extracelulares disminuyen, debido a la hidrofobicidad y la encapsulación de la materia orgánica del suelo y la adsorción de sustancias hidrofóbicas en superficies minerales (Lützow et al. 2006, Borken y Matzner 2009). La baja humedad del suelo provoca también cambios en su estructura edáfica, induciendo la hidrofobicidad de la superficie del suelo (Borken y Matzner 2009).

Por otro lado, cuando el suelo se seca y luego vuelve a humedecerse ocurre un conjunto de cambios físicos, químicos y biológicos, incluyendo cambios en la estructura del suelo, en la materia orgánica y en la microflora (Soulides y Allison 1961, Utomo y Dexter 1982, Hentschel 2007), que generalmente causan un incremento en la descomposición de la materia orgánica del suelo (Soulides y Allison 1961), dado por el aumento en la actividad microbiana (Pulleman y Tietema 1999, Prieme y Christensen 2001, Borken et al. 2003, Lee et al. 2004, Sponseller 2007), aunque la medida en que este efecto ocurre, varía en función de las propiedades del suelo, del tratamiento del suelo, la intensidad y la frecuencia de secado y humedecimiento (Hentschel 2007).

Para comprender cuál es el impacto de las condiciones de humedad del suelo sobre la disponibilidad de $\mathrm{N}$ y $\mathrm{P}$ soluble aprovechable por las plantas, procedente de residuos de cosecha de Eucalyptus grandis y de cubiertas herbáceas de leguminosas, se propuso un estudio experimental en laboratorio donde se exploran los efectos de otros posibles regímenes hídricos. El objetivo fue conocer la influencia de las distintas condiciones de disponibilidad de agua (frecuencia de inundación, capacidad de campo y déficit hídrico) en la concentración de N y P del lixiviado en un suelo arcilloso con agregado de hojas de E. grandis y de leguminosas.

La hipótesis es que la disponibilidad de agua y oxígeno en el suelo influye en la actividad microbiana del suelo, de manera que el déficit y el exceso de agua por periodos prolongados reducirán la tasa de descomposición de los detritos.

\section{Predicción:}

- Periodos de anegamiento breves intercalados con buena disponibilidad de agua y oxígeno en el suelo aumentan la lixiviación de $\mathrm{N}$ y P a la solución del suelo. 
- En los suelos arcillosos, con la sequía la lixiviación de N y P disminuye.

\subsection{MATERIALES Y MÉTODOS}

\subsubsection{Diseño experimental}

El ensayo empleó microlisímetros conteniendo suelo superficial, a los cuales se les agregaron residuos de hojas de E. grandis o de una de dos leguminosas (Canavalia ensiformis y Lotus corniculatus) molido y mezclado con el suelo, y luego sometidos a distintas condiciones hídricas. El diseño experimental consistió en 3 tipos de materiales vegetales y 4 condiciones de disponibilidad de agua. Se realizaron 3 repeticiones para cada tratamiento, que hacen un total de 36 microlisímetros. Además, se reservaron 12 microlisímetros sin residuos vegetales como control, 3 por cada tipo de disponibilidad de agua. Todos los microlisímetros se colocaron en cámara con una temperatura de $23^{\circ} \mathrm{C}$ con un desvío estándar de $2{ }^{\circ} \mathrm{C}$.

Semanalmente se corroboró por diferencia de peso el estado hídrico de cada microlisímetro. Para mantener el contenido de humedad correspondiente a cada tratamiento se procedió como se indica en la sección 4.2.1. Para determinar la lixiviación de nutrientes, los microlisímetros fueron irrigados simulando lluvia cada 4 semanas, durante 10 lavados (último lavado a los 280 días). El lavado se realizó con solución acuosa igual a la descripta en la sección 4.2.1. El líquido percolado fue recogido como se describió en el Capítulo 2 (ver sección 2.2.1, Imagen 2.1) y llevado al laboratorio para analizar su contenido de $\mathrm{N}-\mathrm{NH}_{4}{ }^{+}, \mathrm{N}_{-} \mathrm{NO}_{3}{ }^{-}$y $\mathrm{P}-\mathrm{PO}_{4}{ }^{3-}$.

\subsubsection{Selección y obtención del material vegetal y suelos}

Se utilizaron hojas de E. grandis, y material herbáceo de Canavalia ensiformis L. y Lotus corniculatus L. El suelo utilizado fue un Argiacuol Vertico (localmente arcilloso). La procedencia y recolección del material vegetal y el suelo se realizó como se describe en el Capítulo 2 (ver sección 2.2.2). 


\subsubsection{Microlisímetros}

Fueron construidos como se describe en el Capítulo 2 (ver sección 2.2.3, Imagen 2.2). Para los tratamientos con suelos anegados estos vasos fueron dispuestos en el interior de otro vaso similar sin perforar para contener el agua agregada durante la etapa de inundación, de manera que el volumen de agua sin contacto con el suelo sea mínimo.

El suelo y el material vegetal fueron acondicionados como se describe en el Capítulo 2 (sección 2.2.3). El mantillo seco se molió con molino Wiley, se tamizó en malla de 0,5 mm, se mezcló y homogeneizó con el suelo (MM). Se eligió trabajar con el material molido y mezclado $(\mathrm{MM})$ porque es el que demostró mayor diferencia con el control en los ensayos previos (Capítulos 2 y 4), principalmente mostró -en comparación con la aplicación en forma ES- valores más extremos, que implicaron la reducción de la concentración de N y P en el suelo cuando el suelo estaba anegado.

\subsubsection{Tratamientos}

Cada microlisímetro fue sometido a una de las siguientes condiciones hídricas:

1- Riego frecuente sin estrés para lograr humedad constante (HC): se controló el peso del lisímetro semanalmente, agregándose agua para mantener al suelo constantemente húmedo, a capacidad de campo, y cada 4 semanas se realizó un lavado durante diez ciclos consecutivos.

2- Alternancia quincenal de suelo drenado natural - anegado (AQ): se comenzó el ensayo con un lavado, y durante las 2 siguientes semanas se permitió el drenaje y secado del suelo. Posteriormente, al inicio de la tercera semana se agregó agua a saturación y se mantuvo así durante 2 semanas, en cantidad suficiente para que formara una capa de $1 \mathrm{~mm}$ de agua sobre la superficie del suelo. Finalizado el período de anegamiento se realizó el lavado para recolectar el lixiviado, recomenzando el ciclo. El lixiviado fue recolectado luego de dejar escurrir durante 24 horas, y estuvo constituido por el líquido agregado durante la inundación más la solución de lavado agregada de modo de alcanzar $200 \mathrm{ml}$ totales. Finalizado este período el microlisímetro fue nuevamente dispuesto dentro de otro vaso similar para reiniciar la etapa de sequía. Estas mediciones se realizaron durante diez ciclos consecutivos cada 4 semanas. 
3- Alternancia mensual de suelo drenado natural - anegado (AM): se agregó agua a saturación durante las 4 semanas iniciales. Se realizó un lavado para recolectar el lixiviado. Las siguientes 4 semanas se permitió el drenaje y secado del suelo. Finalizado este período se realizó un nuevo lavado y se recomenzó con el proceso durante un nuevo ciclo bimensual. Se repitieron cinco ciclos bimensuales consecutivos.

4- Estrés por sequía (S): el agua del suelo en el microlisímetro se repuso semanalmente luego de pesarlo a un contenido de agua suficiente para mantener el suelo en un contenido de humedad fijado en -0,8 MPa (estrés no letal para E. grandis, según Graciano et al. 2005). Cada 4 semanas se realizó un lavado durante diez ciclos consecutivos.

\subsubsection{Análisis químicos del lixiviado}

En el líquido lixiviado se determinó el contenido de amonio $\left(\mathrm{N}^{-} \mathrm{NH}_{4}{ }^{+}\right)$, nitrato $\left(\mathrm{N}-\mathrm{NO}_{3}{ }^{-}\right)$y fosfato $\left(\mathrm{P}-\mathrm{PO}_{4}{ }^{3-}\right)$ como se describe en la sección 2.2.4.

Los miligramos de $\mathrm{N}-\mathrm{NH}_{4}{ }^{+}, \mathrm{N}-\mathrm{NO}_{3}{ }^{-}$y de $\mathrm{P}-\mathrm{PO}_{4}{ }^{3-}$ lavados en el lixiviado en cada fecha de muestreo se calcularon multiplicando el volumen de líquido lixiviado por la concentración de $\mathrm{NH}_{4}{ }^{+}, \mathrm{NO}_{3}{ }^{-}$o $\mathrm{PO}_{4}{ }^{3-}$. Se calcularon los miligramos de nutrientes acumulados por kilogramo de suelo para cada especie y para el control como se describe en la sección 2.2.4.

\subsubsection{Análisis estadísticos}

Los valores finales acumulados de lixiviación se analizaron por un ANOVA de 2 factores (abono y humedad), con 4 niveles cada factor. Para simplificar la visualización en los gráficos, se realizó un ANOVA de la última fecha del ensayo con los datos de lixiviación acumulados, considerando un solo factor con 4 niveles (E. grandis; $C$. ensiformis; L. corniculatus y Control). Los resultados de lixiviación de cada régimen de agua (HC, AQ, AM y S) se analizaron por separado. Las medias se compararon mediante el test de Tukey $(\mathrm{p}<0,05)$. 


\title{
5.3. RESULTADOS
}

\subsubsection{Lixiviación de $\mathrm{N}$ en los distintos tratamientos con y sin agregado de detritos}

\author{
5.3.1.1. $\mathrm{N}-\mathrm{NH}_{4}^{+}$
}

En todos los tratamientos de régimen de agua, con el agregado de E. grandis hubo una lixiviación de $\mathrm{N}-\mathrm{NH}_{4}{ }^{+}$menor al control (Figura 5.1, a, c, e y g), aunque esta diferencia no resultó significativa. Con el agregado de detritos de L. corniculatus y $C$. ensiformis hubo una lixiviación de $\mathrm{N}^{-\mathrm{NH}_{4}}{ }^{+}$mayor al suelo sin abono (Figura 5.1, a, c, e y g; Tabla 5.1) en todas las condiciones de disponibilidad de agua, aunque esta diferencia resultó significativa para $L$. corniculatus en todos los tratamientos a excepción de humedad constante (HC), y para C. ensiformis sólo fue significativa en el tratamiento con anegamiento mensual (AM). Con abono de L. corniculatus la lixiviación de $\mathrm{N}^{-\mathrm{NH}_{4}}{ }^{+}$fue significativamente mayor que con abono de $C$. ensiformis en los tratamientos con anegamiento quincenal (AQ) y $\mathrm{AM}$ y $\mathrm{S}$, y no fueron significativamente diferentes a $\mathrm{HC}$.

La lixiviación de $\mathrm{N}^{-\mathrm{NH}_{4}}{ }^{+}$aumentó hasta alrededor de los 60 días de comenzado el ensayo, en los tratamientos HC, AQ y AM (Figura 5.1, a, c, e y g). Posteriormente no se lixivió más $\mathrm{N}_{-} \mathrm{NH}_{4}{ }^{+}$. Con los tratamientos AQ y AM siempre la lixiviación de N$\mathrm{NH}_{4}{ }^{+}$fue mayor, con o sin agregado de detritos, que en el tratamiento $\mathrm{HC}$, aunque la diferencia solo fue significativa entre el tratamiento AM y $\mathrm{HC}$ cuando se agregaron residuos de las dos leguminosas (Tabla 5.1). En el tratamiento $\mathrm{S}$ la lixiviación de N$\mathrm{NH}_{4}{ }^{+}$en cada fecha fue constante y se mantuvo hasta el final del experimento, tal como puede observarse en las líneas rectas que grafican el $\mathrm{N}_{-} \mathrm{NH}_{4}{ }^{+}$acumulado cedido a lo largo del tiempo (Figura 5.1, g). Sin embargo, la cantidad de $\mathrm{N}_{-} \mathrm{NH}_{4}{ }^{+}$lixiviado fue menor a la observada en los otros 3 tratamientos, tal como se puede observar al comparar, en la Figura 5.1g con 5.1a, c y e, siendo esta diferencia significativa en los tratamientos con agregado de L. corniculatus (Tabla 5.1). La máxima lixiviación de N$\mathrm{NH}_{4}{ }^{+}$se observó en AM con la incorporación de cualquier material vegetal. En este tratamiento la lixiviación media de $\mathrm{N}^{-\mathrm{NH}_{4}}{ }^{+}$al final del experimento varió entre 98 y $267 \mathrm{mg} \mathrm{N}-\mathrm{NH}_{4}{ }^{+} / \mathrm{kg}$ suelo según el material colocado, mientras que en $\mathrm{HC}$ los valores medios estuvieron entre 49 y $170 \mathrm{mg} \mathrm{N}-\mathrm{NH}_{4}{ }^{+} / \mathrm{kg}$ suelo. 

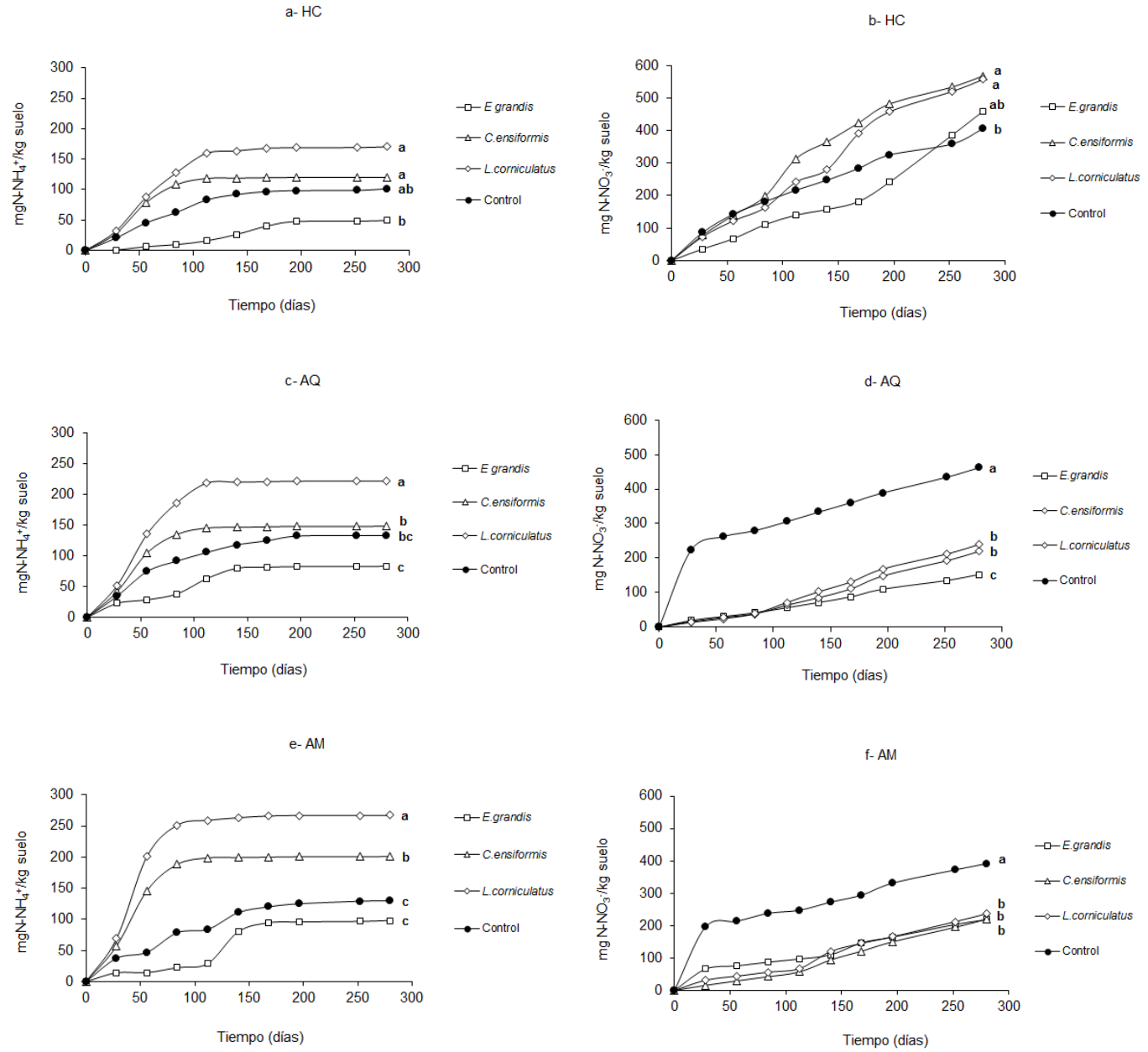

g- $S$

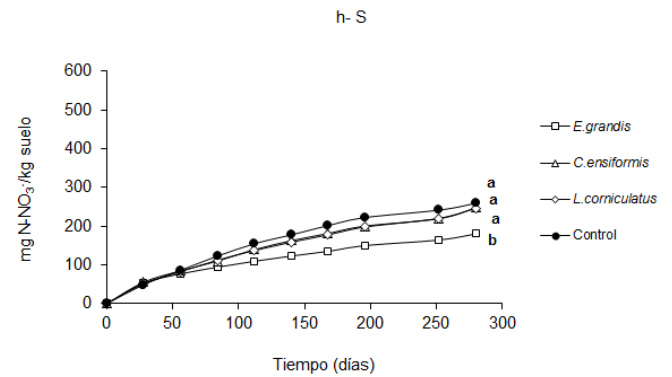

Figura 5.1. a) $\mathrm{N}_{-} \mathrm{NH}_{4}{ }^{+}$acumulado por $\mathrm{kg}$ de suelo a $\mathrm{HC}$; b) $\mathrm{N}^{-\mathrm{NO}_{3}}{ }^{-}$acumulado por kg de suelo

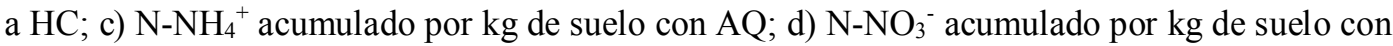

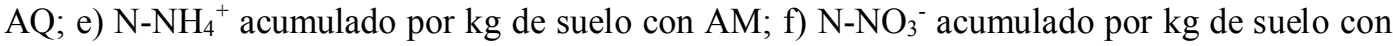

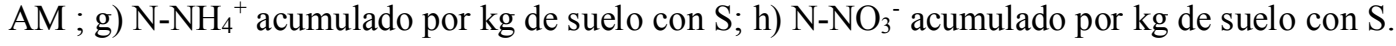
Con letras minúsculas se indica la significancia en la última fecha con datos acumulados, y sólo permiten comparar dentro de cada tipo de disponibilidad de agua. 
Tabla 5.1. Valores acumulados finales de amonio, nitrato y fosfato de los distintos abonos $(E$. grandis, C. ensiformis, L. corniculatus) y el suelo control (sin abono) para las diferentes condiciones de humedad del suelo (HC: Humedad cte. AQ: Anegamiento quincenal. AM: Anegamiento mensual. S: Sequía). Letras diferentes indican medias diferentes según el test de Tukey $(\mathrm{p}<0,05)$. Al pie de la tabla se indica la significancia de cada factor y de la interacción en el ANOVA factorial.

\begin{tabular}{|c|c|c|c|c|}
\hline Abono & Humedad & $\mathrm{N}-\mathrm{NH}_{4}{ }^{+}$ & $\mathrm{N}-\mathrm{NO}_{3}{ }^{-}$ & $\mathrm{P}-\mathrm{PO}_{4}{ }^{-3}$ \\
\hline \multirow[t]{4}{*}{ Control } & S & 95 abcd & $259 \mathrm{~b}$ & $24 a b$ \\
\hline & $\mathrm{HC}$ & $101 \mathrm{bcd}$ & $406 \mathrm{c}$ & 42 cde \\
\hline & $A Q$ & 133 cde & $462 \mathrm{c}$ & $63 \mathrm{f}$ \\
\hline & AM & 130 cde & $391 \mathrm{c}$ & $64 \mathrm{f}$ \\
\hline \multirow[t]{4}{*}{ E. grandis } & $\mathrm{S}$ & $40 a$ & $180 \mathrm{ab}$ & $17 a b$ \\
\hline & $\mathrm{HC}$ & $49 a b$ & $459 \mathrm{c}$ & 30 abcd \\
\hline & $A Q$ & $83 a b c$ & $152 a$ & 34 bcde \\
\hline & AM & 98 abcd & $218 a b$ & $26 a b c$ \\
\hline \multirow[t]{4}{*}{ L. corniculatus } & S & 140 cde & $247 b$ & $18 a b$ \\
\hline & $\mathrm{HC}$ & $171 \mathrm{fgh}$ & $557 \mathrm{~d}$ & 46 def \\
\hline & $A Q$ & 222 hi & $239 a b$ & 34 bcde \\
\hline & AM & $267 \mathrm{i}$ & $236 a b$ & 33 bcde \\
\hline \multirow[t]{4}{*}{ C. ensiformis } & S & 142 cdef & $247 b$ & $14 a$ \\
\hline & $\mathrm{HC}$ & 120 cde & $568 d$ & 48 ef \\
\hline & $A Q$ & 149 def & $219 a b$ & $26 a b c$ \\
\hline & AM & $201 \mathrm{gh}$ & $220 a b$ & $26 a b c$ \\
\hline abono & & $>0,001$ & $>0,001$ & $>0,001$ \\
\hline humedad & & $>0,001$ & $>0,001$ & $>0,001$ \\
\hline abono $\mathrm{x}$ humedad & & 0,01 & $>0,001$ & $>0,001$ \\
\hline
\end{tabular}

\subsubsection{2. $\mathrm{N}-\mathrm{NO}_{3}^{-}$}

La lixiviación de $\mathrm{N}$ en forma de $\mathrm{NO}_{3}{ }^{-}$en general fue mayor que la lixiviación en forma de $\mathrm{NH}_{4}{ }^{+}$. En el tratamiento con $\mathrm{HC}$, con el agregado de $L$. corniculatus y de $C$. ensiformis hubo una lixiviación de $\mathrm{N}^{-\mathrm{NO}_{3}}{ }^{-}$significantemente mayor al control (Figura 5.1, b, d, f y h; Tabla 5.1). En condiciones de S, el agregado de abonos redujo o no modificó en forma estadísticamente significativa la lixiviación de $\mathrm{N}^{-\mathrm{NO}_{3}}{ }^{-}$, en tanto que en los tratamientos AQ y AM, el agregado de estos abonos provocó una lixiviación de $\mathrm{N}-\mathrm{NO}_{3}{ }^{-}$significativamente menor al control (Tabla 5.1). Los tratamientos con abono de E. grandis en ambas situaciones de alternancia de sequía-inundación produjeron menor lixiviación de $\mathrm{N}^{-\mathrm{NO}_{3}}{ }^{-}$con respecto al control, mientras que en $\mathrm{HC}$ y $\mathrm{S}$ no hubo diferencias significativas con el control al final del experimento porque se incrementó la lixiviación de $\mathrm{N}^{-\mathrm{NO}_{3}}{ }^{-}$a partir de los 200 días (Figura 5. 1, b, d, f y h). 
En todas las disponibilidades de agua hubo un pico de lixiviación de $\mathrm{N}^{-\mathrm{NO}_{3}}{ }^{-}$a los 30 días de comenzado el ensayo, siendo particularmente marcado en los tratamientos AQ y AM sin agregado de detritos (Figura 5. 1, b, d, f y h). Los residuos de leguminosas lixiviaron $\mathrm{N}_{-} \mathrm{NO}_{3}{ }^{-}$sólo en condiciones de $\mathrm{HC}$, en tanto que en condiciones de AQ y AM lixiviaron cantidades menores que el suelo sin abono (Figura 5. 1, b, d, f y h; Tabla 5.1). En condiciones de $\mathrm{S}$ la incorporación de E. grandis y de las leguminosas lixiviaron igual cantidad de $\mathrm{N}-\mathrm{NO}_{3}{ }^{-}$que el suelo solo.

\subsubsection{3. $\mathrm{N}$ total: aporte proporcional de $\mathrm{N}-\mathrm{NH}_{4}{ }^{+}$y $\mathrm{N}-\mathrm{NO}_{3}{ }^{-}$}

Las diferentes disponibilidades de agua en el suelo modificaron la forma en la que está presente el $\mathrm{N}\left(\mathrm{NH}_{4}{ }^{+} \mathrm{o} \mathrm{NO}_{3}{ }^{-}\right)$. En el caso de suelo sin abono (control), el anegamiento no incrementó el porcentaje de $\mathrm{N}_{-} \mathrm{NH}_{4}{ }^{+}$con respecto a $\mathrm{HC}$, mientras que se incrementó dicha forma de $\mathrm{N}$ en situación de sequía. Con el agregado de cualquier mantillo el porcentaje de $\mathrm{N}-\mathrm{NH}_{4}{ }^{+}$aumentó en los tratamientos AQ y AM con respecto a HC. La sequía incrementó el porcentaje de $\mathrm{N}^{-\mathrm{NH}_{4}}{ }^{+}$en el suelo con el abono de leguminosas mientras que no se modificó con respecto a $\mathrm{HC}$ en el caso de agregado de E. grandis (Figura 5.2).
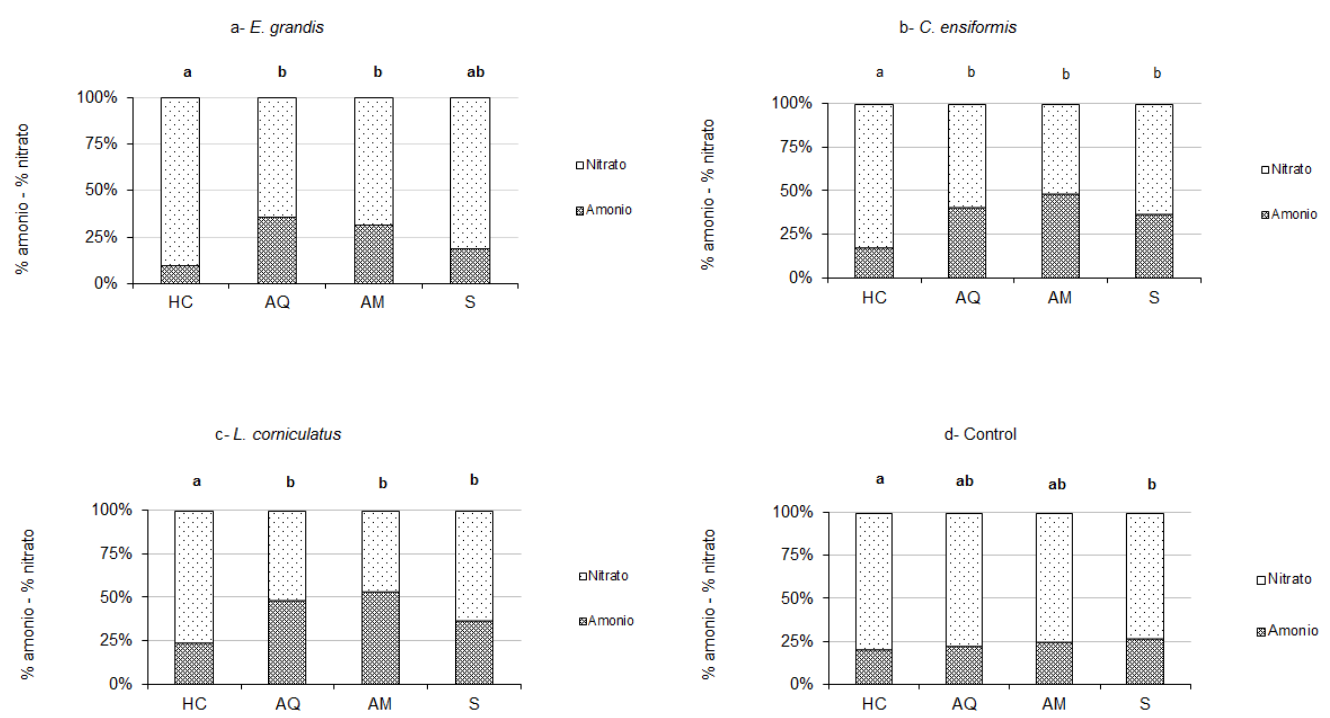

Figura 5.2. Aporte proporcional de $\mathrm{N}_{-} \mathrm{NO}_{3}{ }^{-}$y de $\mathrm{N}-\mathrm{NH}_{4}{ }^{+}$de los distintos abonos y el suelo control (sin abono). a) E. grandis; b) C. ensiformis; c) L. corniculatus; d) Control. HC: Humedad cte. AQ: Anegamiento quincenal. AM: Anegamiento mensual. S: Sequía. Con letras minúsculas se indica la significancia de la relación N-NO3-/N-NH4+ con datos acumulados de la última fecha, y sólo permiten comparar dentro de cada especie. 
Con o sin agregado de abonos, el tratamiento de HC siempre fue el que menor $\mathrm{N}-\mathrm{NH}_{4}{ }^{+}$aportó, seguido por $\mathrm{S}$, y posteriormente AQ y AM (Figura 5.2). Estas diferencias son muy apreciables en los tratamientos con abonos de eucaliptos y de leguminosas, y muy poco marcadas en los tratamientos sin aporte de abonos.

\subsubsection{Liberación de $\mathrm{P}_{-} \mathrm{PO}_{4}{ }^{3-}$ en los distintos tratamientos con y sin agregado de detritos}

En condiciones de $\mathrm{HC}$ no hubo diferencias significativas en la lixiviación de P$\mathrm{PO}_{4}{ }^{3-}$ con o sin agregado de detritos (Figura 5.3; Tabla 5.1). En los tratamientos AQ y AM, el agregado de abonos, tanto de eucalipto como de leguminosas, provocaron una lixiviación de $\mathrm{P}_{-} \mathrm{PO}_{4}{ }^{3-}$ significativamente menor al control que cuando no hubo agregado de detritos, en tanto que con $\mathrm{S}$ no hubo diferencias con el control (Figura 5.3; Tabla 5.1).

Los lisímetros con C. ensiformis y L. corniculatus produjeron lixiviaciones de P$\mathrm{PO}_{4}{ }^{3-}$ significativamente mayores, en el periodo de 280 días de ensayo, en condiciones de $\mathrm{HC}$ (aprox. $47 \mathrm{mg} \mathrm{P}-\mathrm{PO}_{4}{ }^{3-} / \mathrm{kg}$ suelo), seguidas por los tratamientos AQ y AM (cercanos a los $30 \mathrm{mg} \mathrm{P}_{-} \mathrm{PO}_{4}{ }^{3-} / \mathrm{kg}$ suelo $\sin$ diferencias significativas entre sí), y significativamente menores lixiviaciones con $\mathrm{S}\left(18 \mathrm{mg}\right.$ P-PO ${ }_{4}{ }^{3-} / \mathrm{kg}$ de suelo) (Figura 5.3; Tabla 5.1). Sin embargo, en ningún caso lixiviaron más $\mathrm{P}_{-} \mathrm{PO}_{4}{ }^{3-}$ que el suelo sin abono. En los tratamientos con residuos de E. grandis no hubo diferencias significativas entre ninguna de las condiciones hídricas ensayadas (Tabla 5.1). En los lisímetros sin agregado de detritos, la mayor lixiviación de $\mathrm{P}_{-} \mathrm{PO}_{4}{ }^{3-}$ se dio en los tratamientos AQ y $\mathrm{AM}$ (más de $60 \mathrm{mg} \mathrm{P}-\mathrm{PO}_{4}{ }^{3-} / \mathrm{kg}$ de suelo). En HC la lixiviación fue intermedia (42 mg P$\mathrm{PO}_{4}{ }^{3-} / \mathrm{kg}$ de suelo), mientras que en $\mathrm{S}$ fue menor aún (24 mg $\mathrm{P}_{-} \mathrm{PO}_{4}{ }^{3-} / \mathrm{kg}$ de suelo) (Figura 5.3, a-d; Tabla 5.1). 
a- $\mathrm{HC}$

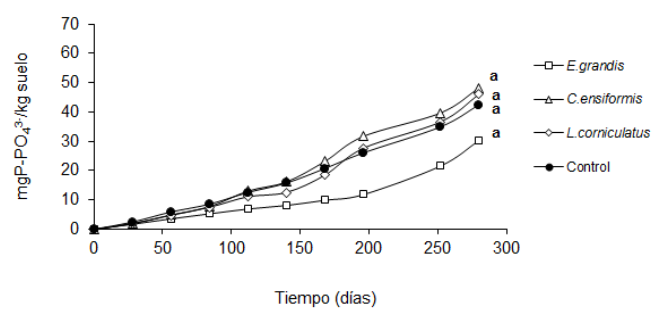

c-AM

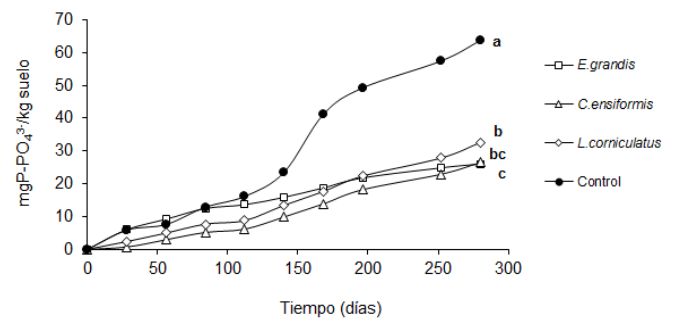

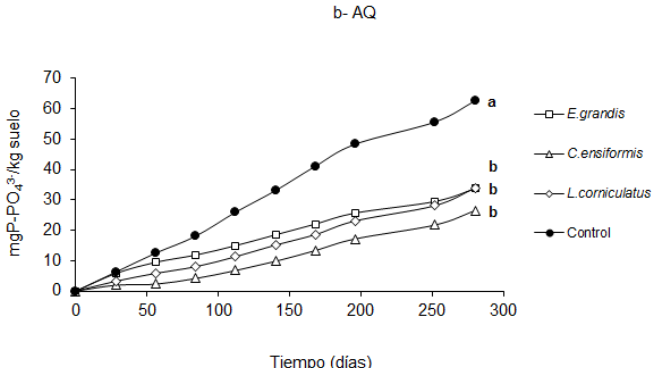

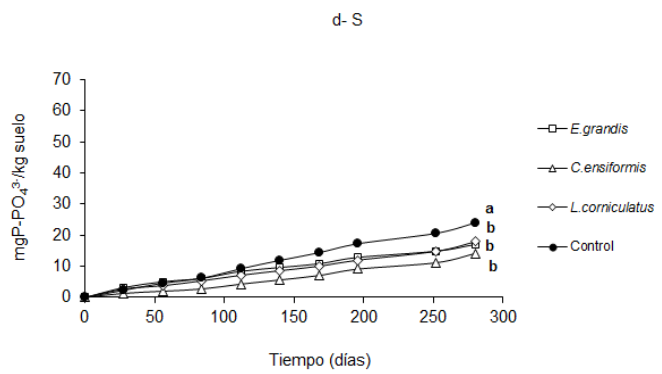

Figura 5.3. $\mathrm{P}_{-} \mathrm{PO}_{4}{ }^{3-}$ acumulado por $\mathrm{kg}$ de suelo para distintas condiciones hídricas. (a) Humedad constante; (b) Anegamiento quincenal; (c) Anegamiento mensual; (d) Sequía. Con letras minúsculas se indica la significancia en la última fecha con datos acumulados, y sólo permiten comparar dentro de cada tipo de disponibilidad de agua.

\subsection{DISCUSIÓN}

Los nutrientes presentes en la solución del suelo, provenientes tanto de la descomposición y mineralización de los residuos orgánicos incorporados en el suelo como de la materia orgánica presente previa a la incorporación de abonos, sufrirán diferentes cambios según sean las condiciones de humedad que prevalezcan en el suelo.

\subsubsection{Liberación de $\mathrm{N}-\mathrm{NH}_{4}{ }^{+}$y $\mathrm{N}-\mathrm{NO}_{3}{ }^{-}$al lixiviado con y sin agregado de detritos}

Se observa un patrón similar para todos los tratamientos en la lixiviación de N$\mathrm{NH}_{4}{ }^{+}$según sean las condiciones hídricas del suelo, ya que siempre se dan las máximas lixiviaciones en los tratamientos de alternancia sequía-inundación, seguidas por los de $\mathrm{HC}$ y las menores lixiviaciones en $\mathrm{S}$. Con aplicación de abonos de las leguminosas $L$. corniculatus y $C$. ensiformis, los suelos arcillosos dieron lugar a la lixiviación de N$\mathrm{NH}_{4}^{+}$de manera significativamente mayor al control cuando hubo ciclos de sequíainundación, probablemente debido a la acumulación de ${\mathrm{N}-\mathrm{NH}_{4}}^{+}$durante la inundación 
producto de la presencia de materia orgánica descomponible en las condiciones anaeróbicas reinantes en esos períodos, cuya mineralización es relativamente más baja, además de una reducción en la nitrificación, como se vio en el Capítulo 4. A diferencia de lo ocurrido con las leguminosas, con el abono de E. grandis el $\mathrm{N}_{-} \mathrm{NH}_{4}{ }^{+}$en el lixiviado fue siempre menor al control, independientemente de la condición hídrica evaluada, indicando posible inmovilización en la biomasa de microorganismos, de acuerdo con los resultados obtenidos en el Capítulo 2.

Con el $\mathrm{N}_{-} \mathrm{NO}_{3}{ }^{-}$hubo un panorama muy diferente según las condiciones hídricas ensayadas. La lixiviación de este nutriente fue mayor con el agregado de abonos únicamente en $\mathrm{HC}$, particularmente cuando se agregaron leguminosas como abono. En los tratamientos de alternancia de períodos de anegamiento y sequía se dio un importante contraste según se hubieran aplicado o no residuos vegetales. En los tratamientos sin abonos, hubo una liberación del $\mathrm{N}_{-} \mathrm{NO}_{3}{ }^{-}$al lixiviado significativamente mayor a los tratamientos con abonos. Este $\mathrm{N}^{-\mathrm{NO}_{3}}{ }^{-}$provino del suelo, y la liberación se produjo al inicio del ensayo. Estos resultados coinciden con los encontrados por Yadvinder-Singh et al. (1988), que observaron mayor liberación de nitrato en el suelo sin abono en comparación con el nitrato liberado del suelo con abono, ya que este nutriente es sujeto a la desnitrificación, dadas las condiciones anaeróbicas presentes durante los períodos de inundación, acompañadas con el adecuado suministro de $\mathrm{NO}_{3}{ }^{-}$, y la oferta de C disponible susceptible a la mineralización (Bijay-Singh et al. 1988, Rice et al. 1988, Beauchamp et al. 1989, Dendooven et al. 1996, Qian et al. 1997, Aulakh et al. 2000b). Yadvinder-Singh et al. (1988) reportaron un aumento en la tasa de desnitrificación por la adición de residuos orgánicos y residuos de cosecha en condiciones de anegamiento del suelo, siendo los abonos verdes los que provocaron la mayor disminución de la concentración de $\mathrm{N}^{-\mathrm{NO}_{3}}{ }^{-}$del suelo.

En condiciones de $\mathrm{S}$, semejante a lo ocurrido con el $\mathrm{N}_{-} \mathrm{NH}_{4}{ }^{+}$, se dieron las más bajas lixiviaciones de $\mathrm{N}_{-} \mathrm{NO}_{3}-$. En las condiciones de la Patagonia se ha indicado que la sequía limita la mineralización y especialmente la nitrificación, de manera que la forma predominante del $\mathrm{N}$ mineralizado es $\mathrm{NH}_{4}^{+}$(Mazzarino et al. 1998). En particular, la sensibilidad de los microorganismos y procesos que intervienen en el ciclo del $\mathrm{N}$ (amonificación, nitrificación, desnitrificación, inmovilización) a la sequía es en gran parte desconocida y requiere mayor investigación (Borken y Matzner 2009).

A pesar de que la duración del período de secado, al igual que el grado y la frecuencia del secado, son factores que afectan la respuesta microbiana del suelo, y por 
ende la mineralización de los nutrientes (Blackwell 2009), en esta Tesis no hubo diferencias significativas entre los tratamientos AQ y AM tanto para $\mathrm{N}^{-\mathrm{NH}_{4}}{ }^{+}$como para ${\mathrm{N}-\mathrm{NO}_{3}}^{-}$, y $\mathrm{PO}_{4}{ }^{3-}$, a excepción del abono de la especie C. ensiformis que lixivió más N$\mathrm{NH}_{4}{ }^{+}$en AM que en AQ (Tabla 5.1).

Las proporciones $\mathrm{N}^{-\mathrm{NO}_{3}}{ }^{-} / \mathrm{N}^{-\mathrm{NH}_{4}}{ }^{+}$a $\mathrm{HC}$ tuvieron los valores más elevados, ya que en suelos oxidados y con buen drenaje $\mathrm{el} \mathrm{NO}_{3}{ }^{-}$está presente en concentraciones más altas en comparación con el $\mathrm{NH}_{4}{ }^{+}$(Fageria 2009). En esta condición hídrica la proporción se mantuvo constante y sin diferencias significativas independientemente del agregado o no de residuos vegetales (Figura 5.3). Esta proporción presenta valores más bajos en los tratamientos con ciclos sequía-inundación, dado que si bien, bajo óptimas condiciones de temperatura y humedad en el suelo la nitrificación se produce a un ritmo muy rápido, como se trata de un proceso de oxidación y depende de la aireación del suelo (Fageria 2009), al alterar la aireación en estos tratamientos, se produjeron alteraciones en este proceso. El crecimiento más lento de los nitrificantes durante el período con menor humedad, posiblemente haya generado una población resultante que no sería suficientemente grande como para poder procesar todo el $\mathrm{NH}_{4}{ }^{+}$producido durante la etapa de humedad (Xiang et al. 2008). A estos efectos se sumaría la pérdida de $\mathrm{N}_{-} \mathrm{NO}_{3}{ }^{-}$por desnitrificación inducida en los suelos inundados y con abonos, y posiblemente la inmovilización de $\mathrm{N}_{-} \mathrm{NO}_{3}{ }^{-}$que podría ocurrir dado el aumento de la mineralización que ocurre en estas condiciones de alternancia de sequía-inundación.

\subsubsection{Liberación de $\mathrm{P}-\mathrm{PO}_{4}{ }^{3-}$ al lixiviado con y sin agregado de detritos}

En condiciones de humedad constante, de manera semejante a lo ocurrido en Capítulo 2 y 4 , los residuos agregados de L. corniculatus no significan un aporte de $\mathrm{P}$ al lixiviado ya que no hay diferencias con el control cuando se agregaron estos residuos. Con los residuos agregados de C. ensiformis, el comportamiento es semejante al ocurrido para L. corniculatus, y a diferencia de lo reportado en el Capítulo 2 para esta especie, no se observó inmovilización de P. Estas diferencias pueden explicarse por las características propias de cada tipo de material. Con el agregado de residuos de $E$. grandis en estas condiciones, la lixiviación de $\mathrm{P}$ no difiere a la del control. Asimismo, como fue detallado en el Capítulo 4, del análisis de los lixiviados de $\mathrm{N}_{-} \mathrm{NH}_{4}{ }^{+}$y N-NO${ }_{3}^{-}$ se deduce que están ocurriendo procesos de descomposición y mineralización por el aporte de residuos verdes en el suelo, por lo que el $\mathrm{P}$ proveniente de dichos abonos 
podría estar en formas de $\mathrm{P}$ orgánico lábil, sin ser detectadas por el método utilizado, y el contenidos de $\mathrm{P}_{-} \mathrm{PO}_{4}{ }^{3+}$ observado en los lixiviados provendría de la mineralización de la materia orgánica del suelo, presente tanto en los ensayos con o sin abonos.

La inundación del suelo tiende a hacer aumentar la disponibilidad de $\mathrm{P}$ para las plantas, tanto por la rápida difusión hacia las raíces y porque el $\mathrm{P}$ se hace más soluble como resultado de la disolución reductiva de los óxidos de hierro. Por el contrario, el drenaje de los suelos inundados resulta en una disponibilidad de P impedida (HugueninElie 2003). Asimismo, la mayoría de los autores coinciden en que el secado y posterior remojo del suelo induce la rápida mineralización de $\mathrm{P}$ durante el re humedecimiento (Chepkwony 2001, Butterly 2010), el cual deriva en parte por la lisis de las células bacterianas que éstas experimentan al sufrir el choque osmótico (Turner 2003). Asimismo, al retomar las condiciones de oxidación en un suelo que previamente estuvo sujeto a condiciones reductoras, ocurre la oxidación del Fe solubilizado durante la reducción, y precipitación bajo formas de óxidos finamente divididos, de gran superficie específica y baja cristalinidad, y con una elevada reactividad por el P. Esto determina que los fosfatos presentes en forma soluble en el suelo reaccionen con estas superficies, disminuyendo su solubilidad, y por consiguiente, su disponibilidad para la planta (Facultad de Agronomía, Universidad de la República 2015). En los tratamientos sin agregado de detritos las máximas liberaciones de $\mathrm{P}$ en el lixiviado se encontraron en los lisímetros sometidos a intervalos de inundación y sequía, donde el P presente en el suelo pudo haber sido solubilizado y liberado al lixiviado. Sin embargo, cuando se agregaron abonos vegetales en los lisímetros sometidos a alternancia sequía e inundación, la lixiviación de $\mathrm{P}$ fue menor que en los suelos sin abonos. Los ciclos de secado y humectación suelen estimular la actividad microbiana y la mineralización del C orgánico y N del suelo (Birch 1960, Haynes 1986, Harris 1988, Cabrera 1993, Bauhus y Khanna 1994), y se ha estimado que entre un 30-60\% del C de la biomasa microbiana puede ser liberada en el suelo durante un evento de re humedecimiento (Bottner 1985, Kieft et al. 1987). Por lo tanto, sería esperable un aumento en la actividad microbiana por el agregado de los abonos con la consecuente mineralización de $\mathrm{P}$, de modo que lo que podría estar ocurriendo es una inmovilización de este nutriente. Se sabe que el secado del suelo es particularmente biocida (Bottner 1985, Kieft et al. 1987, Van Gestel et al. 1993) y varios autores han demostrado claramente que el secado de los suelos aumenta su capacidad para adsorber P (Olsen y Court 1982, Haynes y Swift 1985). Esto causaría una disminución en la disponibilidad de P (Chepkwony 2001), como se 
observa en los tratamientos que fueron sometidos a sequía, donde se dieron siempre las más bajas lixiviaciones de $\mathrm{P}$.

\subsection{CONCLUSIÓN}

Los resultados encontrados en este Capítulo coinciden parcialmente con lo esperado a partir de la hipótesis planteada, la disponibilidad de agua y oxígeno en el suelo influye en la actividad microbiana del suelo, de manera que el déficit y el exceso de agua por periodos prolongados reducirán la tasa de descomposición de los detritos, ya que estas tendencias dependerán del tipo de abono incorporado y de qué nutriente se analice. Con respecto $1^{\circ}$ Predicción, periodos de anegamiento breves intercalados con buena disponibilidad de agua y oxígeno en el suelo aumentan la lixiviación de N y P a la solución del suelo, los resultados encontrados fueron contrapuestos a lo planteado, ya que en estas condiciones hubo inmovilización de nutrientes.

En el suelo arcilloso (Predicción 2), en condiciones de sequía disminuyó la lixiviación de amonio, nitrato y fosfato.

La incorporación al suelo de hojas de E. grandis reduce la disponibilidad de nitrato en la solución del suelo, a valores menores a los registrados cuando no se incorpora ningún material vegetal en condiciones de anegamiento, mientras que con sequía o humedad constante no varía respecto al control. La incorporación de $L$. corniculatus y $C$. ensiformis aumentan el nitrógeno disponible en la solución del suelo en forma de amonio bajo todas las condiciones de humedad del suelo, y de nitrato sólo en condiciones de humedad constante, ya que cuando existen períodos de anegamiento del suelo, hay tendencia a la disminución de la concentración de nitrato posiblemente por desnitrificación o inmovilización.

En condiciones de humedad constante, ninguna da las especies vegetales incorporadas como abonos aumentan la disponibilidad de $\mathrm{P}$ en el lixiviado en cantidad superior al producido en el suelo sin abono. Cuando las condiciones son de inundación alternada con sequía la cantidad de $\mathrm{P}$ en el lixiviado siempre es menor que la producida en el suelo sin abonos, de modo que el $\mathrm{P}$ mineralizado podría quedar retenido en el suelo por inmovilización. 


\section{CAPÍTULO 6}

\section{CRECIMIENTO DE PLANTAS JÓVENES DE EUCALYPTUS \\ GRANDIS EN SUELOS ARENOSOS CON RESIDUOS DE CUBIERTAS VERDES DE LEGUMINOSAS, DE E. GRANDIS Y \\ UREA}

\subsection{INTRODUCCIÓN}

Las plantaciones de Eucalyptus grandis en Argentina se encuentran principalmente en la región mesopotámica (SAGPyA 2001), y en la zona de Entre Ríos se cultiva principalmente sobre suelos de textura arenosa de baja fertilidad. La baja disponibilidad de nutrientes es el principal factor que controla la productividad de la especie (Keith 1997). Dentro de las estrategias posibles para mejorar la disponibilidad de nutrientes en el suelo en la región se encuentran la fertilización (Carpineti et al. 1995, Dalla Tea y Marcó 1996), y la retención de los residuos de cosecha (Corbeels et al. 2003, Graciano et al. 2008) y una alternativa actualmente no utilizada sería el intercultivo de la plantación con leguminosas que pueden emplearse como cubiertas verde (Corbeels et al. 2003, Mendham et al. 2004, Viera et al. 2013).

La urea es una forma habitualmente utilizada para fertilizar con $\mathrm{N}$, debido a su precio competitivo y alta concentración de $\mathrm{N}$ ( $46 \%$ de la masa), con reducidos costos de transporte y distribución. Sin embargo, parte del $\mathrm{N}$ de la urea se pierde en forma de amoníaco y a través de la conversión de amonio a nitrato (Miller y Cramer 2004). En la agricultura, la aplicación de urea es una práctica común que se puede utilizar para mejorar el contenido de amonio del suelo ya que fácilmente se hidroliza (Harper 1984), pero ella misma por tratarse de una molécula orgánica, no es de fácil acceso por parte de las plantas (Criddle et al. 1988).

Los resultados obtenidos en el Capítulo 2 sobre la provisión de $\mathrm{N}$ y $\mathrm{P}$ a la solución del suelo por distintas especies de leguminosas factibles de emplear como cubiertas verdes, y las ventajas que supondría tal uso de las mismas resultan promisorios ya que permiten advertir en qué suelos, tratamiento del mantillo foliar y especies se puede esperar lograr una mayor disponibilidad de nutrientes mediante 
cubiertas verdes herbáceas en la etapa inicial de plantación de eucaliptos en la zona de la Mesopotamia argentina. Sin embargo, la captura eficiente de los nutrientes del suelo por las raíces es en general un tema crítico para las plantas, dado que muchas veces los nutrientes tienen escasa disponibilidad y pueden ser deficientes para el crecimiento óptimo (Richardson et al. 2009). A pesar de que el suministro de nutrientes en el suelo a menudo es aumentado por la aplicación de fertilizantes o abonos verdes, la disponibilidad de dichos nutrientes se rige por una amplia gama de parámetros fisicoquímicos, por los factores ambientales y estacionales, y por las interacciones biológicas (Richardson et al. 2009). Estas variables ocurren particularmente en la rizósfera, la zona de suelo alrededor de las raíces de las plantas donde las propiedades del suelo están influenciadas por la presencia y la actividad de la raíz (Richardson et al. 2009). A través de la rizósfera los nutrientes del suelo se transfieren hacia la superficie de la raíz (Richardson et al. 2009).

En la rizósfera, las raíces de las plantas interactúan con diversas poblaciones de microorganismos del suelo que tienen implicancias significativas para el crecimiento y la nutrición (Curl y Truelove 1986, Bowen y Rovira 1999, Mukerji et al. 2006, Brimecombe et al. 2007). Dado que todos los organismos vivos necesitan casi los mismos nutrientes para su mantenimiento, crecimiento y reproducción, estas interacciones entre plantas y microorganismos suelen ser de competencia interespecífica por los nutrientes disponibles, la que resulta particularmente fuerte en la rizósfera (Kuzyakov y Xu 2013). No sólo la física y la química del suelo son relativamente complejas (Postma et al. 2014), sino también las interacciones de la raíz con los microorganismos del suelo (Giri et al. 2005). Las plantas modifican el ambiente para el desarrollo microbiano, y los microorganismos a su vez modifican la disponibilidad de los nutrientes para las plantas, e implican comunidades altamente complejas que funcionan en entornos muy heterogéneos (Giri et al. 2005).

Las plantas modifican las propiedades fisicoquímicas y la composición biológica de la rizósfera a través de una serie de mecanismos, como la liberación de carbono (C) fácilmente disponibles (Kuzyakov y Domanski 2000, Nguyen 2003). El C disponible es el principal factor que controla la microflora del suelo (Miller y Cramer 2004), conduciendo a un aumento en la abundancia (Newman y Watson 1977, Lynch 1990, Kapoor y Mukerji 2006, Saharan y Nehra 2011), actividad y crecimiento de los microorganismos en la rizósfera (Oger et al. 2004, Blagodatskaya et al. 2009, 2010), y por lo tanto reduce los nutrientes disponibles para las plantas mediante la captación e 
inmovilización microbiana (Zak et al. 2000). Al mismo tiempo, la movilización de nutrientes por el aumento de la descomposición microbiana de la materia orgánica del suelo, lleva a un aumento en el nivel de nutrientes mineralizados disponibles localmente. Esto disminuye la competencia. Los microorganismos poseen una captación sustancialmente más rápida inicial de todas las formas de N. Esto los convierte en ganadores a corto plazo en la competencia. Por el contrario, el corto ciclo de vida de los microorganismos y el flujo unidireccional de $\mathrm{N}$ desde el suelo a las raíces por flujo masal facilita la relocalización de $\mathrm{N}$ de los microorganismos a las raíces. Esto permite a las plantas ser ganadores en el largo plazo (Kuzyakov y Xu 2013).

Por lo tanto, no es suficiente conocer qué especie incorporada como mantillo aporta al lixiviado tal cantidad de nutrientes, ya que cuando estos nutrientes se encuentran en la rizósfera todas la interacciones antes mencionadas ocurren, y por lo tanto es necesario plantearse como objetivo la verificación de las consecuencias de los aportes de los residuos, tanto de leguminosas como de eucaliptos, sobre el crecimiento de las plantas jóvenes de eucaliptos. Posiblemente, los eucaliptos que crezcan en suelos arenosos y con material vegetal herbáceo de las especies que mineralizan más $\mathrm{N}$ (Capítulo 2), incorporado molido y mezclado con el suelo, crecerán más que en el tratamiento con residuos sobre la superficie del suelo mineral, y ambos tratamientos más que en el control. El objetivo de este capítulo es evaluar el efecto de la incorporación de residuos foliares de leguminosas, de eucaliptos y de urea sobre el crecimiento de plantas jóvenes de E. grandis en el suelo arenoso.

\section{Hipótesis:}

A) La forma de disposición de los abonos y su calidad química afecta la tasa de crecimiento de las plantas de E. grandis porque aportan diferente cantidad de N y P a la solución del suelo.

B) El agregado de urea aporta $\mathrm{N}$ más disponible a corto plazo para las plantas de eucaliptos que los residuos vegetales.

\section{Predicciones:}

- A-1) En suelos arenosos con residuos de leguminosas las plantas jóvenes de $E$. grandis crecen más que en aquellos con residuos de E. grandis.

- A-2) Cuando los residuos se agregan con mayor contacto con el suelo, los eucaliptos crecen más que cuando los residuos tienen menor contacto con el suelo. 
- B) Las plantas de E. grandis crecerán más con el agregado de urea que con la incorporación de leguminosas.

\subsection{MATERIALES Y MÉTODOS}

Se realizó un ensayo en condiciones controladas, en el cual se utilizaron un conjunto de macetas con suelo arenoso donde se imitaron los dos tratamientos de ubicación del mantillo foliar fraccionado de leguminosas y de eucalipto -aplicado sobre el suelo mineral, y mezclado con el suelo-, empleados en los microlisímetros de los capítulos anteriores, en las cuales se pusieron plantines de E. grandis y se midió su crecimiento.

\subsubsection{Diseño experimental}

Se utilizaron macetas de 4 litros de capacidad con suelo arenoso (Quartzipsamment Oxico, Entisoles) superficial traído de las plantaciones de E. grandis de Concordia, Entre Ríos. Como mantillo se utilizaron las especies de leguminosas Canavalia ensiformis, Cajanus cajan, Lotus corniculatus y Trifolium pratense, además del mantillo de E. grandis. La procedencia y recolección del material vegetal y el suelo se realizó como se describe en el Capítulo 2 (ver sección 2.2.2). La cantidad de material vegetal utilizado fue de $40 \mathrm{~g}$ por maceta, valor proporcional al utilizado en los microlisímetros de capítulos anteriores. El mismo se incorporó de dos modos diferentes: 1- cortados en trozos grandes y aplicados dentro de la maceta sobre la superficie del suelo (ES), y 2- groseramente molidos a mano, y mezclados con el suelo en un recipiente aparte para lograr una mezcla homogénea $(\mathrm{MgM})$. Luego se llenaron las macetas y se colocó una planta por maceta. Las semillas de las que se obtuvieron las plantas de E. grandis provenían de un Huerto Clonal del Plan de Mejoramiento Genético del INTA EEA Concordia. Al iniciar el ensayo tenían 2 meses de edad y 15 cm de altura. El diseño experimental consistió en un tipo de suelo, 2 modos de aplicación de los residuos, pertenecientes a 5 especies de plantas. Con material vegetal de C. ensiformis, C. cajan, L. corniculatus y E. grandis se realizaron ensayos agregando estos residuos en el suelo MgM y ES. Para la especie T. pratense sólo se ensayó la incorporación del material vegetal MgM. Además, se incorporó un tratamiento con 1 gramo de urea granulada (46-0-0) por planta, ya que es la dosis que permite la respuesta 
de la planta al crecimiento (Graciano et al. 2006b) de adecuado con el tamaño de maceta usado. Se realizaron 10 repeticiones para cada tratamiento con un control que consistió en 10 macetas con plantas de eucaliptos sin agregado de material vegetal ni fertilizante.

Las macetas ubicadas en invernáculo se mantuvieron con riego día por medio. Cada 4 días se alternó la posición de las macetas para minimizar el efecto "borde". Al inicio del ensayo se tomaron 10 plantines de $15 \mathrm{~cm}$ de altura las cuales fueron separadas en hojas, tallo y raíz, se midió su área foliar, y luego fueron secados a estufa y pesados. Asimismo, al finalizar el ensayo, 4 meses después, todas las plantas fueron cosechadas cuidadosamente, separadas en hojas, tallos principales, tallos secundarios, raíz principal y raíz secundaria. Luego de medir su área foliar, fueron secadas en estufa y pesadas. Para determinar peso seco, las muestras se secaron a $65{ }^{\circ} \mathrm{C}$ hasta peso constante y se pesaron con precisión $0,01 \mathrm{~g}$. El área foliar se determinó con un integrador de área (LICOR LI-3100, Nebraska) (Imagen 6.1 y 6.2).

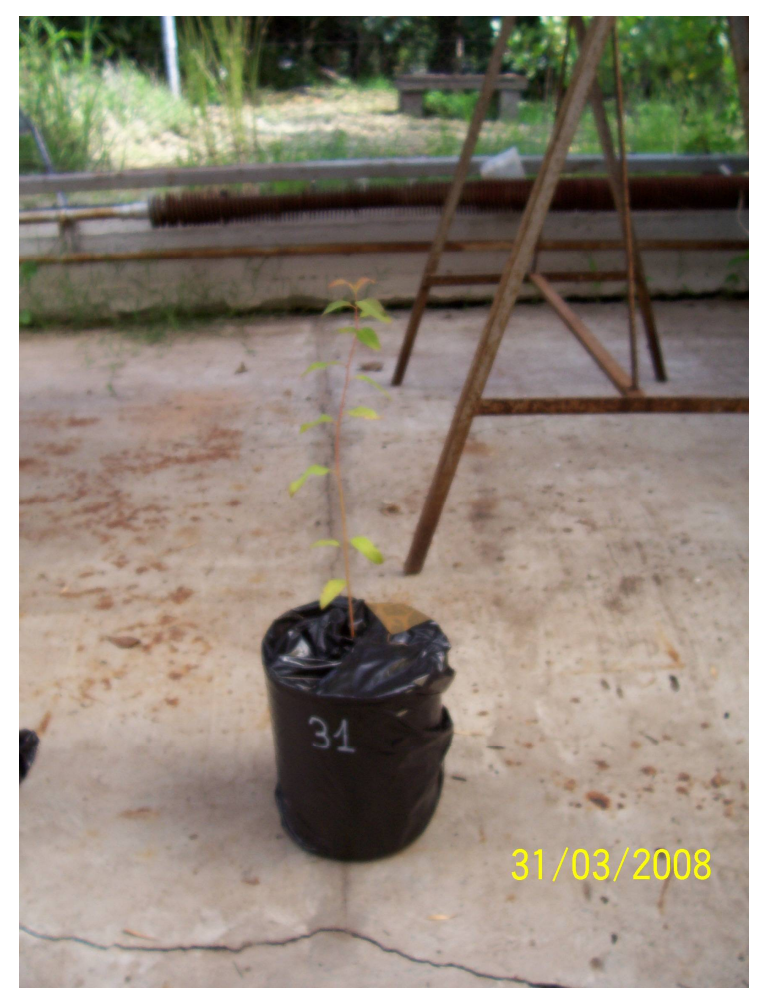

Imagen 6.1. Planta joven de E. grandis al inicio del ensayo 


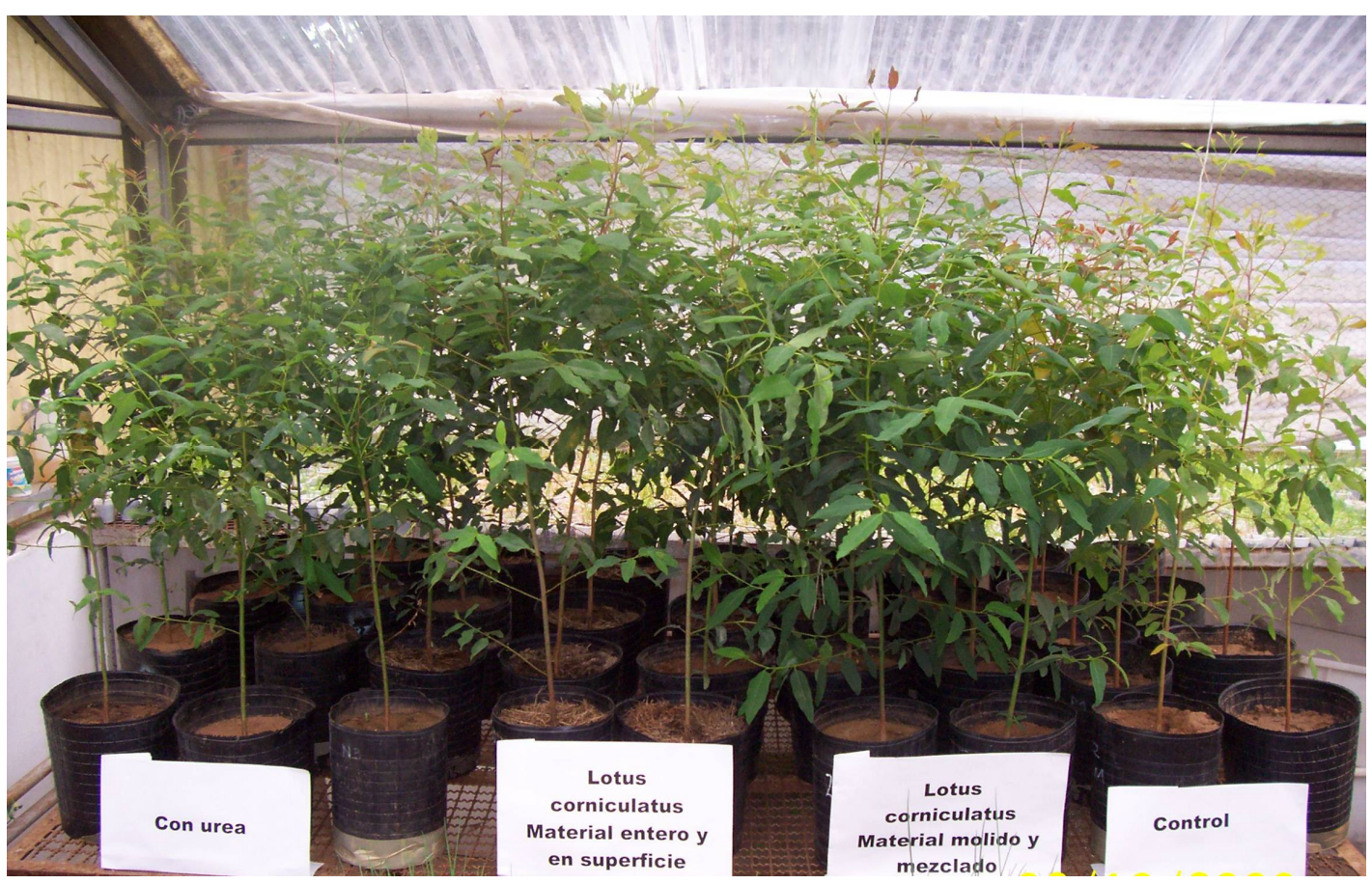

Imagen 6.2. Plantas de E. grandis con abonos de leguminosas, urea y control

\subsubsection{Análisis de los datos}

Los parámetros analizados fueron: área foliar (AF), expresado en $\mathrm{cm}^{2} /$ planta; peso seco total (PST), expresado en g/planta; peso seco aéreo (hojas + tallo)/peso seco raíces (PSA/PSR), expresados en g/planta; peso seco hoja, tallo y raíz al final del experimento, expresado en g/planta; y tasa de crecimiento relativa (RGR) medido en 1/semana; relación de área foliar (LAR) medido en $\mathrm{cm}^{2} / \mathrm{g}$; y tasa de asimilación neta (NAR) expresado en $\mathrm{g} / \mathrm{cm}^{2}$ semana $^{-1}$ entre el inicio del experimento y el final del mismo. Para calcular RGR, LAR y NAR se siguieron las fórmulas de Villar et al. 2004a. Los cálculos de RGR, LAR y NAR se realizaron con el macro de Hunt et al. (2002).

Para cada parámetro analizado se realizó la diferencia con el control (valor neto), considerando cada valor previamente ordenados de menor a mayor, dividiendo luego por el control para obtener la proporción y sentido (positivo o negativo) del cambio relativo. Para restar el control a cada valor se aparearon los datos al azar. El apareo de datos permite tener varios valores por tratamiento y poder realizar un ANOVA de los datos para poder comparar los tratamientos. Dentro de los métodos de apareo, el apareo al azar tiene la ventaja sobre el apareo ordenado que cumple con los preceptos de la 
estadística, aunque aumenta la variabilidad con respecto al apareo luego de ordenar por tamaño a los individuos (Causton y Venus 1981). El ordenamiento se realizó para poder sustraer a cada tratamiento el control, y poder realizar un análisis factorial.

$\Delta_{\text {T-C }}=$ Tratamiento - Control

Cambio relativo $=\Delta{ }_{\mathrm{T}-\mathrm{C}} /$ Control

\subsubsection{Análisis estadísticos}

Para cada parámetro se realizó un ANOVA para comparar cada tratamiento vs su control (Tabla 6.1). Luego, considerando los valores netos de cada parámetro analizado, se realizó un ANOVA considerando un solo factor con 10 niveles, que combina la especie y modo de aplicación del abono (E. grandis MgM; E. grandis ES; C. ensiformis $\mathrm{MgM}$; C. ensiformis ES; C. cajan MgM; C. cajan ES; L. corniculatus MgM; L. corniculatus ES; T. pratense MgM; y con Urea). Las medias se compararon mediante el test de Tukey $(\mathrm{p}<0,05)$.

\subsection{RESULTADOS}

\subsubsection{Efecto de la incorporación de los diferentes abonos}

En los tratamientos con agregado de L. corniculatus, C. cajan y C. ensiformis se observó un incremento del cambio relativo del área foliar con respecto a las plantas sin abonos, en tanto que en aquellos donde se agregó hojarasca de E. grandis y $T$. pratense no se observó un incremento de este parámetro (Tabla 6.1). En los tratamientos con agregado de urea se observó un incremento en el cambio relativo del área foliar de manera similar al observado con el agregado de C. cajan y C. ensiformis (Figura 6.1, a). 
Tabla 6.1. Diferencias para cada especie-tratamiento $v s$ el control, para cada parámetro analizado $(*=$ diferencia significativa, $\mathrm{p}<0,05$; --- diferencia no significativa, $\mathrm{p}>0,05)$; AF: cambio relativo del área foliar ( $\mathrm{cm}^{2} /$ planta); PST: cambio relativo del peso seco total ( $\left.\mathrm{g} / \mathrm{planta}\right)$; PSA/PSR: cambio relativo del peso seco aéreo sobre peso seco subterráneo; PSH: cambio relativo del peso seco hojas (g/planta); PSTallo: cambio relativo del peso seco tallo ( $\mathrm{g} / \mathrm{planta}$ ); PSR: cambio relativo del peso seco raíz (g/planta); RGR: cambio relativo de la tasa de crecimiento relativa (1/semana); LAR: cambio relativo de la relación de área foliar $\left(\mathrm{cm}^{2} / \mathrm{g}\right)$; NAR: cambio relativo de la tasa de asimilación neta $\left(\mathrm{g} / \mathrm{cm}^{2}\right.$ semana $\left.{ }^{-1}\right)$.

\begin{tabular}{|c|c|c|c|c|c|c|c|c|c|}
\hline & \multicolumn{9}{|c|}{ Parámetros analizados } \\
\hline & $\mathrm{AF}$ & PST & PSA/PSR & PSH & PSTallo & PSR & RGR & LAR & NAR \\
\hline E. grandis $\mathrm{MgM}$ & --- & $*$ & --- & $*$ & $*$ & $*$ & $*$ & $*$ & $*$ \\
\hline E. grandis $\mathrm{ES}$ & --- & --- & --- & --- & --- & --- & --- & --- & --- \\
\hline C. ensiformis $\mathrm{MgM}$ & $*$ & * & --- & $*$ & $*$ & $*$ & $*$ & --- & --- \\
\hline C. ensiformis ES & $*$ & $*$ & --- & $*$ & $*$ & $*$ & $*$ & --- & --- \\
\hline C. cajan $\mathrm{MgM}$ & $*$ & $*$ & --- & $*$ & $*$ & $*$ & $*$ & --- & $*$ \\
\hline C. cajan $\mathrm{ES}$ & $*$ & $*$ & --- & $*$ & $*$ & $*$ & * & --- & --- \\
\hline L. corniculatus $\mathrm{MgM}$ & $*$ & $*$ & $*$ & $*$ & $*$ & --- & * & $*$ & --- \\
\hline L. corniculatus ES & $*$ & $*$ & --- & $*$ & $*$ & $*$ & * & --- & --- \\
\hline T. pratense $\mathrm{MgM}$ & --- & $*$ & --- & $*$ & $*$ & $*$ & $*$ & --- & $*$ \\
\hline Urea & $*$ & $*$ & --- & $*$ & $*$ & --- & $*$ & $*$ & --- \\
\hline
\end{tabular}

En los tratamientos con la incorporación de urea y cualquiera de los abonos de leguminosas se observó un aumento en el cambio relativo en el peso seco total con respecto a las plantas sin abono (Figura 6.1, b), siendo el abono de las especies C. cajan, L. corniculatus y $C$. ensiformis los tratamientos donde se observaron los mayores cambios relativos en pesos secos. Con el agregado de E. grandis ES no se observó un incremento en el cambio relativo del peso seco de las plantas (Figura 6.1, b) y cuando se incorporó MgM se observó un menor cambio relativo de peso seco en las plantas que cuando no se agregó ningún abono. 

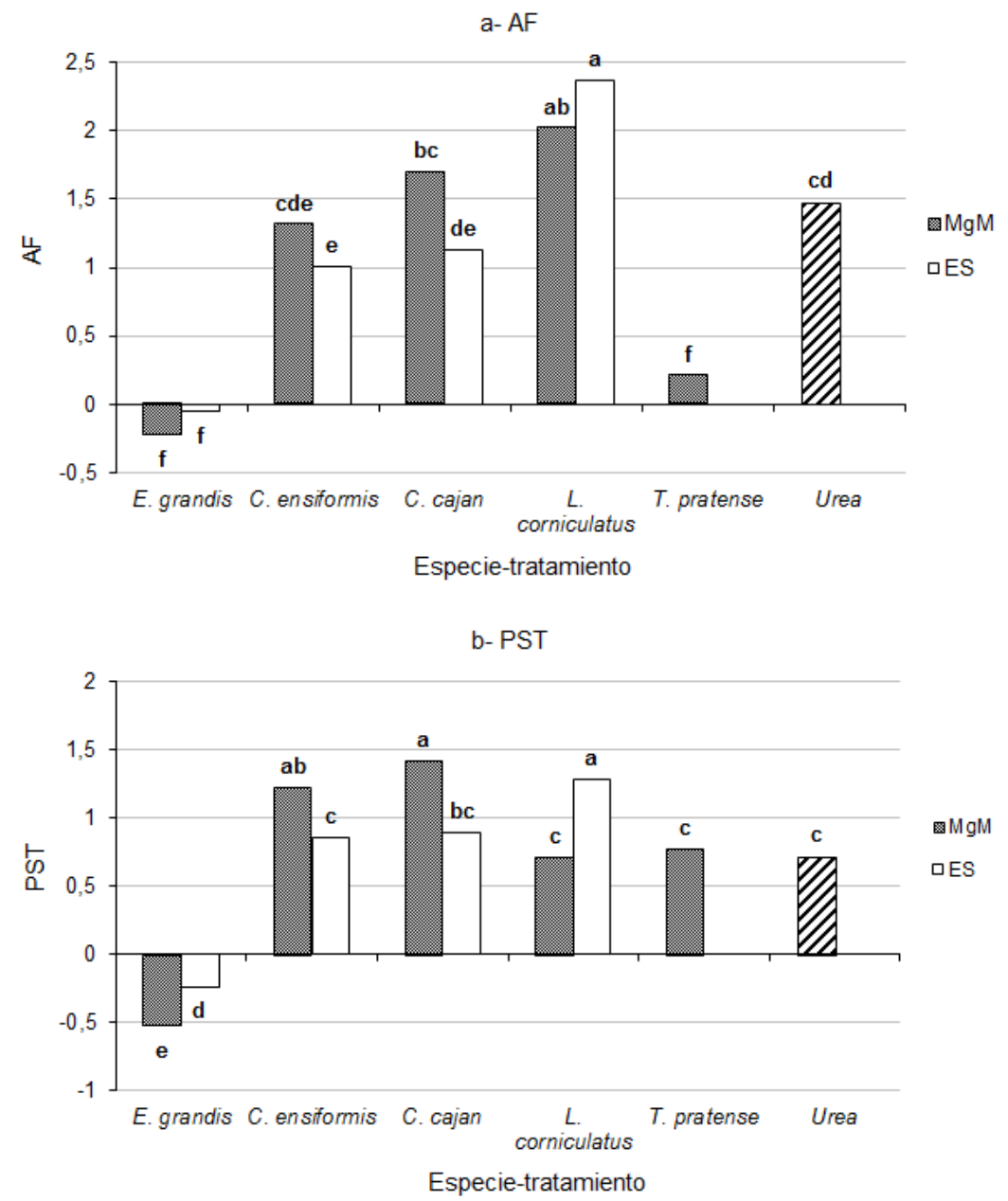

Figura 6.1. a- Cambio relativo en AF (área foliar) por especie y tratamiento. b- Cambio relativo del PST (peso seco total) por especie y tratamiento. MgM: material vegetal agregado molido groseramente y mezclado; ES: material vegetal agregado entero y superficial. Las letras minúsculas indican diferencias significativas $(\mathrm{p}<0,05)$ en cada variable y permiten comparar tanto especies como modo de aplicación.

Se observó un incremento en el cambio relativo en la partición de materia seca hacia la parte aérea (PSA/PSR) en las plantas de eucalipto que crecieron con el agregado de L. corniculatus $\mathrm{MgM}$, mientras que no se modificó con respecto al control con el agregado de los restantes abonos (Tabla 6.1 y Figura 6.2). 


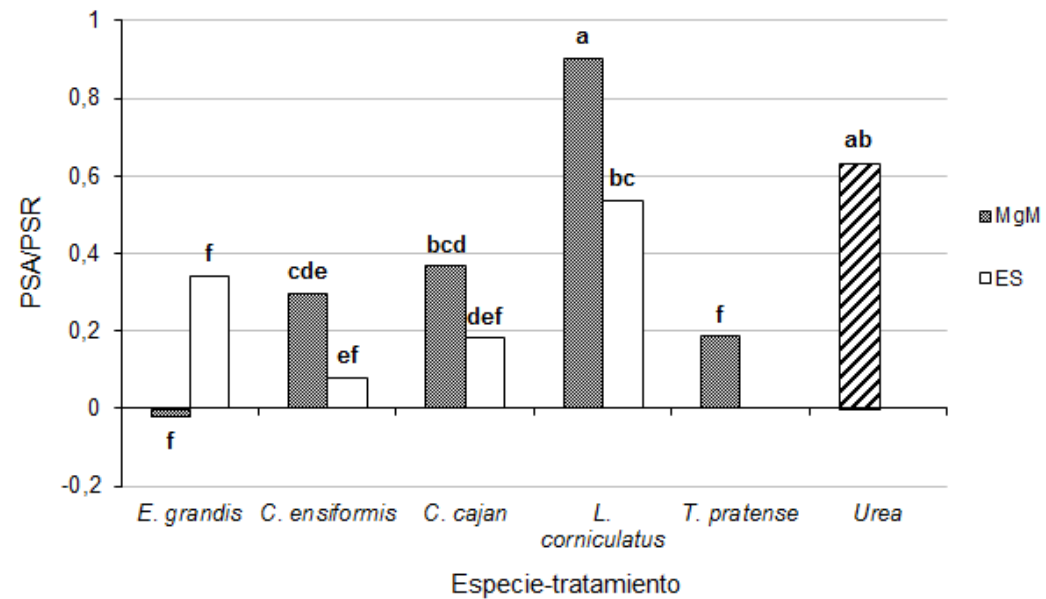

Figura 6.2. Cambio relativo del cociente PSA/PSR (peso seco aéreo/peso seco de raíces) por especie y tratamiento. MM: material vegetal agregado molido y mezclado; ES: material vegetal agregado entero y superficial. Las letras minúsculas indican diferencias significativas $(p<0,05)$ en cada variable y permiten comparar tanto especies como modo de aplicación.

El PS de hojas, tallo y raíz nos permite analizar la asignación de recursos a los órganos de la planta (Villar et al. 2004a) según el agregado o no de cada tipo de abono. En los eucaliptos que crecieron con abonos de L. corniculatus se observó un cambio relativo mayor en el desarrollo de hojas (Figura 6.3, a), mientras que en los eucaliptos que crecieron con abonos de C. cajan se observó un cambio relativo mayor en el desarrollo de tallos (Figura 6.3, b). En los eucaliptos que crecieron con agregado de residuos de E. grandis se observó un cambio relativo menor en el peso seco de hojas, tallo y raíz con respecto a las plantas control sin agregado de residuos (Figura 6.3 a, b y c). El agregado de todas las leguminosas provocaron los mayores crecimientos de raíces de los eucaliptos respecto a las plantas sin abono (Figura 6.3, c), mientras que el agregado de urea no generó un crecimiento de raíces significativamente diferente al control (Tabla 6.1). 
a-

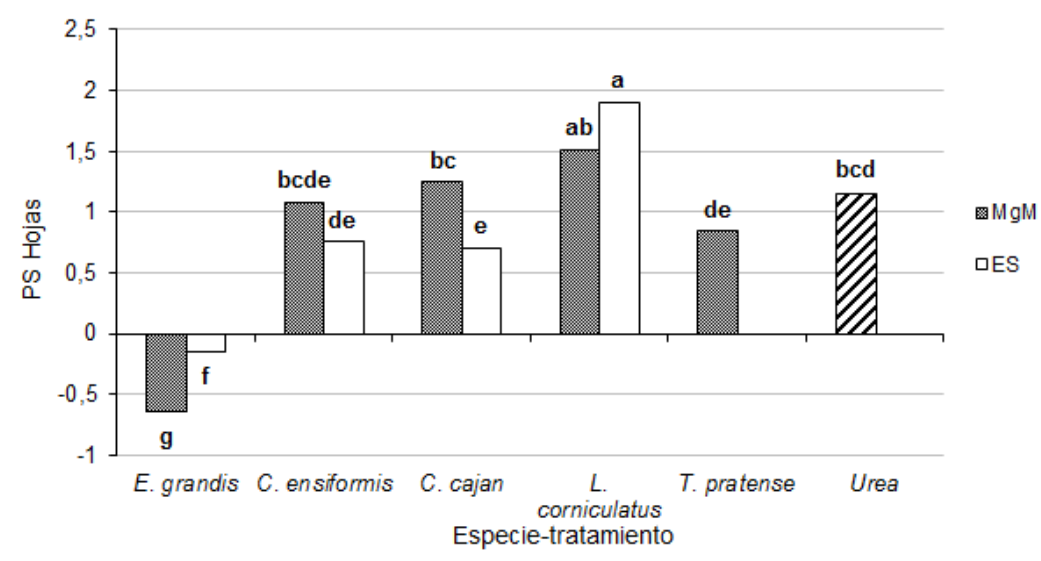

b-

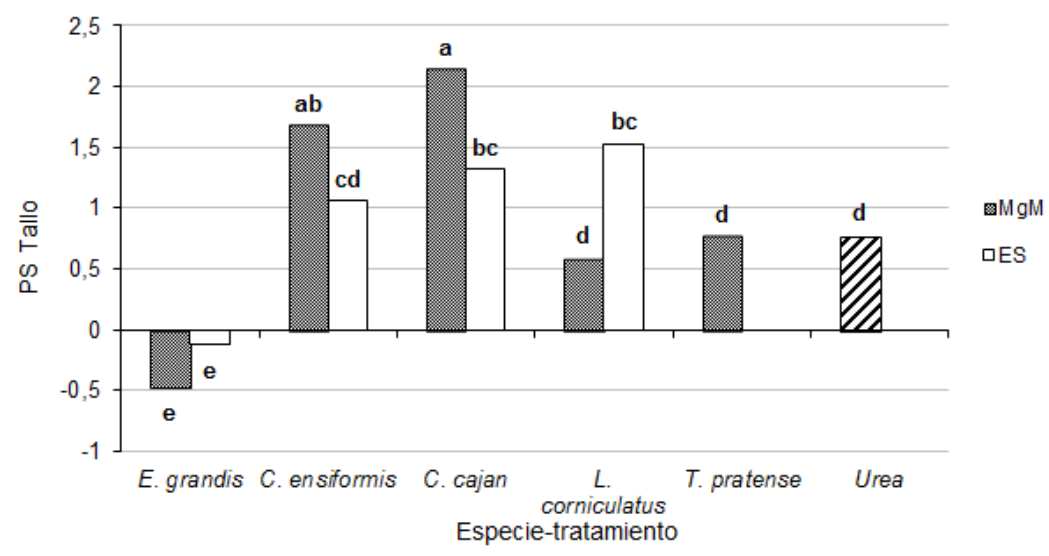

c-

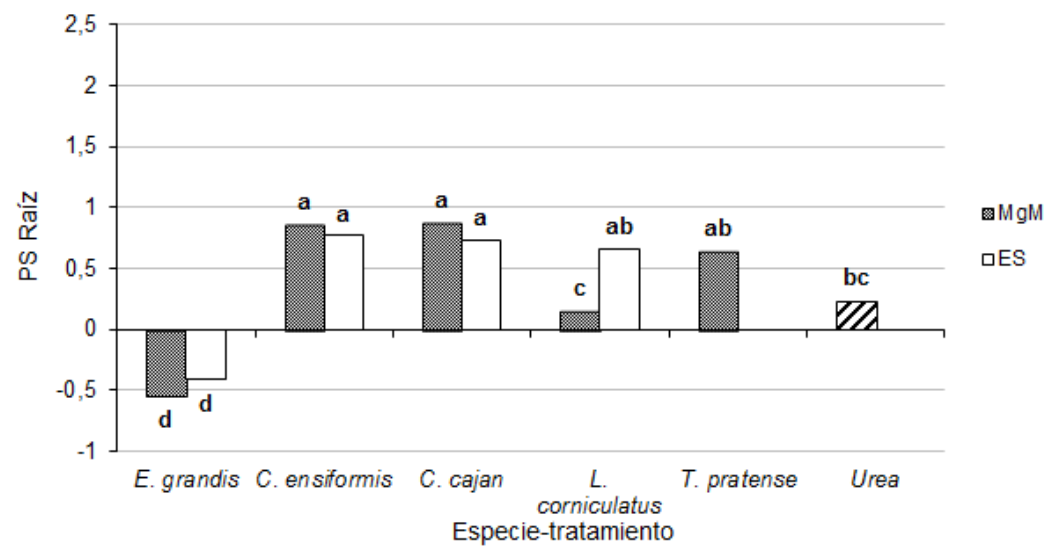

Figura 6.3. a- Cambio relativo en el PS Hojas (peso seco hojas) por especie y tratamiento. bCambio relativo en el PS Tallo (peso seco tallo). c- Cambio relativo en el PS Raíz (peso seco raíz). MgM: material vegetal agregado molido groseramente y mezclado; ES: material vegetal agregado entero y superficial. Las letras minúsculas indican diferencias significativas $(p<0,05)$ en cada variable y permiten comparar tanto especies como modo de aplicación. 
Con respecto a la tasa de crecimiento (RGR), en los eucaliptos que crecieron con el abono de todas las especies de leguminosas se observó un cambio relativo en RGR significativamente mayor que en los eucaliptos que crecieron sin abonos (Tabla 6.1), y sin diferencias significativas entre las especies (Figura 6.4). En las plantas que recibieron el abono de E. grandis se redujo el cambio relativo de RGR con respecto al control (Tabla 6.1). Para los eucaliptos que crecieron con abono de L. corniculatus $\mathrm{MgM}$, E. grandis $\mathrm{MgM}$ y urea se observó un cambio relativo en la relación de área foliar (LAR) mayores al control (Tabla 6.1 y Figura 6.4). Asimismo, se observó que el cambio relativo en la tasa de asimilación neta (NAR) en los plantines abonados con $C$. cajan $\mathrm{MgM}$ y $T$. pratense fue mayor que en aquellos plantines control, y menores al control en plantines con abono verde de E. grandis MgM (Tabla 6.1 y Figura 6.4).

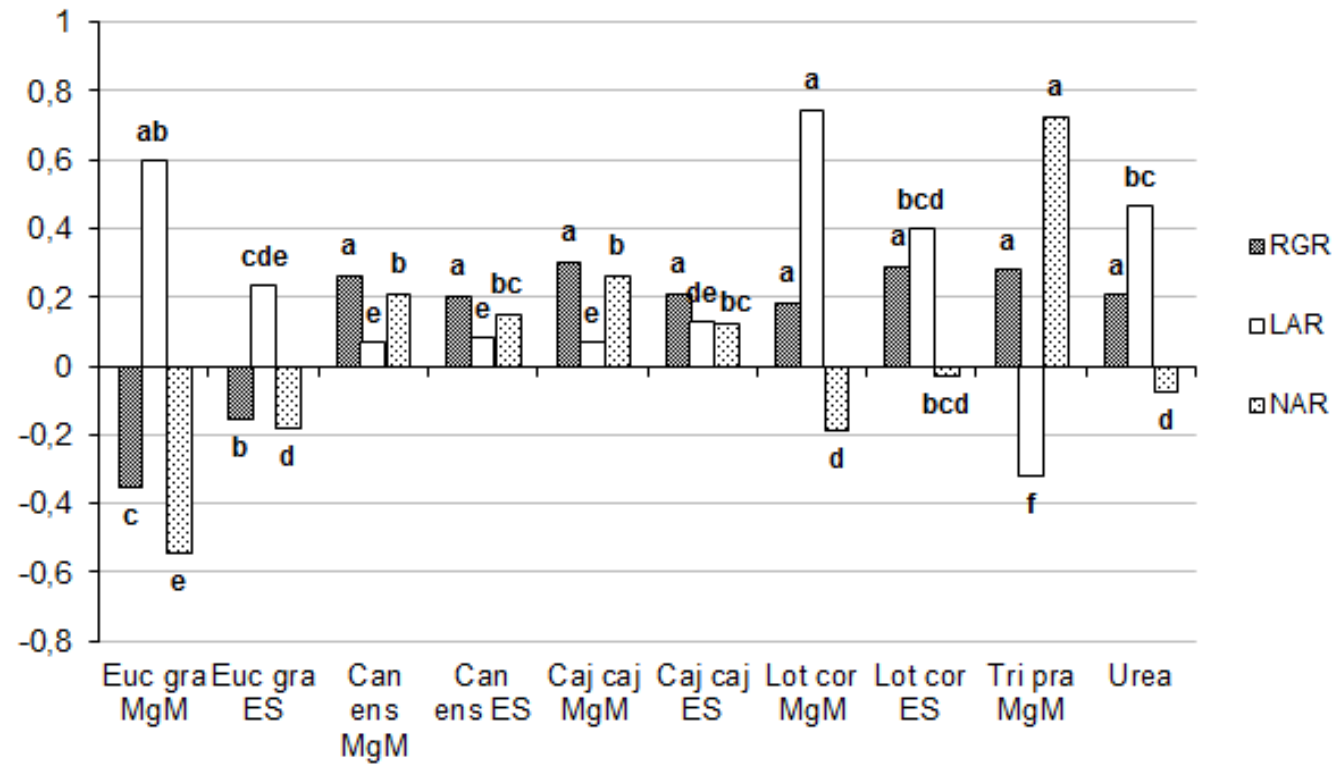

Figura 6.4. Cambio relativo en RGR (tasa de crecimiento), cambio relativo en LAR (relación de área foliar), y cambio relativo en NAR (tasa de asimilación neta) por especie y tratamiento. Euc gra: E. grandis; Can ens: C. ensiformis; Caj caj: C. cajan; Lot cor: L. corniculatus; Tri pra: T. pratense. MgM: material vegetal agregado molido groseramente y mezclado; ES: material vegetal agregado entero y superficial. Las letras minúsculas indican diferencias significativas $(p<0,05)$ en cada variable y permiten comparar tanto especies como modo de aplicación. 


\subsubsection{Efecto del modo de aplicación del abono}

Para ninguno de los eucaliptos que crecieron con abonos agregados se observó diferencias en el área foliar de los eucaliptos según el modo de aplicación utilizado (Figura 6.1, a), a excepción del agregado de C. cajan donde se observó que con el modo de aplicación $\mathrm{MgM}$ el área foliar de los eucaliptos fue significativamente mayor que cuando el residuo se agregó ES.

En cambio, en el análisis del peso seco total, siempre se observaron diferencias significativas según el modo de aplicación del material vegetal en los eucaliptos que crecieron con agregado de abonos (Figura 6.1, b). Cuando el abono agregado fue de las especies $C$. ensiformis y $C$. cajan el modo $\mathrm{MgM}$ redundó en un mayor peso seco de los eucaliptos, en tanto que para el abono de L. corniculatus el mayor peso seco se observó en los plantines que crecieron con este abono agregado al suelo ES. Asimismo, cuando se agregó E. grandis $\mathrm{MgM}$, se observó en las plantas jóvenes un peso seco significativamente menor al de las plantas control, en tanto que este mismo abono agregado ES no representó diferencias con los eucaliptos que crecieron sin abonos (Tabla 6.1 y Figura 6.1, b).

No se observaron diferencias en la partición de materia seca hacia el vástago con respecto a la raíz según el modo de incorporación de los residuos en los eucaliptos que crecieron con el agregado de abonos, excepto para los eucaliptos que crecieron con abono de L. corniculatus agregado MgM donde se observó más materia seca en el vástago que cuando este abono se agregó ES (Tabla 6.1 y Figura 6.2).

Con respecto al peso seco de hojas (Figura 6.3 a), se observaron diferencias en el modo de aplicación para los eucaliptos que crecieron con residuos de $C$. cajan y de $E$. grandis, siendo el modo MgM de C. cajan el que mayor peso seco de hojas produjo con respecto a ES en los plantines, mientras que el menor peso seco se observó en las plantas que crecieron con abonos de E. grandis agregados MgM en comparación con el agregado de dicho abono ES (Tabla 6.1). Con respecto al peso seco del tallo (Figura 6.3, b) de los eucaliptos que crecieron con abonos de C. cajan y $C$. ensiformis incorporado $\mathrm{MgM}$, se observaron diferencias significativas respecto al efecto de estos abonos agregado ES comparativamente que cuando se agregó $\mathrm{MgM}$, mientras que para el abono de L. corniculatus se observó un peso seco del tallo significativamente mayor cuando el abono se incorporó ES en comparación que cuando se agregó MgM. Para el caso del peso seco de la raíz (Figura 6.3, c), en el único caso donde se observaron diferencias 
significativas en el modo de aplicación de los residuos fue para los eucaliptos que crecieron más con el agregado de L. corniculatus ES con respecto a este abono agregado MgM.

Diferencias en el modo de aplicación del material se evidenciaron muy poco al analizar la tasa de crecimiento relativa de los eucaliptos (Figura 6.4), donde únicamente con el agregado de E. grandis se encontraron diferencias, ya que la incorporación de este abono $\mathrm{MgM}$ provocó en los plantines una tasa de crecimiento relativa significativamente menor que cuando se agregó ES (Tabla 6.1). Iguales tendencias se observaron con la tasa de asimilación neta. En el caso de la relación de área foliar, en los tratamientos con abonos agregados de E. grandis y L. corniculatus se observaron diferencias en el modo de aplicación de los mismos, donde con ambos abonos agregados MgM se observaron mayor LAR en los eucaliptos respecto al ES.

\subsection{DISCUSIÓN}

Las condiciones ambientales en la cuales crece una planta influencian su crecimiento, siendo la disponibilidad de abundante agua y nutrientes necesaria para que crezcan más rápido (Villar et al. 2004a). Esto pudo comprobarse al agregarse abonos de L. corniculatus y C. cajan analizando los parámetros de crecimiento de los eucaliptos peso seco total y área foliar. En el Capítulo 2 se había llegado a la conclusión de que el aporte al suelo de estos abonos generaba un lixiviado de $\mathrm{N}$ a la solución del suelo, el elemento mineral que las plantas requieren en más grandes cantidades y cuya deficiencia inhibe rápidamente el crecimiento (Taiz y Zeiger 2006). A pesar de que el $\mathrm{P}$ es un componente integral de las células de plantas y cuya deficiencia puede provocar retraso en el crecimiento en las plantas jóvenes (Taiz y Zeiger 2006), la carencia del aporte de este nutriente no pareció evidenciarse al analizar los parámetros peso seco total y área foliar. Sin embargo, las plantas difieren en su capacidad para adquirir P del suelo (Hanway y Olson 1981, Lorenz y Vittum 1980) debido a varios factores, como las diferencias en la morfología de la raíz (Barley 1970), las asociaciones de micorrizas (Föhse et al. 1991, Bolan 1991), y el efecto de la raíz de la planta sobre la química del suelo y la solubilidad del P (Ibrikci et al. 1994). Asimismo, existen en el suelo complejas interacciones entre las raíces de las plantas y los microorganismos, ya que ambos dependen de los mismos nutrientes y compiten fuertemente por ellos, sobre todo en la rizosfera (Kuzyacov y Xu 2013). Hasta el momento no está claro cómo las raíces y 
los microorganismos coexisten y se benefician mutuamente (Kuzyacov y Xu 2013), ya que a pesar de esta competencia, dependen unos de otros (Kuzyacov y Xu 2013). Lo que está claro es que las raíces de las plantas liberan $\mathrm{C}$ fácilmente disponible estimulando el crecimiento microbiano en la rizosfera, lo que lleva a la extracción de $\mathrm{N}$ adicional de la materia orgánica del suelo (Kuzyakov 2002, Luo et al. 2006), y esto aumenta el contenido de $\mathrm{N}$ en la biomasa microbiana (Hu et al. 2006a). Por lo tanto, la lixiviación de $\mathrm{P}$ de los abonos reportados en el Capítulo 2 puede tener un comportamiento diferente en presencia de las raíces de una planta. Mazzarino et al. (1997), en un experimento en invernadero con Lolium perenne compararon la disponibilidad de $\mathrm{N}$ y $\mathrm{P}$ para la planta a partir de residuos de la acuicultura con los resultados de anteriores incubaciones en laboratorio, y encontraron que a pesar de las tasas de mineralización de $\mathrm{N}$ similares para dos tipos de residuos orgánicos en incubaciones de laboratorio (13\%), uno de los residuos produjo un aumento en los rendimientos de materia seca de L. perenne de 60 a $100 \%$, debido a que la disponibilidad de $\mathrm{N}$ en presencia de la planta fue cinco veces mayor. Estos resultados demuestran que la mineralización de $\mathrm{N}$ estimada en incubaciones de laboratorio sin plantas puede no ser el mejor indicador de la disponibilidad de nutrientes a partir de residuos orgánicos.

Por otro lado, analizando el peso seco total de la planta, el abono agregado de $E$. grandis generó un crecimiento de los eucaliptos menores incluso que las plantas sin agregado de abonos, lo cual es consistente con las conclusiones del Capítulo 2, en el que se describió que las hojas de esta especie agregadas como mantillo reducen la lixiviación de $\mathrm{N}$ al suelo con respecto al control, lo que puede explicarse por la baja descomposición de sus hojas, de su alto cociente $\mathrm{C} / \mathrm{N}$, relacionadas con la posible inmovilización microbiana.

Haciendo un análisis con más detalle del peso seco total alcanzado por la planta, se pudo ver cómo esta invierte sus recursos para la formación de hojas -órganos con función de captación de luz y asimilación de dióxido de carbono-, tallo -órgano de sostén- y raíces -para la captación de agua y nutrientes minerales- (Villar et al. 2004a). El mayor peso seco y área foliar alcanzado por los eucaliptos que crecieron con abono de L. corniculatus son consistentes con la mayor asignación a hojas encontrada en las plantas que crecieron con este abono, ya que una planta que invierte más en tejido foliar tendrá un crecimiento más rápido (Villar et al. 2004a). Diversos estudios con especies leñosas han encontrado una correlación positiva entre la proporción de hoja -respecto a 
tallo y raíz- y la tasa de crecimiento (Cornelissen et al. 1996, Wright y Westoby 2000, Antúnez et al. 2001). Los eucaliptus que recibieron la aplicación de C. cajan, la especie que agregada como abono generó a la par de L. corniculatus los más altos pesos secos alcanzados, tuvieron la mayor asignación de biomasa en el tallo, lo cual puede explicarse ya que la selección favorece una alta inversión de biomasa en hojas y también en tallos (Hara 1984). También se ha encontrado que la tasa de crecimiento está correlacionada negativamente con la proporción de biomasa asignada a raíz (Antúnez et al. 2001), ya que existe un compromiso para la planta entre una mayor asignación de biomasa a hojas, con la consecuente mayor capacidad para captar luz y dióxido de carbono, redundando en su mayor tasa de crecimiento o bien, en una mayor asignación de biomasa a las raíces, consiguiendo así captar más agua y nutrientes minerales del suelo, pero a expensas de un menor crecimiento (Richardson et al. 2009). El mayor desarrollo de las raíces es, por lo tanto, importante para la exploración eficaz de suelo y la interceptación de nutrientes (Tilman 1984, Lynch 1995). En general, el tamaño de la raíz con relación al resto de la planta aumenta cuando N es limitante (Chapin 1980, Ericsson 1995, Miller y Cramer 2004), característica que se observó en este Capítulo, ya que todos los tratamientos que crecieron en el suelo sin abono asignaron más biomasa a raíces que cuando se les agregaron abonos, con la consecuente entrada de nutrientes al suelo. Sin embargo, con el abono de L. corniculatus y de urea estas diferencias fueron significativas, evidenciando el aporte nitrogenado en comparación con los otros abonos. En el Capítulo 2 se encontró asimismo que el abono de E. grandis provocaba un suministro de $\mathrm{N}$ menor al del suelo sin abono, lo cual fue consistente con el menor peso seco de hojas, tallo y raíz de las plantas que crecieron con este abono respecto al control observado en este Capítulo. Analizando la asignación de biomasa a los distintos órganos, para hojas y raíz el comportamiento de las plantas con este abono fue el esperado para un suministro de $\mathrm{N}$ más bajo aún que cuando no está presente este abono, con valores menores al control. Para tallo en cambio hubo una mayor asignación que las plantas sin abonos. Con el agregado de urea las plantas tuvieron mayor peso seco en hojas, tallo y raíz que el control, asignando a hojas y tallo más que el control y menos a raíz, lo que representa una respuesta típica de las plantas al incremento en la disponibilidad de $\mathrm{N}$ en el suelo (Graciano et al. 2006b). En concordancia al gran desarrollo de hojas y bajo desarrollo de raíces que obtuvieron las plantas de eucaliptos que crecieron con L. corniculatus y urea, se encontraron en esas plantas los mayores valores de PS aéreo/PS raíces, aunque fue significativo únicamente para L. corniculatus. 
Mientras que los estudios sobre las relaciones planta-nutrientes a menudo se centran en el $\mathrm{N}$, ya que se requiere en mayor cantidad para la función fotosintética (Field y Mooney 1986, Wright et al. 2004) y se considera el nutriente más universalmente limitante para la ganancia de C (Chapin et al. 1987, Schulze et al. 1994), el P también desempeña un papel primario en el metabolismo de la planta, y hay evidencia de que la eficiencia en la utilización de $\mathrm{P}$ y $\mathrm{N}$ están estrechamente vinculados. Una disminución en la disponibilidad de un nutriente puede conducir a un uso menos eficiente del otro (Lajtha y Klein 1988, Reich y Schoettle 1988, Reich et al. 1994, Raaimakers et al. 1995). A pesar de no haberse encontrado en el Capítulo 2 evidencia de un aporte en P por los abonos de L. corniculatus y C. cajan, y que el aporte de urea es exclusivo de $\mathrm{N}$, en este Capítulo no se encontraron evidencias de la posible limitación del crecimiento de las plantas por $\mathrm{P}$ al añadirse los mencionados abonos, ya que el peso seco total y peso seco por órgano fue mayor en las plantas que recibieron abonos. Esto pudo deberse a que la interacción de los microorganismos del suelo con las raíces de las plantas haya redundado en un aporte de $\mathrm{P}$ para los eucaliptos, como se mencionó más arriba.

$\mathrm{Al}$ analizarse las tasas de crecimiento (RGR), y sus componentes morfológico, la relación de área foliar (LAR), y fisiológico, la tasa de asimilación neta (NAR) (Villar et al. 2004a), se encontraron por un lado mayores tasas de crecimiento respecto al control con el agregado de cualquiera de las leguminosas y de urea, pero sin hallar un abono que provocara una tasa de crecimiento relativo significativamente mayor entre distintos abonos. Por otro lado, hubo diferencias en cuanto a LAR y NAR, ya que por ejemplo, con el agregado de L. corniculatus y de urea hay un valor muy alto de LAR, pero la baja NAR podría estar evidenciando una carencia de $\mathrm{P}$ que se hace limitante al estar el $\mathrm{N}$ más disponible. En cambio con los abonos de C. cajan y C. ensiformis, a pesar de tener valores más bajos de LAR, las plantas abonadas fueron más eficientes que las plantas sin abonos ya que NAR es el resultado del balance neto entre las ganancias por la tasa de fotosíntesis y las pérdidas por las tasas de respiración de hojas, tallos y raíces, además de la distribución de biomasa a diferentes órganos, la composición química y la formación de área foliar (Poorter 1989). Esta mayor eficiencia posiblemente refleja que la incorporación de esos abonos brinda a las plantas un balance de nutrientes adecuado y la capacidad fotosintética de cada hoja es elevada, por lo que puede sostener una alta tasa de crecimiento con baja inversión de carbono en hojas. Por otro lado, las RGR de las plantas que crecieron con abonos de L. corniculatus, urea, C. cajan y C. ensiformis 
resultaron semejantes, a pesar de que las plantas que crecieron con los dos primeros abonos tuvieron NAR menores a las de plantas sin abonos y con los dos segundos abonos valores mayores a las plantas control. Sin embargo hubo grandes diferencias en LAR, parámetro que influyó de manera más grande en RGR. Existe un acuerdo casi general en que el componente morfológico, y en particular el área específica foliar, es el factor más importante tanto para las plantas herbáceas (Poorter 1989, Poorter y Remkes 1990, Garnier 1992, Lambers y Poorter 1992, Marañón y Grubb 1993, Garnier y Laurent 1994, Villar et al. 2004b), como para las leñosas (Reich et al. 1992, Huante et al. 1995, Cornelissen et al. 1996, Antúnez et al. 2001). Este rasgo aparentemente simple de la planta puede explicar en ocasiones hasta el $80 \%$ de la variación en sus tasas de crecimiento, a pesar de que otros factores, como la proporción de biomasa distribuida en los diferentes órganos, las tasas de fotosíntesis y respiración, o la composición química de la hoja, también deben intervenir de forma decisiva en las tasas de crecimiento (Villar et al. 2004a). Aunque se han realizado varios estudios de análisis de crecimiento de especies leñosas, no se ha encontrado un único parámetro que esté asociado con el crecimiento más rápido (Atkin et al. 1998), y mientras que algunos trabajos concluyeron que la RGR está correlacionada positivamente con el área foliar por unidad de masa de hojas (Cornelissen et al. 1996, Atkin et al. 1998, Wright y Westoby 2001), en otros la variación en RGR está más estrechamente relacionado con las diferencias en NAR (Veenendaal et al. 1996, Ryser y Wahl 2001, Shipley 2002).

Finalmente, las plantas que crecieron con abono de E. grandis, tuvieron tasas de crecimiento relativo menores que las plantas sin abonos, ya que si bien tuvieron altos valores de LAR, sus NAR fueron muy bajos, causados posiblemente por la gran demanda de $\mathrm{N}$, ya que el abono de E. grandis causa un menor suministro de $\mathrm{N}$ en la solución del suelo que el control (Capítulo 2).

Respecto al modo de aplicación del material vegetal, y de manera semejante a lo concluido en el Capítulo 2, no existe un patrón general que se repita de modo igual para todos los parámetros analizados. En general el modo de aplicación MgM parece acelerar los procesos o generar valores con mayores diferencias en la mayoría de los abonos, posiblemente por el mayor contacto del sustrato con el suelo, ya que el cociente del área de la superficie del residuo vegetal por la masa del suelo se incrementa (Angers y Recous 1997).

La urea generó crecimientos en las plantas menores a los encontrados con el agregado de L. corniculatus y C. cajan, ya que los abonos verdes, además de ser fuente 
de $\mathrm{N}$ y otros nutrientes, presentan un "efecto priming", mejorando las condiciones físicas del suelo por el aumento de la materia orgánica y el aumento de la actividad microbiana (Muraoka et al. 2001). En un estudio realizado por Muraoka et al. (2001) compararon el efecto del agregado de abonos verdes y de urea por separado y juntos, y concluyeron que los abonos verdes proporcionaron mejor uso del $\mathrm{N}$ que el fertilizante.

A pesar de que con el agregado de L. corniculatus y C. cajan no se verificó en el Capítulo 2 un aporte de $\mathrm{P}$ inorgánico a la solución del suelo, podría haber un aporte de $\mathrm{P}$ orgánico, que podría estar siendo utilizado por las plantas (Turner y Haygarth 2000), o podría estar ocurriendo la mineralización de P impulsado por el "efecto priming".

La especie E. grandis tiene una gran capacidad intrínseca para obtener N, y posiblemente $\mathrm{P}$ del suelo arenoso, cuando estos nutrientes son agregados por medio de la incorporación de abonos orgánicos como por fertilizantes inorgánicos, manifestando crecimientos diferenciales. Sin embargo el costo ambiental no es igual, ya que el agregado de abonos orgánicos viene acompañado de una serie de ventajas, mientras que la aplicación excesiva e inapropiada de fertilizantes comerciales pueden ocasionar graves problemas ambientales y ecológicos, como fueron descriptos en el Capítulo 1. La utilización de abonos verdes, además de aportar los nutrientes que los cultivos requieren, produce una serie de beneficios tales como recuperar la fertilidad del suelo, aumentando del contenido de materia orgánica, de la capacidad de intercambio catiónico y de la disponibilidad de macro y micronutrientes; formación y estabilización de agregados; mejoramiento de la infiltración de agua y aeración; disminución diurna de la amplitud de la variación térmica; control de nemátodos y, en el caso de leguminosas, incorporación al suelo de N, efectuado a través de la fijación biológica (Igue 1984). Asimismo, Muraoka et al. (2001) encontraron que los abonos verdes proporcionaron un mejor uso del $\mathrm{N}$ del fertilizante agregado junto a los abonos verdes, favoreciendo una eficiencia de hasta $79 \%$.

\subsection{CONCLUSIÓN}

Los resultados encontrados dan apoyo a la Hipótesis A: La forma de disposición de los abonos y su calidad química afecta la tasa de crecimiento de las plantas de E. grandis porque aportan diferente cantidad de $N$ y P a la solución del suelo, ya que por un lado las plantas jóvenes de E. grandis crecieron más con residuos de leguminosas que con residuos de E. grandis (Predicción A-1), y a su vez, cuando los residuos se 
agregaron con mayor contacto con el suelo, los eucaliptos crecieron más (Predicción A2).

Las leguminosas L. corniculatus y C. cajan son las que agregadas como abonos, permiten un mayor crecimiento de los eucaliptos: en el caso de L. corniculatus con su gran aporte de $\mathrm{N}$ que permite un gran desarrollo de hojas y en consecuencia una mayor tasa de crecimiento, aunque con baja tasa de asimilación (NAR); para C. cajan generando una mayor tasa de asimilación (NAR). A pesar de que en el Capítulo 2 el agregado de las dos especies aportaron nutrientes al lixiviado no siempre con diferencias significativas respecto del control, lo cual en parte puede atribuirse al uso de los nutrientes por los microorganismos, las plantas de eucaliptos con estos abonos orgánicos crecieron diferencialmente más, lo que sugiere que la competencia con los microorganismos no parece resultar en efectos negativos sobre los eucaliptos.

El abono de E. grandis ocasionó un crecimiento menor de los eucaliptos respecto al suelo sin abono generado por el propio mantillo de E. grandis, posiblemente por el menor aporte de $\mathrm{N}$ a la solución del suelo que se produce en presencia de dicho abono, que podría ser causado dada por la gran avidez de los microorganismos por los nutrientes que aumentan su inmovilización, produciendo una competencia por $\mathrm{N}$ y $\mathrm{P}$ con los plantines, que en estas condiciones crecen menos. Este efecto depresivo en el crecimiento fue de mayor magnitud si el material se incorporó molido y mezclado ya que aumenta la superficie de ataque del residuo por parte de los microorganismos haciendo más intensa la competencia.

Los resultados encontrados apoyaron parcialmente la Hipótesis 2: El agregado de urea aporta $N$ más disponible a corto plazo para las plantas de eucaliptos que los residuos vegetales, ya que las plantas de E. grandis tuvieron un crecimiento intermedio comparativamente con las que crecieron con las especies de leguminosas, ya que con algunas especies agregadas como abono los eucaliptos crecieron más, y en otros casos menos que con urea, ya que la presencia de plantas no sólo aumenta la actividad microbiana, con la consiguiente mineralización de nutrientes, sino que mejora las condiciones físicas del suelo, dando a la raíces de las plantas beneficios adicionales al simple aporte de N. Teniendo en cuenta el creciente interés en la sustentabilidad de los sistemas agrícolas y forestales más allá de la producción, estos resultados resultaron promisorios, ya que con algunos abonos verdes, además de aportar al suelo los nutrientes que las plantas necesitan, aportarían sus múltiples ventajas al sistema sueloplanta. Por el contrario, la utilización de urea como fertilizante no asegura el máximo 
crecimiento en los eucaliptos y su utilización prolongada trae aparejada una serie de prejuicios para el sistema suelo-planta. 


\section{CAPÍTULO 7}

\section{CRECIMIENTO DE PLANTAS JÓVENES DE EUCALYPTUS GRANDIS EN SUELO ARCILLOSO CON RESIDUOS DE CUBIERTAS VERDES DE LEGUMINOSAS EN CONDICIONES DE CAPACIDAD DE CAMPO Y SEQUÍA}

\subsection{INTRODUCCIÓN}

En los ecosistemas terrestres la limitación de recursos es reconocida como un problema crítico en el crecimiento de la planta, el desarrollo y la reproducción (Smith et al. 1997, Hooper y Johnson 1999, Drenovsky y Richards 2004, White y Beadle 2004). Cuando la limitación de recursos altera el equilibrio fisiológico de la planta se produce el estrés (Shao et al. 2008), provocando una amplia variedad de respuestas en las plantas, que van desde la alteración de la expresión génica y el metabolismo celular, hasta cambios en la tasa de crecimiento y la productividad de la planta (Shao et al. 2008).

El contenido de nutrientes es uno de los atributos más importantes de la calidad de la planta (Ritchie 1984). Se ha demostrado una correlación lineal entre la concentración de $\mathrm{N}$ y el crecimiento de las plántulas en especies de árboles (Ingestad y Kahr 1985). El N y el P son importantes nutrientes para la estructura, los procesos y la función de los ecosistemas, ya que limitan la producción de biomasa de la planta (Vitousek y Howarth 1991, Hu y Schmidhalter 2005). Por lo tanto, cuando la disponibilidad de estos nutrientes es limitante, prácticas como la fertilización estimulan, potencialmente, el crecimiento de las plantas (Wu et al. 2008). Sin embargo, la capacidad de un árbol para responder a la fertilización es a menudo limitada por otras condiciones ambientales, particularmente la disponibilidad de humedad del suelo (Fisher y Mexal 1984). Debido a que la adquisición de nutrientes por las raíces depende en gran medida del suministro de nutrientes a la superficie de las raíces, los factores que afectan la absorción de agua por las raíces influyen también en la absorción de $\mathrm{N}$ de la raíz (Inselsbacher y Näsholm 2012).En los ecosistemas terrestres a menudo se 
producen períodos de déficit de agua en el suelo y/o la atmósfera durante el ciclo de vida de la planta, incluso fuera de las regiones áridas y semiáridas, según lo informado para bosques caducifolios templados (Law et al. 2000, Wilson et al. 2001) o de bosques tropicales (Grace 1999). Entre las condiciones limitantes que puede imponer el ambiente, el estrés por sequía es uno de los factores más adversos para el crecimiento de la planta y la productividad (Chaves et al. 2002, Gasper et al. 2002, Chaves et al. 2003, Hu et al. 2006b) ya que no sólo limita el crecimiento de plantas y la supervivencia de forma directa, sino que también, indirectamente, influye en la adquisición de nutrientes (Otsus y Zobel 2004). Las respuestas de las plantas a la escasez de agua son complejas, involucrando cambios adaptativos y/o efectos deletéreos (Chaves et al. 2002). El estrés por sequía reduce la absorción de nutrientes debido a su disponibilidad reducida para el crecimiento (Misra y Tyler 2000, Engelbrecht et al. 2007), y porque disminuye la tasa de transpiración y la permeabilidad de las membranas de las plantas (Huang et al. 2007). Por lo tanto los efectos de los regímenes de suministro de agua y nutrientes en el crecimiento de plantas pueden interactuar significativamente ( $\mathrm{Hu}$ y Schmidhalter 2005) y lo pueden hacer de forma sinérgica o antagonista, modificados por la superposición de otros tipos de estrés (Chaves et al. 2002).

En el Capítulo 5 analizamos la influencia de distintas condiciones de disponibilidad de agua en el aporte de N y P al lixiviado de residuos de cubiertas verdes de Eucalyptus grandis y material herbáceo de leguminosas en un suelo arcilloso mediante un ensayo con microlisímetros. No obstante, la concentración de los nutrientes disponibles en la solución del suelo no se traduce directamente en el crecimiento de la planta ya que en la rizósfera la disponibilidad de dichos nutrientes se rige por una amplia gama de parámetros fisicoquímicos, ambientales y estacionales, y por las interacciones biológicas con los microorganismos del suelo (Richardson et al. 2009). Por tal motivo, el objetivo de este capítulo es constatar el efecto de un suelo bien provisto de agua y uno con sequía, combinado con residuos de leguminosas herbáceas sobre el crecimiento de plantas jóvenes de E. grandis en suelos arcillosos. La hipótesis es que el crecimiento de plantas de $E$ grandis en suelos arcillosos es limitado en mayor medida por la baja disponibilidad de agua que por la disponibilidad de nutrientes. Un mejor conocimiento de estos aspectos podrá guiar y proponer el manejo del riego en suelos arcillosos cuando sea necesario con la 
finalidad de reducir el estrés, asegurar la disponibilidad de los nutrientes y mejorar los crecimientos actuales.

Predicción:

- En suelos arcillosos, la sequía reduce el crecimiento de E. grandis en igual magnitud independientemente de la presencia o no de abonos orgánicos.

\subsection{MATERIALES Y MÉTODOS}

Se realizó un ensayo en condiciones controladas, en el cual se utilizaron un conjunto de macetas con suelo arcilloso donde se agregó mantillo foliar de leguminosas en las cuales se pusieron plantines de E. grandis, bajo condiciones de capacidad de campo (CC) o sequía (S), y se midió su crecimiento.

\subsubsection{Diseño experimental}

Se utilizaron macetas de 4 litros de capacidad con suelo arcilloso (Argiacuol Vertico) superficial traído de las plantaciones de E. grandis de Concordia, Entre Ríos. Como mantillo se utilizaron 2 especies de leguminosas: Canavalia ensiformis y Lotus corniculatus. El mantillo de C. ensiformis provino de EEA INTA Cerro Azul, Misiones, mientras que el de L. corniculatus de la EEA INTA Concepción del Uruguay, Entre Ríos. El material vegetal fue secado al aire.

La cantidad de material vegetal (mantillo) utilizado fue de $40 \mathrm{~g}$ por maceta, valor proporcional al utilizado en los microlisímetros del Capítulo 5. El mismo consistió en hojas de las leguminosas, las que se incorporaron groseramente molidas a mano, y mezcladas con el suelo en un recipiente aparte para lograr una mezcla homogénea. Luego se llenaron las macetas y se colocó la planta. Las semillas de las que se obtuvieron las plantas de $E$. grandis provenían de un Huerto Clonal del Plan de Mejoramiento Genético del INTA EEA Concordia. Al iniciar el ensayo tenían 2 meses de edad y $20 \mathrm{~cm}$ de altura en promedio (Imagen 7.1). Como el ensayo se llevó a cabo a cielo abierto, en el interior de cada maceta se colocó una bolsa de polietileno de manera de poder cerrarla y evitar que las 
precipitaciones humedezcan el suelo de las plantas del tratamiento S. En las plantas del tratamiento $\mathrm{CC}$, las bolsas se dejaron abiertas durante todo el experimento.

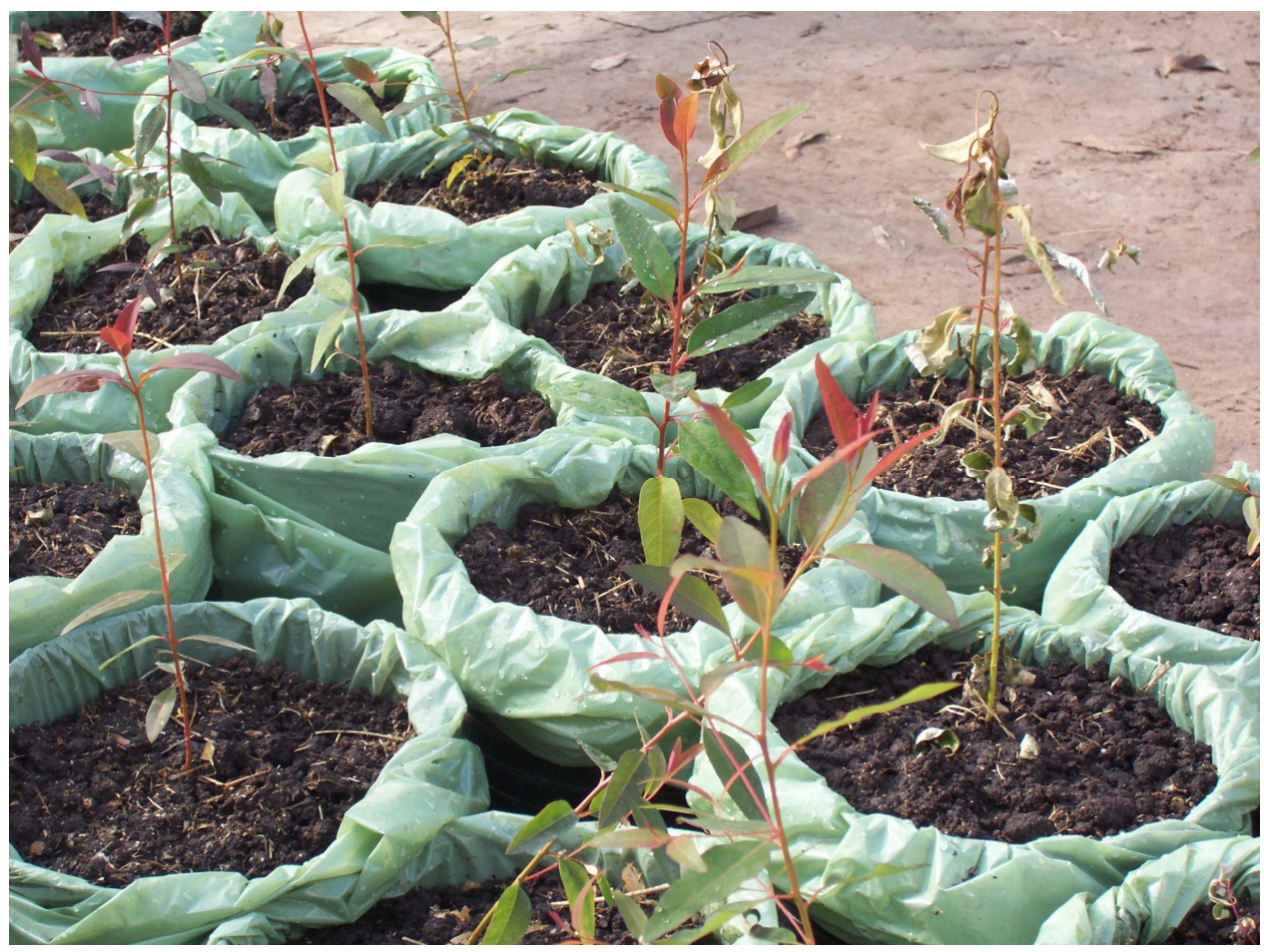

Imagen 7.1. Plantas de eucalipto al inicio del ensayo, sobre suelo arcilloso con material vegetal molido groseramente y mezclado con el suelo.

La cantidad de suelo agregada en cada planta fue de $3,96 \mathrm{~kg}$, que más los $0,040 \mathrm{~kg}$ de material vegetal hacen un total de $4 \mathrm{~kg}$ de peso en cada maceta, a excepción de los controles $\sin$ mantillo que tuvieron $3,96 \mathrm{~kg}$. El suelo utilizado tenía un contenido de humedad del $30 \%$.

El diseño experimental consistió en un tipo de suelo, 2 especies de materiales vegetales, sometidos a 2 regímenes hídricos: capacidad de campo constante (CC) y sequía (S). Se realizaron 10 repeticiones para cada tratamiento con un control para cada condición hídrica, el cuál consistió en 10 macetas cada una con sendas planta de eucaliptos sin agregado de material vegetal (Imagen 7.2). 


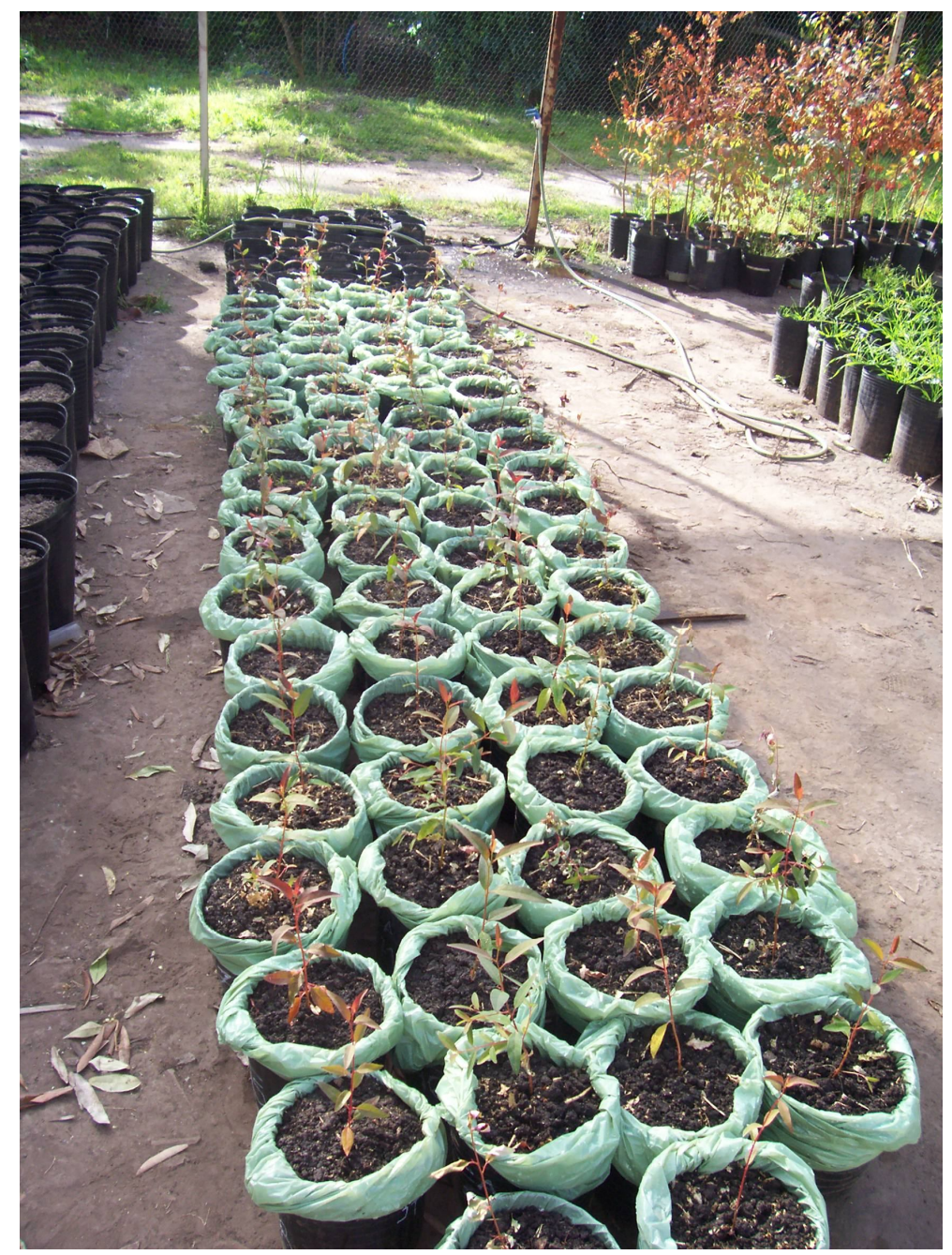

Imagen 7.2. Plantas de eucalipto al inicio del ensayo.

Las macetas recibieron una irrigación cada 3 días, la cual se realizó luego de pesar cada maceta para determinar la cantidad de agua necesaria a agregar de modo de cada maceta alcance la capacidad de campo o permanezca bajo estrés por sequía, según el tratamiento. La cantidad de agua para las macetas a capacidad de campo fue equivalente al porcentaje máximo de retención de agua. El mismo se calculó a partir de 5 muestras de suelo de 100 g cada una, contenidas en el volumen correspondiente a la densidad aparente del suelo, a las cuales se les midió el peso seco a estufa y el peso de la misma muestra de suelo luego de irrigarla a sobresaturación (conseguida al observar pelo de agua en superficie) y luego de dejarla durante una noche goteando por el fondo del lisímetro para que escurriera el agua en exceso de la retenida por la fuerza de la gravedad. La diferencia 
entre ambos pesos fue el máximo contenido de agua retenido por el suelo, que corresponde a un porcentaje peso/peso de 44,65 \%. Para la reposición de agua en los tratamientos con estrés por sequía, se consideró un porcentaje de $28 \%$ de agua ya que en este tipo de suelo genera un potencial hídrico de suelo de $-0,8 \mathrm{MPa}$, que produce estrés no letal en las plantas de Eucalyptus grandis (Graciano et al. 2005).

Se midieron la altura total y el número de hojas de las plantas, en los días 0 (al inicio del ensayo), y en los días 43, 56, 69 y 80 (último día del ensayo) (Imagen 7.3). Cada 4 días se alternó la posición de las macetas para minimizar el efecto "borde". Al inicio del ensayo se tomaron 10 plantines de $20 \mathrm{~cm}$ de altura las cuales fueron separadas en hojas, tallo y raíz, se midió su área foliar, y luego fueron secados a estufa y pesados. Asimismo, al finalizar el ensayo todas las plantas fueron cosechadas cuidadosamente, separadas en hojas, tallos principales, tallos secundarios, raíz principal y raíz secundaria. Luego de medir su área foliar, fueron secadas en estufa y pesadas. Para determinar peso seco, las muestras se secaron a $65^{\circ} \mathrm{C}$ hasta peso constante y se pesaron con precisión 0,01g. El área foliar se determinó con un integrador de área (LICOR LI-3100, Nebraska).

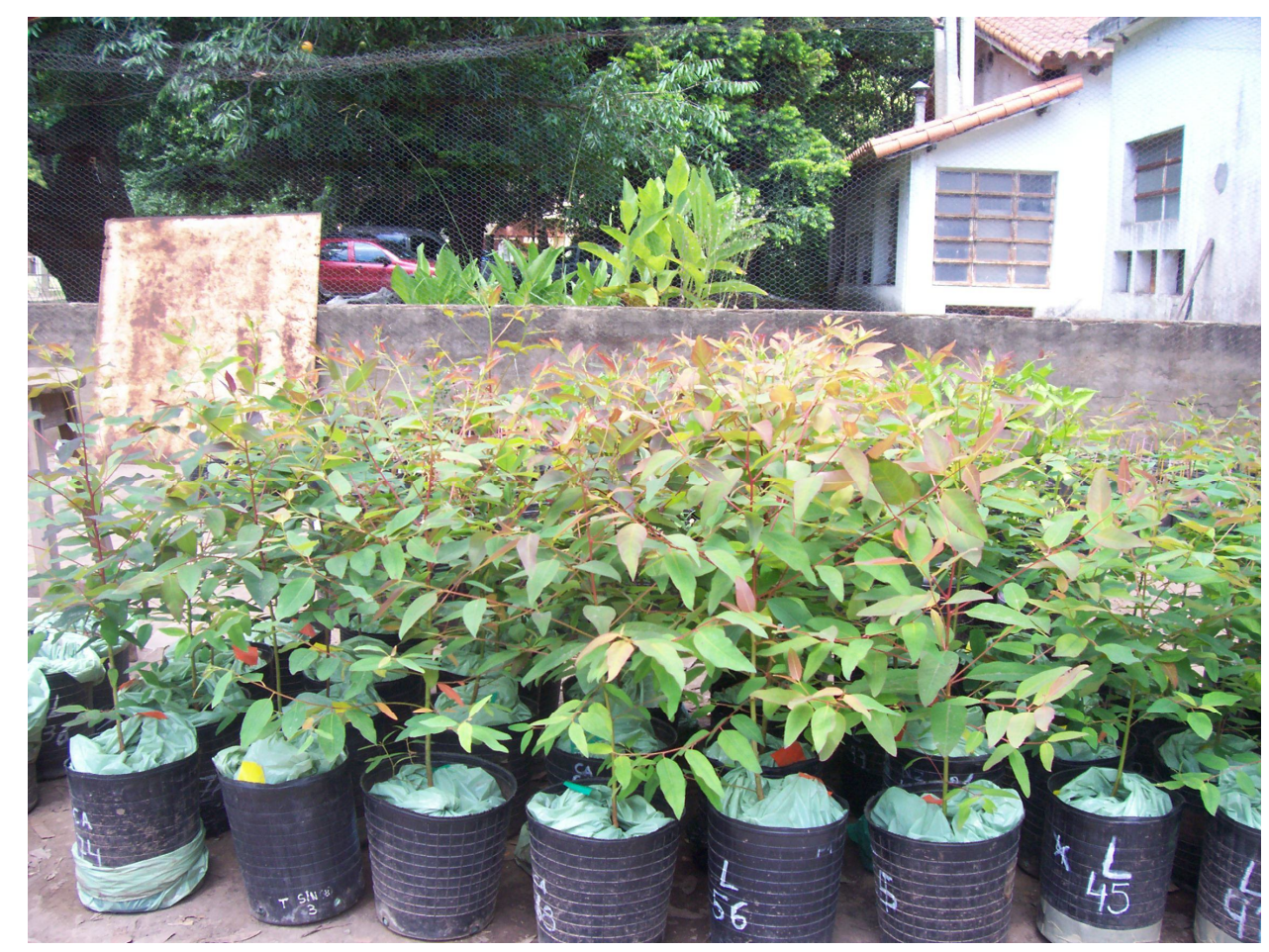

Imagen 7.3. Plantas de eucalipto al final del ensayo. 


\subsubsection{Análisis de los datos}

Las variables analizadas fueron: crecimiento neto en altura (al crecimiento final se le restó la altura inicial de los plantines) medido en $\mathrm{cm}$; número de hojas neto (al número final de hojas alcanzado se le restó el número de hojas iniciales); peso seco total (PST), expresado en g/planta; peso seco aéreo (hojas + tallo)/peso seco raíces (PSA/PSR).

\subsubsection{Análisis estadísticos}

Se realizó para cada variable un ANOVA considerando 2 factores (especie de leguminosa agregada o control, y condición hídrica). Las medias se compararon mediante el test de Tukey $(\mathrm{p}<0,05)$.

\subsection{RESULTADOS}

Se encontraron diferencias entre las plantas control según el régimen hídrico recibido en el crecimiento neto en altura de las plantas alcanzado al finalizar el ensayo (Figura 7.1), ya que las plantas sin residuos mantenidas a CC crecieron significativamente más que aquellas sin residuos que fueron sometidas a $\mathrm{S}$.

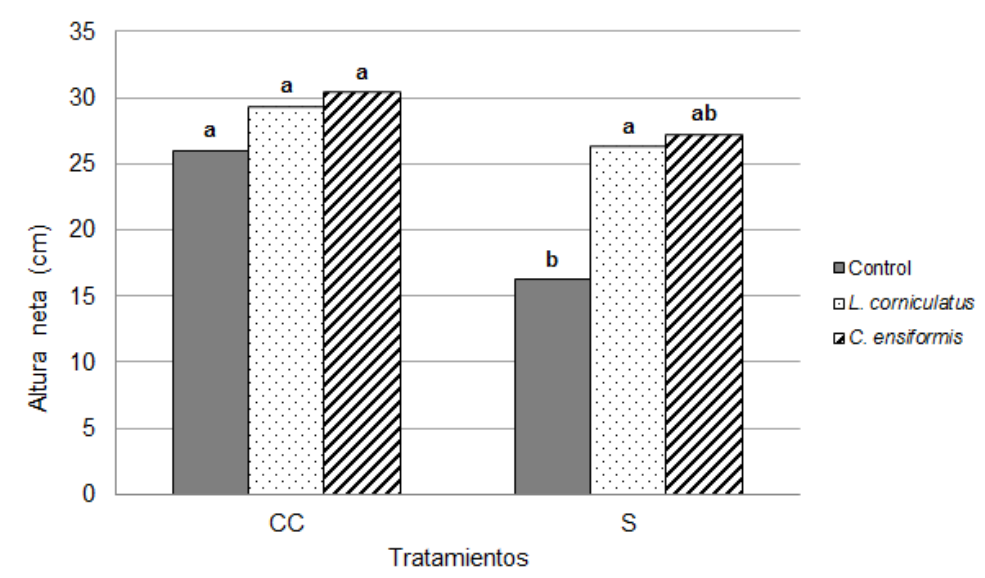

Figura 7.1. Crecimiento neto en altura de las plantas de eucalipto en $\mathrm{cm}$ sin aporte de residuos (Control) o con aporte de leguminosas (L. corniculatus y C. ensiformis), en condiciones de capacidad de campo (CC) o sequía (S). Con letras minúsculas se indica la significancia estadística entre regímenes hídricos y tipos de abonos $(\mathrm{p}<0,05)$. 
En $\mathrm{N}^{\circ}$ de hojas y PST, si bien en el tratamiento control a CC siempre se observó un mayor $\mathrm{N}^{\circ}$ de hojas o PS que cuando se lo sometió a S (Figuras 7.2 y 7.3), las diferencias no fueron significativas.

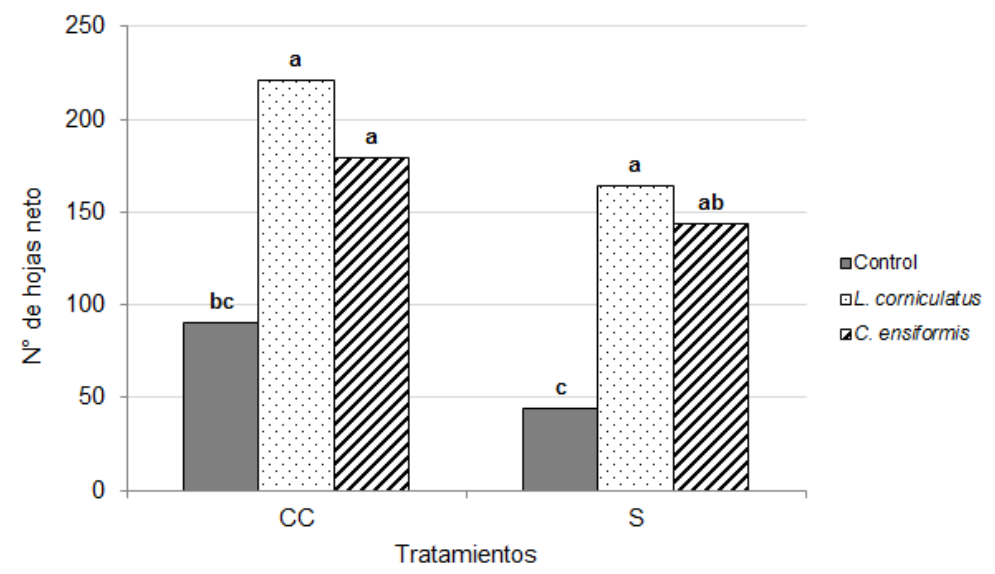

Figura 7.2. Número de hojas de las plantas de eucalipto sin aporte de residuos (Control) o con aporte de leguminosas ( $L$. corniculatus y $C$. ensiformis), en condiciones de capacidad de campo (CC) o sequía (S). Con letras minúsculas se indica la significancia estadística entre regímenes hídricos y tipos de abonos $(\mathrm{p}<0,05)$.

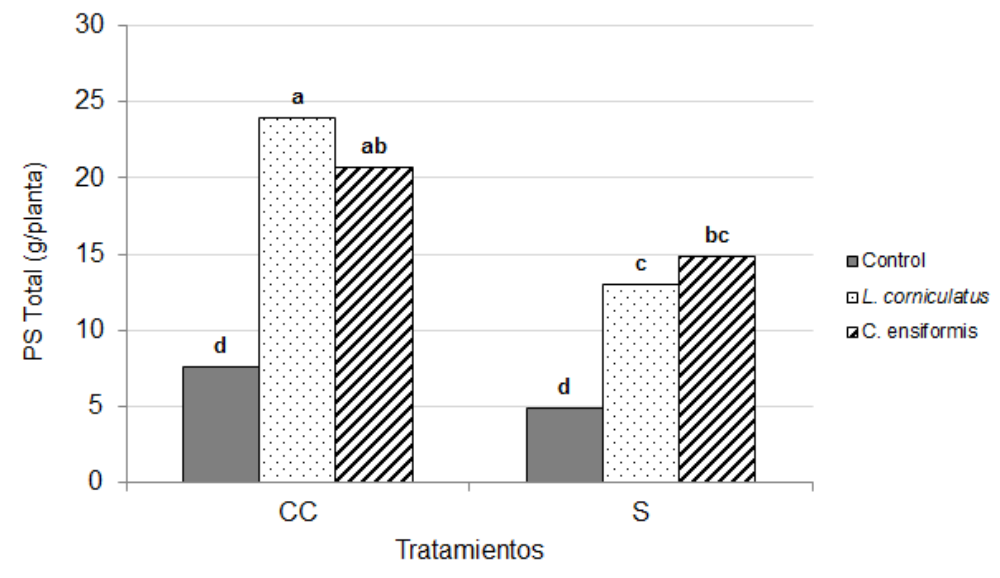

Figura 7.3. Peso seco total (en g/planta) de las plantas de eucalipto sin aporte de residuos (Control) o con aporte de leguminosas (L. corniculatus y C. ensiformis), en condiciones de capacidad de campo (CC) o sequía (S). Con letras minúsculas se indica la significancia estadística entre regímenes hídricos y tipos de abonos $(\mathrm{p}<0,05)$. 
Asimismo, si se compara el comportamiento del abono proveniente de cada especie de leguminosa entre condiciones hídricas ( $\mathrm{CC}$ vs $\mathrm{S}$ ), se observaron diferencias significativas únicamente en PST (Figura 7.3), donde tanto para las plantas que crecieron con abono de L. corniculatus como para las que lo hicieron con residuos de C. ensiformis el tratamiento a CC resultó significativamente mayor que con S. No se observaron diferencias significativas en crecimiento en altura y $\mathrm{N}^{\circ}$ de hojas (Figuras 7.1 y 7.2) entre plantas mantenidas a $\mathrm{CC}$ y S con el agregado de L. corniculatus ni de C. ensiformis.

Al analizar el efecto del agregado de leguminosas como abono verde, ya sea en los tratamientos a CC como en $\mathrm{S}$, hubo un crecimiento significativamente mayor de los eucaliptos con la presencia de estos en comparación con el tratamiento control. Esto pudo verse en $\mathrm{N}^{\circ}$ de hojas y PST (Figuras 7.2 y 7.3), a diferencia de lo observado analizando el crecimiento en altura (Figura 7.1) donde únicamente hubo diferencias significativas entre los eucaliptos del control y los del tratamiento con agregado de L. coniculatus en condiciones de S (Figura 7.1).

Por otro lado el agregado de los residuos de las dos especies leguminosas provocó efectos similares en los eucaliptos, en crecimiento en altura, $\mathrm{N}^{\circ}$ de hojas ni PST en ambas condiciones hídricas (CC y S) (Figuras 7.1, 7.2 y 7.3).

La razón PSA/PAR (Figura 7.4) no varió, ya que los eucaliptos que crecieron a CC o con S, sin agregado de abonos o con agregado de leguminosas, no presentaron diferencias significativas. 


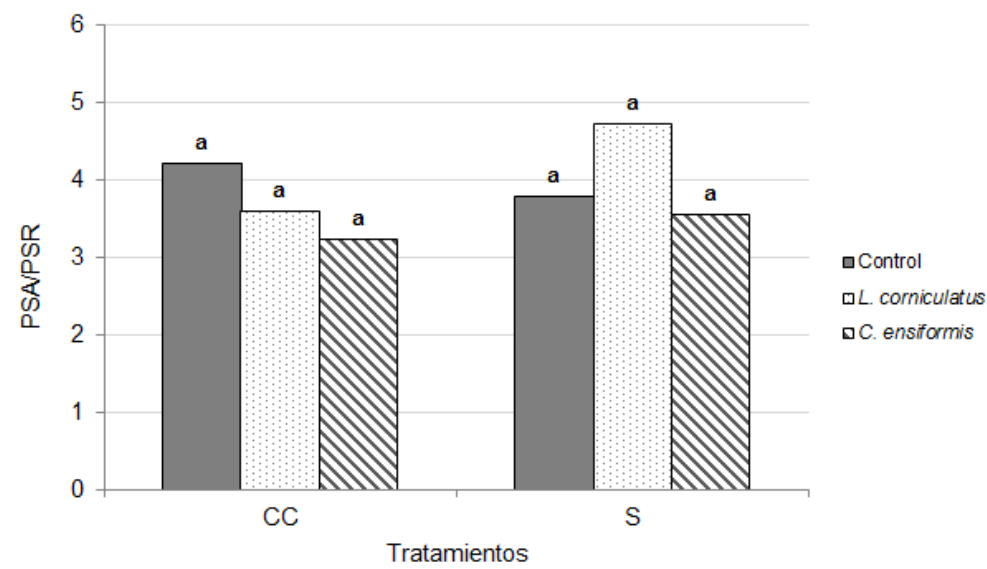

Figura 7.4. Peso seco del vástago/peso seco de raíz (PSA/PSR) de las plantas de eucalipto sin aporte de residuos (Control) o con aporte de leguminosas (L. corniculatus y C. ensiformis), en condiciones de capacidad de campo (CC) o sequía (S). Con letras minúsculas se indica la significancia estadística entre regímenes hídricos y tipos de abonos $(\mathrm{p}<0,05)$.

\subsection{DISCUSIÓN}

El "efecto priming" es causado, entre otros factores, por la entrada al suelo de abonos. Dicho efecto se refiere a un cambio (en su mayoría una aceleración) en los procesos de mineralización naturales a través de un disparador, como la entrada de una fuente de energía fácilmente descomponible, como en este caso el material vegetal de las leguminosas, que resulta en un aumento en la liberación de $\mathrm{C}$ o $\mathrm{N}$, con el consiguiente aumento en la actividad microbiana (Kuzyakov et al. 2000). Además, se encontró que el "efecto priming" puede ocurrir no sólo para $\mathrm{C}$ y $\mathrm{N}$, sino también para $\mathrm{P}$ (Fokin y Radzhabova 1996), S (O'Donnell et al. 1994, Lefroy et al. 1994, Chapman 1997), y algunos otros nutrientes también (Kuzyakov et al. 2000). Asimismo, los abonos verdes mejoran las condiciones físicas del suelo (Muraoka et al. 2002), y aceleran la descomposición de la materia orgánica.

Las plantas control, que no recibieron el agregado de abono, manifestaron el estrés hídrico a través de la reducción de la altura y una reducción no significativa del peso seco total. La falta de significancia posiblemente se debe al gran tamaño de las plantas de los otros tratamientos, que aumenta la variabilidad total y torna no significativas las diferencias 
entre plantas control (sin abonos) S y CC. De hecho, la diferencia entre plantas sin abono que crecieron a capacidad de campo vs las de sequía, se torna significativa cuando sólo se comparan las plantas control en ambas condiciones hídricas $(\mathrm{p}=0,017)$. El agregado de abono de leguminosas incrementó marcadamente el crecimiento en materia seca en ambas condiciones de disponibilidad de agua (Figura 7.3), aunque el efecto en el crecimiento en altura fue moderado (Figura 7.1). Si bien el estrés hídrico redujo el crecimiento en las plantas con abonos, estas plantas crecieron más que las plantas sin abono en cualquiera de las dos condiciones hídricas. Es decir, el agregado de abono permitió a las plantas aún en condiciones de sequía crecer más que las plantas sin abonos. Esto indica que el crecimiento de las plantas en este tipo de suelo está limitado por la disponibilidad de nutrientes, y que el agregado de abonos reduce dicha limitación.

El porcentaje de reducción en acumulación de materia seca es $36 \%$ en plantas control sometidas a sequía, con respecto a las plantas con buena disponibilidad de agua. En las plantas con abono de L. corniculatus la disminución del crecimiento por la sequía fue de $46 \%$, mientras que con C. ensiformis fue del $29 \%$. Estos valores indican que la reducción en crecimiento por la sequía es similar en plantas con y sin abono, es decir, el mayor crecimiento debido a la mayor disponibilidad de nutrientes no tiene un efecto negativo en la tolerancia al estrés por sequía. Contrariamente, la aplicación de fertilización nitrogenada en forma inorgánica (urea) estimuló el crecimiento en plantas de E. grandis de edad similar, tanto en suelos arenosos como arcilloso, cuando la disponibilidad de agua era elevada, pero no tuvo efecto positivo en el crecimiento en condiciones de estrés hídrico (Graciano et al. 2005, 2006b). De manera similar, la aplicación de fertilización inorgánica fosforada (super fosfato triple de calcio) en suelos arenosos estimuló el crecimiento sólo si la disponibilidad de agua era elevada. Sin embargo, en suelo arcilloso la fertilización fosforada aumentó el crecimiento con alta y baja disponibilidad de agua (Graciano et al. 2005, 2006b). La diferencia encontrada entre la aplicación de fertilización inorgánica y la aplicación de abonos posiblemente se deba a que la incorporación de materia orgánica aumenta la capacidad de retención hídrica y la conductividad hidráulica del suelo. Dado que la sequía reduce la movilidad de nutrientes en el suelo, y por lo tanto la llegada de iones a la rizosfera, es esperable que las plantas bajo sequía no respondan a la fertilización. Sin embargo, la reducción en la movilidad de nutrientes es menor en suelos con mayor 
conductividad hidráulica (Arya et al. 1999). Por lo tanto, el agregado de abonos estimula el crecimiento aún en suelos secos posiblemente porque mejora la capacidad de retención hídrica y la conductividad hidráulica del suelo, modificaciones que permiten actividad microbiana y que los nutrientes lleguen a la rizosfera aún bajo sequía.

Las plantas con y sin abono tuvieron igual partición de materia seca a las raíces con respecto al vástago, independientemente de la disponibilidad de agua. Las plantas ajustaron el área transpirante (hojas) a la cantidad de materia seca de raíces (superficie absorbente) de manera que este cociente fue conservado a pesar de los cambios en la disponibilidad de agua y nutrientes. Se ha observado que las plantas de E. grandis que crecen con más disponibilidad de nutrientes, especialmente el $\mathrm{N}$, tienden a reducir la proporción de raíces con respecto al vástago, porque con menor exploración del suelo pueden satisfacer sus demandas nutricionales (Graciano el al 2005). Al contrario, las plantas que son sometidas a sequía leve y alta disponibilidad de $\mathrm{N}$ en el suelo arcilloso tienden a aumentar la proporción de raíces, y de esta manera aumenta la exploración del suelo y la capacidad de absorber agua. Sin embargo el $\mathrm{P}$ reduce la partición hacia raíces, tanto con alta como con baja disponibilidad de agua (Graciano el al 2005). En este experimento, ni los cambios en disponibilidad de nutrientes ni los cambios en disponibilidad de agua alteraron la relación vástago/raíz, a pesar de que el crecimiento fue diferente entre tratamientos. Esto posiblemente se debe a que los abonos aportan varios nutrientes en simultáneo además de mejorar la capacidad de retener agua del suelo. Posiblemente por eso la partición de materia seca no se modificó, porque el cambio en la disponibilidad de nutrientes fue moderado.

El efecto por el agregado de leguminosas como abono verde fue el esperado, ya que en presencia de dichos abonos las plantas de eucaliptos crecieron más, tanto a CC como en S. En suelos a capacidad de campo, estos abonos liberaban $\mathrm{N}$ al lixiviado (Capítulos 4 y 5), pero en suelo sometido a sequía los abonos no aumentan la disponibilidad de $\mathrm{N}$ y $\mathrm{P}$ en el lixiviado. Por lo tanto las plantas son capaces de tomar los nutrientes en suelos secos porque le ganan en la competencia a los microorganismos o modifican la dinámica de descomposición de los restos orgánicos. Esto es posible porque las raíces si bien consumen agua y secan el suelo de la rizosfera, el posterior movimiento de agua desde el suelo hacia la rizosfera a favor del gradiente de potencial generado, mantienen la humedad en el suelo cerca de las raíces. En determinados casos las raíces pueden llegar a mover agua desde 
sectores más húmedos del suelo a sectores más secos, por medio de un mecanismo llamado redistribución hidráulica (Querejeta et al. 2012), el cual es el movimiento pasivo del agua desde capas de suelo mojado a seco a través de los sistemas de raíces de las plantas (Burgess et al. 1998). En la actualidad hay datos de cerca de 30 especies que muestran que los sistemas de raíces pueden facilitar la transferencia de agua desde las capas profundas hacia las capas superficiales del suelo (Caldwell et al. 1998), proceso que puede mejorar significativamente el contenido de agua de la planta y el estado nutricional (Burgess et al. 1998), y ejercer múltiples efectos beneficiosos sobre el balance de agua de la planta, tales como la mejora de la transpiración durante los períodos secos y retrasar la aparición de estrés por sequía (Caldwell y Richards 1989, Caldwell et al. 1998, Meinzer et al. 2004). Asimismo, la presencia de raíces facilita la descomposición de los residuos vegetales por sus exudados ricos en $\mathrm{C}$ que activan la actividad microbiana.

El agregado de L. corniculatus como de C. ensiformis como abonos presentaron efectos muy similares en el crecimiento de los eucaliptos en las distintas condiciones, resultado esperable según el aporte que realizan estos abonos en los microlisímetros analizados en el Capítulo 4, donde la liberación de nutrientes al lixiviado desde ambos tipos de abono fue semejante.

\subsection{CONCLUSIÓN}

La hipótesis del presente Capítulo El crecimiento de plantas de E. grandis en suelos arcillosos es limitado en mayor medida por la baja disponibilidad de agua que por la disponibilidad de nutrientes, es rechazada, ya que en suelos arcillosos, la buena disponibilidad de agua sin el agregado de abonos aumentó el peso seco total un 33\% con respecto a plantas bajo sequía, pero el abono aumentó el crecimiento un $200 \%$ con respecto a las plantas sin abonos, en ambas condiciones hídricas. Además, la sequía redujo el crecimiento proporcionalmente de manera similar en plantas con y sin abonos. Esto quiere decir que la baja disponibilidad de agua en el suelo reduce el crecimiento en igual magnitud independientemente de la disponibilidad de nutrientes que tenga la planta.

El agregado de las leguminosas L. corniculatus y C. ensiformis como abono verde fue muy beneficioso para el crecimiento de las plantas, ya que, aún en condiciones de 
sequía, los eucaliptos crecieron más que las plantas sin residuos (más de 160\% de aumento en el pesos seco total).

Los abonos verdes además presentan la ventaja respecto a los fertilizantes inorgánicos, que no afectan negativamente la tolerancia al estrés en condiciones de sequía. 


\section{CAPÍTULO 8}

\section{CONCLUSIÓN GENERAL}

El suelo arenoso, de textura gruesa, con menor cantidad de materia orgánica y menor actividad de microorganismos, presenta un comportamiento interno más sencillo de predecir. En el suelo arcilloso, la dinámica de la descomposición y liberación de nutrientes es más compleja dada por las múltiples interacciones de factores, la gran cantidad de materia orgánica presente en el suelo y la consecuente alta actividad de los microorganismos. El aporte potencial de nutrientes incorporados por los abonos al suelo arenoso representa en algunas especies el $50 \%$ del $\mathrm{N}$ total disponible en el suelo, por lo tanto representa un aporte muy importante. En el suelo arcilloso, representa un incremento del 20\% al $\mathrm{N}$ total del suelo. En cuanto al $\mathrm{P}$, para ambos suelos los abonos pueden incrementar el P disponible un $10 \%$ aproximadamente (Tabla 8.1). Sin embargo, debido a la diferente velocidad de mineralización, es muy variable el porcentaje de $\mathrm{N}$ y P potencial que pasa a la solución del suelo en el término de 11 meses, aún si se analizan sólo las leguminosas. El porcentaje de liberación a la solución del suelo del $\mathrm{N}$ varió entre 12 y 71 $\%$, mientras que la del P entre el 21 y $75 \%$ del total disponible (Tabla 8.2). Es importante notar que en el caso del $\mathrm{P}$, la incorporación de varios de los abonos (E. grandis, C. cajan y T. pratense) no solamente no aumentó la disponibilidad de $\mathrm{P}$ en solución en ninguna condición de aplicación (modo de incorporación, humedad del suelo), sino que siempre la disminuyó con respecto a microlisímetros sin abonos. 
Tabla 8.1. a) Aporte potencial de N y P al suelo en cada microlisímetro a partir del suelo y de los mantillos agregados. Los valores corresponden a la totalidad del nutriente contenido. b) Máximo aporte de $\mathrm{N}$ y $\mathrm{P}$ al suelo registrado. Entre paréntesis se indica el tipo de suelo, condición de disponibilidad de agua, y modo de incorporación del material donde se registró el valor. El signo negativo indica la disminución en la lixiviación del nutriente con respecto a los microlisímetros sin el agregado de abonos (control). En estos casos, se seleccionó el tratamiento que menos redujo la disponibilidad de $\mathrm{P}$.

\begin{tabular}{|c|c|c|}
\hline a) & $\mathrm{N}(\mathrm{mg})$ & $\mathrm{P}(\mathrm{mg})$ \\
\hline & \multicolumn{2}{|c|}{ Aporte total del suelo } \\
\hline Suelo arcilloso (53 g) & 116,6 & 15,4 \\
\hline \multirow[t]{2}{*}{ Suelo arenoso $(79 \mathrm{~g})$} & 31,6 & 17,4 \\
\hline & \multicolumn{2}{|c|}{ Aporte potencial de los abonos } \\
\hline E. grandis $(1 \mathrm{~g})$ & 22,0 & 1,2 \\
\hline C. ensiformis $(0,5 \mathrm{~g})$ & 13,5 & 0,4 \\
\hline C. cajan $(0,5 \mathrm{~g})$ & 19,0 & 1,4 \\
\hline L. corniculatus $(0,5 \mathrm{~g})$ & 20,5 & 1,0 \\
\hline T. pratense $(0,5 \mathrm{~g})$ & 23,0 & 1,1 \\
\hline b) & \multicolumn{2}{|c|}{ Máximo aporte a la solución del suelo registrado } \\
\hline Suelo arcilloso & $31,5(A Q)$ & $3,4(\mathrm{AM})$ \\
\hline Suelo arenoso & $8,98(\mathrm{HC})$ & $0,01(\mathrm{HC})$ \\
\hline E. grandis & 3,98 (Arci-HC- ES) & $-0,18$ (Arci- AQ- ES) \\
\hline C. ensiformis & 9,6 (Arci-HC-MM) & 0,3 (Arci-HC-MM) \\
\hline C. cajan & 7 (Are- HC- MM) & $-0,43$ (Arci- HC- ES) \\
\hline L. corniculatus & 11,7 (Arci-HC-MM) & 0,21 (Arci-HC-MM) \\
\hline T. pratense & 2,7 (Are- HC-ES) & $-0,31$ (Arci- HC- ES) \\
\hline
\end{tabular}

Tabla 8.2. Máximo porcentaje de N y P disponible en la solución del suelo en los microlisímetros con respecto al contenido de nutrientes en los suelos y en los diferentes mantillos agregados. Los valores negativos indican la mínima disminución en la disponibilidad de los nutrientes, con respecto a los microlisímetros control ( $\sin$ abonos).

\begin{tabular}{l|c|c} 
& $\mathrm{N}(\mathrm{mg})$ & $\mathrm{P}(\mathrm{mg})$ \\
\hline Suelo arcilloso & $26 \%$ & $22 \%$ \\
Suelo arenoso & $28 \%$ & $0,06 \%$ \\
\hline E. grandis & $18 \%$ & $-15 \%$ \\
C. ensiformis & $71 \%$ & $75 \%$ \\
C. cajan & $36 \%$ & $-31 \%$ \\
L. corniculatus & $57 \%$ & $21 \%$ \\
T. pratense & $12 \%$ & $-28 \%$
\end{tabular}


Para el suelo arenoso podría recomendarse la utilización de leguminosas como abono verde en las plantaciones de E. grandis, ya que sus hojas de alta calidad química y altas tasas de descomposición, pueden lixiviar $\mathrm{N}$ al suelo y dejarlo disponible para los eucaliptos. En particular, el uso de L. corniculatus y de C. cajan como abono verde puede aumentar la disponibilidad inmediata de $\mathrm{N}$ en la solución del suelo. Dadas las intensas interacciones entre la transformación de la materia añadida al suelo y los ciclos del $\mathrm{N}$ y $\mathrm{C}$ (Kuzyakov et al. 2000), la entrada al suelo de estas leguminosas usadas como abono verde puede haber generado un "efecto priming". Este efecto consiste en un rápido aumento en la liberación a la solución del suelo de $\mathrm{C}$ y $\mathrm{N}$, que acelera los procesos de mineralización por los microorganismos, a partir de un disparador, que en este caso serían los abonos. De esta manera, los microorganismos disponen de una fuente de energía fácilmente disponible (Kuzyakov et al. 2000), con el consecuente aumento de la descomposición y mineralización de la materia orgánica del suelo y de los restos incorporados.

A pesar de que la especie T. pratense tuvo el contenido de $\mathrm{N}$ más alto (Tabla 8.2) este rasgo no se tradujo en una mayor lixiviación de $\mathrm{N}$ en el suelo, ya que fue la especie que menos $\mathrm{N}$ mineralizó (12\%), y no hubo ningún indicador de calidad química que se correlacionara con la lixiviación de $\mathrm{N}$ en este suelo. Esto puede haber ocurrido en parte porque el alto grado de autocorrelación entre las características químicas de los residuos (Taylor et al. 1991, Parton et al. 1994) y su integración biológica dentro de los tejidos, hace muchas veces un ejercicio inútil (Prescott 2005) la búsqueda de un único factor que controla la velocidad de descomposición, como se destacó en el Capítulo 3. Asimismo, el contenido de $\mathrm{C}$ fácilmente disponible proveniente de los residuos puede ser un factor clave para comprender la dinámica de la mineralización, por lo que el residuo con mayor contenido de $\mathrm{N}$ no será necesariamente el que aporte más $\mathrm{N}$, ya que depende de qué tan rápido pueda descomponerse y mineralizarse, procesos relacionados con los contenidos de lignina y otras sustancias recalcitrantes de la hoja. Alonso et al. (2001), en un estudio de mineralización de hojas de 4 leguminosas arbustivas, encontraron que especies con contenidos muy similares en $\mathrm{N}$ tuvieron coeficientes de mineralización de la materia orgánica muy diferentes, relacionándose más este proceso con el contenido de $\mathrm{C}$ lábil y con la fracción lignocelulósica de la hoja. Un comportamiento diferente al registrado con $T$. pratense se observó con el agregado de residuos de C. ensiformis, especie que a pesar de 
tener el menor contenido de $\mathrm{N}$ y $\mathrm{P}$, tiene la mayor potencialidad para liberar los nutrientes, ya que mineralizó un $71 \%$ del $\mathrm{N}$ y un 75\% del $\mathrm{P}$ (Tabla 8.1 y 8.2). Esta especie se caracteriza también por un bajo contenido en lignina, característica que pudo haber influido en la rápida descomposición y mineralización de sus nutrientes.

La posibilidad de utilizar estas especies de leguminosas como fuente de $\mathrm{N}$ para las plantas es muy importante dado que los fertilizantes artificiales además de generar diferentes problemas en el ambiente, no siempre producen los mejores rendimientos en comparación con los abonos verdes. La incorporación de abonos conlleva beneficios adicionales, como el mejoramiento de las condiciones físicas del suelo por el aumento de la materia orgánica, y la reducción de la pérdida del $\mathrm{N}$ por lixiviación o volatilización por el aumento de las actividades microbiana (Muraoka et al. 2002). En contraste con los ecosistemas naturales, las áreas con agricultura intensiva tienen un exceso de $\mathrm{N}$ mineral añadido como fertilizantes que no pueden ser retenido por los microorganismos debido a la falta de $\mathrm{C}$ disponible, dando lugar a una biomasa y actividad microbiana considerablemente menor (Kuzyakov y Xu 2013). La incapacidad de los microorganismos para tomar y retener el $\mathrm{N}$ proveniente de los fertilizantes conduce a pérdidas de $\mathrm{N}$ por lixiviación considerablemente altas en suelos agrícolas (Havlin et al. 1999, Kirchmann et al. 2002). Por lo tanto, el agregado de abonos orgánicos debe ser valorado no sólo por el aporte de N, sino a su importancia como fuente de $\mathrm{C}$ fácilmente disponible para la actividad microbiana.

En el caso de la incorporación de abonos en las macetas con plantas, se observa que los abonos potencialmente pueden incrementar un 50\% de $\mathrm{N}$ en el suelo arenoso y entre un 10-20\% en el suelo arcilloso (Tabla 8.3). El N incorporado con la hojarasca de E. grandis equivalen a aproximadamente $2 \mathrm{~g}$ de urea por maceta, y el máximo aporte de $\mathrm{N}$ se logra con la aplicación de $T$. pratense que equivale aproximadamente a $4 \mathrm{~g}$ de urea. A pesar de que el fertilizante inorgánico aporta menos cantidad total de $\mathrm{N}$, este nutriente está inmediatamente disponible para la planta. En el caso de los abonos, el tiempo que tarda en estar disponible para las plantas es muy variable, como se ha analizado, y justamente el abono que más $\mathrm{N}$ aportaría es el que liberó el menor porcentaje en los microlisímetros. 
Tabla 8.3. Aporte potencial de N y P en los ensayos con macetas, por el aporte del suelo y de los mantillos.

\begin{tabular}{lcc} 
& $\mathrm{N}(\mathrm{mg})$ & $\mathrm{P}(\mathrm{mg})$ \\
\hline Suelo arcilloso $(4,2 \mathrm{~kg})$ & 9240 & 1218 \\
Suelo arenoso $(6,3 \mathrm{~kg})$ & 2520 & 1386 \\
\hline & \multicolumn{2}{c}{ aporte potencial } \\
\hline E. grandis & 880 & 49,6 \\
C. ensiformis & 1080 & 34 \\
C. cajan & 1520 & 112 \\
L. corniculatus & 1640 & 79,2 \\
T. pratense & 1840 & 91,2 \\
Urea & 460 & 0
\end{tabular}

Cuando se analiza el comportamiento de las leguminosas incorporadas como abono orgánico en presencia de plantas, el análisis podría ser más complejo, ya que en el ambiente de la rizosfera se dan una multiplicidad de interacciones que involucran a los nutrientes disponibles, la actividad microbiana y la toma de nutrientes por la planta. Dado que las plantas y los microorganismos en todos los suelos están limitados principalmente por $\mathrm{N}$ y $\mathrm{P}$, la absorción continua de nutrientes por las plantas conduce al desarrollo de fuertes zonas de agotamiento alrededor de las raíces. Asimismo, la liberación de grandes cantidades de C fácilmente disponibles en la rizosfera (Kuzyakov y Domanski 2000, Nguyen 2003) conduce a un aumento en la abundancia (Newman y Watson 1977, Lynch 1990, Kapoor y Mukerji 2006, Sahara y Nehra 2011), la actividad y el crecimiento de microorganismos en la rizosfera (Oger et al. 2004). En consecuencia, existe una fuerte competencia entre las raíces y los microorganismos por los nutrientes (Kuzyakov y $\mathrm{Xu}$ 2013). A pesar de esta competencia, los microorganismos y las raíces dependen unos de otros y han desarrollado diversos mecanismos para la convivencia simbiótica, como la fijación biológica de $\mathrm{N}_{2}$ atmosférico (Newton et al. 2008, Franche et al. 2009), o el desarrollo de hongos micorrícicos (Kuzyakov y Xu 2013). Por lo tanto, mutualismo, neutralismo y competencia pueden observarse en las interacciones entre plantas y microorganismos (Kuzyakov y Xu 2013). Sin embargo, hasta el momento, no está claro cómo las raíces y microorganismos coexisten y se benefician unos a otros, a pesar de que dependen de los mismos nutrientes y compiten fuertemente por ellos, sobre todo en la rizosfera (Kuzyakov y Xu 2013). En 
nuestro sistema experimental, las plantas parecen haber ganado en la competencia a los microorganismos. En los ensayos realizados en macetas con plantas jóvenes de eucaliptos, el agregado de L. corniculatus y $C$. cajan como abonos verde resultó en un mayor crecimiento de las plantas, coincidiendo con el mayor aporte de N lixiviado por estas especies en los microlisímetros en suelo arenoso. Sin embargo, no siempre se observa dicha relación. Muraoka et al. (2001) en un ensayo donde se comparó la eficiencia de 2 leguminosas usadas como abono verde en suministrar $\mathrm{N}$ en un cultivo, encontraron que a pesar de que una especie contenía mayor cantidad de $\mathrm{N}$ que la otra, no hubo diferencias entre ambas especies en la producción de grano. Asimismo, Mazzarino et al. (1997), encontraton que un tipo de abonos orgánico proveniente de la acuicultura produjo mayor rendimiento en plantas que otro, a pesar de que en incubaciones de laboratorio ambos abonos presentaron tasas de mineralización de $\mathrm{N}$ similares. Por lo que es importante destacar la importancia de complementar estudios de incubación donde se analice la cantidad de nutrientes que potencialmente pueda liberar un abono, con ensayos en maceta donde se pueda medir la respuesta de una planta a dicho abono, ya que la planta modificará la dinámica de la descomposición y mineralización, y por lo tanto un residuo que potencialmente libera más nutrientes podría no traducirse en un mayor crecimiento de la planta, y por el contario, un residuo que en incubación sin planta libera pocos nutrientes, podría liberarlos en presencia de las raíces.

En el manejo de los residuos de cosecha de las plantaciones de eucaliptos, se debe tener en cuenta que la hojarasca de E. grandis no provee $\mathrm{N}$ rápidamente para las plantas luego de su incorporación al suelo, ya que cuando es incorporado como abono verde, inmoviliza $\mathrm{N}$ y retrasa el crecimiento de los eucaliptos incluso más que en el suelo sin agregado de abonos. Esta dinámica está probablemente ligada a las altas relaciones $\mathrm{C} / \mathrm{N}$ y $\mathrm{C} / \mathrm{P}$ de sus hojas y altos contenidos de fenoles, y una lenta tasa de descomposición, por lo que produce hojas de muy baja calidad, que resulta en el almacenamiento de cantidades significativas de nutrientes en el suelo (Adams y Attiwill 1986), por medio de la inmovilización de nutrientes. Los pisos forestales de las plantaciones de eucaliptos se han asociado asimismo con una reducción de las poblaciones de la fauna y flora del suelo (Kardell et al. 1986, Hingston et al. 1989, Saxena 1991, Bi et al. 1992), la producción de compuestos alelopáticos (Bernhard- Reversat 1988, Bi et al. 1992, Sanginga y Swift 1992, 
Singh y Kohli 1992), y efectos anti-microbianas (Della Bruna et al. 1989, 1991). Los eucaliptos crecen rápidamente, y tienen una gran capacidad de tomar los nutrientes del suelo necesarios para su crecimiento. En una plantación joven la reserva de nutrientes del suelo proveniente del horizonte mineral legado de la vegetación natural preexistente, se consume rápido en los primeros años, cuando el mantillo de eucaliptos se acumula y el aporte de $\mathrm{N}$ desde él es bajo, lo que lleva a una gran reducción de su disponibilidad en el suelo mineral en pocos años. Por lo tanto, cuando en una plantación se incorporan hojas de E. grandis en el suelo, los microorganismos deben descomponer este material inmovilizado $\mathrm{N}$ y P. Pero cuando se agregan abonos de leguminosas, las poblaciones de microorganismos crecen con más disponibilidad de $\mathrm{N}$ y $\mathrm{P}$, entonces se quedan en solución del suelo elementos que quedarán disponibles para las plantas. Por lo tanto, el mantillo de E. grandis puede limitar la disponibilidad de nutrientes en el suelo para el crecimiento de los eucaliptos, inmovilizando $\mathrm{N}$ y $\mathrm{P}$, y aumentando en consecuencia la competencia entre microorganismos y plantas, las que crecerán menos en estas condiciones.

Un camino posible para mejorar la liberación de nutrientes de la hojarasca de eucaliptos, podría ser a través de la mezcla con otros tipos de hojas, ya que la liberación más rápida de un tipo de residuo podría estimular la descomposición en el otro (Seastedt 1984), ayudando en la sincronización de la liberación de nutrientes que quedarían disponibles para la absorción por las plantas (Briones e Ineson 1996). Se han realizado varios trabajos que han investigado el efecto de un tipo de hojarasca de especies arbóreas sobre la descomposición de la hojarasca de otras especies (Seastedt 1984, Carlyle y Malcolm 1986, Klemmedson 1987, Chapman et al. 1988, Blair et al. 1990), y se han encontrado interacciones positivas en ciertas mezclas que resultaron en un aumento en la liberación de nutrientes (Carlyle y Malcolm 1986, Chapman et al. 1988) y en la descomposición de la hojarasca y en el aumento de las tasas de respiración microbiana (Ineson y McTiernan 1992, Chapman et al. 1988). Dada la dificultad en poder predecir a partir de la calidad química de los residuos la potencial de la interacción positiva o negativa de las mezclas de residuos (Fyles y Fyles 1993), se propone realizar nuevos ensayos en microlisímetros y macetas con mezclas de hojas de E. grandis y las leguminosas utilizadas en esta Tesis. De esta manera se probaría la posibilidad de reducir la inmovilización de nutrientes que realiza la hojarasca de E. grandis, que reduce el crecimiento inicial de las 
plantas de la misma especie durante los primeros meses posteriores al trasplante, como se observó en esta Tesis. De esta manera se podría aumentar la disponibilidad inicial de nutrientes en el inicio de una plantación de segundo ciclo o ciclos posteriores, que es la situación más frecuente en la zona productora de eucaliptus de Argentina.

Para el caso de los suelos arcilloso inundables, el agregado de leguminosas como abono verde podría ser una opción de manejo para mejorar la nutrición de las plantas, siempre que se tenga en cuenta que el agregado de los residuos se haga sobre la superficie y no incorporado al suelo, de modo que al mantener contacto con el aire lixivien $\mathrm{N}$ en lugar de inmovilizarlo. En dichas condiciones de alternancia de períodos de sequía seguidos de inundación, se produce un aumento en la mineralización de la materia orgánica descripto como "efecto Birch", el cual podría considerarse un tipo de "efecto priming", ya que el secado y rehumedecimiento es una de las intervenciones, que junto con la entrada de abono orgánico o mineral al suelo, el exudado de sustancias orgánicas por las raíces, o el tratamiento mecánico de suelo, pueden causar el súbito aumento de $\mathrm{N}$ y otros nutrientes en la solución del suelo (Kuzyakov et al. 2000). Estas consideraciones son de gran importancia para programar el manejo de los residuos de abono verde en ambientes donde condiciones de sequía seguidos de fuertes lluvias suelen ocurrir, como es el caso de las plantaciones con E. grandis en los suelos arcillosos en Entre Ríos. Asimismo, sería importante complementar el análisis con ensayos en macetas con agregado de abonos de leguminosas donde se imiten condiciones de sequía seguidas de inundación, ya que como se ha mencionado, la presencia de plantas puede modificar la dinámica de la descomposición y mineralización de la materia orgánica. Como se ha demostrado en esta Tesis, en condiciones de sequía el agregado de leguminosas como abono verde es una opción que provee $\mathrm{N}$ al suelo.

El aporte de P por los abonos es bajo y puede incrementar como máximo el 10\% del $\mathrm{P}$ disponible, en cualquiera de los suelos (Tabla 8.3). En los suelos arcillosos este nutriente puede quedar adsorbido por las partículas del suelo además de ser inmovilizado por los microbios, por lo que resulta muy difícil predecir su comportamiento cuando es mineralizado dentro del suelo a partir de residuos vegetales. Las fosfatasas juegan un rol importante en la mineralización de $\mathrm{P}$ orgánicos de los suelos, y existe un amplio rango de microorganismos que a través de sus actividades de fosfatasas son capaces de mineralizar 
todos los fosfatos de origen vegetal. La actividad de la fosfatasa aumenta en los suelos con el aumento del contenido de $\mathrm{C}$, pero también está afectada por el $\mathrm{pH}$, humedad, temperatura y otros factores. Asimismo, la mineralización del $\mathrm{P}$ orgánico ocurre más rápidamente en el suelo adyacente a las raíces de las plantas que en el resto del suelo, dado que las raíces exudan enzimas capaces de liberar P inorgánico a partir de ciertos compuestos de P. Estas enzimas están presentes en las superficies de las raíces y en sus recubrimientos mucilaginosos, además de los exudados de las raíces que pueden acelerar la actividad microbiana, como se ha mencionado anteriormente. En general en los ensayos con microlisímetros con suelo arcilloso, cuando se agregan leguminosas como abono verde la tendencia del $\mathrm{P}$ es a quedar retenido. Sin embargo podría esperarse un comportamiento diferente en la presencia de plantas, por lo que se recomendaría ensayos en macetas con suelos arcillosos y abono de leguminosas antes de descartar la utilización de estas especies como abono verde, ya que el efecto positivo en el crecimiento de los abonos puede darse no sólo por el aporte de N y P sino a que estos abonos además mejoran la calidad del suelo.

Es interesante destacar que cada abono liberó el máximo $\mathrm{N}$ y $\mathrm{P}$ registrado en diferentes condiciones de humedad del suelo y de modo de disposición del material (MM o ES) (Tabla 8.2). Por lo tanto, no se puede hacer una recomendación general sobre el mejor modo de aplicación, sino que debería tenerse en cuenta resultados más puntuales sobre qué tipo de residuo lixivió más nutrientes con cada modo de aplicación del material. Sin embargo, en el suelo arcilloso, sobre el que se probaron diferentes condiciones de humedad del suelo, en general la mayor lixiviación fue con $\mathrm{HC}$, y la sequía o el anegamiento redujeron la liberación de $\mathrm{N}$ y $\mathrm{P}$.

\section{Recomendaciones finales}

En suelos arenosos se podría recomendar la utilización como abono verde de las leguminosas L. corniculatus y C. cajan, utilizando el modo de incorporación que implique un menor costo económico.

En suelos arcillosos se puede recomendar la utilización de L. corniculatus como abono verde, aún en sitios donde se probable que las plantas estén expuestas a periodos de 
baja disponibilidad de agua en el suelo. No se descartaría la opción de las demás leguminosas como abonos verdes sin un previo ensayo en macetas con dichos residuos.

Sería interesante evaluar el efecto en el aporte de nutrientes al suelo y en el crecimiento de las plantas jóvenes de mezclas de hojarasca de E. grandis con leguminosas, simulando el cultivo de leguminosas en un sitio en el que ya se cosechó una plantación de E. grandis. 


\section{BIBLIOGRAFÍA GENERAL}

Abad M. 1998. Limitaciones y riesgos del uso agrícola de los residuos orgánicos. En: Orozco F \& Osorio W (Eds.). Residuos Orgánicos. Aprovechamiento Agrícola como Abono y Sustrato. Sociedad Colombiana de la Ciencia del Suelo. Comité Regional de Antioquia. Universidad Nacional de Colombia. Sede Medellín. Instituto de Ciencias Naturales y Ecológicas. Impresos Caribe, Ltda. Medellín, Colombia. pp. 9-19.

Aber JD \& Melillo JM. 1980. Litter decomposition: measuring relative contribution of organic matter and nitrogen to forest soils. Canadian Journal of Botany 58: 416-421.

Aber JD, Melillo JM \& McClaugherty CA. 1990. Predicting long-term patterns of mass loss, nitrogen dynamics, and soil organic matter formation from initial fine litter chemistry in temperate forest ecosystems. Canadian Journal of Botany 68: 22012208.

Abdul-Baki AA \& Teasdale JR. 1993. A no-tillage tomato production system using hairy vetch and subterranean clover mulches. Hort Science 28:106-108.

Abdul-Baki AA \& Stommel JR. 1996a. Hairy vetch mulch favorably impacts yield of processing tomatoes. Hort Science 31: 338-340.

Abdul-Baki AA, Teasdale JR, Korcak R, Chitwood DJ \& Huettel RN.1996b. Fresh-market tomato production in a low-imput alternative system using cover-crop mulch. Hort Science 31: 65-69.

Adair EC, Parton WJ, Del Grosso SJ, Silver WL, Harmon ME, Hall SA, Burke IC \& Hart SC. 2008. Simple three-pool model accurately describes patterns of long-term litter decomposition in diverse climates. Global Change Biology 14: 2636-2660.

Adams MA \& Attiwill PM.1986. Nutrient cycling and nitrogen mineralization in eucalypt forests of South-eastern Australia. II. Indices of nitrogen mineralization. Plant and Soil 92: 341-362.

Addiscott TM, Whitmore AP \& Powlson DS. 1991. Farming, fertilizers and the nitrate problem. CAB International, Wallingford. p. 170.

Adu JK \& Oades JM. 1977. Physical factors influencing decomposition of organic materials in soil aggregates. Soil Biology and Biochemistry 10:109-115.

Aerts R. 1997. Climate, leaf litter chemistry and leaf litter decomposition in terrestrial ecosystems: a triangular relationship. Oikos 79: 439-449. 
Ågren GI, Bosatta E \& Magill AH. 2001. Combining theory and experiment to understand effects of inorganic nitrogen on litter decomposition. Oecologia 128: 94-98.

Ajmone-Marsan F, Côté D \& Simard RR. 2006. Phosphorus transformations under reduction in long-term manured soils. Plant and Soil 282: 239-250.

Al-Darby AM. 1996. The hydraulic properties of a sandy soil treated with gel- forming soil conditioner. Soil Technology 9: 15-28.

Alemán R \& Flores M. 1993. Algunos datos sobre Canavalia ensiformis. Informe técnico No. 10. CIDICCO Coberturas para la agricultura, Honduras.

Allison FE. 1973. Soil organic matter and its role in crop production. Elsevier, Amsterdam. p. 637.

Alonso N, Alegre J, López-Vela D \& Yébenes L. 2001. Mineralización de la hojarasca de leguminosas arbustivas en condiciones controladas. En: Proceedings of the Montes para la Sociedad del Nuevo Milenio. III Congreso Forestal Español. Tomo IV (ed. Junta de Andalucía Consejería de Medio Ambiente), Granada. Junta de Andalucía, Consejería de Medio Ambiente, pp 360-366.

Altieri M \& Nicholls CI. 2000. Teoría y práctica para una agricultura sustentable. Serie Textos Básicos para la Formación Ambiental. PNUMA. Red de Formación Ambiental para América Latina y el Caribe. México, 235pp.

Amato M, Jackson RB, Butler JHA \& Ladd JN. 1984. Decomposition of plant material in Australian soils. II. Residual organic ${ }^{14} \mathrm{C}$ and ${ }^{15} \mathrm{~N}$ from legume plant parts decomposing under field and laboratory conditions. Australian Journal of Soil Research 22: 331-341.

Ambus P \& Jensen ES. 1997. Nitrogen mineralization and denitrification as influenced by crop residue particle size. Plant and Soil 197: 261- 270.

Andrén O, Zhao X \& Liu X. 1994. Climate and litter decomposition in Naiman, Inner Mongolia, China. AMBIO. A Journal of the Human Environment 23: 222-224.

Angers DA \& Recous S. 1997. Decomposition of wheat straw and rye residues as affected by particle size. Plant and Soil 189: 197-203.

Antúnez I, Retamosa EC \& Villar R. 2001. Relative growth rate in phylogenetically related deciduous and evergreen woody species. Oecologia 128: 172-180. 
Aparicio JL, Larocca F \& Dalla Tea F. 2005. Silvicultura de establecimiento de Eucaliptus grandis. IDIA XXI Forestales. Año 5. Nº 8: 64-67.

Appel T. 1998. Non-biomass soil organic $\mathrm{N}-$ the substrate for $\mathrm{N}$ mineralization flushes following soil drying-rewetting and for organic $\mathrm{N}$ rendered $\mathrm{CaCl}_{2}$-extractable upon soil drying. Soil Biology and Biochemistry 30: 1445-1456.

Arya LM, Leij FJ, Shouse PJ \& van Genuchten MT. 1999. Relationship between the hydraulic conductivity function and the particle-size distribution. Soil Science Society of America Journal 63, 1063-1070.

Asghari S, Neyshabouri MR, Abbasi F, Aliasgharzad N \& Oustan S. 2009. The effects of four organic soil conditioners on aggregate stability, pore size distribution, and respiration activity in a sandy loam soil. Turkish Journal of Agriculture and Forestry 33: 47-55.

Aslyng HC. 1964. Phosphate potential and phosphate status of soils. Acta Agriculturae Scandinavica 14: 261-285.

Atkin OK, Schortemeyer M, McFarlane N \& Evans JR. 1998. Variation in the components of relative growth rate in ten Acacia species from contrasting environments. Plant, Cell and Environment 21: 1007-1017.

Attiwill PM \& Leeper GW. 1987. Forest Soils and Nutrient Cycles. Melbourne University Press, Melbourne, Australia. p. 202.

Aulakh MS, Doran JW \& Mosier AR. 1992. Soil denitrification-Significance, measurement, and effects of management. Advances in Soil Science 18:1-57.

Aulakh MS, Khera TS \& Doran JW. 2000a. Mineralization and denitrification in upland, nearly saturated and flooded subtropical soil. II. Effect of organic manures varying in $\mathrm{N}$ content and C:N ratio. Biology and Fertility of Soils 31: 168-174.

Aulakh MS, Khera TS \& Doran JW. 2000b. Mineralization and denitrification in upland, nearly saturated and flooded subtropical soil. I. Effect of nitrate and ammoniacal nitrogen. Biology and Fertility of Soils 31: 162-167.

Bailey RA, Clark HM, Ferris JP, Krause S \& Strong RL. 2002. Chemistry of the Environment (Second Edition). Academic Press, San Diego. p. 835. 
Balasubramanian V \& Singh L. 1982. Efficiency of nitrogen fertilizer use under rain fed maize and irrigated wheat at Kadawa northern Nigeria. Fertilizer Research 3: 315324.

Baldock JA \& Skjemstad JO. 2000. Role of the soil matrix and minerals in protecting natural organic materials against biological attack. Organic Geochemistry 31: 697710.

Baldwin IT, Olson RK \& Reiners WA. 1983. Protein binding phenolics and the inhibition of nitrification in subalpine balsam fir soils. Soil Biology and Biochemistry 15: 419423.

Barak P, Jobe BO, Krueger AR, Peterson LA \& Laird DA. 1997. Effects of long-term soil acidification due to nitrogen fertilizer inputsin Wisconsin. Plant and Soil 197: 61-69.

Barbarossa RA, Gallego JJ \& Miñón DP. 2013a. CAPITULO VI. Producción de forraje de cultivares de Lotus corniculatus 1. bajo riego en el Noreste Patagónico. En: Miñón DP, Gallego JJ \& Barbarossa RA. 2013. Producción de forraje de especies y cultivares de leguminosas en valles regados norpatagónicos. Información técnica $\mathrm{N}^{\circ}$ 33 Año $7 \mathrm{~N}^{\circ}$ 15. ISSN 1666-6054. EEA Valle Inferior-Convenio Provincia de Río Negro-INTA, Argentina.

Barbarossa RA, Gallego JJ \& Miñón DP. 2013b. Capítulo III. Producción de forraje de cultivares de trébol blanco (Trifolium repens L.) bajo riego en valles norpatagónicos. En: Miñón DP, Gallego JJ \& Barbarossa RA. 2013. Producción de forraje de especies y cultivares de leguminosas en valles regados norpatagónicos. Información técnica $\mathrm{N}^{\circ} 33$ Año $7 \mathrm{~N}^{\circ}$ 15. ISSN 1666-6054. EEA Valle Inferior-Convenio Provincia de Río Negro-INTA, Argentina.

Bargali SS \& Singh SP. 1991. Aspects of productivity and nutrient ciclyng in an 8-year-old Eucalyptus plantation in a moist plain area adjacent to central Himalaya, India. Canadian Journal of Forest Research 21: 1365-1372.

Barley KP. 1970. The configuration of the root system in relation to nutrient uptake. Advances in Agronomy 22: 159-201.

Bartos DL \& DeByle NV. 1981. Quantity, decomposition, and nutrient dynamics of aspenlitter fall in Utah. Forest Science 27: 381-390. 
Bauhus J \& Khanna PK. 1994. Carbon and nitrogen turnover in two acid forest soils of southeast Australia as affected by phosphorus addition and drying and rewetting cycles. Biology and Fertility of Soils 17: 212-218.

Beauchamp EG, Trevors JT \& Paul JW. 1989. Carbon sources for bacterial denitrification. Advances in Soil Science 10: 113-142.

Begon M, Harper JL \& Townsend CR. 2006. Ecology From Individuals to Ecosystems. 4a. ed. Blackwell Scientific Publications, USA. p. 741.

Bell D \& Williams JJ. 1997. Eucalypt ecophysiology. Chapter 8, pages 168-196. En Williams JE \& Woinarski JCZ (ed). 1997. Eucalypt Ecology. Individuals to ecosystems. Cambridge University Press, Cambridge, UK.

Below FE. 2002. Fisiología, nutrición y fertilización nitrogenada de maíz. Instituto de la Potasa y el Fósforo. Informaciones Agronómicas (54): 3-9.

Bending GD \& Turner MK. 1999. Interaction of biochemical quality and particle size of crop residues and its effects on the microbial biomass and nitrogen dynamics following incorporation into soil. Biology and Fertility of Soils 29: 319-327.

Berendse F. 1998. Effects of dominant plant species on soils during succession in nutrientpoor ecosystems. Biogeochemistry 42: 73-88.

Berg B \& Staaf H. 1980. Decomposition rate and chemical changes in Scots pine needle litter. 2. Influence of chemical composition. Ecological Bulletins 32: 363-372.

Berg B, McClaugherty CA \& Johansson MB. 1993. Litter mass-loss rates in late stages of decomposition at some climatically different pine sites. Long-term decomposition in Scots pine forest. VIII. Canadian Journal of Botany 71: 680-692.

Berg B \& Laskowski R. 1997. Changes in nutrient concentrations and nutrient release in decomposing needle litter in monocultural systems of Pinus contorta and Pinus sylvestris - a comparison and synthesis. Scandinavian Journal of Forest Research 12: $113-121$.

Berg B, Johansson MB \& Meentemeyer V. 2000. Litter decomposition in a transect of Norway spruce forests: substrate quality and climate control. Canadian Journal of Forest Research 30: 1136-1147. 
Bernays EA, CooperDriver G \& Bilgener M. 1989. Herbivores and plant tannins. En: Begon M, Fitter AH, Ford ED \& MacFadyen A (eds). Advances in Ecological Research, Vol. 19, Academic Press, London, p. 263-302.

Bernhard-Reversat F. 1988. Soil nitrogen mineralization under Eucalyptus plantation and a natural Acacia forest in Senegal. Forest Ecology and Management 23: 233-244.

Bernhard-Reversat F. 1993. Dynamics of litter and organic matter at the soil-litter interface in fast-growing tree plantations on sandy ferralliticsoil (Congo). Acta Ecológica 14: 179-195.

Bhupinderpal-Singh, Rengel Z \& Bowden JW. 2006. Carbon, nitrogen and sulphur cycling following incorporation of canola residue of different sizes into a nutrient-poor sandy soil. Soil Biology and Biochemistry 38: 32-42.

Bi H, Turvey ND \& Heinrich P. 1992. Rooting density and tree size of Pinus radiuta (D. Don) in response to competition from Eucalyptus obliqua (L'Herit). Forest Ecology and Management 49:3 1-42.

Biair JM, Parmelee RW \& Beare MH. 1990. Decay rates, nitrogen fluxes and decomposer communities of single- and mixed-species foliar litter. Ecology 71: 1976-1985.

Bijay-Singh, Ryden JC \& Whitehead DD. 1988. Some relationships between denitrification potential and fractions of organic carbon in air dried and field moist soils. Soil Biology and Biochemistry 20: 737-741.

Binkley D. 1992. Mixtures of nitrogen-fixing and non-nitrogen-fixing species. En: Cannell MGR, Malcolm DC \& Robertson PA (eds). The ecology of Mixed-Species Stands of Trees. Blackwell Scientific, Oxford, p. 99-123.

Binkley D \& Giardina C. 1998. Why do tree species affect soils? The Warp and Woof of tree-soil interactions. Biogeochemistry 42: 89-106.

Birch HF \& Friend MT. 1956. Humus decomposition in East African soils. Nature 178: 500-501.

Birch HF. 1960. Nitrification in soils after different periods of dryness. Plant and Soil 12: 81-96.

Blackwell MSA, Brookes PC, de la Fuente-Martinez N, Murray P, Snars KE, Williams JK \& Haygarth PM. 2009. Effects of soil drying and rate of re-wetting on concentrations and forms of phosphorus in leachate. Biology and Fertility of Soils 45: 635-643. 
Blagodatskaya EV, Blagodatsky SA, Anderson T-H \& Kuzyakov Y. 2009. Contrasting effects of glucose, living roots and maize straw on microbial growth kinetics and substrate availability in soil. European Journal of Soil Science 60: 186-197.

Blagodatskaya E, Littschwager J, Laurer M \& Kuzyakov Y. 2010. Growth rates of rhizosphere microorganisms depend on competitive abilities of plants and $\mathrm{N}$ supply. Plant Biosystems 144: 408-413.

Bohn H1, McNeal BL \& O'Connor GA. 1993. Química del Suelo. Cap. 5. Materia Orgánica. Limusa, México, p. 155-173.

Boland DJ, Brooker MIH, Chippendale GM, Hall N, Hyland BMP, Johnston RD, Kleinig DA, McDonald MW \& Turner JD. 1984. Forest trees of Australia. Melbourne, Australia: Nelson-CSIRO, 687 p.

Bolan NS. 1991. A critical review on the role of mycorrhizal fungi in the uptake of phosphorus by plants. Plant and soil 134(2): 189-207.

Bolan NS, Hedley MJ \& White RE. 1991. Processes of soil acidification during nitrogen cycling with emphasis on legume based pastures. Plant and Soil 134: 53-63.

Bordelon BP \& Weller SC. 1997. Preplant cover crops affect weed and vine growth in firstyear vineyards. Hort Science 32: 1040-1043.

Borken W, Davidson EA, Savage K, Gaudinski J \& Trumbore SE. 2003. Drying and wetting effects on $\mathrm{CO}_{2}$ release from organic horizons. Soil Science Society of America Journal 67: 1888-1897.

Borken W \& Matzner E. 2009. Reappraisal of drying and wetting effects on $\mathrm{C}$ and $\mathrm{N}$ mineralization and fluxes in soils. Global Change Biology 15: 808-824.

Bottner P. 1985. Response of microbial biomass to alternate moist and dry conditions in a soil incubated with ${ }^{14} \mathrm{C}$ - and ${ }^{15} \mathrm{~N}$-labelled plant material. Soil Biology and Biochemistry 17: 329-337.

Bowen GD \& Rovira AD. 1999. The rhizosphere and its management to improve plant growth. Advances in Agronomy 66: 1-102.

Bowen P \& Freyman S. 1995. Ground covers affect raspberry yield, photosynthesis, and nitrogen nutrition of primocanes. HortScience 30: 238-241.

Brady NC \& Weil RR. 1996. The nature and properties of soils. New Jersey, Prentice Hall. 740 p. 
Brimecombe MJ, De Leij FAAM \& Lynch JM. 2007. Rhizodeposition and microbial populations. En: Pinton R, Varanini Z \& Nannipieri P (eds). The rhizosphere: Biochemistry and organic susbstances at the soil plant interface. CRC Press, Boca Ratón, Florida, p. 73-109.

Briones MJI \& Ineson P. 1996. Decomposition of Eucalyptus leaves in litter mixtures. Soil Biology and Biochemistry 28(10): 1381-1388.

Brown WH. 1978. Timbers of the world. Australia. Timber Research and Development Association. High Wycombe, Buckinghamshire, England. Vol. 8, 93 p.

Bünemann EK \& Condron LM. 2007. Phosphorus and sulphur cycling in terrestrial ecosystems. En: Marschner P \& Rengel Z (eds). Nutrient Cycling in Terrestrial Ecosystems. Springer, p. 65-92.

Burgess SSO, Adams MA, Turner NC \& Ong CK. 1998. The redistribution of soil water by tree root systems. Oecologia 115: 306-311.

Burket JZ, Hemphill DD \& Dick RP. 1997. Winter cover crops and nitrogen management in sweet corn and broccoli rotations. HortScience 32: 664-668.

Butterly CR, Bünemann EK, McNeill AM, Baldock JA \& Marschner P. 2009. Carbon pulses but not phosphorus pulses are related to decreases in microbial biomass during repeated drying and rewetting of soils. Soil Biology and Biochemistry 41: 1406-1416.

Butterly CR, Marschner P, McNeill AM \& Baldock JA. 2010. Rewetting $\mathrm{CO}_{2}$ pulses in Australian agricultural soils and the influence of soil properties. Biology and Fertility of Soils 46: 739-753.

Cabrera ML. 1993. Modeling the flush of nitrogen mineralization caused by drying and rewetting soils. Soil Science Society of America Journal 57: 63-66.

Cadisch G \& Giller KE (eds). 1997. Driven by nature: plant residue quality and decomposition. CAB International, Wallingford, UK. 409 p.

Caldwell MM \& Richards JH. 1989. Hydraulic lift: water efflux from upper roots improves effectiveness of water uptake by deep roots. Oecologia 79:1-5.

Caldwell MM, Dawson TE \& Richards JH. 1998. Hydraulic lift: consequences of water efflux from the roots of plants. Oecologia 113: 151-161. 
Carlyle JC \& Malcolm DC. 1986. Nitrogen availability beneath pure spruce and mixed larch + spruce stands growing on deep peat. I. Net mineralization measured by field and laboratory incubations. Plunt and Soil 93: 95-1 13.

Carpenter SR, Caraco NE, Correll DL, Howarth RW, Sharpley AN \& Smith VH. 1998. Nonpoint Pollution of Surface Waters with Phosphorous and Nitrogen. Ecological Applicacions 8:559-568.

Carpineti LA, Dalla Tea F, Glade JE \& Marcó M. 1995. Manual para productores de Eucaliptos de la Mesopotamia Argentina. Secretaría de Agricultura, Ganadería y Pesca. Instituto Nacional de Tecnología Agropecuaria, Argentina. p. 162.

Causton DR \& Venus JC. 1981. The biometry of plant growth. Edward Arnold (publishers) Ltd, London.

Ceballos D, Frangi J \& Jobbagy E. 2012. Soil volume and carbon storage shifts in drained and afforested wetlands of the Parana River Delta. Biogeochemistry 112: 359-372.

Chapin FS III. 1980. The mineral nutrition of wild plants. Annual Reviewof Ecology and Systematics 11: 233-260.

Chapin FS III, Bloom AJ, Field CB \& Waring RH. 1987. Plant responses to multiple environmental factors. BioScience 37: 49-57.

Chapin FS III, Walker BH, Hobbs RJ, Hooper DU, Lawton JH, Sala OE \& Tilman D.1997.Biotic control over the functioning of ecosystems. Science 277:500-504.

Chapman K, Whittaker JB \& Heal 0W. 1988. Metabolic and faunal activity in litters of three mixtures compared with pure stands. Agriculture, Ecosystems and Environment 24, 33-40.

Chapman SJ. 1997. Carbon substrate mineralization and sulphur limitation. Soil Biology and Biochemistry 29: 115-122.

Chaves MM, Pereira JS, Maroco J, Rodrigues ML, Ricardo CPP, Osorio ML, Carvalho I, Faria T \& Pinheiro C. 2002. How plants cope with water stress in the field. Photosynthesis and growth. Annals of Botany 89: 907-916.

Chaves MM, Maroco JP \& Pereira JS. 2003. Understanding plant responses to drought from genes to the whole plant. Functional Plant Biology 30: 239-264. 
Chepkwony CK, Haynes RJ, Swift RS \& Harrison R. 2001. Mineralization of soil organic $\mathrm{P}$ induced by drying and rewetting as a source of plant-available $\mathrm{P}$ in limed and unlimed samples of an acid soil. Plant and Soil 234: 83-90.

Coleman DC, Anderson RV, Cole CV, McClellan JF, Woods LE, Trofymow JA \& Elliot ET. 1984. Roles of protozoa and nematodes in nutrient cycling. P. 17-28. En Giddens JE y Todd RL (Ed.) Microbial-plant interactions. ASA Spec. Publ. 47. Soil Science Society of America, American Society of Agronomy and Crop Science Society of America, Madison, WI.

Comerford NB. 2005. Soil factors affecting nutrient bioavailability. En: BassiriRad H (Ed): Nutrient acquisition by plants an ecological perspective. Ecological Studios 181, Springer, Alemania. pp 1-14.

Condron LM. 2004. Phosphorus - surplus and deficiency. P. 69-84. En Schjønning P, Elmholt S, Christensen BT (Eds). Managing soil quality: challenges in modern agriculture. CAB International, Wallingford, UK.

Constantinides M \& Fownes JH. 1994. Nitrogen mineralization from leaves and litter of tropical plants: relationship to nitrogen, lignin and soluble polyphenol concentrations. Soil Biology and Biochemistry 26: 49-55.

Corbeels M, O’Connell AM, Grove TS, Mendham DS \& Rance SJ. 2003. Nitrogen release from eucalypt leaves and legume residues as influenced by their biochemical quality and degree of contact with soil. Plant and Soil 250: 15-28.

Cork SJ. 1984. Utilization of Eucalyptus foliage by arboreal marsupials. Proceed. Of the Nutrition Society of Australia 9: 88-97.

Cork SJ \& Foley WJ. 1991. Digestive and metabolic strategies of arboreal mammalian folivores in relation to chemical defensas in temperate and tropical forests. p. 133166. En: Palo RT \& Robbins CT (eds). Plant defenses against Mammalian herbivory. CRC Press, Boca Ratón, Florida, USA.

Cornelissen JHC. 1996. An experimental comparison of leaf decomposition rates in a wide range of temperate plant species and types. Journal of Ecology 84: 573-582

Cornelissen JHC, Castro-Diez P \& Hunt R. 1996. Seedling growth, allocation and leaf attributes in a wide range of woody plant species and types. Journal of Ecology 84: 755-765. 
Cornelissen JHC \& Thompson K. 1997. Functional leaf attributes predict litter decomposition rate in herbaceous plants. New Phytologist 135: 109-114.

Cornelissen JHC, Pérez Harguindeguy N, Díaz S, Grime JP, Marzano B, Cabido M, Vendramini F \& Cerabolini B. 1999. Leaf structure and defence control litter decomposition rate across species and life forms in regional floras of two continents. New Phytologist 143: 191-200.

Cornelissen JHC, Quested HM, Gwynn-Jones D, Van Logtestijn RSP, De Beus MAH, Kondratchuk A, Callaghan TV \& Aerts R. 2004. Leaf digestibility and litter decomposability are related in a wide range of subarctic plant species and types. Functional Ecologist 18: 779-786.

Cornelissen JHC, Quested HM, van Logtestijn RSP, Pérez-Harguindeguy N, Gwynn-Jones D, Díaz S, Callaghan TV, Press MC \& Aerts R. 2006. Foliar pH as a new plant trait: can it explain variation in foliar chemistry and carbon cycling processes among subarctic plant species and types? Oecologia 147: 315-326.

Cortez J, Garnier E, Pérez-Harguindeguy N, DebusscheM \& Gillon D. 2007. Plant traits, litter quality and decomposition in a Mediterranean old-field succession. Plant and Soil 296: 19-34.

Costa F, García C, Hernández T \& Polo A. 1991. Residuos Orgánicos Urbanos. Manejo y Utilización. Consejo Superior de Investigaciones Científicas. Centro de Edafología y Biología Aplicada del Segura. Murcia. España. 181 pp.

Cotrufo MF, Ineson P \& Rowland AP. 1994. Decomposition of tree leaf litters grown under elevated $\mathrm{CO}_{2}$ : Effect of litter quality. Plant and Soil 163: 121-130.

Couteaux MM, Bottner P, Berg B. 1995. Litter decomposition, climate and litter quality. Tree 10: 63-66.

Criado AC. 2014. LOTUS “PAMPA” INTA Una herramienta de trabajo para los suelos bajos-inundables. EEA Cuenca del Salado Publicación Técnica Marzo de 2014.

Criddle RS, Ward MR \& Huffaker RC. 1988. Nitrogen uptake by wheat seedlings, interactive effects of four nitrogen sources: $\mathrm{NO}_{3}{ }^{-}, \mathrm{NO}_{2}{ }^{-}, \mathrm{NH}_{4}{ }^{+}$, and urea. Plant physiology 86(1), 166-175.

Curl EA \& Truelove B. 1986. The rhizosphere. Advanced Series in Agricultural Sciences 15. Springer-Verlag, Heidelberg. 
Curtin D, McCallum FM \& Williams PH. 2003. Phosphorus innlight fraction organic matter separated from soils receiving long-term applications of superphosphate. Biology and Fertility of Soils 37: 280-287.

Cusack DF, Chou WW, Yang WH, Harmon ME, Silver WL, The TLIDET Team. 2009. Controls on long-term root and leaf litter decomposition in neotropical forests. Global Change Biology 15: 1339-1355.

Dalla Tea F \& Marcó M. 1996. Fertilizers and eucalypt plantations in Argentina. p. 327333 En: Attiwill P \& Adams M (eds.). Nutrition of Eucalypts. CSIRO Publishing, Collingwood, Australia.

Della Bruna E, Fernandes B, Borges AC, Almeida Filho J \& Barros NF. 1989. Efeito do extrato de serapilheira de Eucalyptus sobre o crescimento microbiano. Pesquisa Agropecuaria Brasileira 24: 1523-1528.

Della Bruna E, Borges AC, Fernandes B, Barros NF \& Mucovej RMC. 1991. Actividade da microbiota de solos adicionados de serapilheira de eucalipto e de nutrientes. Revista Brasileira de Ciencia do Solo 15: 15-20.

Dendooven L, Splatt P \& Anderson JM. 1996. Denitrification in permanent pasture soil as affected by different forms of C substrate. Soil Biology and Biochemistry 28: 141149 .

Denef K, Six J, Bossuyt H, Frey SD, Elliott ET, Merckx R \& Paustian K. 2001. Influence of dry-wet cycles on the interrelationship between aggregate, particulate organic matter, and microbial community dynamics. Soil Biology and Biochemistry 33: 15991611.

Dias-Filho MB, Davidson EA \& de Carvalho CJR. 1999. Pastures. En: McClain, ME, Victoris RL- \& Richey JE (eds.) The Biogeochemistry of the Amazon Basin. OxfordUniversity Press, New York.

Dorrepaal E, Cornelissen JHC, Aerts R, Wallén B \& Van Logtestijn RSP. 2005. Are growth forms consistent predictors of leaf litter quality and decomposability across peatlands along a latitudinal gradient? Journal of Ecology 93: 817-828.

Drenovsky RE \& Richards JH. 2004. Critical N: P values: predicting nutrient deficiencies in desert shrublands. Plant and Soil 259: 59-69. 
Drury CF, Zhang TQ \& Kay DB. 2003. The non-limiting and least limiting water ranges for soil nitrogen mineralization. Soil Science Society of America Journal 67: 13881404.

Duchaufour P. 1975. Manual de edafología. Toray-Masson. Barcelona, España, 477 p.

Egelkraut TM, Kissel DE \& Cabrera ML. 2000. Effect of Soil Texture on Nitrogen Mineralized from Cotton Residues and Compost. Journal of Environmental Quality 29: $1518-1522$.

Elliott ET, Anderson RV, Coleman DC \& Cole CV. 1980. Habitable pore space and microbial trophic interactions. Oikos 35: 327-335.

Engelbrecht BMJ, Comita LS, Condit R, Kursar TA, Tyree MT, Turner BL \& Hubbell SP. 2007. Drought sensitivity shapes species distribution patterns in tropical forests. Nature 447: 80-82.

Enriquez S, Duarte CM \& Sand-Jensen K. 1993. Patterns in decomposition rates among photosynthetic organisms: the importance of detritus C:N:P content. Oecologia 94: 457-471.

Ericsson T. 1995. Growth and shoot:root ratio of seedlings in relation to nutrient availability. Plant and Soil 168/169: 205-214.

Eviner VT \& Chapin FS III. 2003. Functional matrix: a conceptual framework for predicting multiple plant effects on ecosystem processes. Annual Reviewof Ecology and Systematics 34: 455-485.

Fageria NK \& Gheyi HR. 1999. En: Efficient crop production. Campina Grande, Paraiba, Brazil: University of Paraiba.

Fageria NK, Slaton NA \& Baligar VC. 2003. Nutrient management for improving lowland rice productivity and sustainability. Advances in Agronomy 80: 63-152.

Fageria NK. 2009. The use of nutrients in crop plants. CRC Press Taylor \& Francis Group, $448 \mathrm{p}$.

Fairhurst T, Lefroy RDB, Mutert E \& Batjes N. 1999. The importance, distribution and causes of phosphorus deficiency as a constraint to crop production in the tropics. Agroforestry Forum 9: 2-8. 
FAO. 1980. El Eucalipto en la Repoblacion Forestal. Colección FAO: Montes $\mathrm{N}^{\circ} 11$ Organización de las Naciones Unidas para la Agricultura y la Alimentacion Roma, 1981.

Facultad de Agronomía, Universidad de la República, 2015. Fósforo. Curso de Fertilidad de suelos. Disponible en: www.fagro.edu.uy/ fertilidad/publica/tomo_P_completo1.pdf

Fassbender HW. 1982. Química de suelos, con énfasis en suelos de América Latina. IICA, San José, Costa Rica.

Ferreira PJT, Gamelas JAF, Carvalho MGVS, Duarte GV, Canhoto JMPL \& Passas R. 2013. Evaluation of the papermaking potential of Ailanthus altissima. Industrial Crops and Products 42: 538-542.

Field C \& Mooney HA. 1986. The photosynthesis-nitrogen relationship in wild plants. p. 25-55 En: Givinish TJ (ed). On the economy of plant form and function. Cambridge University, Cambridge, Reino Unido.

Fierer N \& Schimel JP. 2002. Effects of drying-rewetting frequency on soil carbon and nitrogen transformations. Soil Biology and Biochemistry 34: 777-787.

Findlay WPK. 1934. Studies in the physiology of wood-decay fungi. I. The effect of nitrogen content upon the rate of decay. Annals of Botany 46: 109-117.

Fisher JT \& Mexal JG. 1984. Nutrition management: A physiological basis for yield improvement. p. 271-299. En: Duryea ML \& Brown DN (eds). Seedling Physiology and Reforestation Success. Martinus Nijhoff/Dr. W. Junk Publishers, Dordrecht, Holanda.

Fisher R \& Binkley D. 2000. Ecology and Management of forest soils. John Wiley and Sons Inc. 489 pp.

Fox RH, Myers RJK \& Vallis I. 1990. The nitrogen mineralization rate of legume residues in soil as influenced by their polyphenol, lignin, and nitrogen contents. Plant and Soil 129: $251-259$.

Föhse D, Claassen N \& Jungk A. 1991. Phosphorus efficiency of plants II.Significance of root radius, root hairs and cationanion balance for phosphorus influx in seven plant species. Plant and Soil 132: 261-272. 
Fokin AD \& Radzhabova PA. 1996. Availability of phosphates in soils as a function of the state and transformation of organic matter. Eurasian Soil Science 29 1216-1221.

Frame J. 1998. Lotus corniculatus. FAO. http://www.fao.org./AG/aGp/agpc/doc/DATA/pf00344.HTM. Consultado mayo de 2012.

Franche C, Lindström K, Elmerich C. 2009. Nitrogen-fixing bacteria associated with leguminous and non-leguminous plants. Plant and Soil 321: 35-59.

Frangi, JL, Richter LL, Barrera MD \& Aloggia M. 1997. Decomposition of fallen woody debris in Nothofagus forests of Tierra del Fuego, Argentina. Canadian Journal of Forest Research 27: 1095-1102.

Frangi JL, Barrera MD, Puigdefábregas J, Yapura P, Arambarri AM \& Richter LL. 2004. Ecología de los Bosques de la Tierra del Fuego. Capítulo 18, 88 p. En: Arturi MF, Frangi JL \& Goya JF (eds). 2004. Ecología y Manejo de los Bosques de Argentina. EDULP (Editorial Universidad Nacional de La Plata). ISBN 950-34-0307-3. Disponible on-line en SEDICI-UNLP.

Freeze RA \& Cherry JA. 1979. Groundwater. Prentice Hall, Englewood Cliffs, N.J. p. 604.

Fyles JW \& Fyles IH. 1993. Interaction of Douglas-fir with red alder and salal foliage litter during decomposition. Canadian Journal of Forest Research 23(3): 358-361.

Gallardo A \& Merino J. 1993. Leaf decomposition in 2 Mediterranean ecoystems of Southwest Spain - influence of substrate quality. Ecology 74: 152-161.

Gallegos-Vázquez, C, Olivares Sáenz, E, Vázquez-Alvarado R. \& Zavala-García, F. 2000. Absorción de nitrato y amonio por plantas de nopal en hidroponía. Terra Latinoamericana 18(2): 133-139.

Galloway JN, Schlesinger WH, Levy H, Michaels A \& Schnoor JL. 1995. Nitrogen fixation: Anthropogenic enhancement-environmental response. Global Biogeochemical Cycles 9(2): 235-252.

Garnier E. 1992. Growth analysis of congeneric annual and perennial grass species. Journal of Ecology 80: 665-675.

Garnier E \& Laurent G. 1994. Leaf anatomy, specific mass and water content in congeneric annual and perennial grass species. New Phytologist 128: 725-736. 
Gasper T, Franck T, Bisbis B, Kevers C, Jouve L, Hausman JF \& Dommes J. 2002. Concepts in plant stress physiology. Application to plant tissue cultures. Plant Growth Regul 37: 263-285.

Gillon D, Joffre R \& Ibrahima A. 1994. Initial litter properties and decay rate: a microcosm experiment on Mediterranean species. Canadian Journal of Botany 72: 946-954.

Giri B, Giang PH, Kumari R, Prasad R \& Varma A. 2005. Microbial diversity in soils. P 195-212 En: Buscot F \& Varma A (Eds) Microorganisms in soils: Roles in genesis and functions. Springer-Verlag, Heidelberg.

Göering HK \& Van Söest PJ. 1970. Forage fiber analyses. U.S. Department of Agriculture, Handbook No 379. pp.20.

Goldman JC, Caron DA \& Dennett MR. 1987. Regulation of gross growth efficiency and ammonium regeneration in bacteria by substrate C:N ratio. Limnol Oceanogr 32: 1239-1252.

Gonçalves JLM, Barros NF, Nambiar EKS \& Novais, RF. 1997. Soil and stand management or shortrotation plantations. In: Nambiar, E.K.S. and Brown, A.G. (eds.) Management of soil, water and nutrients in tropical plantation forests, 379-417. Australian Centre for International Agricultural Research (ACIAR), Monograph 43, Canberra.

González R, Treasure T, Wright J, Saloni D, Phillips R, Abt R \& Jameel H. 2011. Exploring the potential of Eucalyptus for energy production in the Southern United States: financial analysis of delivered biomass. Part I. Biomass Bioenerg 35 (2), 755766.

Gosz JR, Likens GE \& Bormann FH. 1973. Nutrient release from decomposing leaf and branch litter in the Hubbard Brook Forest New Hampshire. Ecological Monographs 43:173-191.

Gower ST \& Son Y. 1992. Differences in soil and leaf litterfall nitrogen dynamics for five forest plantations. Soil Science Society of America Journal 56: 1959-1966.

Goya JF, Frangi JL \& Dalla Tea F. 1997a. Relación entre biomasa aérea, área foliar y tipos de suelos en plantaciones de Eucalyptus grandis del NE de Entre Ríos, Argentina. Revista de la Facultad de Agronomía de La Plata 102 (2): 11-21 (Con referato). 
Goya JF, Frangi JL, Dalla Tea F, Marcó MA \& Larocca F. 1997b. Biomasa, productividad y contenido de nutrientes en plantaciones de Eucalyptus grandis en el NE de la Provincia de Entre Ríos. XII Jorn. Forestales de Entre Ríos, Concordia, octubre de 1997, III: 1-19.

Goya JF, Pérez C, Frangi JL \& Fernández R. 2003. Impacto de la cosecha y destino de los residuos sobre la estabilidad del capital de nutrientes en plantaciones de Pinus taeda L. Ecología Austral 13, 139-150.

Goya J, Frangi JL, Denegri G \& Larocca F. 2004. Impacto de diferentes regímenes de cosecha sobre el capital de nutrientes e indicadores económicos en plantaciones de Eucalyptus grandis del NE de Entre Ríos, Argentina. II Reunión Binacional de Ecología, XXI Reunión Argentina de Ecología, XI Reunión de la Sociedad de Ecología de Chile. Mendoza.

Goya JF, Frangi JL, Pérez C \& Dalla Tea FL. 2008. Decomposition and mineralization of Eucalyptus grandis leaf-litter in three soils of Entre Rios, Argentina. BOSQUE (Valdivia, Chile), 29(3): 217-226.

Goya JF, Frangi JL, Denegri G \& Larocca F. 2009. Simulación del impacto de diferentes regímenes de cosecha sobre el capital de nutrientes e indicadores económicos en plantaciones de Eucalyptus grandis del NE de Entre Ríos, Argentina. AUGMDOMUS 1: $1-17$.

Goya JF, Arturi M, Sandoval DM, Pérez C \& Frangi JL. 2013. Efecto de las Plantaciones de Eucalyptus grandis sobre el Contenido de N del Suelo en el NE de Entre Rios. IV Congreso Forestal Argentino y Latinoamericano. Puerto Iguazú, Misiones, Argentina.

Grace J. 1999. Environmental controls of gas exchange in tropical rain forest. En: MC Press, Scholes JD \& Barker MC (Eds) Physiological plants ecology. British Ecological Society. London, UK.

Graciano C, Guiamet JJ \& Goya JF. 2005. Impact of nitrogen and phosphorus fertilization on drought responses in Eucalyptus grandis seedlings. Forest Ecology and Management 212: 40-49.

Graciano C, Goya JF, Frangi JL \& Guiamet JJ. 2006a. Fertilization with phosphorus increases soil nitrogen absorption in young plants of Eucalyptus grandis. Forest Ecology and Management 236: 202-210. 
Graciano C, Guiamet JJ \& Goya JF. 2006b. Fertilization and water stress interactions in young Eucalyptus grandis plants. Canadian Journal of Forest Research 36: 10281034.

Graciano C, Goya JF, Arturi M, Pérez C \& JL Frangi. 2008. Fertilization in a fourth rotation Eucalyptus grandis plantation with minimal management. Journal of Sustainable Forestry 26 (2): 155-169.

Greenberg AE, Trussell RR \& Clesceri. 1985. Standard methods. For the examination of water and wastewater. Washington: American Public Health Association, American Water Works Association and Water Pollution Control Federation.

Grierson PF, Comerford NB \& Jokela EJ. 1998. Phosphorus mineralization kinetics and response of microbial phosphorus to drying and rewetting in a Florida spodosol. Soil Biol. Biochem, 30 (10/11): 1323-1331.

Grime JP, Cornelissen JHC, Thompson K \& Hodgson JG. 1996. Evidence of causal connection between anti-herbivore defence and the decomposition rate of leaves. Oikos 77:489-494.

Grime JP. 2001. Plant strategies, vegetation processes, and ecosystem properties. $2^{\text {nd }}$ Edition. Wiley, Chichester, UK

Guarnaschelli AB, Mantese AI \& Battaglia A. 2009. Cambios anatómicos y morfológicos en plántulas de Eucalyptus sp. en respuesta a diferentes niveles de luz. Boletín de la Sociedad Argentina de Botánica 44 (3-4): 273-285. 2009.

Guo L, Sims R, Horne D. 2002. Biomass production and nutrient cycling in Eucalyptus short rotation energy forests in New Zeland. I: biomass and nutrient accumulation. Bioresour. Technol 85 (3), 273-283.

Güsewell S, Verhoeven JTA. 2006 Litter N:P ratios indicate whether N or P limits the decomposability of graminoid leaf litter. Plant Soil 287:131-143.

Hageman RH. 1992. Ammonium versus nitrate nutrition of higher plants. En: Hauck RD, Beaton JD, Goring CAI, Hoeft RG, Randall GW \&y Russel DA (eds). Nitrogen in crop production. American Society of Agronomy, Crop Science Society of America and Soil Society of America. Madison, WI, USA. 67-88 pp. 
Hallberg GR.1989. Nitrate in ground water in the United States, in Nitrogen Management and Groundwater Protection, Developments in Agricultural and Managed-Forest Ecology 21: 35-74.

Halverson LJ, Jones TM \& Firestone MK. 2000. Release of intracellular solutes by four soil bacteria exposed to dilution stress. Soil Science Society of America Journal 64: 1630-1637.

Handayanto E, Cadisch G \& Giller KE. 1994. Nitrogen release from prunings of legume hedgerow trees in relation to quality of the prunings and incubation method. Plant and Soil 160: 237-248.

Hanway J \& Olson R. 1980. Phosphate nutrition of corn, sorghum, soybeans, and small grains. En: Khasawneh $\mathrm{F}$ et al. (ed) The role of phosphorus in agriculture. ASACSSA-SSSA. Madison, Wisconsin. USA. Pag. 681-691.

Hara T. 1984. A stochastic model and the moment dynamics of the growth and size distribution in plant populations. Journal of Theoretical Biology 109: 173-190.

Harper JE. 1984. Uptake of organic nitrogen forms by roots and leaves. Nitrogen in crop production, (nitrogenincropp). 165-170p.

Harris PJ. 1988. Ecology of the Soil Population. P 472-499 En: Wild A (Ed.) Russell's Soil Conditions and Plant Growth. Longman Scientific and Technical, Harlow.

Harrison RB, Reis GG, Reis MDGF, Bernardo AL \& Firme DJ. 2000. Effect of spacing and age on nitrogen and phosphorus distribution in biomass of Eucalyptus camaldulensis, Eucalyptus pellita and Eucalyptus urophylla plantations in southeastern Brazil. Forest Ecology and Management 133: 167-177.

Haslam E. 1981. Vegetable tannins. In The Biochemistry of Plants. Vol. 7 Conn, E.E., ed, pp. 527-544, Academic Press.

Hassink J, Bouwman LA, Zwart KB \& Brussard L. 1993. Relationships between habitable pore space, soil biota and mineralization rates in grassland soils. Soil Biology and Biochemestry 25: 47-55.

Hättenschwiler S \& Vitousek PM. 2000. The role of polyphenols in terrestrial ecosystem nutrient cycling. Trends in Ecology and Evolution 15 (6): 238-242. 
Hättenschwiler S, Tiunov AV, Scheu S. 2005. Biodiversity and litter decomposition in terrestrial ecosystems. Annual Review of Ecology, Evolution, and Systematics 36:191-218.

Havlin JL, Beaton JD, Tisdal SL \& Nelson WL. 1999. Soil fertility and fertilizers. An introduction to nutrient management, 6th ed. Bergen, NJ, USA: Prentice Hall.

Haynes RJ \& Swift RS. 1985. Effects of air-drying on the adsorption and desorption of phosphate and levels of extractable phosphate in a group of acid soils of New Zealand. Geoderma 35: 145-157.

Haynes RJ \& Swift RS. 1986. Effects of soil acidification and subsequent leaching on levels of extractable nutrients in a soil. Plant and Soil 95:327-336.

Haynes RJ. 1986. The decomposition process: mineralization, immobilization, humus formation, and degradation. En: Haynes RJ (Ed.) Mineral nitrogen in the plant-soil system. Academic Press, Orlando, Florida, USA. Pp 52-126.

Heal OW, Anderson JM \& Swift MJ. 1997. Plant litter quality and decomposition: an historical overview. In: Cadisch G, Giller KE (eds) Driven by nature: plant litter quality and decomposition. CAB International, Wallingford, pp 3-30.

Hebebrand C. 2015. Responsible Plant Nutrition - Point of view n4. 20pp. Disponible en: http://www.fertilizer.org/imis20/images/Library_Downloads/2015_farm_pointofview hebebrand_en.pdf?WebsiteKey=411e9724-4bda-422f-abfc8152ed74f306\&=404\%3bhttp $\% 3 \mathrm{a} \% 2 \mathrm{f} \% 2$ fwww.fertilizer.org $\% 3 \mathrm{a} 80 \% 2$ fen $\% 2$ fimages \%2fLibrary Downloads\%2f2015 farm pointofview hebebrand en.pdf

Hedley MJ, Mortvedt JJ, Bolan NS \& Syers JK. 1995. Phosphorus fertility management in agroecosystems. En: Tiessen H (Ed.) Phosphorus in the Global Environment. Transfers, Cycles and Management. John Wiley \& Sons, Chichester.

Hentschel K, Borken W \& Matzner E. 2007. Leaching losses of inorganic N and DOC following repeated drying and wetting of a spruce forest soil. Plant and Soil 300: 2134.

Heredia OS. 2000. Ciclos biogeoquímicos de elementos: Fósforo. En: Conti ME (editor), Principios de edafología, con énfasis en suelos argentinos. $2^{\circ}$ Ed. Editorial Facultad de Agronomía (EFA), Buenos Aires, Argentina. 427pp. International Fertilizer Industry Association. 
Herrán JAF, Sañudo R, Rojo G, Martínez R \& Portugal V. 2008. Importancia de los abonos orgánicos. Ra Ximhai 4(1): 57-67.

Hingston FJ, O’Connell AM \& Grove TS. 1989. Nutrient cycling in Jarrah forest. En: Dell B, Have1 JJ \& Malajczuk N (Eds).The Jarrah Forest, A Complex Mediterranean Ecosystem Kluwer Academic, Dordrecht, The Netherlands. pp 155-177.

Hobbie SE. 1996. Temperature and plant species control over litter decomposition in Alaskan tundra. Ecological Monographs 66: 503-522.

Hook JE. 1983. Movement of phosphorous and nitrogen in soil following application of municipal wastewater, in Chemical Mobility and Reactivity in Soil Systems, editado por D.W. Nelson, Soil Science Society of America, Madison, Wis. pp.241-255.

Hooper DU \& Johnson L. 1999. Nitrogen limitation in dry land ecosystems: responses to geographical and temporal variation in precipitation. Biogeochemistry 46: 247-293.

Houba VJG, Novozansky I, Huybregts AWM \& Van der Lee JJ. 1986. Comparison of soil extractions by $0.01 \mathrm{M} \mathrm{CaCl}$, by EUF and by some conventional extraction procedures. Plant Soil 76: 433-437.

Hu YC \& Schmidhalter U. 2005. Drought and salinity: a comparison of their effects on mineral nutrition of plants. Journal of Plant and Nutrition and Soil Science 168: 541549.

Hu YC, Shao HB, Chu LY \& Wu G. 2006b. Relationship between water use efficiency (WUE) and production of different wheat genotypes at soil water deficit. Colloids and Surfaces B: Biointerfaces 53(2): 271-277.

Hu S, Tu C, Chen X \& Gruver JB. 2006a. Progressive N limitation of plant response to elevated CO2: a microbiological perspective. Plant and Soil 289: 47-58.

Huang ML, Deng XP, Zhao YZ, Zhou SL, Inanaga S, Yamada S \& Tanaka K. 2007. Water and nutrient use efficiency in diploid, tetraploid and hexaploid wheats. Journal of Integrative Plant Biology 49 (5): 706-715.

Huante P, Rincón E \& Acosta I. 1995. Nutrient availability and growth rate of 34 woody species from a tropical deciduous forest in Mexico. Functional Ecology 9: 849-858.

Huber DM. 1981. The use of fertilizers and organic amendments in the control of plant disease. En: Pimentel D (Ed) CRC Handbook of pest management in agriculture. CRC Press, Boca Raton, Florida. pp. 357-394. 
Huguenin-Elie O, Kirk GJD \& Frossard E. 2003. Phosphorus uptake by rice from soil that is flooded, drained or flooded then drained. European Journal of Soil Science 54: 7790.

Hunt R, Causton DR, Shipley B \& Askew AP. 2002. A modern tool for classical plant growth analysis. Annals of Botany 90: 485 \pm 488 ,

Ibrikci H, Comerford NB, Hanlon EA \& Rechcigl JE. 1994. Phosphorus uptake by bahiagrass from Spodosols: Modeling of uptake from different horizons. Soil Science Society of America Journal 58(1): 139-143.

Igue K. 1984. Dinâmica da matéria orgânica e seus efeitos na propriedade do solo. pp. 232-267. In: Adubo verde no Brasil. Fundação Cargill, Campinas, SP. Brasil.

Ingestad T \& Kahr M. 1985. Nitrogen and growth of coniferous seedlings at varied relative nitrogen addition rate. Physiol Plant. 65: 109-116.

Inselsbacher E \& Näsholm T. 2012. The below-ground perspective of forest plants: soil provides mainly organic nitrogen for plants and mycorrhizal fungi. New Phytologist 195: 329-334.

Ineson P \& McTieman KB. 1992. Decomposition of foliar litter mixtures: a microcosm experiment. En: Teller A, Mathy P \& Jeffers JNR (Eds). Responses of Forest Ecosystems to Environmental Changes. Elsevier Applied Science, Barking. pp. 703706.

Iyamuremye FR, Dick RP \& Baham J. 1996. Organic amendments and phosphorus dynamics. II: Distribution of soil phosphorus fractions. Soil Science 161:436-443.

Jaime S. 2000. Incorporación de eucaliptos en establecimientos ganaderos-arroceros de la zona centro-norte de la provincia de Entre Ríos: Evaluación económica-financiera. Trabajo para obtener el grado de Licenciado en Administración Agraria en la Facultad de Agronomía de la Universidad Nacional del Centro de Buenos Aires.

Jensen ES. 1994. Mineralization-immobilization of nitrogen in soil amended with low C:N ratio plant residues with different particle sizes. Soil Biology \& Biochemistry 26: 519-521.

Jensen ES. 1997. Nitrogen immobilization and mineralization during initial decomposition of 15N-labelled pea and barley residues. Biology and Fertility of Soils 24, 39-44. 
Jingquan Y \& Dewei C. 1988. Effects of different nitrogen forms on tomato grown in carbonized rice hull. Soilless Culture 4: 51-61.

Jones MJ. 1976. Effects of three nitrogen fertilizers and lime on $\mathrm{pH}$ and exchangeable cation content at different depths in cropped soils at two sites in the Nigerian savanna. Tropical Agriculture 53: 243-254.

Kaiser EA \& Heinemeyer O. 1993. Seasonal variations of soil microbial biomass carbon within the plough layer. Soil Biology \& Biochemistry 25: 1649-1656.

Kapoor R \& Mukerji KG. 2006. Rhizosphere microbial community dynamics. P 55-66 En: Mukerji KG, Manoharachary $\mathrm{C}$ \& Singh J (Eds.) Microbial activity in the rhizosphere. Springer, Berlin, Germany.

Kardell L, Steen E \& Fabiao A. 1986. Eucalyptus in Portugal- a threat or a promise. Ambio 15: 7-13.

Kazakou E, Vile D, Shipley B, Gallet C \& Garnier E. 2006. Covariations in litter decomposition, leaf traits and plant growth in species from a mediterranean old-field succession. Functional Ecology 20:21-30

Keith H. 1997. Nutrient cycling in eucalypt ecosystems. En: Williams JE \& JCZ Weinarski (Ed). Eucalypt ecology, individuals to ecosystems. Cambridge University Press. Cap 9, 197-226.

Kibblewhite, RP, Johnson BI \& Shelbourne CJA. 2000. Kraft pulp qualities of Eucalyptus nitens, E. globulus, and E. maidenii, at ages 8 and 11 years. New Zealand. J. For. Sci. 30 (3): 447-457.

Kieft TL, Soroker E \& Firestone MK. 1987. Microbial biomass response to a rapid increase in water potential when dry soil is wetted. Soil Biology and Biochemistry 19: 119126.

Killham K, Amato M \& Ladd JN. 1993. Effect of substrate location in soil and soil porewater regime on carbon turnover. Soil Biology and Biochemistry 25: 57-62.

Kimmins JP. 1974. Sustained yield, timber mining, and the concept of ecological rotation; a British Columbian view. The Forestry Chronicle 50: 27-31.

Kirchmann H, Johnston AE \& Bergström LF. 2002. Possibilities for reducing nitrate leaching from agricultural land. AMBIO: A Journal of the Human Environment 31(5): 404-408. 
Klemmedson J0. 1987. Influence of oak in pine forests of central Arizona on selected nutrients of forest floor and soil. Soil Science Society of America Journal 51: 16231628.

Knapic, S. Pirralho M, Louzada JL \& Pereira H. 2014. Early assessment of density features for 19 Eucalyptus species using X-ray microdensitometry in a perspective of potential biomass production. Wood Sci. Technol. 48 (1), 37-49.

Kordsachia O, Wandinger B \& Patt R. 1992. Some investigations on ASAM pulping and chlorine free bleaching of Eucalyptus from Spain. Holz Roh-Werkst 50: 85-91.

Kronzucker HJ, Siddiqi MY \& Glass ADM. 1997. Root discrimination against soil nitrate and the ecology of forest succession. Nature 385: 59-61.

Kruse JS, Kissel DE \& Cabrera ML. 2004. Effects of drying and rewetting on carbon and nitrogen mineralization in soils and incorporated residues. Nutrient Cycling in Agroecosystems 69: 247-256.

Kuiters AT. 1990. Role of phenolic substances from decomposing forest litter in plant-soil interactions. Acta Botanica Neerlandica 39: 329-348

Kumar K \& Goh KM. 2000. Crop residues and management practices: effects on soil quality, soil nitrogen dynamics, crop yields, and nitrogen recovery. Advances in Agronomy 68:197-319.

Kuzyakov Y, JK Friedel \& Stahr K. 2000. Review of mechanisms and quantification of priming effects. Soil Biology and Biochemistry 32: 1485-1498.

Kuzyakov Y \& Domanski G. 2000. Carbon input by plants into the soil: review. Journal of Plant Nutrition and Soil Science 163: 421-431.

Kuzyakov Y. 2002. Review: Factors affecting rhizophere priming effects. Journal of Plant Nutrition and Soil Science 165: 382-396.

Kuzyakov Y \& Xu X. 2013. Competition between roots and microorganisms for nitrogen: mechanisms and ecological relevance. New Phytologist 198: 656-669.

Kwak YW, Min BH \& Lee JM. 1989. Effects of nitrogen source on growth and fruit development of tomatoes grown in nutrient solution. Abstracts of Communicated Horticultural Science 7: 60-61 
Kwabiah AB, Palm CA, Stoskopf NC \& Voroney RP. 2003a. Response of soil microbial biomass dynamics to quality of plant materials with emphasis on P availability. Soil Biology \& Biochemistry 35: 207-216.

Kwabiah AB, Stoskopf NC, Palm CA \& Voroney RP. 2003b. Soil P availability as affected by the chemical composition of plant materials: implications for P-limiting agriculture in tropical Africa. Agriculture, Ecosystems and Environment 100: 53-61.

Lajtha K \& Klein M. 1988. The effect of varying nitrogen and phosphorus availability on nutrient use by Larrea tridentata, a desert evergreen shrub. Oecologia, 75: 348-353.

Lambers H \& Poorter H. 1992. Inherent variation in growth rate between higher plants: A search for physiological causes and ecological consequences. Advances in Ecological Research 23: 187-261.

Landsberg JJ \& Cork SJ. 1997. Herbivory: interactions between eucalypts and the vertebrates and invertebrates that feed on them. Chapter 14, pags: 342-372. En JE Williams y JCZ Woinarski (ed) 1997. Eucalypt Ecology. Individuals to ecosystems. Cambridge University Press, Cambridge, UK.

Law BE, Williams M, Anthoni PM, Baldocchi DD \& Unsworth MH. 2000. Measuring and modeling seasonal variation of carbon dioxide and water vapour exchange of a Pinus ponderosa forest subjet to soil water deficit. Global Change Biology 6: 613-630.

Lee BJ. 1974. Effects of mirex on litter organisms and leaf decomposition in a mixed hardwood forest in Athens, Georgia. Journal of Environment Quality 3 305-311.

Lee X, Wu HJ, Sigler J, Oishi C \& Siccama T. 2004. Rapid and transient response of soil respiration to rain. Global Change Biology 10: 1017-1026.

Lefroy RDB, Chaiter W \& Blair GJ. 1994. Release of sulfur from rice residues under flooded and non-flooded soil conditions. Australian Journal of Agricultural Research 45: 657-667.

Lima MDRR, Santos AT, Espinosa RG \& Cerrato RF. 2000. Producción de papa y biomasa microbiana en suelo con abonos orgánicos y minerales. Agrociencia 34: 261-269.

Lin C, Busscher WJ \& Douglas LA. 1983. Multifactor Kinetics of phosphate reactions with minerals in acidic soils. I. Modeling and simulation. Soil Science Soc. Am. J. 47:1097-1103. 
Liski J, Nissinen A, Erhard M \& Taskinen O. 2003. Climatic effects on litter decomposition from arctic tundra to tropical rainforest. Global Change Biology 9: $575-584$.

Lorenz OA \& Vittum MT. 1980. Phosphate nutrition of corn, sorghum, soybeans and small grains. En: Khasawneh FE et al. (ed). The role of phosphorus in agriculture. ASA, CSSA, and SSSA, Madison, WI. Pp 681-692.

Lousier JD \& Parkinson D. 1978. Chemical element dynamics in decomposing leaf litter. Canadian Journal of Botany 56:2795-2812.

Luo Y, Field CB, Jackson RB. 2006. Does nitrogen constrain carbon cycling, or does carbon input stimulate nitrogen cycling? Ecology 87: 3-4.

Lützow M, Kögel-Knabner I, Ekschmitt K, Matzner E, Guggenberger G, Marschner B \& Flessa H. 2006. Stabilization of organic matter in temperate soils: mechanisms and their relevance under different soil conditions - a review. European Journal of Soil Science 57: 426-445.

Lynch JM. 1990. Introduction: some consequences of microbial rhizosphere competence for plant and soil. p 1-10 En: Lynch JM (Ed.) The rhizosphere. John Wiley \& Sons Ltd, Chichester, UK.

Lynch J. 1995. Root architecture and plant productivity. Plant Physiology 109: 7-13.

Magid J \& Nielsen NE. 1992. Seasonal-variation in organic and inorganic phosphorus fractions of temperate-climate sandy soils. Plant and Soil 144: 155-165.

Maldonado JM. 1993. Asimilación del nitrógeno y del azufre. En: J. Azcon B \& Talon M. Fisiología y bioquímica vegetal. Interamericana-McGraw-Hill, Madrid. pp. 215-236.

Marañón T \& Grubb PJ. 1993. Physiological basis and ecological significance of the seed size and relative growth rate relationship in Mediterranean annuals. Functional Ecology 7: 591-599.

Marcó MA, Glade JE, Larocca LH \& Larocca F. 1994. Posibilidades del Eucalyptus grandis en el área ganadera del noreste de Entre Ríos. PROFOME EEA INTA Concordia. Entre Ríos. 19 pp.

Marschner H .1995. Mineral nutrition of higher plants, Second edition. Academic Press, Amsterdam. 889 pp. 
Martin JP, Filip Z \& Haider K. 1976. Effect of montmorillonite and humate on growth and metabolic activity of some actinomycetes. Soil Biology \& Biochemistry 8: 409-413.

Matson PA, Parton WJ, Power AG \& Swift MJ. 1997. Agricultural intensification and ecosystem properties. Science 277(5325): 504-509.

Maynard DG y Kalra YP. 1993. Nitrate and exchangeable ammonium nitrogen. P 25-37 En: Carter MR (ed) Soil sampling and methods of analysis. Canadian Society of Soil Science, Lewis Publishers, Boca Raton, Fla.

Mazzarino MJ, Walter I, Costa G, Laos F, Roselli L \& Satti P. 1997. Plant response to fish farming wastes in volcanic soils. Journal of environmental quality 26(2): 522-528.

Mazzarino MJ, Bertiller MB, Sain C, Satti P \& Coronato F. 1998. Soil nitrogen dynamics in northeastern Patagonia steppe under different precipitation regimes. Plant and Soil 202(1): 125-131.

McClaugherty CA, Pastor J, Aber JD. 1985. Forest litter decomposition in relation to soil nitrogen dynamics and litter quality. Ecology 66:266-275

McKenney DJ, Wang SW, Drury CF \& Findlay WI. 1995. Denitrification, immobilization, and mineralization in nitrate limited and non limited residue-amended soil. Soil Science Society of America Journal 59: 118-124.

Meentemeyer V. 1978. Macroclimate and lignin control of litter decomposition rates. Ecology 59:465-472

Meister RT. 1995. Farm chemicals handbook '95, Vol. 81. Meister Publ. Co., Willowby, $\mathrm{OH}$.

Meinzer FC, Brooks JR, Bucci SJ, Goldstein G, Scholz FG \& Warren JM. 2004. Converging patterns of uptake and hydraulic redistribution of soil water in contrasting woody vegetation types. Tree Physiol. 24: 919-928.

Melillo JM, Aber JD \& Muratore JF. 1982. Nitrogen and lignin control of hardwood leaf litter decomposition dynamics. Ecology 63: 621-626.

Melillo JM, Aber JD, Linkins AE, Ricca A, Fry B \& Nadelhoffer KJ. 1989. Carbon and nitrogen dynamics along the decay continuum: Plant litter to soil organic matter. Plant and Soil 115: 189-198.

Mendham DS, Kumaraswamy S, Balasundaran M, Sankaran KV, Corbeels M, Grove TS, O’Connell AM \& Rance SJ. 2004. Legume cover cropping effects on early growth 
and soil nitrogen supply in eucalypt plantations in south-western India. Biology and Fertility of Soils 39: 375-382.

Mengel K \& Kirkby EA. 1987. Principles of plant nutrition. 4th ed. International Potash Institute, Bern.

Mengel K, Kirkby A, Kosegarten H \& Appel T. 2001. Principles of plant nutrition, 5th edition. Dordrecht, The Netherlands: Kluwer Academics.

Meskimen GF \& John K. 1990. Eucalyptus grandis Hill ex Maiden. Rose gum eucalyptus. En: Burns, Russell M.; Honkala, Barbara H., eds. Silvics of North America: 2. Hardwoods. Agric. Handb. 654. Washington, DC: U.S. Department of Agriculture, Forest Service: 305-312.

Mikkelsen RL. 2007. Biuret in urea fertilizers. Better crops with plant food 91(3): 6-7.

Miller AJ \& Cramer MD. 2004. Root nitrogen acquisition and assimilation. Plant and Soil 274: $1-36$.

Miller AE, Schimel JP, Meixner T, Sickman JO \& Melack JM. 2005. Episodic rewetting enhances carbon and nitrogen release from chaparral soils. Soil Biology \& Biochemistry 37: 2195-2204.

Misra A \& Tyler G. 2000. Effects of wet and dry cycles in calcareous soil on mineral nutrient uptake of two grasses, Agrostis stolonifera L. and Festuca ovina L. Plant and Soil 224: 297-303.

Monleon VJ \& Cromack K. 1996. Long-term effects of prescribed underburning on litter decomposition and nutrient release in ponderosa pine stands in central Oregon. Ecology Management 81:143-152

Mukerji KG, Manoharachary C \& Singh J. 2006. Microbial activity in the rhizosphere. Soil Biology Vol 7. Springer, Heidelberg.

Muraoka T, Ambrosano EJ , Zapata F, Bortoletto N, Martins ALM, Trivelin PCO, Boaretto AE \& Scivittaro WB. 2001. Efficiency of green manure (Crotalaria and Mucuna) and Urea as Nitrogen Source for Rice Crop. Terra 20: 17-23.

Muraoka T, Ambrosano EJ, Zapata F, Bortoletto N, Martins ALM, Trivelin PCO, Boaretto AE, Scivittaro WB. 2002. Eficiencia de abonos verdes (Crotalaria y mucuna) y urea, aplicados solos o juntamente, como fuentes de $\mathrm{N}$ para el cultivo de arroz. Terra Latinoamericana 20 (1): 17-23 
Murrell TS. 2003. Transformaciones de los nutrientes del suelo. Instituto de la Potasa y el Fósforo (INPOFOS, Quito, Ecuador). Informaciones Agronómicas. Boletín No 49 (abril):16 p.

Muslera Pardo E \& Ratera García C. 1984. Praderas y Forrajes. Mundi-Prensa Libros S.A. $702 \mathrm{p}$.

National Academy of Sciences. 1980. Firewood crops: shrub and tree species for energy production. Washington, DC: National Academy of Sciences. $236 \mathrm{p}$.

National Academy of Sciences. 1979. Tropical Legumes: Resources for the Future. Washington D.C.

Navarro-García F, Casermeiro MA \& Schimel JP. 2012. When structure means conservation: Effect of aggregate structure in controlling microbial responses to rewetting events. Soil Biology \& Biochemistry 44: 1-8.

Neiva D, Fernandes LS, Araújo A, Lourenc J, Gominho R \& Simões HP. 2015. Chemical composition and kraft pulping potential of 12 eucalypt species. Industrial Crops and Products 66 (2015) 89-95.

Neuhauser EF \& Hartenstein R. 1978. Phenolic content and palatability of leaves and wood to soil isopods and diplopods. Pedobiologia 18: 99-109.

Newman ACD. 1984. The Significance of Clays in Agriculture and Soils. Phil. Trans. R. Soc. Lond. A 311: 375-389.

Newman EI \& Watson A. 1977. Microbial abundance in the rhizosphere: a computer model. Plant and Soil 48: 17-56.

Newton WE, Dilworth MJ, Sprent J \& James EK. 2008. Leguminous nitrogen-fixing symbioses. Dordrecht, the Netherlands: Springer.

Nguluu SN, Probert ME, Myers RJK \& Waring SA. 1996. Effect of tissue phosphorus concentration on the mineralisation of nitrogen from stylo and cowpea residues. Plant and Soil 191: 139-146.

Nguyen C. 2003. Rhizodeposition of organic C by plants: mechanisms and controls. Agronomie 23: 375-396.

Nieder R \& Benbi DK. 2008.Chapter 2: Carbon and Nitrogen Cycles in Terrestrial Ecosystems. En: Nieder R y DK Benbi (ed). Carbon and Nitrogen in the Terrestrial Environment, 2008 Springer. 
Nommik H \& Vahtras K. 1982. Retention and fixation of ammonium and ammonia in soils. In: Nitrogen in agricultural soils. F. J. Stevenson Ed. 123-171. Madison, WI: ASA, CSSA, and SSSA.

Northup RR, Dahlgren RA \& McColl JG. 1998. Polyphenols as regulators of plant-littersoil interactions in northern California's pygmy forest: a positive feedback? Biogeochemistry 42: 189-220.

Nyamangara J, Gotosa J \& Mpofu SE. 2001. Cattle manure effects on structural stability and water retention capacity of a granitic sandy soil in Zimbabwe. Soil and Tillage Research 62: 157-162.

Nyhan JW. 1976. Influence of soil temperature and water tension on the decomposition rate of carbon-14 labeled herbage. Soil Science 121: 288-293.

Nziguheba G, Merckx R, Palm ChA, Rao MR. 2000. Organic residues affect phosphorus availability and maize yields in a Nitisol of western Kenya. Biology and Fertility of Soils 32:328-339.

O'Connell AM. 1987. Litter dynamics in karri (Eucalyptus diversicolor) forest of southwestern Australia. Journal of Ecology 75: 781-796.

O’Connell AM \& Sankaran KV. 1997. Organic matter accretion, decomposition and mineralization. En: Nambiar, E.K.S. \& A.G. Brown (Ed). Management of soil, nutrients and water in tropical plantation forests. GPO Box 1571, Canberra ACT 2601, Australia. Cap 13, 443-480.

O'Donnell AG, Wu J \& Syers JK. 1994. Sulfate S amendements in soil and their effects on the transformation of soil sulfur. Soil Biology \& Biochemistry 26 1507-1514.

Oger PM, Mansouri H, Nesme X \& Dessaux Y. 2004. Engineering root exudation of Lotus toward the production of two novel carbon compounds leads to the selection of distinct microbial populations in the rhizosphere. Microbial Ecology 47: 96-103.

Olsen RG \& Court MN. 1982. Effect of wetting and drying of soils on phosphate adsorption and resin extraction of soil phosphate. Journal Soil Science 33: 709-712.

Olson JS. 1963. Energy storage and the balance of producers and decomposers in ecological systems. Ecology 44: 322-331.

Ona T, Sonoda T, Ito K, Shibata M, Tamai Y, Kojima Y, Ohshima J, Yokota S \& Yoshizawa N. 2001. Investigation of relationships between cell and pulp properties in 
Eucalyptus by examination of within-tree property variations. Wood Science and Technology 35 (3): 229-243.

Ottow JCG \& Fabig W. 1985. Influence of oxygen aeration on denitrification and redox level in different bacterial cultures. En: Caldwell DE, Brierley JA \& Brierley CL (Eds) Planetary ecology. Van Nostrand Reinhold, New York. 427-440 pp.

Otsus M \& Zobel M. 2004. Moisture conditions and the presence of bryophytes determine fescue species abundance in a dry calcareous grassland. Oecologia 138: 293-299.

Paavilainen L. 2000. Quality-competitiveness of Asian short-fibre raw materials in different paper grades. Paperi ja Puи 82 (3): 156-161.

Palm CA \& Sanchez PA. 1990. Decomposition and nutrient release patterns of the leaves of three tropical legumes. Biotropica 22: 330-338.

Palm CA \& Sanchez PA. 1991. Nitrogen release from the leaves of some tropical legumes as affected by their lignin and polyphenolic contents. Soil Biology \& Biochemistry 23: 83-88.

Palma RM \& Segat AL. 2000. Nitrógeno del suelo. En: Conti M.E. (editor), Principios de edafología, con énfasis en suelos argentinos. $2^{\circ}$ Ed. Editorial Facultad de Agronomía (EFA), Buenos Aires, Argentina. 427pp.

Paneque-Pérez VM. 2010. Manual de técnicas analíticas para análisis de suelo, foliar, abonos orgánicos y fertilizantes químicos. Ediciones INCA (Instituto Nacional de Ciencias Agrícolas), La Habana, Cuba. Pag. 160.

Parkin, TB \& Meisinger JJ. 1989. Denitrification below the crop rooting zone as influenced by surface tillage. Journal of Environmental Quality 18:12-16.

Parton WJ, Schimel DS, Ojima DS \& Cole CB. 1994. A general model for soil organic matter dynamics. In: Bryant RB, Arnold RW (eds) Sensitivity to litter chemistry, texture and management. Soil Sci Soc Am Spec Publ 38:137-167.

Parton W, Silver WL, Burke IC, Grassens L, Harmon ME, Currie WS et al. 2007. Globalscale similarities in nitrogen release patterns during long-term decomposition. Science 315: 361-364.

Pastor J, Aber JD, McClaugherty CA, Melillo JM. 1984. Aboveground production and N and $\mathrm{P}$ cycling along a nitrogen mineralization gradient on Blackhawk Island,Wisconsin. Ecology 65:256-268. 
Paul EA \& Clark FE. 1988. Soil Microbiology and Biochemistry. San Diego, CA: Academic Press.

Pérez-Harguindeguy N, Díaz S, Cornelissen JHC, Vendramini F, Cabido M \& Castellanos A. 2000. Chemistry and toughness predict leaf litter decomposition rates over a wide spectrum of functional types and taxa in central Argentina. Plant and Soil 218: 2130.

Peterson DL \& Rolfe GL .1982. Nutrient dynamics and decomposition of litterfall in floodplain and upland forests of central Illinois. Forest Science 28:667-681.

Pfeiffer DA. 2003. Comiendo combustibles fósiles. From The Wilderness. Disponible en: https://scholar.google.com/scholar?q=Pfeiffer + DA. $+2003 .+$ Comiendo + combustibles $+\mathrm{f} \% \mathrm{C}$ $3 \%$ B3siles. + From + The + Wilderness $\& b t n G=\& h l=e s \&$ as $\_s d t=0 \% 2 \mathrm{C} 5$

Poorter H. 1989. Interspecific variation in relative growth rate: On ecological causes and physiological consequences. P 45-68 En: Lambers H, Cambridge ML, Konings H \& Pons TL (Edit). Causes and consequences of variation in growth rate and productivity of higher plants. SPB, La Haya, Países Bajos.

Poorter H \& Remkes C. 1990. Leaf area ratio and net assimilation rate of 24 wild species differing in relative growth rate. Oecologia 83: 553-559.

Postma JA, Schurr U \& Fiorani F. 2014. Dynamic root growth and architecture responses to limiting nutrient availability: linking physiological models and experimentation. Biotechnology Advances 32:53-65.

Prause J \& Fernandez Lopez C. 2007. Litter decomposition and lignin/cellulose and lignin/total nitrogen rates of leaves in four species of the Argentine Subtropical forest. Agrochimica 51(6): 294-300.

Prescott CE, Chappell HN \& Vesterdal L. 2000. Nitrogen turnover in forest floors of coastal Douglas-fir at sites differing in soil nitrogen capital. Ecology 81:1878-1886.

Prescott CE. 2005. Cap 2: Decomposition and Mineralization of Nutrients from Litter and Humus. Ecological Studies,Vol. 181 H.BassiriRad (Ed.) Nutrient Acquisition by Plants An Ecological Perspective (C) Springer-Verlag Berlin Heidelberg 2005

Prieme A \& Christensen S. 2001. Natural perturbations, drying- wetting and freezingthawing cycles, and the emission of nitrous oxide, carbon dioxide and methane from farmed organic soils. Soil Biology \& Biochemistry 33: 2083-2091. 
Pulleman M \& Tietema A. 1999. Microbial C and N transformations during drying and rewetting of coniferous forest floor material. Soil Biology and Biochemistry 31: 275285.

Qian JH, Doran JW, Weier KL, Mosier AR, Peterson TA \& Power JM. 1997. Soil denitrification and nitrous oxide losses under corn irrigated with high-nitrate groundwater. Journal Environment Quality 26: 348-360.

Querejeta JI, Egerton-Warburton LM, Prieto I, Vargas R \& Allen MF. 2012. Changes in soil hyphal abundance and viability can alter the patterns of hydraulic redistribution by plant roots. Plant and Soil 355: 63-73.

Quested HM, Cornelissen JHC, Press MC, Callaghan TV, Aerts R, Trosien F, Riemann P, Gwynn-Jones D, Kondratchuk A \& Jonasson SE. 2003. Decomposition of sub-arctic plants with differing nitrogen economies: a functional role for hemiparasites. Ecology 84, 3209-3221.

Raaimakers D, Boot RGA, Dijkstra P, Pot S \& Pons T. 1995. Photosynthetic rates in relation to leaf phosphorus content in pioneer versus climax tropical rainforest trees. Oecologia 102: 120-125.

Reich PB \& Schoettle AW. 1988. Role of phosphorus and nitrogen in photosynthetic and whole plant carbon gain and nutrient-use efficiency in eastern white pine. Oecologia 77: $25-33$.

Reich PB, Walters MB \& Ellsworth DS. 1992. Leaf life-span in relation to leaf, plant, and stand characteristics among diverse ecosystems. Ecological Monographs 62: 365392.

Reich PB, Walters MB, Ellsworth DS \& Uhl C. 1994. Photosynthesis-nitrogen relations in Amazonian tree species. I. Patterns among species and communities. Oecologia 97: 62-72.

Reich PB, Grigal DF, Aber JD \& Gower ST. 1997. Nitrogen mineralization and productivity in 50 harwood and conifer stands on diverse soils. Ecology 78:335-347.

Rhue RD \& Harris WG. 1999. Phosphorus sorption/desorption reactions in soils and sediments. En: Reddy KR, O’Connor GA \& CL Schelske (Eds). Phosphorus Biogeochemistry in Subtropical Ecosystem. Lewis Publishers, Boca Raton, 187-206. 
Rice CW, Sierzega PE, Tiedje JM \& Jacobs LW. 1988. Stimulated denitrification in the micro-environment of a biodegradable organic waste injected into soil. Soil Science Society of America Journal 52: 102-108.

Rice EL \& Pancholy SK. 1973. Inhibition of nitrification by climax ecosystems. II. Additional evidence and possible role of tannins. American Journal of Botany 60: $691-702$

Richardson AE, Barea JM, McNeill AM \& Prigent-Combaret C. 2009. Acquisition of phosphorus and nitrogen in the rhizosphere and plant growth promotion by microorganisms. Plant and Soil 321: 305-339.

Ritchie GA. 1984. Assessing seedling quality. P 243- 259. En: Duryea ML \& Landis TD (Eds) Forest Nursery Manual: Production of Bareroot Seedlings. Martinus Nijhoff/Dr W Junk Publishers, The Hague, Boston, Lancaster. Ryel RJ, Caldwell MM, Yoder CK, Or D \& Leffler AJ. 2002. Hydraulic redistribution in a stand of Artemisia tridentata: evaluation of benefits to transpiration assessed with a simulation model. Oecologia 130: 173-184.

Robinson CH, Wookey PA, Parsons AN, Potter JA, Callaghan TV, Lee JA et al. 1995. Responses of plant litter decomposition and nitrogen mineralisation to simulated environmental change in a high arctic polar semi-desert and a subarctic dwarf shrub heath. Oikos 74: 503-512.

Rockwood LD, Rudie WA, Ralph, SA, Zhu YJ \& Winandy EJ. 2008. Energy product options for Eucalyptus species grown as short rotation woody crops. Int. J. Mol. Sci. $9(8), 1361-1378$,

Rodríguez H \& Fraga R. 1999. Phosphate solubilizing bacteria and their role in plant growth promotion. Biotechnology Advances 17: 319-339.

Rodríguez A, Durán J, Fernández-Palacios JM \& Gallardo A. 2009. Spatial variability of soil properties under Pinus canariensis canopy in two contrasting soil textures. Plant and Soil 322(1-2), 139-150.

Rustad LE. 1994. Element dynamics along a decay continuum in a red spruce ecosystem in Maine, USA. Ecology 75:867-879.

Ryser R \& Wahl S. 2001. Interspecific variation in RGR and the underlying traits among 24 grass species grown in full daylight. Plant Biology 3: 426-436. 
Saggar SA, Parshotam GP, Sparling CW, Feltham \& Hart PBS. 1996. 14C-Labelled ryegrass turnover and residence times in soils varying in clay content and mineralogy. Soil Biology and Biochemistry 28: 1677-1686.

SAGPyA. 2001. Sector Forestal, Anuario sobre régimen de promoción de plantaciones forestales. Secretaria de Agricultura, Pesca y Alimentación, Dirección de Forestación. Buenos Aires. Argentina.

SAGPyA 2014. Argentina: plantaciones forestales y gestión sostenible. Ministerio de Agricultura, Ganadería y Pesca.

Saharan BS \& Nehra V. 2011. Plant growth promoting rhizobacteria: a critical review. Life Science and Medicine Research 21: 1-30.

Salisbury FB \& Ross CW. 1994. Fisiología vegetal. Grupo Editorial Iberoamérica. México, D.F.

Sandoval DM, Goya J, Arturi M, Burns S \& Pérez C. 2012. Efecto de plantaciones de Eucalyptus grandis (Hill ex Maiden) sobre el contenido de carbono en suelos en el NE de la provincia de Entre Ríos. XV Jornadas Técnicas Forestales y Ambientales. Eldorado, Misiones, Argentina.

Sanginga N \& Swift MJ. 1992. Nutritional effects of Eucalyptus litter on the growth of maize (Zea mays). Agriculture, Ecosystems and Environment 41: 55-65.

Sankaran KV. 1993. Decomposition of leaf litter of albizia (Paraserianthes falcataria), eucalypt (Eucalyptus tereticornis) and teak (Tectona grandis) in Kerala, India. Forest Ecology and Management 56: 225-242.

Sankaran KV, Grove TS, Kumaraswamy S, Manju VS, Mendham DS \& O'Connell AM. 2005. Export of nutrients in plant biomass following harvest of eucalypt plantations in Kerala, India. Journal of Sustainable Forestry 20 (3): 15-36.

Saxena NC. 1991. Crop losses and their economic implications due to growing of Eucalyptus on field bunds-a pilot study. Agroforestry Systems 16: 231-245.

Scalenghe R, Edwards AC, Ajmone Marsan F \& Barberis E. 2002. The effect of reducing conditions on $\mathrm{P}$ solubility for a diverse range of European agricultural soils. Eur. Journal Soil Science 53: 439-447.

Scalenghe R, Edwards AC, E Barberis \& Ajmone Marsan F. 2010. The influence of pulsed redox conditions on soil phosphorus. Biogeosciences Discuss. 7: 9009-9037. 
Schimel DS, Coleman DC \& Horton KA. 1985. Soil organic matter dynamics in pairerangeland and cropland toposequences in North Dakota. Geoderma 36: 201-214.

Schimel JP, Cates RG \& Ruess R. 1998. The role of balsam poplar secondary chemicals in controlling soil nutrient dynamics through succession in the Alaskan taiga. Biogeochemistry 42: 221-234.

Schjørring JK. 1998. Atmospheric ammonia and impacts of nitrogen deposition: uncertainties and challenges (Atmospheric ammonia and impacts of nitrogen deposition). New Phytol. 139: 59-60.

Schlatter JE, Gerding V \& Calderón S. 2006. Aporte de la hojarasca al ciclo biogeoquímico en plantaciones de Eucalyptus nitens, X Región, Chile. Bosque 27(2): 115-125.

Schofield RK. 1955. Can a precise meaning be given to 'available' soil phosphorus. Soils Fertility 18: 373-375.

Schulze ED, Kelliher FM, Körner C, Lloyd J \& Leuning R. 1994. Relationships among maximum stomatal conductance, ecosystem surface conductance, carbon assimilation rate, and plant nitrogen nutrition: a global ecology scaling exercise. Annual Review of Ecology and Systematics 25: 629-660.

Scott NA \& Binkley D. 1997. Foliage litter quality and annual net $\mathrm{N}$ mineralization: comparison across North American forest sites. Oecologia 111:151-159.

Seastedt TR. 1984. The role of microarthropods in decomposition and mineralisation processes. Annual Review of Entomology 29, 25-46.

Secretaría de Minería de La Nación 2016. http://www.mineria.gob.ar/estudios/irn/entrerios/e-1.asp.

Sen KK \& Bhadoria PBS. 1987. The effect of soil conditioners on water movement through lateritic sandy loam soil. Agronomy and Crop Science 159: 241-244.

Seneviratne G, Van Holm LHJ \& Kulasooriya SA. 1998. Quality of different mulch materials and their decomposition and $\mathrm{N}$ release under low moisture regimes. Biology and Fertility of Soils 26: 136-140.

Seneviratne G, Van Holm LHJ, Balachandra LJA \& Kulasooriya SA. 1999. Differential effects of soil properties on leaf nitrogen release. Biology and Fertility of Soils 28: $238-243$. 
Seneviratne G. 2000. Litter quality and nitrogen release in tropical agriculture: a synthesis. Biology and Fertility of Soils 31:60-64.

Sepliarsky, F. y Dalla Tea F. 1993. Crecimiento de Eucalyptus grandis en relación con factores edáficos. Congreso Forestal Argentino y Latinoamericano. AFoA. Paraná. Entre Ríos.

Shao HB, Chu LY, Jaleel CA \& Zhao CX. 2008. Water-deficit stress-induced anatomical changes in higher plants. C. R. Biologies 331: 215-225.

Sharma SC \& Pande PK. 1989. Patterns of litter nutrient concentrations in some plantation ecosystems. Forest Ecology and Management 29: 151-163.

Shaw MR \& Harte J. 2001. Control of litter decomposition in a subalpine meadowsagebrush steppe ecotone under climate change. Ecological Applications 11: 12061223.

Shipley B. 2002. Trade-offs between net assimilation rate and specific leaf area in determining relative growth rate: relationship with daily irradiance. Functional Ecology 16: 682-689.

Sims JL \& Frederick LR .1970. Nitrogen immobilization and decomposition of corn residue in soil and sand as affected by residue particle size. Soil Science Society of America Journal 109:355-361.

Singh BB \& Jones JP. 1976. Phosphorus sorption and desorption characteristics of soil as affected by organic residues. Soil Science Society of America Journal 40: 389-394.

Singh D \& Kohli RK. 1992. Impact of Eucalyptus tereticornis Sm. shelterbelts on crops. Agroforestry Systems 20: 253-266.

Singh O, Sharma DC \& Rawat JK.1993. Production and decomposition of leaf litter in sal, teak, Eucalyptus and poplar forests in Uttar Pradesh. Indian Forester 119: 112-121.

Singogo W, Lamond WJ \& Marr CW. 1996. Fall-planted cover crops support good yields of muskmelons. HortScience 31:62-64.

Skopp J, Jawson MD \& Doran JW. 1990. Steady-state aerobic microbial activity as a function of soil water content. Soil Science Society of America Journal 54: 16191625 .

Smith SD, Monson RK \& Anderson JE. 1997. Physiological ecology of North American desert plants. Springer-Verlag, Berlin, Germany. 
Sommers LE, Gilmour CM, Wildung RE \& Beck SM. 1981. The effect of water potential on decomposition processes in soils. P 97-140 En: Parr JF et al. (ed.) Water potential relations in soil microbiology. SSSA Spec. Publ. 9. SSSA, Madison, WI.

Sørensen LH. 1981. Carbon-nitrogen relationships during the humification of cellulose in soils containing different amounts of clay. Soil Biology and Biochemistry 13: 313321.

Sorensen P, Ladd JN \& Amato M. 1996. Microbial assimilation of ${ }^{14} \mathrm{C}$ of ground and unground plant materials decomposing. in a loamy sand and a clay soil. Soil Biology \& Biochemistry 28 (10-11):1425-1434.

Soulides DA \& Allison FE. 1961. Effect of drying and freezing soils on carbon dioxide production, available mineral nutrients, aggregation, and bacterial population. Soil Science 91: 291-298.

Sparling GP, Whale KN \& Ramsay AJ. 1985. Quantifying the contribution from the soil microbial biomass to the extractable P levels of fresh and air-dried soils. Aust Journal Soil Res. 23: 613-621.

Specht RL. 1996. The influence of soils on the evolution of Eucalypts. En Nutrition of Eucalypts Eds. P.M. Attiwill y M. Adams. CSIRO Publishing, Collinwoods, pp. 3160.

Sponseller RA. 2007. Precipitation pulses and soil CO2 flux in a Sonora Desert ecosystem. Global Change Biology 13: 426-436.

Staaf H. 1980. Release of plant nutrients from decomposing leaf litter in a South Swedish beech forest. Holarct Ecol 3:129-136.

Staaf H \& Berg B. 1982. Accumulation and release of plant nutrients in decomposing Scots pine needle litter. Long-term decomposition in a Scots pine forest, II. Canadian Journal of Botany 60:1561-1568.

Stehouwer RC \& Johnson JW. 1991. Soil adsorption interactions of band-injected anhydrous ammonia and potassium chloride fertilizers. Soil Science Society of America Journal 55:1374-1381.

Stevenson FJ. 1986. Cycles of soil. Carbon, nitrogen, phosphorus, sulfur, micronutrients. John Wiley and Sons, New York., USA, 380p. 
Stevenson FJ \& Cole MA. 1999. The carbon cycle. En: Stevenson FJ \& Cole MA (eds) Cycles of Soil. John Wiley and Sons, New York. pp1-45.

Stewart JWB \& Tiessen H. 1987. Dynamics of soil organic phosphorus. Biogeochemistry 4: 41-60.

Stickler FC \& Frederick LR. 1959. Residue particle size as a factor in nitrate release from tops and roots. Agronomy Journal 51: 271-274.

Stott DE, Elliott LF, Papendick RI \& Campbell GS. 1986. Low temperature or low water potential effects on the microbial decomposition of wheat residue. Soil and Biology and Biochemistry 18:577-582.

Stumm W \& Morgan JJ. 1981. Aquatic Chemistry, 2a ed., John Wiley, New York. p. 780.

Stumm W \& Sulzgerger B. 1992. The cycling of iron in natural environments: considerations based on laboratory studies of heterogeneous redox processes. Geochim. Cosmochim. Acta, 56: 3233-3257.

Stumpe JM \& Vlek LG. 1991. Acidification induced by different nitrogen sources in columns of selected tropical soils. Soil Science Society of America Journal 55: 145151.

Swamy RH. 1989. Study of organic productivity, nutrient cycling and small watershed hydrology in natural forests and in monoculture plantations in Chikmagalur District, Karnataca. J.C.B.M. College, Karnataka. Final Report submitted to Government of India $261 \mathrm{p}$.

Swift MJ, Heal OW \& Anderson JM. 1979. Decomposition in Terrestrial ecosystems Studies in Ecology. Blackwell, Oxford. 372 p.

Taiz L \& Zeiger E. 2002. Plant Physiology, 3 edn. Sinauer Associates, Inc. Publishers, Sunderland, Massachusetts.

Taiz L \& Zeiger E. 2006. Fisiología vegetal. Publicacions de La Universitat de Jaume I de Castellón. Dos volúmnes, traducción de la $3^{\circ}$ edición en inglés de 2002.España.

Taylor BR, Parkinson D y WFJ Parsons. 1989. Nitrogen and lignin content as predictors of litter decay rates: a microcosm test. Ecology 70: 97-104.

Taylor BR, Prescott CE, Parsons WFJ, Parkinson D. 1991. Substrate control of litter decomposition in four Rocky Mountain coniferous forests. Canadian Journal of Botany 69:2242-2250. 
Tenny FG \& Waksman SA. 1929. Composition of natural organic materials and their decomposition in the soil: IV. The nature and rapidity of decomposition on the various organic complexes in different plant materials under aerobic conditions. Soil Science 28: 55-84.

Tesón N. 2012. Balance hidrológico y flujo de nutrientes en plantaciones de Eucalyptus grandis, en Concordia, Entre Ríos. Tesis Doctoral en Ciencias Naturales. La Plata, Argentina. Facultad de Ciencias Naturales y Museo, Universidad Nacional de La Plata: $171 \mathrm{p}$.

Tester CF. 1990. Organic amendment effects on physical and chemical properties of a sandy soil. Soil Science Society of America Journal 54: 827-831.

Thayer GW. 1974. Identity and regulation of nutrients limiting phytoplankton production in the shallow estuaries near Beaufort, N.C. Oecologia 14:75-92.

Thippayarugs S, Toomsan B, Vityakon P , Limpinuntana V, Patanothai A \& Cadisch G. 2008. Interactions in decomposition and $\mathrm{N}$ mineralization between tropical legume residue components. Agroforestry Systems 72:137-148.

Tiedje JM. 1988. Ecology of denitrification and dissimilatory nitrate reduction of ammonia. P 179-244 En: Zehnder AJB (ed) Biology of anaerobic microorganisms. Wiley, New York.

Tilman GD. 1984. Plant dominance along an experimental nutrient gradient. Ecology 65: 1445-1453.

Tilman D, Knops J, Wedin JD, Reich PB, Ritchie M, Siemann E. 1997. The influence of functional diversity and composition on ecosystem processes. Science 277:494-499.

Tilman D, Fargione J, Wolff B, D'Antonio C, Dobson A, Howarth R, Schindle D, Schlesinger WH, Simberloff D \& Swackhamer D. 2001. Forecasting agriculturally driven global environmental change. Science 292(5515): 281-284.

Titus BD \& Malcolm DC. 1999. The long-term decomposition of Sitka spruce needles in brash. Forestry 72:207-221.

Toky OP \& Singh V. 1993. Litter dynamics in short-rotation high density tree plantations in an arid region of India. Agriculture, Ecosystems and Environment 45: 129-145. 
Trinsoutrot I, Recous S, Bentz B, Lineres M, Cheneby D \& Nicolardot B. 2000. Biochemical quality of crop residues and $\mathrm{C}$ and $\mathrm{N}$ mineralization kinetics under nonlimiting N conditions. Soil Science Society of America Journal 64: 918-926.

Tsai LM. 1998. Studies on Acacia mangium in Kamasul Forest, Malaysia. I. Biomass and productivity. Journal of Tropical Ecology 4: 293-302.

Turner BL \& Haygarth PM. 2000. Phosphorus forms and concentrations in leachate from four grassland soil types. Soil Science Society of America Journal 64 (3): 1090-1097.

Turner BL, Driessen JP, Haygarth PM \& Mckelvie ID. 2003. Potential contribution of lysed bacterial cells to phosphorus solubilisation in two rewetted Australian pasture soils. Soil Biology \& Biochemistry 35: 187-189.

Universidad Pública de Navarra (UPNA). 2007. Lotus corniculatus Lam, cuernecillo, familia Leguminosae. Flora pratense y forrajera cultivada en la Península Ibérica. Herbario UPNADepartamento de Producción Agraria.

Utomo WH \& Dexter AR. 1982. Changes in soil aggregate water stability induced by wetting and drying cycles in non-saturated soil. Journal of Soil Science 33: 923-937.

Vadstein O \& Olsen Y. 1989. Chemical composition and phosphate uptake kinetics of limnetic bacterial communities cultures in chemostats under phosphorus limitation. Limnolgy and Oceanography 34 (5), 939-946.

Vaieretti MV, Pérez Harguindeguy N, Gurvich DE, Cingolani AM \& Cabido M. 2005. Decomposition dynamics and physico-chemical leaf quality of abundant species in a montane woodland in central Argentina. Plant and Soil 278:223-234.

Vallis I \& Jones RJ. 1973. Net mineralization of nitrogen in leaves and leaf litter of Desmodium intortim and Phaseolus atropurpureus mixed with soil. Soil Biology and Biochemistry 5:391-398.

Van Gestel M, Merckx R \& Vlassak K. 1993. Microbial biomass responses to soil drying and rewetting: the fate of fast- and slow-growing microorganisms in soils from different climates. Soil Biology \& Biochemistry 25: 109-123.

Van Vuuren MMI, Berendse F \& W De Visser. 1993. Species and site differences in the decomposition of litters and roots from wet heathlands. Canadian Journal of Botany 71: 167-173. 
Vance CP. 2001. Symbiotic nitrogen fixation and phosphorus acquisition: plant nutrition in a world of declining renewable resources. Plant Physiology 127: 390-397.

Vance CP, Uhde-Stone C \& Allan DL. 2003. Phosphorus acquisition and use: critical adaptations by plants for securing a nonrenewable resource. New Phytologist 157: 423-447.

Veenendaal EM, Swaine MD, Lecha RT, Walsh MF, Abebrese IK \& Owusu-Afriyie K. 1996. Responses of west African forest tree seedlings to irradiance and soil fertility. Functional Ecology 10: 501-511.

Vessey J K, Pawlowski K \& Bergman B. 2004. Root-based N2- fixing symbioses: Legumes, actinorhizal plants, Parasponia sp and cycads. Plant and Soil 266: 205230.

Vesterdal L. 1999. Influence of soil type on mass loss and nutrient release from decomposing foliage litter of beech and Norway spruce. Canadian Journal of Forest Research 29:95-105.

Viera M, Schumacher MV, Liberalesso E, Winckler Caldeira MV \& Farinha Watzlawick L. 2013. Plantio misto de Eucalyptus spp. com leguminosas arbóreas fixadoras de nitrogênio. Floresta e Ambiente 20 (1): 16-25.

Vigil MF \& Kissel DE. 1991. Equations for estimating the amount of nitrogen mineralized from crop residues. Soil Science Society of America Journal 55:757-761.

Villar R, Ruiz-Robleto J, Quero JL, Poorter H, Valladares F \& Marañón T. 2004a. Tasas de crecimiento en especies leñosas: aspectos funcionales e implicaciones ecológicas. $\mathrm{P}$ 191-227 En: Valladares F Ecología del bosque mediterráneo en un mundo cambiante. Ministerio de Medio Ambiente, EGRAF, S. A., Madrid.

Villar R, Marañón T, Quero JL, Panadero P, Arenas F \& Lambers M. 2004b.Variation in growth rate of 20 Aegilops species (Poaceae) in the field: The impotance of net assimilation rate or specific leag rea depends or the time scale. Plant and Soil 272: $11-27$.

Visser S. 1985. Role of the soil invertebrates in determining the composition of soil microbial communities. In: Fitter AH (ed) Ecological interactions in soil. Blackwell, Boston, pp 297-317. 
Vitousek PM \& Howarth RW. 1991. Nitrogen limitation on land and in the sea-how can it occur. Biogeochemistry 13: 87-115.

Vitousek PM \& Matson PA. 1993. Agriculture, the global nitrogen cycle, and trace gas flux. Biogeochemistry of Global Change Springer US. pp 193-208.

Vitousek PM, Turner DR, Parton WJ \& Sanford RL. 1994. Litter decomposition on the Mauna Loa environmental matriz, Hawai: patterns, mechanisms, and models. Ecology 72: 418-429.

Vogt KA, Grier CC \& Vogt DJ. 1986. Production, turnover, and nutrient dynamics of above-and below ground detritus of world forests. Advances in Ecology Research 15, $303-377$.

Walker TW \& Syers JK. 1976. The fate of phosphorus during pedogenesis. Geoderma $15: 1-19$

Wang WJ, Baldock JA, Dalal RC \& Moody PW. 2004. Decomposition of plant materials in relation to nitrogen availability and biochemistry determined by NMR and wetchemical analysis. Soil Biology and Biochemistry 36:2045-2058

Wang H, Shirong L \& Mo J. 2010. Correlation between leaf litter and fine root decomposition among subtropical tree species. Plant Soil 335:289-298.

Ward MH, Mark SD, Cantor KP, Weisenburger DD, Correa-Villaseñor A \& Zahm SH. 1996. Drinking water nitrate and the risk of non-Hodgkin's lymphoma. Epidemiology $7: 465-471$

Wardle DA, Zackrisson O, Hörnberg G \& Gallet C. 1997. The influence of island area on ecosystem properties. Science 277:1296-1299.

Wardle DA \& Lavelle P. 1997. Linkages between soil biota, plant litter quality and decomposition. En: Cadisch G \& Giller KE (eds). Driven by Nature: Plant Litter Quality and Decomposition, CAB International. pp 107-124.

Wardle DA, Barker GM, Bonner KI \& Nicholson KS. 1998. Can comparative approaches based on plant ecophysiological traits predict the nature of biotic interactions and individual plant species effects in ecosystems? Journal of Ecology 86:405-420

Wedin DA \& Tilman DT. 1990. Species effects on nitrogen cycling: a test with perennial grasses. Oecologia 84:433-441. 
Weyman-Kaczmarkowa W \& Pędziwilk Z. 2000. The development of fungi as affected by $\mathrm{pH}$ and type of soil, in relation to the occurrence of bacteria and soil fungistatic activity. Microbiological research 155(2): 107-112.

White DA \& Beadle CL. 2004. Physiological regulation of productivity and water use in Eucalyptus: a review. Forest Ecology and Management 19: 113-140.

Wild A. 1992. Condiciones del suelo y desarrollo de las plantas según Russell. Mundiprensa, Madrid. 1045 pp. International Fertilizer Industry Association.

Willett IR. 1989. Causes and prediction of changes in extractable phosphorus during flooding. Australian Journal of Soil Research 27: 45-54.

Williams FJ, Hutchinson GL \& Fehsenfeld FC. 1992. NOx and $\mathrm{N}_{2} \mathrm{O}$ emissions from soil. Global Biogeochemical Cycles 6(4); 351-388.

Williams JE \& Broker MIH. 1997. Eucalypts: an introduction. Chapter 1, pags 1-15. En JE Williams y JCZ Woinarski (ed) 1997. Eucalypt Ecology. Individuals to ecosystems. Cambridge University Press, Cambridge, UK.

Wilson KB, Baldocchi DD \& Hanson PJ. 2001. Leaf age affects the seasonal pattern of photosynthetic capacity and net ecosystem exchange of carbon in a deciduous forest. Plant cell and environment 24: 571-583.

Wright IJ \& Westoby M. 2000. Cross-species relationships between seedling relative growth rate, nitrogen productivity and root $v s$. leaf function in 28 Australian woody species. Functional Ecology 14: 97-107.

Wright IJ \& Westoby M. 2001. Understanding seedling growth relationships through specific leaf area and leaf nitrogen concentration: generalisations across growth forms and growth irradiance. Oecologia 127: 21-29.

Wright IJ, Reich PB, Westoby M, Ackerly DD, Baruch Z, Bongers F, Cavender-Bares J, Chapin FS, Cornelissen JHC, Diemer M, Flexas J, Garnier E, Groom PK, Gulias J, Hikosaka K, Lamont BB, Lee T, Lee W, Lusk C, Midgley JJ, Navas ML, Niinemets Ü, Oleksyn J, Osada N, Poorter H, Poot P, Prior L, Pyankov VI, Roumet C, Thomas SC, Tjoelker MG, Veneklaas EJ \& Villar R. 2004. The world-wide leaf economics spectrum. Nature 428: 821-827. 
Wu J \& Brookes PC. 2005. The proportional mineralization of microbial biomass and organic matter caused by air-drying and rewetting of a grassland soil. Soil Biology \& Biochemistry 37: 507-515.

Wu F, Bao W, Li F \& Wu N. 2008. Effects of drought stress and N supply on the growth, biomass partitioning and water-use efficiency of Sophora davidii seedlings. Environmental and Experimental Botany 63: 248-255.

Xiang S, Doyle A, Holden PA \& Schimel JP. 2008. Drying and rewetting effects on C and $\mathrm{N}$ mineralization and microbial activity in surface and subsurface California grassland soils. Soil Biology \& Biochemistry 40: 2281-2289.

Yadvinder-Singh, Bijay-Singh, Maskina MS \& Meelu OP. 1988. Effect of organic manures, crop residues and green manure (Sesbania aculeata) on nitrogen and phosphorus transformations in a sandy loam at field capacity and under waterlogged conditions. Biology and Fertility Soils 6: 183 - 187.

Yamaya T \& Oaks A. 2004. Metabolic regulation of ammonium uptake and Assimilation. Cap 2: 35-64 En: Amâncio S \& Stulen I (Eds) Nitrogen Acquisition and Assimilation in Higher Plants. Academic Publishers, Dordrecht, The Netherlands.

Zak DR, Pregitzer KS, King JS \& Holmes WE. 2000. Elevated atmospheric $\mathrm{CO}^{2}$, fine roots and the response of soil microorganisms: a review and hypothesis. New Phytologist 147: 201-222. 


\section{Luciana Alcaraz \\ (Tesista)}

\section{Jorge Luis Frangi \\ (Director)}

\section{Corina Graciano}

(Codirectora) 